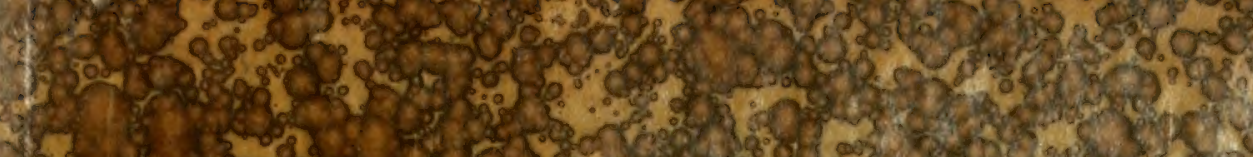
2.

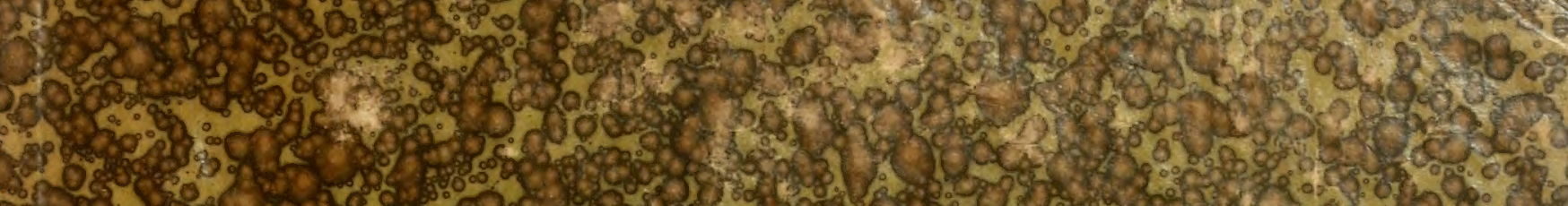
T.5.

150 \% $\frac{10}{10}$

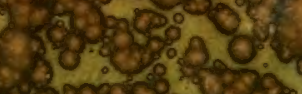

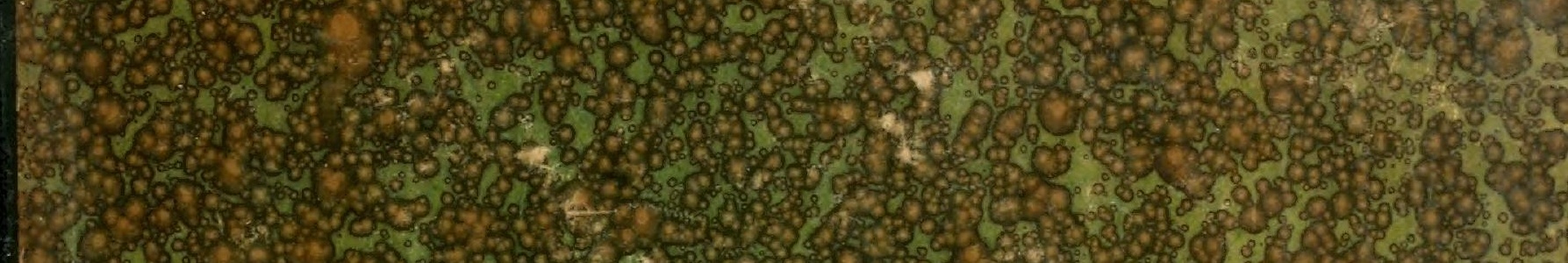

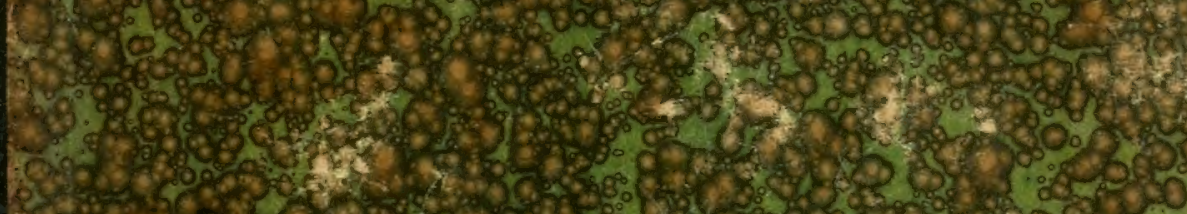

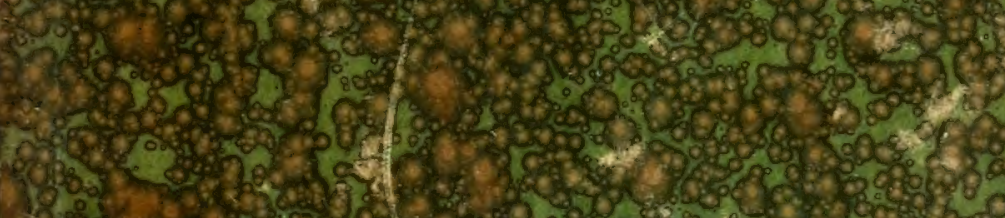

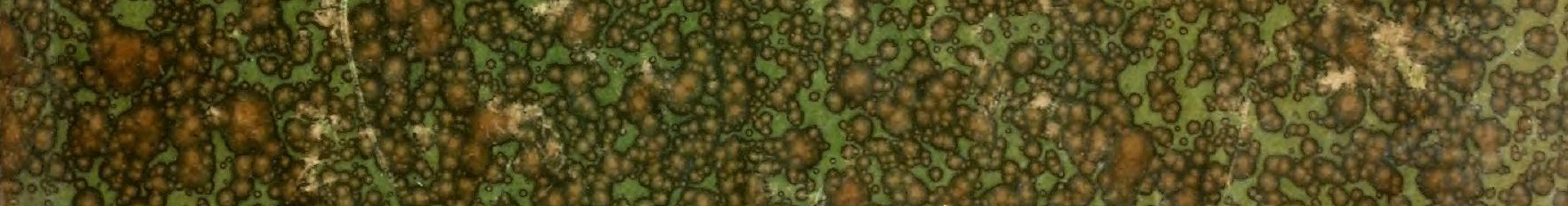

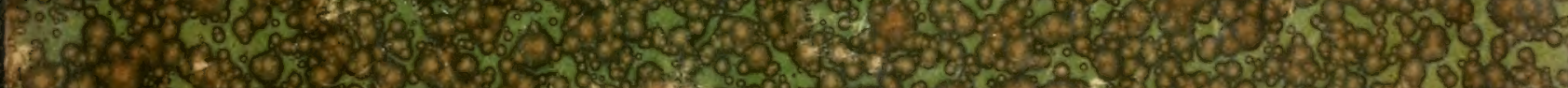

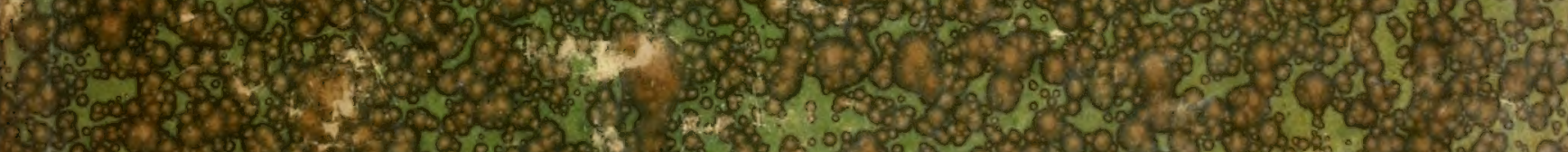

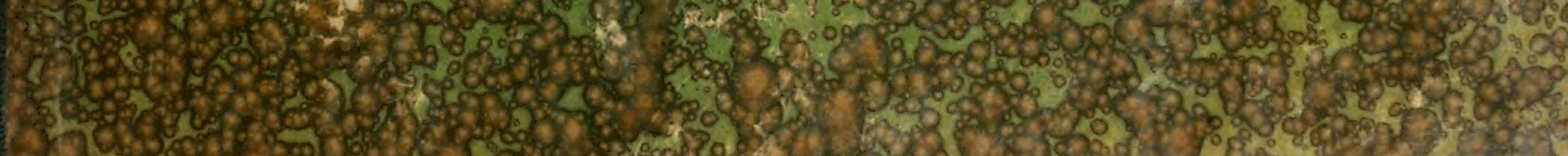

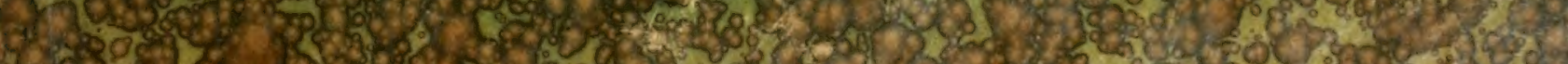

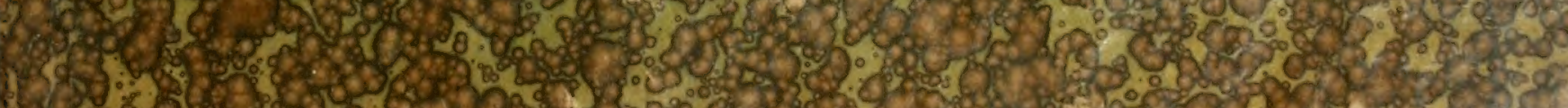

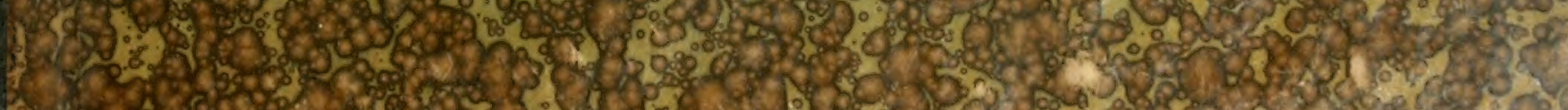

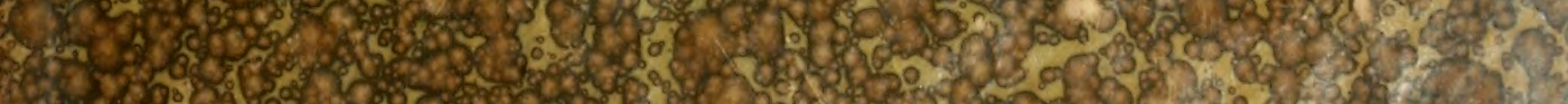

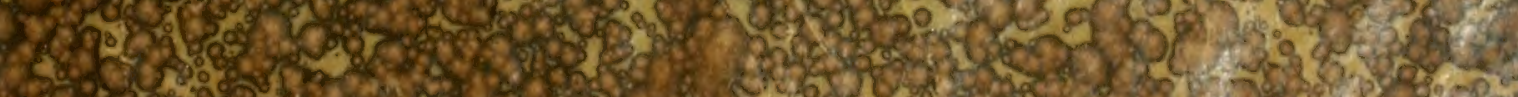
3.

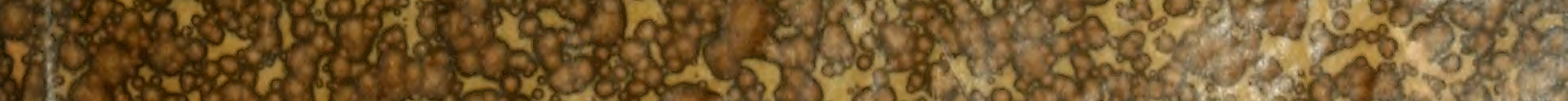

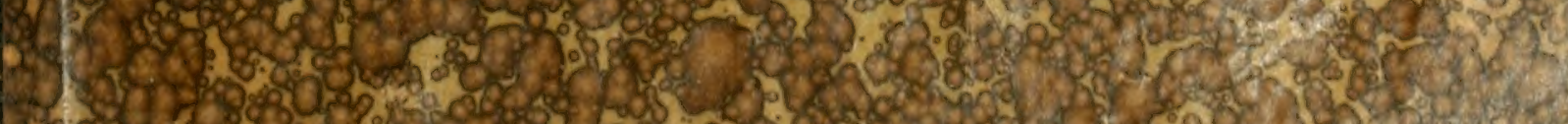

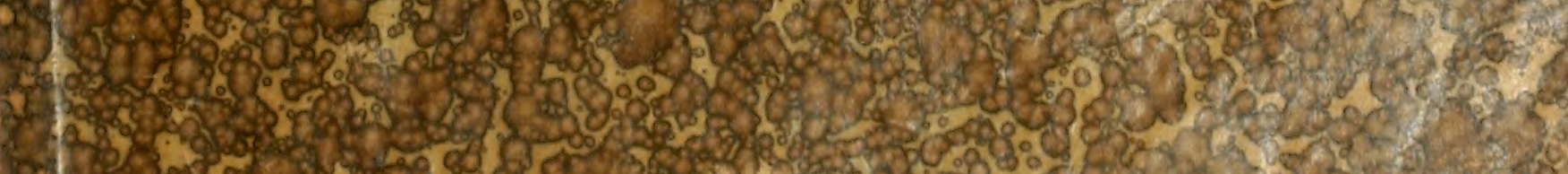

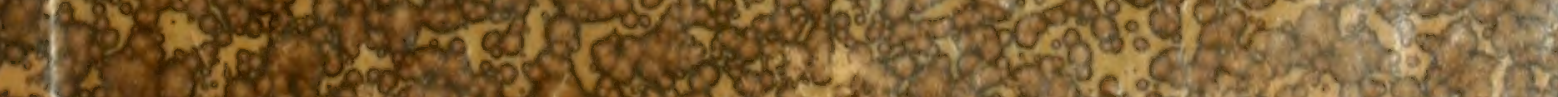




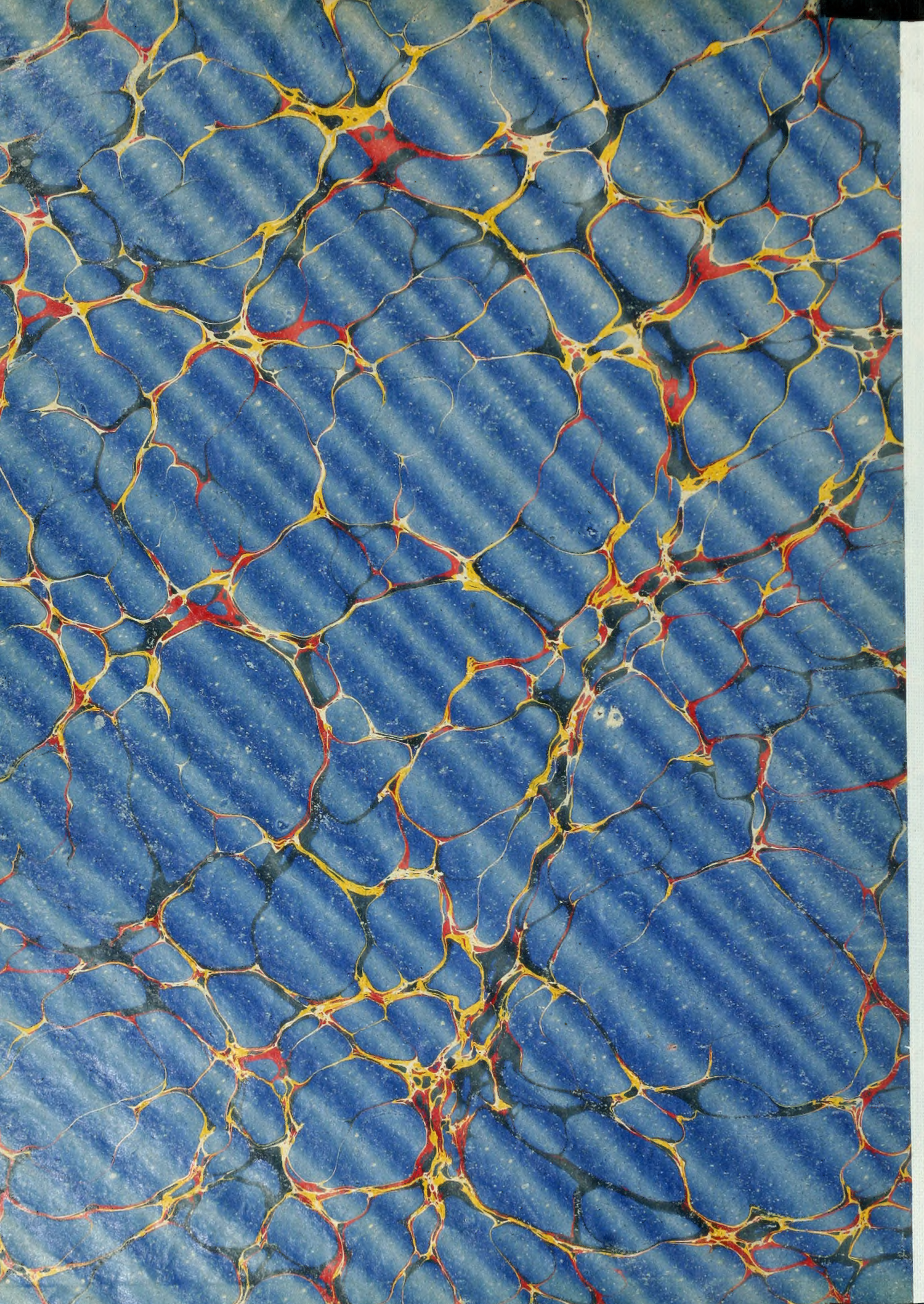




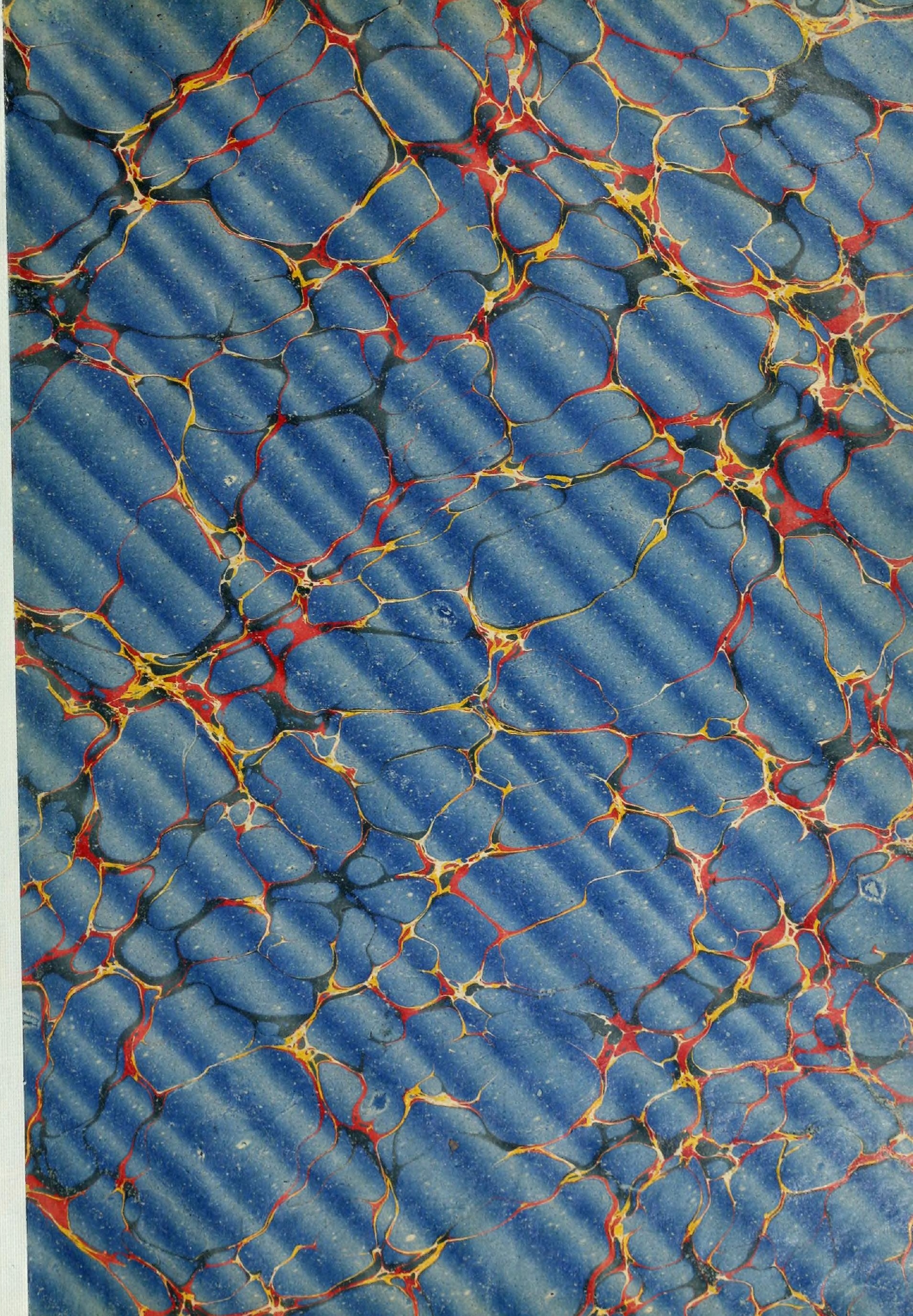


Digitized by the Internet Archive in 2010 with funding from University of Toronto 


$$
\begin{aligned}
& \text { QE } \\
& 806 \\
& \text { A78 }
\end{aligned}
$$




$$
\begin{aligned}
& \text { Beitrage } \\
& \text { zur }
\end{aligned}
$$

$$
\begin{aligned}
& \text { Paläontologie und Seologie } \\
& \text { Österreich-Ungarns und des Orients }
\end{aligned}
$$

$$
\text { vol. } 10-1896 \text {. }
$$

\title{
DIE CEPHALOPODENFAUNA DER REIFLINGER KALKE.
}

\author{
Von \\ GUSTAV VON ARTHABER, \\ Dr. phil., Assistent am Palăontologischen Institut der Universităt Wien. \\ (Mit Taf. I-X $[\mathrm{I}-\mathrm{X}]$.)
}

\section{GEOLOGISCHER THEIL.}

Die stratigraphische Bezeichnung: Reiflinger Kalke und Dolomite rührt von Dionys Stur her, der sie zum ersten Male in seiner Abhandlung: Die geologische Karte der nordöstlichen Kalkalpen (Jahrbuch k. k. geol. R.-A. I865, Bd. XV, Verhandlungen, pag. 42) verwendet.

Er bezeichnete damals im steirischen Antheil der Karte ungefähr dasselbe, für was im niederösterreichischen Gebiete im Jahre 1864 von Lipold der Name der Gösslinger Schichten eingeführt worden war. Später hingegen änderte er seine Auffassung insoferne, dass er die Reiflinger Kalke als den vorwiegend Cephalopoden führenden Horizont in Gegensatz zu den vorwiegend Brachiopoden führenden tieferen Kalken setzt, welche er auch in den Nordalpen als Recoarokalke ausscheidet. Kurz er versteht unter seiner Localbezeichnung eine Schichtgruppe, welche den mittleren und oberen alpinen Muschelkalk umfasst.

Die Bezeichnung wurde den Kalken nach dem Orte Gross-Reifling im Ennsthal gegeben, in dessen Umgebung sie in grosser Mächtigkeit anstehen und theils natürlich angeschnitten, z. B. kurz vor dem Einflusse der Salza in die Enns, theils künstlich in zwei mächtigen Steinbrüchen aufgeschlossen sind, von denen der ältere, welcher schon im XVI. Jahrhundert urkundlich benützt wurde und seit dem vorigen Jahre wieder neu in Betrieb gesetzt worden ist, sich auf der linken Thalseite am Eingange des Scheiblinggrabens, also südwestlich von Gross-Reifling befindet, während der jüngere nordöstlich davon, oberhalb des Zusammenflusses von Salza und Enns, den Eingang in den kleinen Tiefengraben markirt.

Als kartographische Grundlage dient das Blatt Zone I5, Col. XI der Specialkarte I :75.000.

Die geologischen Verhältnisse der näheren und weiteren Umgebung von Gross-Reifling sind schon zu wiederholten Malen in gründlicher Weise beschrieben worden.

Stur schildert sie theilweise in den Begleitworten der Vorlage seiner oben citirten Karte; ${ }^{1}$ ) am ausführlichsten in seiner Geologie der Steiermark, $\left.{ }^{2}\right)$ pag. 2 I $6 \mathrm{ff}$.

\footnotetext{
1) Jahrbuch k. k. geol. R.A. Bd. XV, Verhandlg., pag. 42 und pag. 245

2) Graz $187 x$. 
In neverer Zeit wurde Dr. A. Bittner mit der Neubegehung dieser Gebiete für die geologische Karte betraut, der hierüber in gründlicher Weise, speciell über die nächste Umgebung von Reifling selbst und den hier in Rede stehenden Fundort, in mehreren Mittheilungen berichtete, betitelt: "Geologische Verhältnisse der Umgebung von Gross-Reifling a. d, Enns (Verhandlungen, geol. R.-A. I884, Nr. 13, pag. 260) und: »Aus den Ennsthaler Kalkalpen (Verhandlungen, k. k. geol. R.-A. 1885, Nr. 5 , pag. I43), sowie auch partim: ¿ Zur Verbreitung der Opponitzer Kalke in den nordsteirischen und angrenzenden oberösterreichischen Kalkalpen (Verhandlungen, k. k. geol. R.-A. I887, Nr. 3, pag. 8r).

Neue geologische Aufnahmen bringt daher die vorliegende Arbeit keineswegs; ich beschränkte und musste mich auch eben auf die Verfolgung der Studien meiner Vorgänger beschränken, umsomehi da die neuen Kartenblätter noch nicht publicirt sind, was ich insoferne bitter empfand, da mir nur die ältere Stur'sche Aufnahmskarte zur Verfügung stand und es mir leider nicht möglich war, Einsicht in die neuere Karte Bittner's zu nehmen. Allerdings hob Dr. Bittner diesen Mangel insoferne auf, dass er gesprächsweise mir Aufschlüsse über seine neuere Karte ertheilte. Herrn Dr. Bittner verdanke ich auch die Anregung zur Ausbeutung des alten, von Stur entdeckten Fundortes "Tiefengraben", der die im Folgenden zur Beschreibung gelangende und über alle Erwartungen reiche Fauna barg.

Die Fundstelle selbst befindet sich auf dem kleinen Fahrweg, der von der Reifling-Palfauer Strasse bei der aufgelassenen Kohlung „Wasserstein a abzweigt, das rechte Thalgehänge des Tiefengrabens langsam hinansteigt, dann in einigen Serpentinen die Höhe des Thalabschlusses erreicht und zu den jenseits der Passhöhe gelegenen Köhlereien führt; sie ist von der Strassenkreuzung aus in einer guten Viertelstunde zu erreichen.

Stur gibt von dieser Localität in den oben citirten Schriften an:

Nautilus quadrangulus Beyr.,

* (Pleuronautilus) Pichleri Hauer,

Ammonites (Ptychites) megalodiscus Beyr.,

Rhynchonella cfr. semiplecta Münster

(Rhynchon. trinodosi Bittner).

Bei Bittner finden wir ferner in seinen Brachiopoden der alpinen Trias') von demselben Fundorte erwähnt:

Waldheimia (Cruratula) cfr. Eudora Laube.

Rhynchonella trinodosi Bittner.

* ex. aff. trinodosi Bittner.

Spiriferina (Mentzelia) Mentzelii Dunk. sp.

Ausserdem hat Fr. $v$. Hauer in seiner Arbeit über $₫$ Die Cephalopoden der unteren Trias der Alpen $\left.{ }^{2}\right)$ aus dem von Stur gesammelten Materiale beschrieben:

Nautilus (Pleuronautilus) Pichleri Hauer,

Ammonites (Ptychites) Studeri Hauer (wohl Ptychites flexuosus Mojs.).

Bei E. v. Mojsisovics finden wir in den Cephalopoden der mediterranen Triasprovinz ${ }^{3}$ ) von eben derselben Fundstelle beschrieben:

Pleuronautilus distinctus Mojs.

und in den "Cephalopoden der Hallstädter Kalke* ${ }^{4}$ ), Bd. II, den

Anolcites Elisabethae Mojs.

Hiemit ist Alles erschöpft, was bis jetzt von der Localität "Tiefengraben * bekannt geworden war.

1) Abhandig. k. k. geol. R.-A. Bd. XIV.

2) Sitzungsberichte der kais. Akad, der Wissensch. Mat.-nat, Classe, Bd, LII, Abth. I, pag. 605

3) Abhandlg. k. k. geol. R.-A. I882, Bd. X.

4) Abhandlg. k. k. geol. R.A. r893, Bd. VI, I. Abtheilung. 
Es ist leicht begreiflich, dass meine Vorgänger nicht eine grössere Anzahl von Fossilien von dieser Fundstelle zusammenbrachten, wenn man bedenkt, dass ihnen nicht so viel Zeit zur Ausbeutung der Localität zur Verfügung stand wie mir, sondern dass sie nur nebenbei, neben der Hauptaufgabe, den geologischen Aufnahmsarbeiten, dieser Localität ihre Aufmerksamkeit widmen konnten, während ich mir die Ausbeutung selbst zum Ziel gesetzt hatte und dasselbe durch die Arbeit zweier Sommer erreicht habe.

Das Vorkommen hier ist ein linsenförmiges in der Art, wie es auch von anderen MuschelkalkLocalitäten, z. B. Schreyeralm, bekannt geworden ist und wie ich auch in der neuesten Zeit durch Auffindung zweier neuer Fundorte wiederholt zu constatiren vermochte. Es sind keine auf grössere Entfernungen hin zu verfolgende, fossilführende Bänke, sondern nur kleine Nester oder Linsen, welche mitunter von geradezu verblüffendem Fossilreichthum sind und welche die Horizontalerstreckung von $\mathrm{I} \frac{1}{2}$ bis $2 \mathrm{~m}$ bei einer Höhe von kaum $\mathrm{I} \mathrm{m}$ und Dicke von 20 bis $80 \mathrm{~cm}$ wohl kaum überschreiten.

Das Gestein dieser Nester ist im frischen Zustande ein schwarzgrauer, thoniger, stark bituminöser Kalk, welcher an der Sonne rasch dünnblättrig, gelb, auch fast weiss wird, mitunter thonig zerfällt und die Fossilien selbst braun auswittern lässt. Er erinnert in diesem angewitterten Zustande lebhaft an die die Reiflinger Kalke direct überlagernden Aonschiefer (Trachyceras Schfr. Mojs.), von denen er sich neben dem Fehlen der charakteristischen Fossilien dieses Niveaus nur durch den geringen Kieselsäuregehalt und durch grössere Dicke der immerhin dünnen Lagen unterscheidet.

Eine solche Stelle, an welcher die Reiflinger Kalke im verwitterten Zustande den Habitus der Aonschiefer fast zum Verwechseln angenommen haben, befindet sich auf ungefähr halbem Wege zwischen der Stelle, von welcher der Fussweg, der zum » Kernerbauer « führt, von der Reifling-Palfauer Strasse abzweigt und durch den Wald emporsteigt. Hier haben wir in der Höhe von circa $4 \mathrm{~m}$ und Breite von circa $3 \mathrm{~m}$ aufgeschlossen die Reiflinger Kalke der feinkörnigen Facies, in denen ich selbst wohl nichts finden konnte, jedoch nach meiner Ansicht ein eifriges Suchen nicht ohne Erfolg bleiben dürfte.

Was die geologische Zusammensetzung des ganzen Gebietes anbelangt, so finden wir als tiefstes Glied den Werfner Schiefer. Er tritt als Unterlage der ganzen Trias an verschiedenen Stellen heraus, besonders dort, wo die später zu besprechenden tektonischen Linien durchstreichen. Wir finden ihn östlich in einem kleinen Aufbruch beim Reiter, unterhalb Palfau, im unteren Salzathal, wo die oberen Partien desselben mit schlecht erhaltenen Fossilien, Naticella, Gervillia und der bezeichnenden Myophoria costata aufgeschlossen ${ }^{1}$ ) sind.

In bedeutenderer Mächtigkeit finden wir ferner die Werfner Schiefer wieder bei Weissenbach a. d. Enns und im unteren Laussabachthale einerseits und gegen St. Gallen zu andererseits. Hier treten in den rothgefärbten oberen Lagen Gypse und Anhydrite auf, und Stur ${ }^{2}$ ) erwähnt auch eine kleine Salzquelle beim Einflusse des Buchaubaches in die Enns. Gegen oben gehen die Werfner Schiefer in schwarze Kalke und Dolomite, poröse, rauhwackenähnliche Kalke und grobzellige Rauhwacken über, mit denen sie mehrfach scheinbar oder wirklich wechsellagern. ${ }^{3}$ ) Diese Kalke, welche als Gutensteiner Kalke aufzufassen sind, treten auf der Linie Weissenbach-St. Gallen, besonders bei letzterem Orte, in bedeutender Mächtigkeit auf und führen dort schlecht erhaltene Versteinerungen, von denen Stur (loc. cit.) Durchschnitte der Terebratula vulgaris und anderer Petrefacten angibt. Bittner (loc. cit.) findet an der Laussabachseite mannigfaltigere Fossilführung, bestehend aus Modiolen, Gervillien und myophoriaartigen Bivalven, in den porösen Kalken auch kleine Gastropoden. Diese Fauna weist auf die Facies der Reichenhaller Kalke hin; die harten, dunklen Kalke der Gutensteiner Serie sind von zahlreichen weissen Kalkspathadern durchzogen und enthalten auf Klüften das schon

\footnotetext{
1) Bittrit, Verhandlg. k. k. geol. R.-A. I886, Nr. IO, pag. 247.

2) Stur, Geologie der Steiermark, pag. 220.

2) Bittuer, Verhandig. k. k. geol. R.A. I884, Nr. 13, pag. 26r.
} 
längst bekannte Vorkommen ${ }^{1)}$ meist violblauer, seltener rosenrother Flussspathkrystalle. Auch an das östliche Vorkommen des Werfner Horizontes bei Palfau schliesst sich ein kleiner Aufschluss von Gutensteiner Kalken an.

Mit dieser Aufzählung ist jedoch das Auftreten dieser tiefster Triasniveaux keineswegs erschöpft, die vielmehr an verschiedenen Stellen, wie z. B. der Linie Erb-Landl-Gams, in grösserer oder geringerer Mächtigkeit erschlossen sind.

Als nächsthöherer Horizont folgt der - wie Stur ihn (loc. cit. pag. 2I6) bezeichnet - Complex der Reiflinger Dolomite und Kalke. Freilich muss diese Schichtenserie heute in ganz anderem als dem alten, Stur'schen Sinne gedeutet werden, wie das Bittner auch in seinem Aufnahmsberichte besonders betont hat. ${ }^{2}$ ) Für Stur war massgebend betreffs seiner Anschauung, die Reiflinger Serie beginne mit einer bedeutenden Dolomitmasse, dass einestheils der Gutensteiner Kalk die Dolomite unterlagere und andererseits der Reiflinger Kalk sie bedecke. Thatsächlich ist dies allerdings der Fall, jedoch liegen die Verhältnisse keineswegs so einfach, dass dieses Raisonnement auch vollständig richtig wäre. Das ganze Gebiet von Altenmarkt-St. Gallen-Reifling bis gegen Palfau ist fast vollständig von Bruchlinien begrenzt, unter deren Einfluss die natürliche Schichtfolge gelöst worden ist.

In diesem Gebiet finden wir das Aufeinandertreffen zweier fast rechtwinkelig von einander abweichender Streichungsrichtungen, von denen die eine nach Westnordwest und Nordwest (Züge der Mittellaussa), die andere nach Ostnordost verläuft (Züge des Gamsstein und der Voralpe ${ }^{3}$ ). Beide Züge gehen nicht ineinander über, sondern treffen längs einer Linie aufeinander, welche über Landl-St. Gallen, Pfarralpe-Weisswasser streicht. Es ist daher naheliegend, dass der stratigraphische Contact der Dolomite mit ihrer Unterlage und Bedeckung nicht mehr der ursprüngliche ist, sondern nachträglich erst durch diese Erscheinungen hergestellt wurde.

Deshalb wendet sich Bittnc ${ }^{4}$ ) gegen die Stur'sche Auffassung, dass der Reiflinger Dolomit die Basis der Reiflinger Kalke bilde, und begründet diese Ansicht damit, dass im Südwest des in Rede stehenden Gebietes das Verhältniss zwischen dem Stur'schen Reiflinger- und dem Haupt-Dolomit, welche beide hier aufeinander treffen müssten, so unklar ist, dass eine Trennung zur Unmöglichkeit wird, ja überhaupt unwahrscheinlich ist. Tritt doch in der Tiefe des Wolffsbachgrabens, im Liegenden der Dolomite noch petrefactenreicher Opponitzer Kalk auf, wo man im Stur'schen Sinne eher Gutensteiner Kalk erwarten sollte. Auch ich schliesse mich der Ansicht Dr. Bittner's vollständig an, jedoch mit der Einschränkung, dass ich das Auftreten von Dolomiten in der Reiflinger Serie keineswegs leugne, ihnen jedoch nicht die Bedeutung im Stur'schen Sinne zusprechen kann, so dass daraufhin eine Gleichstellung derselben mit dem Mendoladolomit (loc, cit. pag. 22I) gestattet sei.

Steigt man den kleinen Scheiblinggraben, der am Westausgange von Gross-Reifling beginnt, hinan, so sieht man sofort die knolligen Bänke des Reiflinger Kalkes in wechselnder Lagenstärke, von dicken, $80 \mathrm{~cm}$ starken Bänken wechselnd bis zu Lagen von nur Millimeter Dicke. Thalaufwärts bekommt man die älteren Glieder der Kalkserie zu sehen, deren Bänke dann eine Zeit lang papierdünn bleiben, mit eingeschalteten, circa $10 \mathrm{~cm}$ dicken Lagen. Hier schliesst sich aber auf einmal an die dunklen Kalke ein lichtgelblicher, dünngebankter, kalkiger Dolomit an, dem im Liegenden ein dickbankiger Horizont folgt, welcher wieder von dünneren Bänken unterlagert wird. Dieser Dolomit braust, mit Salzsäurelösung behandelt, nur ausserordentlich wenig auf, ist also sehr stark an Magnesiagehalt. Das ganze Niveau hat eine Mächtigkeit von circa $20 \mathrm{~m}$.

Im Liegenden folgen dann wieder Bänke đes Kalkes von wechselnder Stärke von Io bis circa $80 \mathrm{~cm}$ und ausserordentlicher Härte, welche eine Thalstufe bilden, über die der Bach des Scheib-

Huidinger's Berichte. 1847 , Bd. III, Nr. 5, pag. 36r.

Verhandlg. k. k. geol. R.-A. 1887 , pag. 82.

3) Bittuer, Verhandlg. k. k. geol. R.A. 1886, pag. 2x.

${ }^{4}$ ) Verhandlg. k. k. geol. R.-A. I887, pag. 82 . 
lingsgrabens herabstürzt. Dann ändert sich plötzlich das Bild, das Thal weitet sich und nach einer hleinen Strecke verworrenen und verstürzten Terrains befinden wir uns im typischen Hauptdolomit von lichtgrauer Färbung mit schwach röthlichen Adern.

Beide Dolomitniveaux sind so ausserordentlich von einander verschieden, dass kein Gedanke einer Zusammengehörigkeit hier aufkommen kann. Für mich gibt es in Folge dieser Ausführungen ebenfalls keinen Reiflinger Dolomit, welcher sich als stratigraphisches Glied ausscheiden liesse, jedoch muss ich kalkige Dolomite von untergeordneter Mächtigkeit in der geschlossenen Serie der Reiflinger Kalke als thatsächlich vorhanden betonen.

In den Reiflinger Kalken lässt sich schwer eine Trennung, basirt auf den petrographischen Habitus, vornehmen; daher kann ich mich auch der Scheidung Bittncr's ${ }^{1}$ ) in einen unteren Horizont, welcher dünnbankig ist und nur wenig Hornstein führt, im Gegensatz zum oberen, dicker gebankten und stark hornsteinführenden Knollenkalk nicht vollständig anschliessen.

Der Reiflinger Kalk ist sowohl in seiner unteren als oberen Partie charakterisirt durch meist sehr hohen Kieselsäuregehalt, der sich auf den Schichtflächen vielfach durch knollige Beschaffenheit derselben verräth und dem Gestein ausserordentliche Härte und lichte Farbe verleiht. Dazwischen finder sich wieder sowohl unten als oben Partien mit geringem Kieselsäuregehalt, bedeutend zurücktretendem knolligen Habitus, gelblicher bis bräunlicher Farbe und theilweise geringerer Härte. Nur ein Niveau bleibt so ziemlich constant, das sich aber nicht als fortlaufende Bank, sondern durch local auftretende Linsen, charakterisirt durch dunkle Farbe und thonigen, splitternden Kalk, auszeichnet, welcher stellenweise direct als «stinkend $\approx u$ bezeichnen ist. Durch die Verwitterung verliert er den theilweise reichen Bitumengehalt und wird blätternd und licht. Durch das Auftreten dieser Linsen, welche theils reiche Fossilführung aufweisen, theils vollkommen leer sind, sich aber stets durch blaubis grauschwarzen, harten, thonigen Kalk auszeichnen und bezüglich der Gesammtmächtigkeit der Reiflinger Kalke in deren unteren Partie auftreten, möchte ich allein eine Scheidung in untere und obere Reiflinger Kalke vornehmen, von denen die letzteren die bedeutend mächtigeren sind im Gegensatze zu den unteren, welche das oben angeführte Niveau des kalkigen Dolomites zwischen ihren Kieselkalken eingeschlossen enthalten. Ich rechne hiebei - es ist dies allerdings nur eine subjective Anschauung - den thonig-kalkigen Horizont mit zur unteren Partie. Dieser gehören die bis heute aufgefundenen Fundstellen an, unter denen die Localität sTiefengraben die interessanteste ist und sich durch Artenreichthum auszeichnet, welchen der paläontologische Theil der vorliegenden Arbeit zu schildern suchen wird.

In zweiter Linie ist ein Fundort zu nennen, den mir erst in jüngster Zeit, fast schon nach Abschluss dieser Arbeit, zu entdecken gelungen ist, welcher sich im Gegensatz zu dem Früheren weniger durch Arten, als Individuenreichthum auszeichnet und eine ungeahnte Fülle von Balatoniten bei starkem Zurücktreten fast aller anderen Elemente lieferte. Diese Localität befindet sich ebenfalls östlich von Gross-Reifling und wird in einem Nachtrage separat behandelt werden.

An dritter Stelle ist ein Fundort zu nennen, welcher sich westlich von Reifling, im oben erwähnten Scheiblinggraben befindet und Fossilreste in demselben Gestein in geringerer Menge geliefert hat.

Erwähnen wir ausserdem noch ein ron Dr. Bittncr"2) entdeclites ähnliches Vorkommen desselben Horizontes in einem kleinen Seitengraben der Gallensteiner Schlucht bei St. Gallen, welcher seinige schwer auslösbare Ceratiten rom Mluschelkalktypus lieferte, so sind hiemit alle Fundorte angeführt, welche in diesem kalkigrthonigen Niveau bis jetzt bekannt geworden sind. Sie grehören alle der unteren Partie der Reiflinger Serie an und eröfnen zugleich die Fossilführung in derselben. 
Die oberen Reiflinger Kallic zeigen, wie schon erwähnt, denselben knolligen Habitus mit meist reichem Kieselsäuregehalt in den Kalken selbst und meist lichte Farbe. Sie sind, wie eingangs angeführt, in zwei grossen Steinbrüchen aufgeschlossen und lieferten bisher das theilweise erhaltene Skelet eines Sauriers; auf derselben Platte fand sich auch ein Cephalopode, sein Rest ciner in die lamilie der Aones gehörigen Art mit drei Knotenreihen auf der Seitenwand «, 1) welcher von P. Engelb. Prangncr in den Vierzigerjahren dort gefunden worden war. Dieser Steinbruch liegt im Westen von GrossReifling, während der grosse Bruch im Osten bis jetzt noch nichts geliefert hat. E. \%. Mojsisovics²) citirt nun (pag. 693, Taf. roo, Fig. 2) ebenfalls einen Trachyceraten, den

Anolcites Elisabethac Mojs.,

jedoch von der Localität »Tiefengrabena. Sollte hier nicht eine Verwechslung der Fundorte vorliegen und dies das alte Ifaidinger'sche Stück sein?

Sonst sind keine bestimmbaren Reste aus den oberen Kinollenkalken bekannt. Man findet zwar, wenn man längs der Holzschleifbahn von Reifling zur Salzaschleusse geht, auf den Schichtbänken nicht selten Durchschnitte von Cephalopoden, jedoch ist der Erhaltungszustand derselben in den groben Innollenkalken ein zu ungünstiger, und ausserdem ist es unmöglich, sie aus den hier meist dicken Bänken herauszuschlagen.

Gegen oben finden sich in diesen Kalken Einschaltungen von Mergeln, welche sehr rasch an Mächtigkeit gewinnen und als Zwischenlagen kleinere Bänke, hellen Kalkes vom Typus des liegenden Kalkes aufweisen. Sie sind von grünlichgrauer Färbung, zerfallen an der Luft stengelig und stehen im Flussbett knapp unterhalb des Einflusses der Salza in die Enns an, wo sie in einer Mächtigkeit von circa Io m aufgeschlossen sind. Leider liegt dieser Aufschluss sehr ungünstig, weil er fast in der Höhe des Normalstandes der Enns liegt und daher nur bei niedrigem Wasserstande zu besuchen ist. Ausserdem wird im Sommer die Salza tagtäglich betreffs der Holztrifft geschwellt, wodurch auch der Fundort fast vollständig, täglich einmal, unter Wasser gesetzt wird, was wieder unter dem Einflusse der Sonne ein ausserordentlich starkes Zerspellen der weichen Mergel zur Folge hat. Besonders schichtweise ist der Fossilreichthum dieser Mergel sehr gross; ganze Flächen sind mit Posidonomyen und Halobienbrut bedeckt.

Herr Dr. Bithur, dem ich mein hier gesammeltes Bivalven- und Brachiopodenmaterial übergab, hatte die Freundlichkeit, die Bestimmung desselben vorzunehmen, welche folgende Formen ergab:

Eine grosse Posiodonomya sp., welche sehr häufig hier auftritt; mitunter sehr grosse und noch mit Schale erhaltene Exemplare der Halobia Lommeli Vissm., welche sich von südalpinen Exemplaren gar nicht unterscheiden lässt, und eine feingerippte, wahrscheinlich neue Halobia sp.

Gleichzeitig sei hier hervorgehoben, dass bis heute nur zwei Fundorte in den nordöstlichen Kalkalpen bekannt geworden sind, ${ }^{3}$ ) welche die echte Halobia Lommeli geliefert haben: Steinbachgraben bei Lunz, woselbst es Dr. Bittncr, und Gross-Reifling, Einfluss der Salza in die Enns, wo es mir gelungen war, dieses charakteristische Leitfossil zu finden. Alle anderen Angaben der älteren und jüngeren Literatur über den Nachweis der Halobia Lommeli in den Nordalpen beziehen sich nicht auf diese selbst, sondern nur auf verwandte Formen.

Von Brachiopoden führt Dr. Bittner's Bestimmung Steinkerne der

Waldheimia (Cruratula) cfr. Eudora Laube an.

Auch Cephalopoden sind (in Bruchstücken) vertreten:

Anolcites cfr. doleriticus Mojs,

Protrachyceras cfr. regoledanus Mojs.,

Atractites nov. spec, indet.

1) Stur, Geologie der Steiermark, pag. 219

$\Rightarrow$ Gebirge um Ifallstadt, Bd. II.

3) Bittmer, Verhandlg, k, k. geol. R.-A. I894, Nr. I4, pag. 382. 
Gegen oben werden dann die Kalkzwischenlagen mächtiger und einige Bänke in Gesammtmächtigkeit von $3 \mathrm{~m}$ und Aussehen des liegenden Reiflinger Kieselkalkes schliessen den Mergelhorizont im Grossen und Ganzen ab. Es folgen sodann ebenflächige, blaugraue, harte, thonige Kallie, welche wir unter der Brücke, die über die Salza kurz vor ihrem Einflusse fülhrt, anstehend finden, zwischen denen sich ein Mergelschieferniveau einschaltet, das einen ausserordentlichen Reichthum an Halobien ebenso wie übrigens die direct unter- und überlagernden Kalke aufweist; aus letzteren wittern die Versteinerungen sehr schön aus. Es findet sich jedoch keine Spur mehr der Halobia Lommeli, die in so grosser Menge im Mergelniveau auftritt, sondern

Halobia intermedia Mojs.,

welche von eben diesem Fundorte schon von E. \%. Mojsisorics ${ }^{1}$ ) beschrieben worden ist (pag. 30 , Taf. III, Fig. 5, 6).

Hiemit schliesst hier die Schichtfolge der Reiflinger Kalke ab und die höheren Horizonte liegen unter einer mächtigen Bedeckung junger Schotter- und Conglomeratmassen begraben, auf denen sich das Gehöft des Salzabauern befindet. Erst weiter im Osten finden wir Opponitzer Kalk und Hauptdolomit. Die Ueberlagerung der obersten Reiflinger Kalke lässt sich im oberen Tiefengraben kurz unter der Passhöhe in nicht besonders günstiger Weise beobachten, besser hingegen im Scheibling. graben im Westen von Reifling.

Dort fehlt die Einschaltung der Mergelschiefer in den oberen Kalken, die sich homogen bis zur oberen Grenze fortsetzen, auch ein Beispiel für den raschen Wechsel der Faciesentwicklung in den Reiflinger Kalken, die besonders Bitncr ${ }^{2}$ ) in seiner Arbeit: "Partnach Sch. mit Konninckina Leonhardi im Thale von Kaltenleutgeben bei Wien* (pag. I62) betont hat.

Es schliessen also die Reiflinger Kalke mit denselben lichten Kinollenkalken ab, die hier nur dünnbankiger werden unđ am rechten Thalgehänge in einem Steinbruch abgebaut werden, knapp neben der Weggabelung, von der aus der Steig zum Gehöft des Scheiblingbauern hinanführt. Links (im Anstiege) von diesem kann man gut die Ueberlagerung der oberen Reiflinger Kalke durch Aonschiefer beobachten, der concordant aufliegt.

Es sind schwarze, ebenflächige Kalke, die hier in papierdünnen Schichten übereinander folgen, dazwischen dickere Lagen eines ausserordentlich harten, bräunlichen, stellenweise sogar farblosen und durchscheinenden Kieselkalkes, der die charakteristischen Fossilien des Aonschiefers führt:

\section{Brut von Halobia sp.,}

Posidonomya wengensis,

flachgedrüclite Trachyceraten in grosser Menge, insbesondere:

Trachyceras Aon Münst.,

Protrachyceras Archelaus Laube sp.s

Fischschuppen,

mitunter in sehr grossen Exemplaren

Voltzia heterophylla Schimp. u. Mong.

Auf diese Schiefer folgt sodann in directer Ueberlagerung der schwarze, stengelig an der Luft zerfallende Raingrabener Schiefer, welcher an dieser Localität Halobia rugosa Gümb. allein geliefert hat und der die Basis der Lunzer Serie bildet, die wohl nicht gut aufgeschlossen ist, jedoch sich in bedeutender Mächtigkeit nachweisen lässt, auf welcher der oben genannte Bauernhof liegt und die niederen Höhen bildet, deren weiche Terrainformen in so scharfem Gegensatze zu den wilden Dolomit. bergen des Lerchkogel, Grandenberg etc. stehen.

i) Ueber die triadischen P'elecypodengattungen Daonella und Halobia. Abhandls. der k, k, seol. K.A. IS7ł 13d. VIT, Heft 2.

2) Billnir, Verhandlg. k. k. geol. R.-A. I893, pag. 16 . 
Auch im Osten unseres Gebietes im oberen 'Tiefengraben kann man, wie schon bemerkt, die Ueberlagerung der obersten Reiflinger Kalkbänke durch Aonschiefer, Raingrabener Schiefer und Lunze: Sandstein beobachten; jedoch sind die tektonischen Verhältnisse hier local complicirter als auf der IVestseite.

NWW.

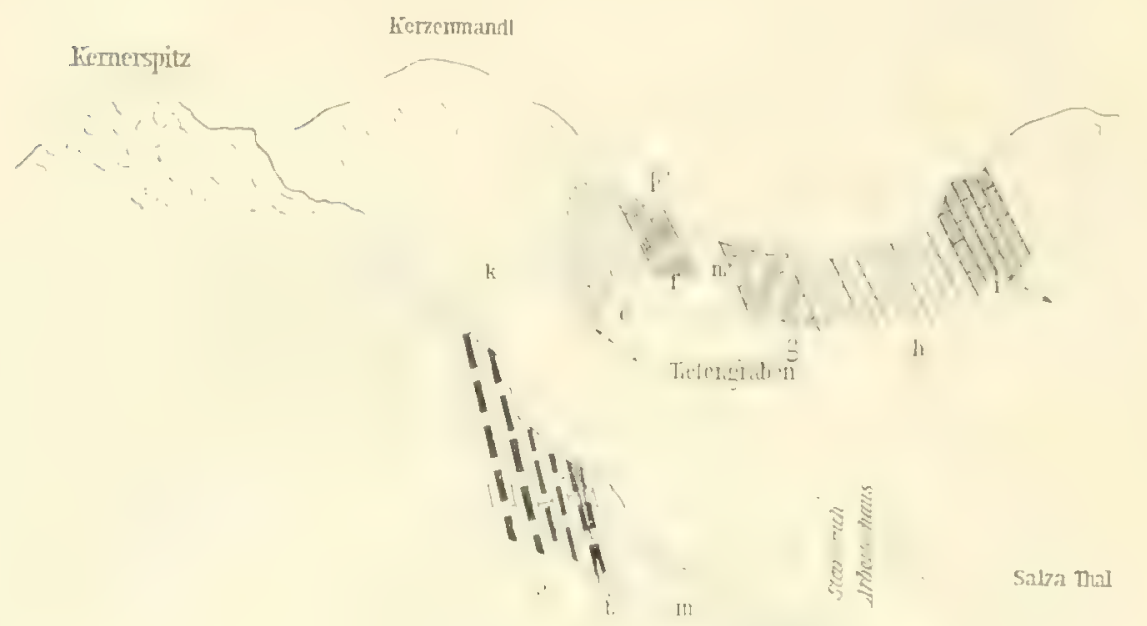

so.

Vicrwerfing

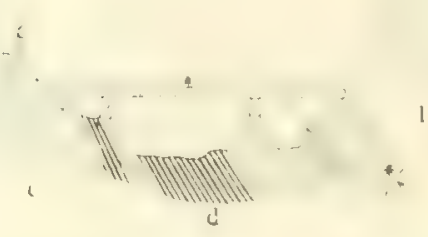

Schematisches Profil, die Entwicklung der Reiflinger Kalke zeigend.

a) Untere Reiflinger Kalke.

i) $\gg$ Cephalopoden-Horizont.

c) Obere Reiflinger Kalke.

(t) \$, Mergelniveau, Schichten mit Halobia Lommeli Wissm. sp.

i) Oberste Reiflinger Kalke und Schichten mit Ha. lobia intermedia Mojs.

f) Aonschiefer. s) Raingrabener Schiefer.

h) Lunzer Sandstein.

i) Opponitzer Kalk.

k) Hauptdolomit.

l) Schotterterrassen.

m) Gehär gschutt.

(1) $\beta$ angenommene Verwerfungstläche.

Ueber den Lunzer Sandsteinen folgt sodann der helle Opponitzer Kalk, in dem es mir nicht gelang, die bezeichnenden Versteinerungen zu finden, während mir Dr. Bittner mittheilte, dass er auch dort Corbis Mellingi Hauer,

Perna Bouéi Hauer,

Ostrea montis caprilis Klipst.

gefunden habe. Reicher freilich ist die Fossilliste, die er von dem eingangs erwähnten Fundorte Wolffsbachgraben im Westen von Reifling mittheilt: ${ }^{1}$ )

Fischschüppchen,

Gastropoden in ganzen Bänken,

Myophoria cfr. lineata Mstr.,

Myoconcha sp.,?

b) Verhandle. k. k. geol. R.-A, I8S7, pag. 82. 
Pecten filosus Hauer in Bänken,

Hinnites cfr. obliquus Mstr.,

Ostrea montis caprilis Klipst.,

Platten ganz aus kleinen Bivalven bestehend.

Auf diese Opponitzer Kalke folgt sodann in mächtigen Massen der Hauptdolomit, welcher die Triasablagerungen beschliesst.

$I_{i j} \cdot 2$.

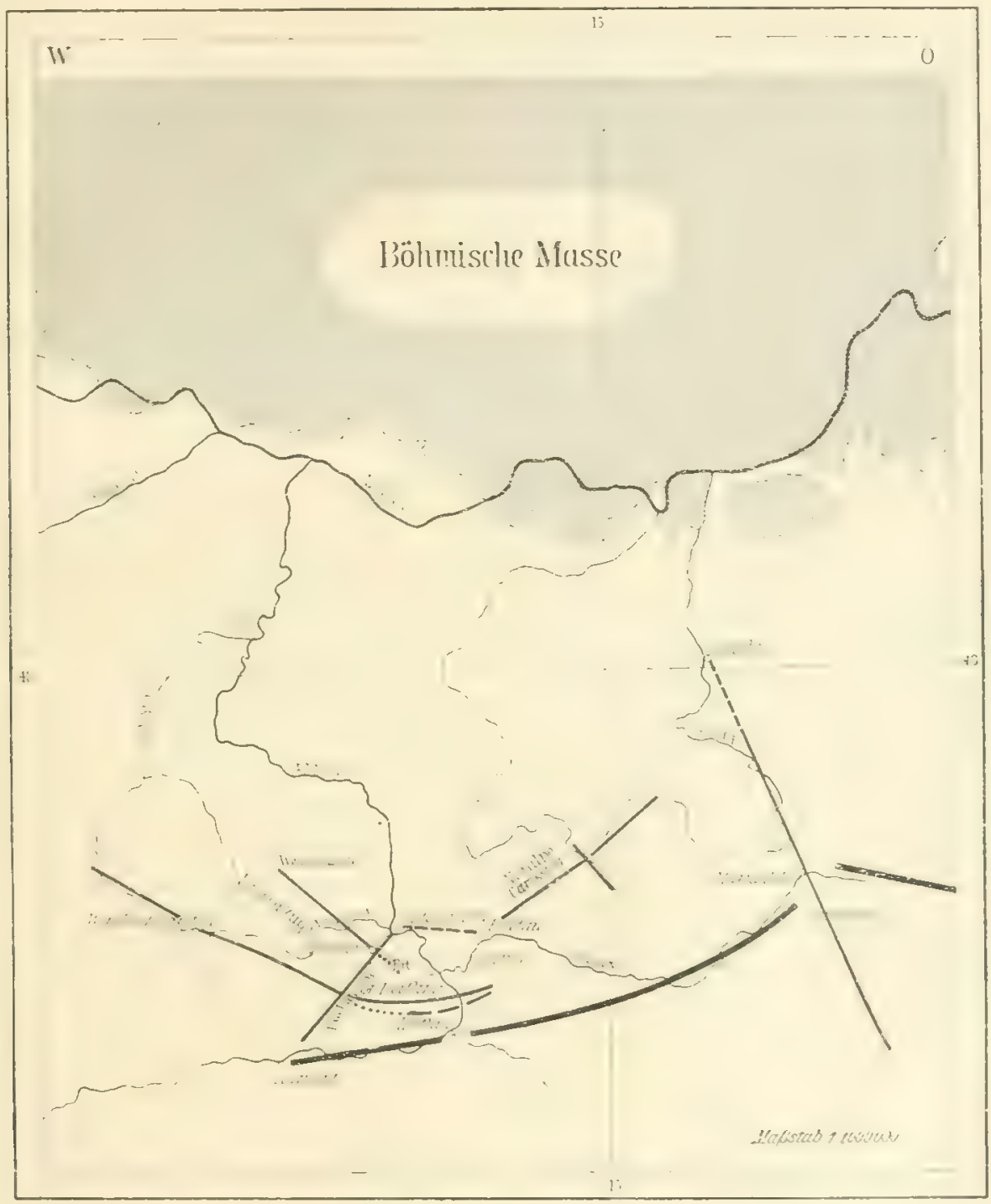

Situationskarte nach A. Bittner.

Dic grosse 'Trennungslinie zwischen Kalkmittelgebirge und Kalkhochgebirse

Wie man sieht, sind diese letzteren eben in dem Reiflinger Gebiete in vollständiger und ununterbrochener Reihe vom Werfner Schiefer bis in den Hauptdolomit entwickelt.

Das in Fig. I gegebene Profil sucht die Situation, wie wir sie am Eingange des Salzathales und des keinen Tiefengrabens finden, zu veranschaulichen. Es ist nur schematisch, weil dic eigentlich bestehenden drei verticalen Schnittfächen der Uebersichtlichkeit halber auf zwei reducirt werden mussten, wodurch eine Combination von Profil und Ansicht sich ergeben musste. 
In Hintergrunde sehen wir den Abschluss des Tiefengrabens, welcher auf der Höhe die oberen Triasglieder vom obersten Reiflinger Kalk bis zum Hauptdolomit zeigt, deren Fortsetzung gegen das vordere Profil im kleinen Thalkessel des Tiefengrabens erodirt ist und dort sowohl wie im vorderen Profil unter der Decke junger Conglomerate (Höhe des Gehöftes des Salzabauern) begraben liegen. Die Grenzen sind mit Sternchen bezcichnet.

Auf der rechten Thalseite — also der Nordwestseite - finden wir im vorderen Profil den unteren, im hinteren Profil den oberen Reiflinger Kalk discordant dem Hauptdolomit anlagern; wir sind also gezwungen, eine Verwerfung hier anzunehmen, welche entsprechend den zwei Schnittfächen nicht als Linie, sondern als Fläche $(\%, \beta)$ zum Ausdruck gebracht werden musste.

Um die tektonischen Verhältnisse des Reiflinger Gebietes klarzustellen, ist es nothwendig, etwas weiter auszuholen. Als Grundlage der folgenden Ausführung dienen in erster Linie die von

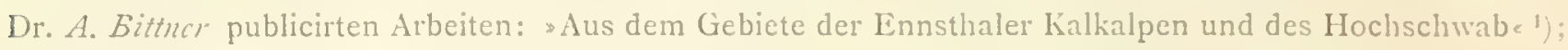
»Aus der Umgebung von Wildalpen in Obersteiermark und Lunz in Niederösterreich (pag. 74)"); sAus dem Gebiet des Hochschwab und der nördlich angrenzenden Gebirgsketten ${ }^{3}$ ); daneben müssen die älteren Arbeiten Haum's ${ }^{4}$ ) und Stur's ${ }^{5}$ ) herrorgehoben werden.

Wie schon oben kurz erwähnt, bildet die weitere Umgebung von Gross-Reifling, im Allgemeinen begrenzt durch die Punkte Altenmarkt a. d. Enns, Admont, Hieflau, Palfau, ein telitonisch hervorragend interessantes Gebiet, weil es nicht als einheitliches Stück erscheint, sondern durch die zahlreich durchstreichenden telitonischen Linien in einzelne Schollen zerlegt wird.

Die nach den oben angeführten Arbeiten Dr. A. Bittncr's construirte Kartenskizze (Fig. 2) sucht dies zu veranschaulichen. Wir sehen auf ihr axiale Linien und transversale, welche die ersteren kreuzen oder abschneiden. In welcher Weise die Aufbruchlinien und Gebirgszüge nördlich der grossen Hauptlinie Admont-Gusswerk beeinflusst sind, erklärt sich durch den stauenden Einfluss der Südwestspitze des böhmischen Massives, der nicht bis zu jener Haupttiefenlinie reichte. Nördlich und südlich derselben ist stets ein Einfallen der angrenzenden Gebirgstheile gegen diese Linie zu beobachten, was die hohe Bedeutung derselben in tektonischer Beziehung illustrirt.

Die Hauptlinie Admont-Gusswerk findet ihr Westende am Schiefergebirge und ist im Osten von der Transversallinie Kindberg-Mariazell_Scheibs abgeschnitten, an welcher östlich die Fortsetzung der ersteren, die Linie Mariazell-Buchberg, ihrerseits ihr Westende findet. Diese Transversallinie zeigt auffallend parallelen Verlauf mit einer seismischen Linie, für welche Prof. Sutss den Namen der Kampthallinie gewählt hat. Südwestlich der Mariazell-Scheibser Linie fällt uns eine zweite, jedoch viel kürzere Transversallinie auf, welche ähnlichen süđöstlichen bis nordwestlichen Verlauf zeigt und die telitonische Ursache des Göstlinger Ipsdurchbruches ist.

Als Querverwerfung unseres Gebietes ist ferner die Buchauer Linie zu nennen, welche, nördlich Admont beginnend, durch das Buchauthal zieht und in der Gegend ron Altenmarkt a. d. Enns ihr Ende findet.

Nördlich der grossen axialen Linie finden wir Aufbruchslinien, welche alle mehr oder weniger gegen diese convergiren und fast rechtwinklig gegen einander verlaufen. Die südwestlichste ist die Linie Windischgarsten-Admonter Höhe, welche von der Buchauer Querlinie hier geschnitten wird und sich jenseits derselben einestheils über den Landler Uebergang bis Gams fortsetzt, andererseits eine streckenweise parallel verlaufende Secundärlinie aufweist, die durch die Linien Bruckwirth AlmJodelbauer $\mathrm{Alm}$ gegeben ist und sich bei Gams mit der ersteren wieder vereinigt.

1) Verhandleg. k. k. seol. K.-A. I $\$ 87$, pag. $\$ 9$.

I888, "7I.

$1890,=306$

i) Jahrbuch k. k. seol. R.-A. IS6S, Bd. XVIII, Heft I; I853, Heft 4, pag. 7 I8.

Geologie der Steiermark, pag. 3 I6 ff. 
Fast parallel zu dieser zieht die Aufbruchslinie Weisswasser-St. Gallen-Erb, weiche ebenfalls ron der Buchauer Linie geschnitten wird und gegen Gams gravitirt, ron wo aus beide ihren Anschluss an die Hauptlinie suchen. Als gebrochene Linie desselben Typus möchte ich die Linie auffassen. welche östlich Altenmarkt beginnt und bis in die Gegend ron Palfau fortsetzt.

Entgegen diesem nordwest-südöstlichen Verlauf der Aufbruchslinien finden wir südwest-nordöstlich streichende, deren bedeutendste die Linie Palfau (südlicher Fuss des Gamssteines)_-Polzberg bei Lunz ist, welche durch die oben erwähnte kleine Transversallinie des lpsdurchbruches in zwei Theile zerschnitten wird.

Gerade im Reiflinger Gebiet haben wir das Aufeinandertreffen dieser beiden fast go" ron einander abweichenden Streichungsrichtungen, welche im Osten durch die Züge des Gamssteines und der Voralpe (Esslingalm) gegeben sind, während die westlichen nach Bittn'r als Züge der Mittellaussa zusammengefasst werden können. Beide sind, besonders die südlichen Ketten, fast senkrecht aufgerichtet und scheinen früher ein Ganzes gebildet zu haben, das durch die Buchauer Linie, bei Verschiebung der einzelnen Theile gegen einander, getrennt worden ist.

Das gemeinsame Merkmal dieser tektonischen Linien finden wir darin, dass sie in die Tiefe bis auf den Werfner Schiefer hinabreichen. Eine unterscheidet sich aber von den anderen Linien dieses Gebietes dadurch, dass in den durch die Störung geschaffenen Depressionen partienweise Kreideablagerungen nachgewiesen wurden, sie folglich unbedingt rorcretacisch sein muss, im Gegensatze zu den anderen, möglicherweise erst postcretacischen Linien. Es ist dies die Störungslinie Windischgarsten-Gams, deren Fortsetzung sich noch stückweise gegen Nordwesten verfolgen lässt. Im Osten finden wir erst bei Mariazell wieder Gosau, also schon jenseits der grossen TranswersalStörungsinie Krindberg-Scheibs.

Aus diesen oben geschilderten Verhältnissen ergibt sich daher ron selbst, dass für đie nächste Umgebung ron Gross-Reifling die Hauptstreichungsrichtung von Nordost gegen Südwest verläuft und jenseits der Enns sich ein Umschwenken gegen Nordwest bemerkbar macht. Das Fallen der Schichten ist meist ein sehr steiles, süđöstlich gerichtetes im Osten und fast südliches im Westen von Reifling. Besonders schön sieht man das Einfallen am Eingange des Tiefengrabens, das hier in weiteren Zusammenhang mit dem Fallen der. Schichten des Gamssteines zu setzen ist.

Die faunistischen Ergebnisse, welche sich zunächst aus der beigegebenen Tabelle ergeben. sind folgende:

In dem $S_{5}$ Nummern zählenden Verzeichniss - da Ceratites sondershusanus Picard sp. als nicht in die Reiflinger Fauna gehörig hier nicht in Betracht kommt - finden sich $S$ z systematisch verwerthbare Cephalopoden, welche sich auf

$$
\begin{aligned}
& 20 \text { Gattungen (I6 behannte und } 4 \text { neue) } \\
& \text { mit } S \text { I Species ( } 2 S \text {, } 53 \text { ? }
\end{aligned}
$$

vertheilen. Der grosse Procentsatz an neuen Elementen darf insoferne nicht sonderlich überraschen, wenn man bedenkt, dass die Muschelkalkfauna überhaupt noch recht unvollständig bekannt ist und dass, wenn ein neuer Fundort wieder neues Material lieferte, wie z. B. Han Bulog, stets eine Fülle

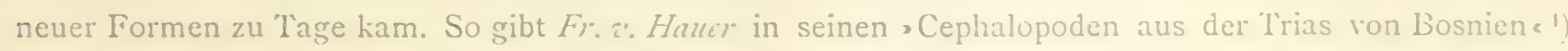
(pag. 4) die Uebersicht, dass von den 120 Arten, welche der Fundort Han Bulog lieferte, sich 52 mit schon beschriebenen Formen identificiren liessen und folglich $6 S$ Arten als neu übrig bleiben, ohne dass in beiden Fällen die Fassung des Speciesbegriffes eine zu enge wäre.

Zur Altersbestimmung der Cephalopodenfauna des Fundortes Tiefengraben sind ron den SI Species selbstrerständlich in erster Linie die $2 S$ schon beschriebenen Arten heranzuzichen, während für die 53 neten Arten eben nur die lerwandtschaftsverhältnisse mit schon bekanten lormen einen 
Maassstab minderer Bedeutung abgeben. Ls ist dies in der Tabelle auch durch die beiden Rubriken: "Bekannt $\propto$ und Verwandt zum Ausdrucke gebracht worden, wobei in letzterer del Index unter dem Kreuzchen die Anzahl der verwandten Formen angibt.

Von diesen 28 Species fallen 2 fort, weil diese bisher nur in höheren *onene nachgewiesen wurden:

in der Archelaus- und Aon-\%one und

$$
\text { Orthoceras politum Kilipst. }
$$

Nautilus cfr. granulatostriatus Klipst.

in der Zone des Trachyceras Aon.

Es verbleiben somit 26 Arten, welche sich derart auf die beiden Muschelkalkzonen vertheilen, dass 6 davon der Zone des Ceratites binodosus und 20 der Zone des Ceratites trinodosus angehören.

Diese sind für die Zone des Ceratites binodosus Hauer:

Ceratites binodosus Hauer.

Balatonites balatonicus Mojs.,

Acrochordiceras pustericum Mojs.,

Norites cfr. gondola Mojs.,

Ptychites dontianus Hauer,

$$
\text { * domatus Hauer, }
$$

für die Zone des Ceratites trinodosus Mojs.:

Orthoceras campanile Mojs.,

T'emnocheilus binodosus Hauer,

Pleuronautilus Pichleri Hauer sp.,

Nautilus cfr. lilianus Mojs., subgemmatus Mojs.,

Balatonites cfr. semilaevis Hauer,

Acrochordiceras enode Hauer,

Arcestes ventricosus Hauer,

Procladiscites Brancoi Mojs.,

Pinacoceras cfr. Damesi Mojs.,

Sageceras Walteri Mojs,

Norites gondola Mojs.,

Beyrichites cfr. maturus Mojs. sp.,

Ptychites Oppeli Mojs.,

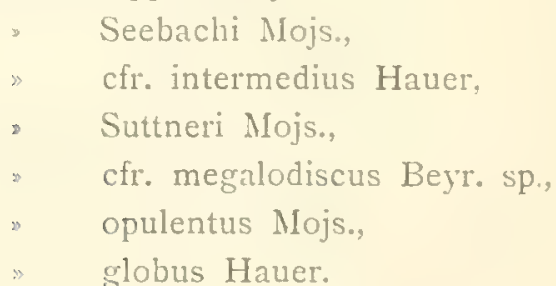

Es ist klar, dass nicht jede der angeführten Arten dieselbe Bedeutung für die Altersbestimmung der Schichte, welche sie lieferte, haben kann. Es sind daher vorerst die Formen in Wegfall zu bringen, deren Bestimmung sich nicht mit Sicherheit fixiren liess und daher nur als ähnlich - cfr. - bestimmt wurden. Es verbleiben somit der Binodosus-Zone 5 sicher bestimmbare Arten und der Trinodosus-Zone deren I4. Unter diesen gibt es jedoch wiederum Arten, welche vermöge ihrer charakteristischen Form oder engen verticalen Verbreitung sich besonders zu Leitfossilien eignen, während wieder für andere eine grössere verticale Verbreitung oder grosse Variationsfähigkeit der Individuen schon erwiesen ist. 
$\mathrm{Zu}$ den vertical weitverbreiteten rechne ich Sageceras Walteri Mojs., welcher sich sowohl in der Trinodosus-Zone als in der Zone des Protrachyceras Archelaus findet, ferner Orthoceras campanile Mojs.; zu den stark varirenden Formen aber die Ptychiten, unter denen sich Ptychites Suttneri Mojs. durch ganz besondere Variationsfähigkeit der Individuen auszeichnet.

Von dieser Ansicht ausgehend, müssen wir als minderwerthig für die Altersbestimmung aus dem Verzeichniss der Trinodosusformen wieder drei vernachlässigen, so dass es nur mehr II Arten enthält, unter denen gerade die charakteristischen Trachyostraca sehr benachtheiligt erscheinen, da wir nur mehr eine trachiostrace Form finden:

\section{Acrochordiceras enode Hauer}

im Verhältniss zu 3 Nautiliden- und 7 leiostracen Arten. Für die Binodosus-Zone stellen sich die Verhältnisse viel günstiger, da wir dort drei trachyostrace und zwei leiostrace Formen antreffen, und unter ersteren sich besonders typische Formen finden, welche längst als Leitfossilien anerkannt worden sind; darunter

Ceratites binodosus Hauer,

Balatonites balatonicus Mojs.,

Acrochordiceras pustericum Mojs.

Auffallend ist es, dass aus der Menge der bekannten Ceratiten der Trinodosus-Zone sich keine einzige hier findet oder iiberhaupt irgend eine trachyostrace Form, die doch an Localitäten dieses Niveaus keineswegs selten zu sein pflegen.

Aus dem Vorbergehenden ergeben sich als Verhältniss der Faunenelemente der Binodosuszur Trinodosus-Zone 5: I4. Im Ganzen sind uns aber aus der Zone des Ceratites binodosus bis heute nur 25 Arten bekannt, während die Zone des Ceratites trinodosus deren bis jetzt schon 158 geliefert hat. Es ist daher das Verhältniss 5:I4 entschieden viel grösser als das Verhältniss $25: 158$, weshalb auch dieses statistische Moment zu Gunsten der Annahme spricht, dass wir es im Fundorte Tiefengraben mit einer Localität der Binodosus-Zone, d. h. des unteren Muschelkalkes zu thun haben.

In der Rubrik »Verwandte Formen interessiren uns in erster Linie die Trachyostraca, denn hier muss der Ausfall gerade dieser Gattungen und Arten in der Rubrik » Bekannt von gedeclit werden. Als weitere Erklärung möchte ich nur noch beifügen, dass eine und dieselbe nov. spec. sowohl mit bekannten Formen der Binodosus- als Trinodosus-Zone recht gut verwandtschaftiche Merkmale aufweisen kann, was dann in dieser Kubrik zum Ausdruck gebracht worden ist.

In der That finden wir hier den Ersatz an Ceratiten, Balatoniten, Acrochordiceraten etc., deren Fehlen unter den schon beschriebenen Arten unbedingt auffallen musste; es sind deren 32 Arten. Hier finden wir die typischen Gattungen des Muschelkalkes durch neue Formen vertreten: Ceratites, Balatonites; Acrochordiceras, zu denen sich die neue Gattung Reiflingites gesellt. Die rerwandtschaftlichen Verhältnisse weisen auf ${ }_{3}$ Arten der Binodosus- und 23 Arten der Trinodosus-Zone hin, was entschieden einem Missverhältnisse in Anbetracht der grossen, respective geringen Formenmenge beider Zonen entspricht.

Von der Gattung Balatonites waren bisher I 7 Arten bekannt, jetzt treten 8 neue hinzu. Im Ganzen betrachtet, weisen die verwandtschaftlichen Verhältnisse auf If Irormen der Zone des Cerat. binodosus und 28 Formen der Zone des Cerat. trinodosus hin, während wir doch, würde die Verwandtschaft der höheren Zone präivaliren, mindestens dic sechsfache Formenmenge der l3inodosus in der Trinodosus-Zone voraussetzen müssten.

Wenn ich auch der Ansicht bin. dass auf die Relation der Verwandtschaftssummen nicht zu grosses Gewicht grelegt werden darf, so dient dieselbe trotz alledem zur weiteren Illustration der im Früheren mitgetheilten 'Thatsachen.

Dic Mittelrubrik der Tabelle lässt die Verbreitung der identificirten oder als sihnlich bezeichneten Arten erkennen. Zum Vergleiche wurde hicr das Gebiet des Balionywaldes in Ungarn und 
Südtirol herangezogen, während von den bekanntesten Localitüten des oberen Muschelkalkes der Nordostalpen, Reutte und Alles das, was unter den Begriff Schreyeralm fillt, Aufnahme fand und die

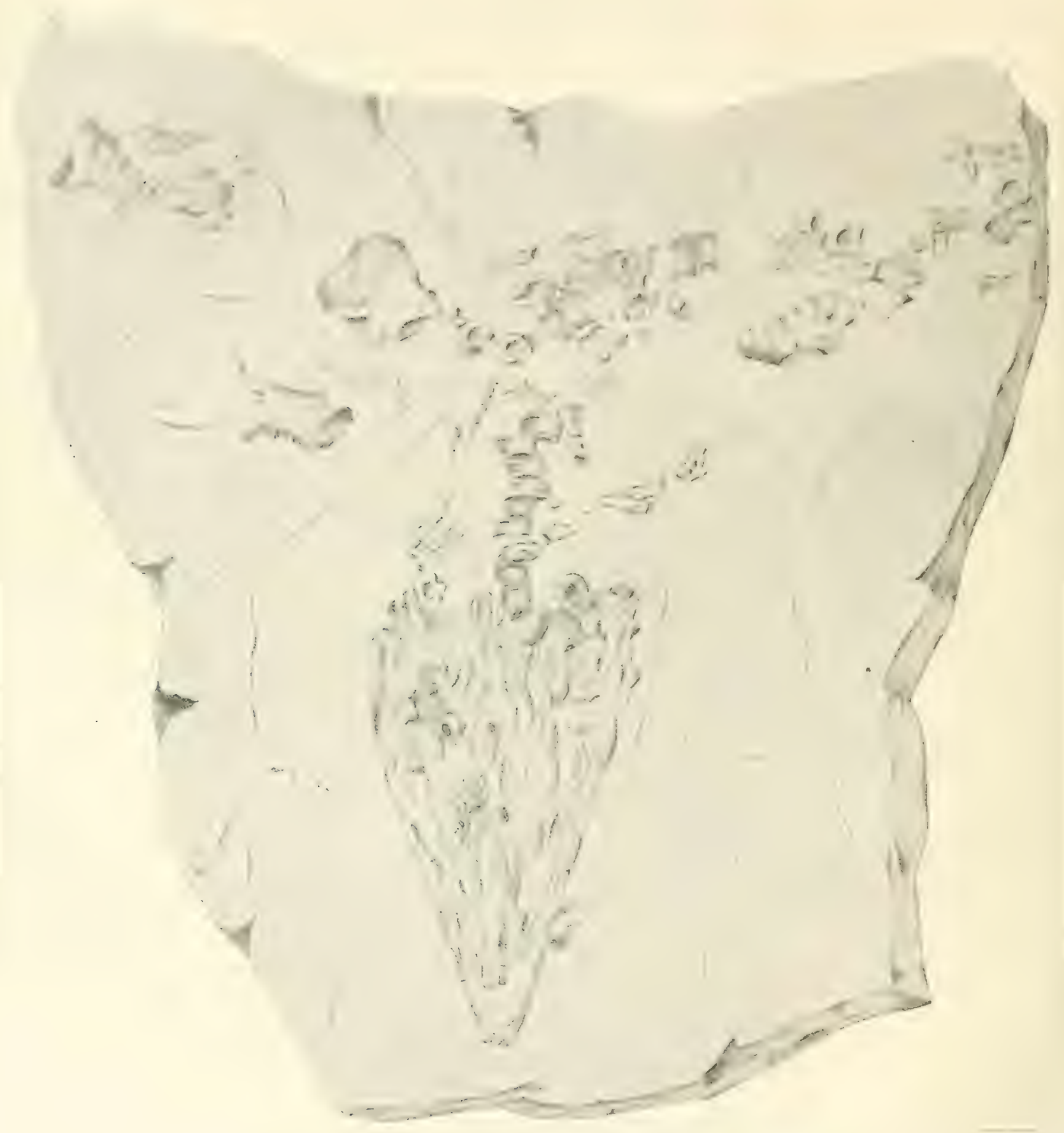

Abbildung des Saurierfundes von I'. Enselb. Pransmer im oberen Reiflinger Kalke des Scheiblinggrabens bei Gross-Reifling. Zeichnung des Landschreibers und Forstbesorgers Schmitt (vom Ende der Vierzigerjahre stammend). Circa $1 / 4$ der nat. Grösse.

'Tabelle endlich mit dem bosnischen Fundorte »Han Bulog abgeschlossen wurde. Da ist es nun auffallend, dass wir keine einzige Art finden, welche aus dem oberen Muschelkalke des Baliony oder 
Südtirols beschrieben wurde. Mit Reutte fanden sich nur zwei gemeinsame Formen, während Schrejeralm und Han Bulog. mit je dreizehn figuriren, während der untere Muschelkalk der oben angeführten Gebiete zehn Arten lieferte. Auch dieses Verhältniss: 10:28 spricht nicht sonderlich zu Gunsten der Trinodosus-Zone, da dieser kaum die dreifache Formenmenge angehört.

Bedenken wir, wie viele Formen speciell von den Nordostalpen aus der Trinodosus-Zone bekannt geworden sind, und vergleichen wir hiemit die Cephalopodenfauna des Tiefengrabens, so fällt uns in der markantesten Weise das Fehlen fast aller charakteristischen Formen dieser Zone auf, während die tiefere, bisher in den Nordostalpen nicht nachgewiesene Zone durch bekannte Leitfossilien vertreten erscheint. Ist es daher wahrscheinlich, dass die 'Trinodosus-Zone der Nordostalpen gerade hier an diesem neuen Fundorte Formen enthalten sollte, welche den anderen, viel reicheren Fundpunkten dieser Districte bisher fehlten, und andererseits wieder einen auffallenden Mangel an charakteristischen Leitfossilien aufweist, welche durch neue und nur verwandte Typen ersetzt sind?

Würde man trotzdem diese neue lFauna der höheren Zone zuweisen wollen, so hiesse das die faunistisch glücklich abgegrenzten Glieder des unteren und oberen alpinen Muschelkalkes wieder willKürlich verändern. Es bleibt natürlich hiebei die Annahme nicht ausgeschlossen, dass die Fauna des Tiefengrabens eventuell eine hohe Stellung in der Binodosus-Zone einnimmt und ein gewisser Grad der Mischung der höheren mit den tieferen Faunenelementen erreicht worden ist.

Aus all den oben angeführten Gründen, glaube ich, ist der Schluss vollkommen berechtigt, dass die Fauna, welche der Fundort Tiefengraben geliefert hat, der Zone des Ceratites binodosus angehört. Die Folge davon ist, dass die den fossilführenden Horizont unterlagernden Kalke älter sein müssen, und dass diese letzteren mit dem fossilführenden Horizont, dem unteren Reiflinger Kalk, die Aequivalente des unteren Muschelkalkes des Bakony und der Südalpen endlich auch in den Nordostalpen nachgewiesen werden konnten.

Es führten diese Schlüsse mich schliesslich zu derselben Ansicht, welche Herr Oberbergrath E. Mojsisorics nach Besichtigung meines Materiales aussprach, gegen deren Annahme ich mich aber lange Zeit sträubte.

Nachdem die Cephalopodenfauna auf ihr Alter geprüft wurde, muss auch die bis jetzt bearbeitete Brachiopodenfauna desselben Fundortes in Rechnung gezogen werden, deren Verzeichniss oben, pag. 2, gegeben wurde.

Wir finden daselbst vier Arten, von denen nur zwei als selbstständige, sicher bestimmte Formen in Betracht lommen:

\section{Rhynchonella trinodosi Bittner, \\ Spiriferina (Mentzelia) Mentzelii Dunk. sp.}

Erstere tritt im unteren Muschelkalk ${ }^{1}$ ) (Brachiopodenschichten des Dosso alto) der Südalpen auf und findet sich ebenso im oberen Muschelkalk (bei Wengen und St. Cassian), sowic letztere ebenfalls sowohl im Recoarokalk als bei Reutte gefunden wurde (loc. cit. pag. 25, 26). Daraus ergibt sich, dass wenigstens für die genauere Niveaubestimmung sich hier die Brachiopoden nicht verwenden lassen.

Entsprechend dem oben im geologischen Abschnitte gemachten Vorschlage, die kieselig-knolligen Reiflinger kalke nach dem fossilführenden Horizonte in untere und obere Kalke zu trennen, würde die ganze Serie, welche über diesem Niveau sich aufbaut, dem oberen Reiflinger Kalke zufallen. Die Hoffnung, auch in dieser oberen Partie fossilführende Ablagerungen zu finden, scheint nicht ohne jede Aussicht auf Èrfüllung zu sein, wenn wir bei Dr. Bittur ${ }^{2}$ ) das berüclisichtigen, was er ïber die Verhältnisse sagt, welche er auf dem Gamsstein bei Palfau gefunden hat. I)ort sind die Schichten fast

1) fitther, Abhandli. k. k. geol. R.-A., Bd. XIV, pas. I3.

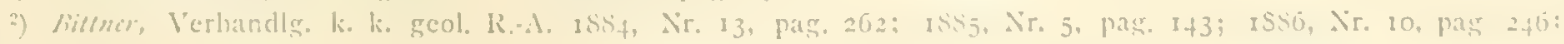
$1892, \mathrm{Nr}, 16$, pag. 306. 
senkrecht aufgerichtet und daher die Lagerung schwer sicherzustellen, jedoch lässt sich so viel constatiren, dass über dunklen Kalken Kieselknollenkalke von Reiflinger 'lypus folgen, in deren Horizont graue, grïnflaserige Kalke cinzubeziehen sind, welche bis jetzt nur

Orthoceras sp.,

Ptychites Studeri Hauer sp.,

flexuosus Mojs.

geliefert haben, also eine Fauna, »welche zunächst lebhaft an Lercheck-Schreycralm erinnest* (Verhandlg. 1884, pag. 262). Bezüglich des Ptych. Studeri ist die Bestimmung wohl nicht über allen Zweifel erhaben, da diese Form bis jetzt nur im unteren Muschelkalk von Dalmatien und Südtirol gefunden worden ist. Erinnert die obige Fauna aber thatsächlich an Lercheck oder Schreyeralm, dann haben wir am Gamsstein wohl schwerlich den echten Ptych. Studeri, sondern höchstwahrscheinlich - da er von Ptych. flexuosus verschieden sein muss - entweder den Ptych. acutus Mojs. oder den Ptych. indistinctus Mojs. Ueber diesen Kieselknollenkalken folgen dann lichte Kalke und Dolomite, die Gamssteinkalke Bittncr's, welche er früher als Wettersteinkalke bezeichnete. Hier am Gamsstein hätten wir also möglicherweise den oberen Muschelkalk fossilführend als Trinodosus-Zone vertreten. Klarheit lässt sich freilich nur dann erlangen, wenn sich auch Fossilien in den Liegendkalken nachweisen lassen und wenn diese der Binodosus-Zone angehören würden.

Die oberen Partien der oberen Reiflinger Kieselknollenkalke, welche schon petrographisch lebhaft an die Südtiroler Entwicklung der Buchensteiner Knollenkalke erinnern, eine Analogie, auf die schon Stur in seiner. Geologie der Steiermark (pag. 22I) besonders hinwies, wären - gesetzt den Fall, es liesse sich am Gamsstein thatsächlich die Trinodosus-Zone fossilführend nachweisen — vermöge ihrer geologischen Stellung über derselben und unter dem pag. 6 besprochenen Mergelhorizont, der unterhalb des Einflusses der Salza in die Enns aufgeschlossen ist, als Aequivalent des Südtiroler Buchen. steiner Kalkes (Zone des Protrachyceras Curionii) aufzufassen. Paläontologisch wird sich, wenigstens hier bei Gross-Reifling, diese Parallele nicht nachweisen lassen, weil der Erhaltungszustand der Fossilien in den groben Kieselknollenkalken ein zu ungünstiger ist.

Der nun folgende Mergelhorizont, welcher sich direct aus diesen Knollenkalken entwickelt, würde dann. das Aequivalent des Wengener Horizontes (Zone des Protrachyceras Archelaus) bilden.

Die pag. 6 angeführten Fossilien deuten entschieden auf ein ähnliches Niveau. Zieht man Analogien zum Vergleiche heran, so findet man das von Bittuc 'b beschriebene Vorkommen desselben Mergelhorizontes bei der Waldmühle (Kaltenleutgebener Thal, südwestlich von Wien). Auch dort treten im oberen Reiflinger Kalk Mergelschiefer auf von hellem, grünlichgrauem oder gelblichem Aussehen, welche eingelagert härtere Bänke oder Linsen eines dunkleren Kalkes enthalten, dessen Oberfäche die höckerige Beschaffenheit des Reiflinger Kalkes zeigt (loc, cit. pag. I62). Hier fand Bittncr in diesen Kalklinsen die bezeichnende Koninckina Leonhardi, Wissm. sp. der Partnachschichten Nordtirols und Oberbayerns. Haben wir aber hier die Aequivalente der Partnachschiefer anzunehmen, so deutet dies schon von selbst auf die grosse Wahrscheinlichkeit, welche der Parallelisirung desselben Mergelhorizontes - im oberen Reiflinger Kalke - mit dem Wengener Schiefer Südtirols zukommt.

Auch in diesem Falle hat Stu in der Geologie der Steiermarke, pag. 232, zum ersten Male diese Ansicht ausgesprochen, wenngleich er dem Wengener Schiefer eine zu grosse Ausdehnung gab (vgl. Bitner, Verhandlg. I894, pag. 382, Fussnote), da er auch die allerobersten Reiflinger Kalke, welche bei der Salzabrücke (pag. 7) Halobia intermedia lieferten, sammt dem niederösterreichischen Aonschiefer mit einbezog, während im Gegentheil Halobia Lommeli noch nie an der Grenze der Reiflinger Kalke nachgewiesen werden konnte, sondern - bis jetzt wenigstens - in diesen Grenzschichten schon durch Hal. intermedia ersetzt wird und daher auch im Aonschiefer nicht mehr auftreten kann. 
Bezüglich des Vorkommens auf dem Gamsstein bei Palfau liegt vielleicht ein Analogon zu den Verhältnissen in der Partnachklamm und der Zugspitze vor, wo ebenfalls der Mergelschiefer durch helle Wettersteinkalke überlagert erscheint.

Zum Schlusse sei noch das Auftreten von Riffbildungen erwähnt, welche Bittncr ${ }^{1}$ ) aus dem Traisenthale beschreibt. Es sind dunkle Gyroporellenkalke (Gyroporella pauciforata und G. minutula Gümb.), deren Alter den Gutensteiner oder Reichenhaller Kalken angehören dürfte, während die hellen Gyroporellenkalke jüngeren Niveaux der unteren Trias anzugehören scheinen.

Die folgende Tabelle zeigt die Eintheilung der Reiflinger Kalke in verticaler Richtung, sowie die thatsächliche oder eventuelle Aequivalirung dieser Theile mit Gliedern anderer Ausbildungsgebiete in verticaler Erstreckung.

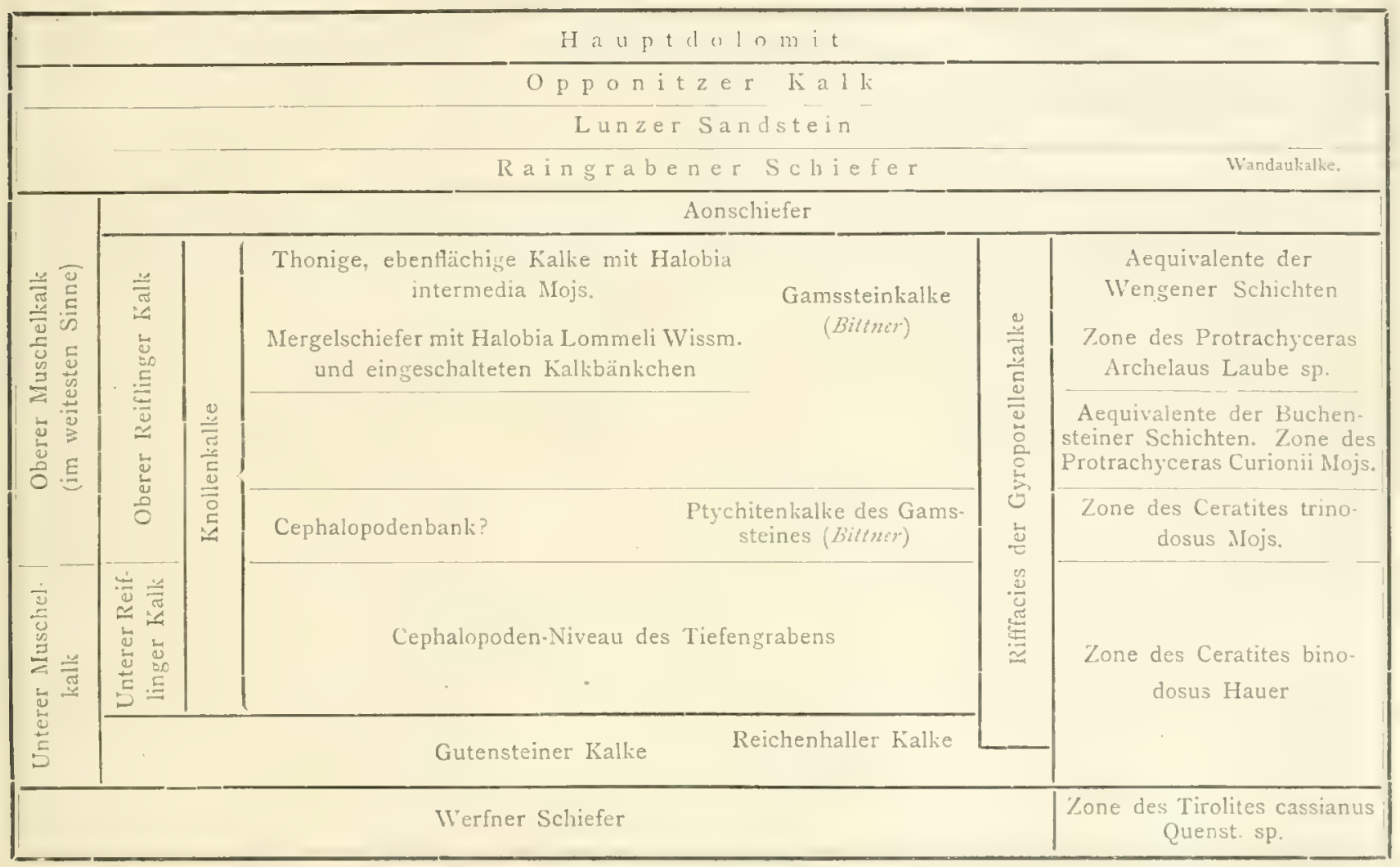

Schliesslich wird mir die angenehme Pficht zu Theil, allen Jenen meinen verbindlichsten Danli auszusprechen, welche mich mit Rath und That bei der Arbeit unterstützt haben; an erster Stelle meinem hochverehrten Lehrer, Hern Prof. Dr. W. Wargen, dessen reicher Erfahrung ich eine Fülle von Anregungen verdanke; dem Herrn Director der k. k. geologischen Reichsanstalt, Oberbergrath Dr. G. Stache, für die gütige Ueberweisung des Reiflinger Cephalopoden-Materiales aus dem Besitze der Anstalt; ferner Herm Intendanten Hofrath Fr. Ritter $\%$ Honcr. welcher mir in liebenswirdigster Weise gestattete, die Originalstücke von Han Bulog bei Vergleichen benützen zu dürfen; Herm Dr. A. Bitlncr für seine werthvollen Angaben bezüglich seines Reiflinger Aufnahmsgebietes, und Herm A. Picard in Sondershausen für die freundliche Uebersendung eines Abgusses des Ceratites sondershusanus Picard sp.

Eine fast vollständige Suite des Cephalopoden-Materiales befindet sich im Paläontologischen Institute der k. k. Universitait Wien.

$$
\text { り) Verhandlg. k. k. geol. R.A. } 189+\text {, pag. } 383 .
$$




\section{Verzeichniss}

der Cephalopodenfauna der Reiflinger Kalke.

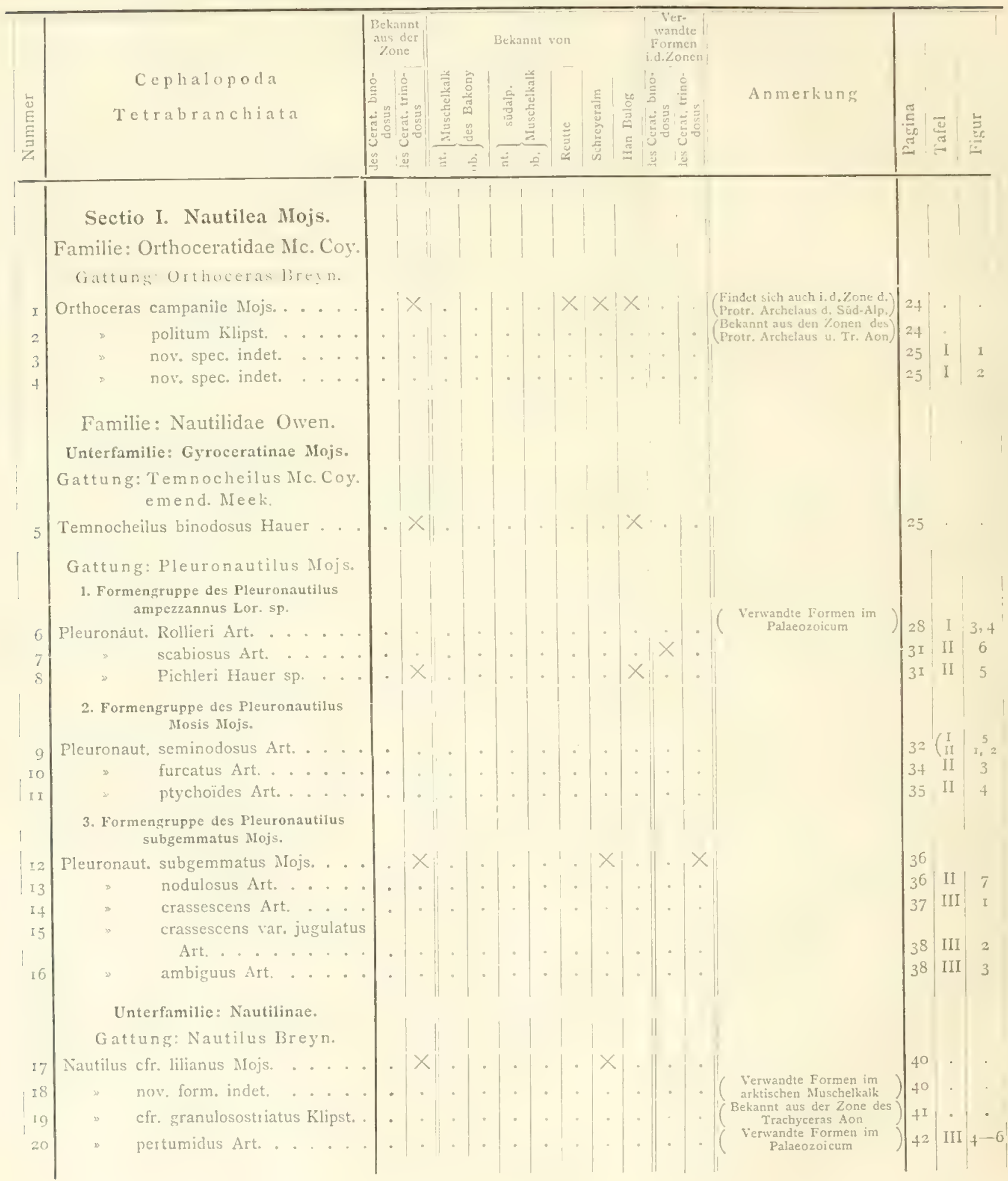




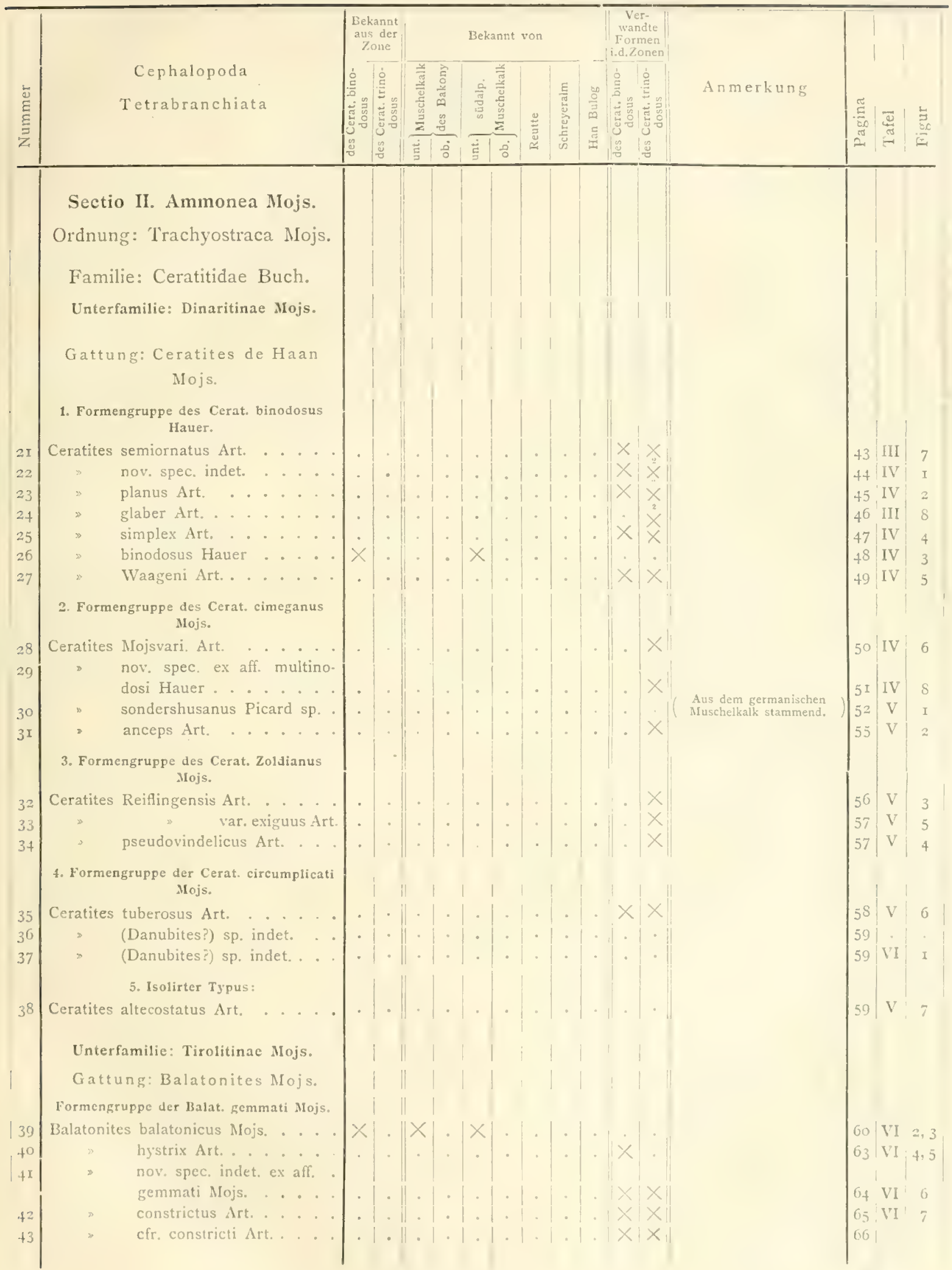




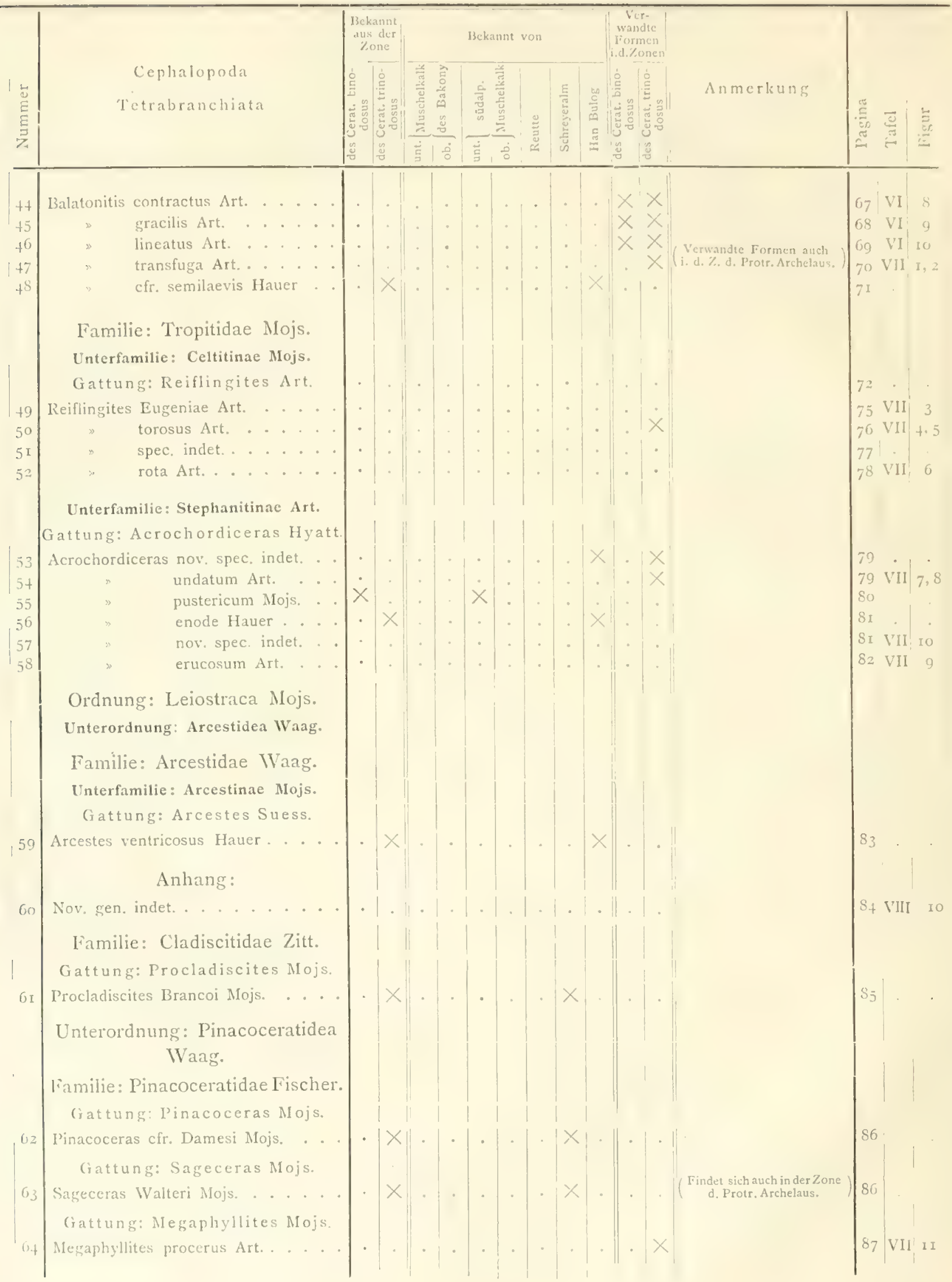




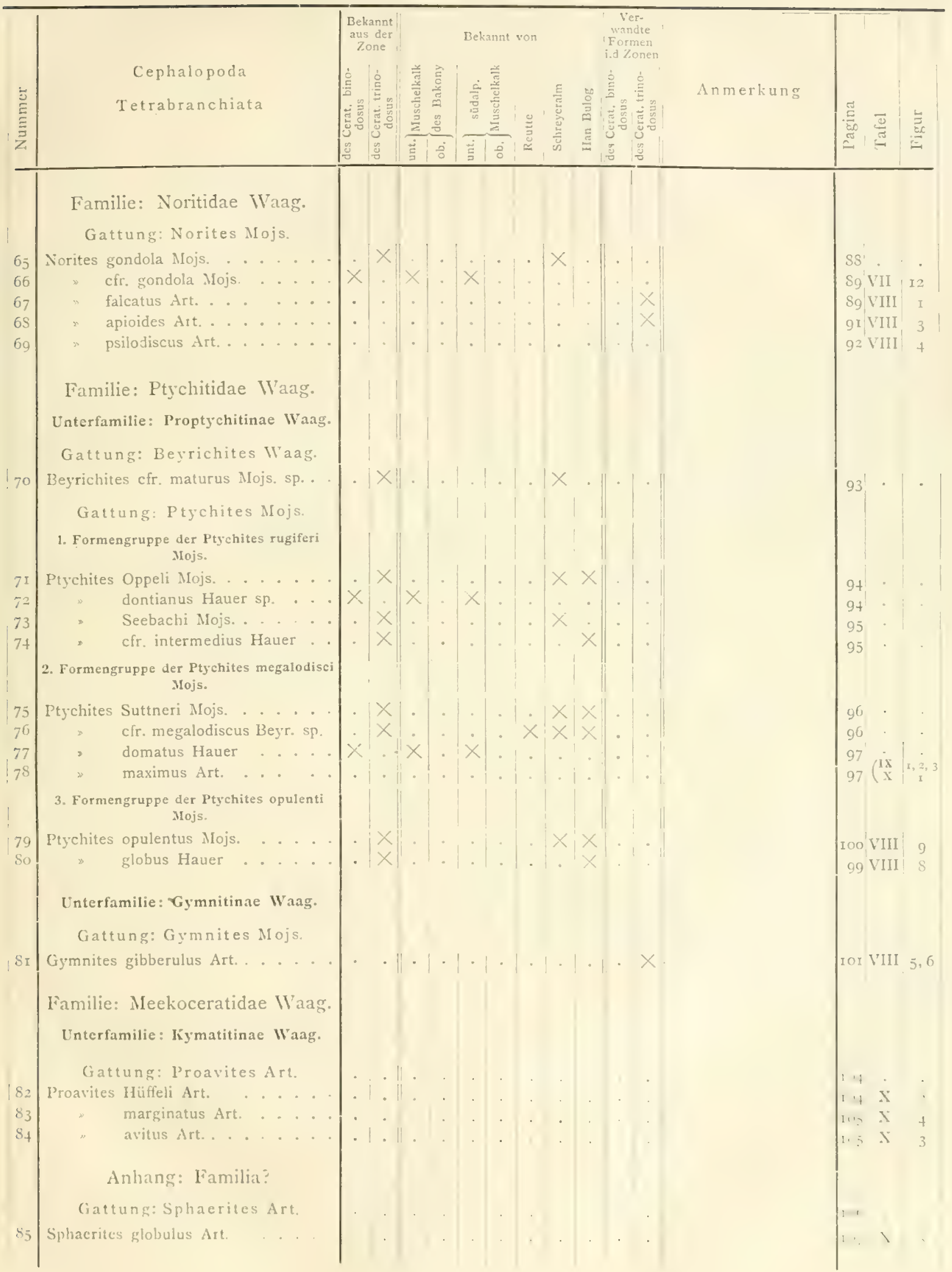




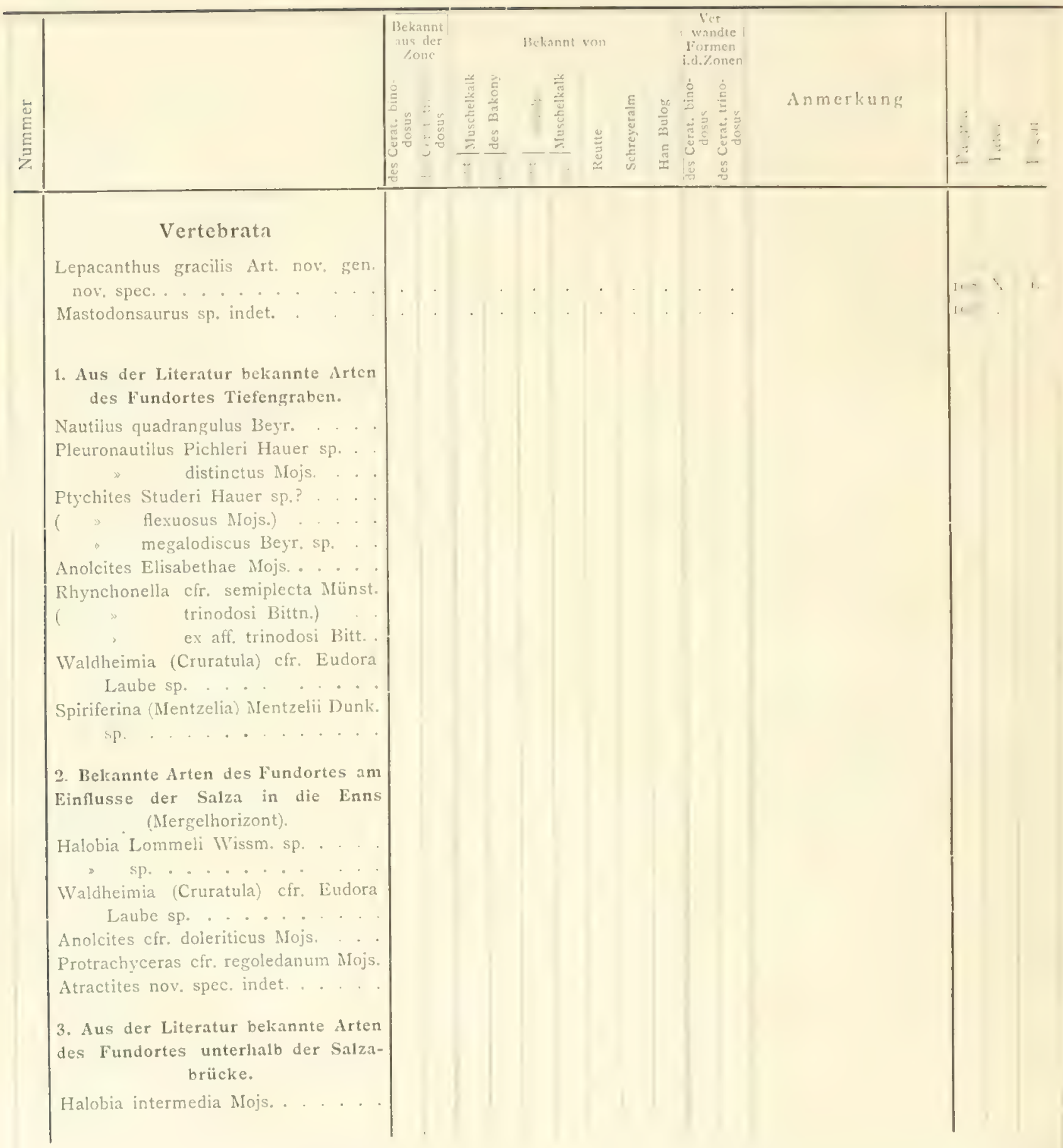

Anmerkung: Das kleine Gasteropoden-Material des Fundortes Tiefengraben wird in Zusammenhang mit anderen triadischen Gasteropoden seinerzeit durch Herrn Emst Kit th bearbeitet werden. Dr. A. Billme hat die wenigen Bivalven des Fundortes: Einfluss der Salza in die Enns freundlichst zur Bearbeitung übernommen. 


\title{
PALÄONTOLOGISCHER THEIL.
}

\author{
I. ABTHIILLNi. \\ LITERATURVERZEICHNISS.
}

Literaturangabe der am häufigsten benützten und im Texte nur abgekürzt citirten Werke:

Biyrick E, Ueber einige Cephalopoden aus dem Muschelkalke der Alpen und über verwandte Arten.

Abhandlungen der kgl. Aliademie der WVissenschaften für I866. Berlin I867, pag. I05.

IJaner Fy. $v$, Die Cephalopoden des bosnischen Muschelkaikes von Han Bulog bei Sarajevo.

Denkschriften der kais. Akademie der Wissenschaften. Math.-nat. Cl, Bd. LIV. Wien I 887.

- Beiträge zur Kenntniss der Cephalopoden aus der Trias von Bosnien. - I. Neue Funde aus dem Muschelkalk von Han Bulog bei Sarajevo.

Denkschriften der kais. Akademie der Wissenschaften. Math.-nat. Cl., Bd. LIX.

Klipstiin A. $\%$, Beiträge zur geologischen Kenntniss der östlichen Alpen.

Giessen I 843 .

Mojsisozics E. $v$., Die Cephalopoden der mediterranen Triasprovinz.

Abhandiungen der $k . k$. geologischen Reïchs-Anstalt, Bd. X. Wien I882.

- Das Gebirge um Hallstatt. I. Theil. (I. Hälfte.)

Abhandlungen der k. k. geologischen Reichs-Anstalt, Bd. VI. Wien I873.

- - Die Cephalopoden der Hallstätter Kalke. 1. Abtheilung. (2. Hälfte.)

Abhandlungen der k. k. geologischen Reichs-Anstalt, Bd. VI. Wien 1893.

OAp d 1\%, Ueber ostindische Fossilreste aus den secundären Ablagerungen von Spiti und Gnari Khorsum in Tỉet. Paläontologische Mittheilungen aus dem Museum des ligl. bayerischen Staates, Bd. I. München 1863.

Wiagen II:, Fossils from the Ceratite formation. Part. I. Pisces - Ammonoildea.

Palaeontologia indica Scr. XIII. Salt-Range fossils. Vol. II. Calcutta 1895 . 


\title{
CEPHALOPODA.
}

\section{Sectio I. Nautilea Mojs.}

\author{
Familie: Orthoceratidae Mc. Coy. \\ Gattung: Orthoceras Breyn. \\ Orthoceras campanile Ilojs.
}

1859. Orthoceratites dubius Stoppani partim. Pétrifications d'Esino, pag. 112, Taf. XXIV, IVig. I.

1865. Orthoceras sp. Hauer, Cephalopod, d. unt. Trias. Sitzungsber. k. k. Akad. d. Wissen. mat.-nat. Cl., pag. 6ro, Wien. I\$67. Orthoceras cfr. dubium Beyrich, Cephalopod. a. d. Muschelk. d. Alp. Abhandlg. k. Akad. d. Wissen. I866, pag. 138, Taf. III, Fig. 3, Berlin.

I869. Orthoceras campanile Mojsisovics, Beiträge zur Kenntniss der Cephalopodenfauna d. alp. Muschelk. Jahrb. k. k. seol. R.-A. pag. 590, Wien.

ISS2. Orthoceras campanile Mojsisovics, Cephalopod. d. Medit. Triaspr., pag. 29I, Tat. XClII, Fig. I- t, II. Abhandlg. k. li, geol. R.-A. Bd. I. WVien.

Das beste der vorliegenden Lxemplare zeigt bei einer Länge von $86 \mathrm{~mm}$ einen Durchmesser von I5 mm am Ende der Wohnkammer; diese selbst ist in einer Länge von $25 \mathrm{~mm}$ erhalten.

Das Stück zeigt die charakteristischen Merkmale der Species und stimmt besonders mit dem von Mojsisovics in Fig. 3 abgebildeten Exemplar überein. Der Wachsthumswinlel beträgt ungefähr $5^{\prime \prime}$.

Diese Species ist ziemlich häufig, aber selten gut erhalten, und wird von Mlojsisovics aus der Trinodosus-Zone der Schreyeralm angeführt und mit dem von Bcyrich aus dem schwarzen Kalkstein von Reutte angeführten Orthoceras cf. dubium Hauer identificirt.

\section{Orthoceras politum Klipst.}

I8 \$3. Orthoceras politum Klipstein, Beiträge zur geolog. Kenntniss d. östl. Alpen, pag. I44, Taf. IX, Fig. 6. Giessen,

I859. Orthoceratites dubius Stoppani, partim. Pétrifications d'Esino, pag. II2, Taf. XXIV, Fig. 2-4.

I859. Orthoceratites dimidiatus Stoppani, ibidem pag. II3, Taf. XXIV, Fig. 5, 6,

IS69 Orthoceras politum Laube, Fauna der Sch, von St. Cassian. Denlischr. k. Aliad. d. Wissen. mat.-nat. Cl., Bd. X.XX. pag. 60, Taf. XXXVI, Fig. 8.

1877. Orthoceras politum Klipst. Barrande, Systême silurien du centre de la Bohème. Vol. II, 5, pag. I325. pl. 488 , Case Xi, Xil.

t882. Orthoceras politum Klipst. Mojsisovics E. Y.. Cephalopod. d. Medit. Triaspr., pag. 293, Taf. XCII, Fig. I3, It; Taf. XCIII, Fig. 7, 8 .

Das vorliegende Ǩammerfragment zeigt bei einer Länge von $85 \mathrm{~mm}$ einen grössten Querschnitt von $17 \mathrm{~mm}$, kleinsten von $8 \mathrm{~mm}$ und einen Wachsthumswinkel von fast 6". Durch Druck ist der Querschnitt elliptisch deformirt; die Kammerabstände sind ungleich und der Sipho central gelegen. Die Schale ist theilweise noch erhalten, zeigt feine bandförmige Horizontalstreifen und stellenweise eine breitere seichte Einschnürung.

Klipstcin führt diese Species unter seinen Versteinerungen von St. Cassian und IFojsisoaics ebendaher von den Sturoeswiesen, aus der Zone des Trach. Aon, ferner auch vom Monte Clapsaron im Irriaul aus der Archelaus-Zone an. 
Orthoceras nov. spec. indet.

Taf. I, Fig. I.

Das grösste der vorhandenen Exemplare hat eine Länge von circa $80 \mathrm{~mm}$ bei einem grössten Durchmesser von $I^{\circ} 7 \mathrm{~mm}$, kleinsten von $12 \mathrm{~mm}$ und Wachsthumswinkel von circa $5^{\circ}$.

Der geringe Abstand der Kammerscheidewände, welcher grösser als bei Orthoc. subellipticum d'Orb. ${ }^{1}$ ), aber kleiner als bei irgend einer der von Mojsisovics abgebildeten Formen des Orthoc. campanile Mojs. ${ }^{2}$ ) (pag. 29I, Taf. XCIII, Fig. I-4 und Fig. II) ist, unterscheidet diese Species von anderen. An einzelnen noch vorhandenen Schalenfragmenten lässt sich eben noch constatiren, dass die Schale keine Streifen, sondern mikroskopisch feine Körnelung aufweist, was vielleicht aber auch nur auf die Art der Erhaltung zurückzuführen ist. Der Querschnitt ist rundlich, das abgebildete Stück aber seitlich verdrückt; der Sipho liegt central.

Diese Species erreichte jedenfalls bedeutende Grösse, da auch ein Bruchstück mit theilweise erhaltener Wohnkammer von $42 \mathrm{~mm}$ Durchmesser vorliegt.

\section{Orthoceras nov. spec, indet.}

Taf. I, Fig. 2

Das kleine Fragment hat eine Länge von $22 \mathrm{~mm}$, grössten Durchmesser von Io mm, kleinsten von $8 \mathrm{~mm}$ und Wachsthumswinkel von $\mathrm{S}^{\circ}$.

Wir finden hier die mikroskopische, bandförmige Streifung wieder, welche Ilojsisovics $^{3}$ ) bei seiner nov. fo indet (pag. 293, Taf. XCIII, Fig. 5, 6) aus der Zone des Protrach. Curionii aus dem Bakonywalde angibt. Die vorliegende Species, die sich nur durch grössere, theilweise variirende Kammerabstände unterscheidet, scheint auch ähnliche Grössenverhältnisse wie jene zu haben.

Familie: Nautilidae Owen.

\section{Unterfamilie: Gyroceratinae Mojs.}

Gattung: Temnocheilus Mc. Coy. emend. Meek.

\section{Temnocheilus binodosus Hauer.}

ISS7. Hazer Fr. v., Cephalop. bosn. Muschelk. Denlischrift. mat.nat. CI. Bd. LIV, pag. I8, Taf. III, Fig. 5.

Das vorliegende Exemplar ist ein kleines Schalenbruchstück von $22 \mathrm{~mm}$ Länge und I7 mm Höhe. Erhalten ist von demselben ein Theil der Flanke mit einem Nabelknoten, ferner die geknotete Externkante, sorvie ein Theil des Externtheiles. Man sieht deutlich die länglich-rundlichen und etwas schräg gestellten Externknoten, sowie einen der flachen Nabelknoten. Die Flanke ist fast flach und zeigt nur eine ganz minimale, rippenförmige Auftreibung. Es treten ferner auf ihr zarte, radial angeordnete Anwachsstreifen auf, welche sich jenseits der Externkante scharf nach rüchwärts biegen. Hier auf dem Externtheil heben sich einzelne dieser Anwachsstreifen stïrker heras und scheiden dadurch ungefäh I mm breite, flache Bänder mit feiner Streifung ab. An dem vorliegrenden Stüclie sind auch die undulirten Längsstreifen, von welchen Haur sagt, dass sic stellenweise zu sehen sind, als ganz zarte, nur mikroskopisch wahrnehmbare Linien zu beobachten. An dem vorliegenden Stücke liessen sich die Kammerscheidewände nicht beobachten.

T'emnocheilus binodosus wird ron Haucr aus dem Muschelkalk von Han Bulor beschrieben.

1) d'Orbigny', I'rodrôme de Paléont, stratignraph. I, paş. I79. IS 49 .

3) Mojsisovios lí. a', Cephalop. Medit. 'Iriaspr.

3) Mojsisontics Li. $z^{\prime}$, Cephalop. Medit. 'T'riaspr. 


\section{Gattung: Pleuronatilus Mojs.")}

Das Reiflinger Material lieferte einige neue Momente, welche zur Vervollständigung der (inttungsdefinition, wic sie Arojsisozics pag. 273 gegeben hat, hier Aufnahme finden müssen und daher in die wörtlich citirte Definition eingeschaltet werden:

"Der Externtheil der rechteckigen oder trapezoïdalen, cinander nur wenigr umhüllenden, wcitnabeligen Formen ist, wie bei Temnocheilus, glatt, sculpturfrei; die Seiten sind flach oder flach gewölbt und in der Regel mit kräftigen, leicht geschwungenen Querrippen (P'. ampezzanus Mojs., pag. 277), seltener geraden (Pl. Wulfeni Mojs, Geb. um Hallstatt, pag. Io), oder Spaltrippen (Pl. furcatus Art, pag. 34), oder mit Längssrippen (I'l. subgemmatus Mojs., pag. 277) bedeckt. Dic meisten Formen mit Radialrippen zeigen auf diesen mehr oder weniger leichte lnotenförmige Anschwellungen oder eine oder melurere Knotenspiralen.

Die längsgerippten Formen hingegen haben weine Crenelirung bis deutlich radial gestellte Beknotung. Die Umbilicalwand ist meist hoch und sehr steil gestellt.

Die Kammerscheidewände weisen stets Extern-, Lateral- und Internlobus auf, welche meh oder weniger stark entwickelt sind. Der Sipho liegt meist unterhalb der halben Mündungshöhe und rückt nur bei einigen frormen (Pl. ampezzanus Loretz sp., Pl. superbus Mojs., I'. Ramsaueri Hauer sp.) nahe an die Internwand heran. Der Nabel ist meist perforirt. Linige Formen lösen sich im erwachsenen Zustande von der Spirale ab (PI. Rollieri Art. und seminodosus Art.). Auffallender Veise haben beide letztgenannten Formen auf dem Steinkerne den Rand der Externbucht des Aundrandes in derselben Art aufgestülpt, wie es bei paläozoischen Nautiliden bekannt ist."

Die Formenmenge der triadischen Pleuronautilen lässt sich gut in drei Formengruppen zusammen. fassen. Nachdem die Gattung, im Grunde genommen, auf das Auftreten von Falten oder Rippen auf dem Lateraltheil hin aufgestellt wurde, so benütze ich diesen Eintheilungsfactor auch zur Aufstellung folgender Formengruppen:

\section{Formengruppe des Pleuronautilus ampezzanus Loretz sp.}

unfasst Formen mit trapezoidalem oder mehr rundlichem Querschnitt; die Flanken sind mit geraden, meist leicht nach rückwärts geschwingenen Falten bedeckt, welche bei höher entwiclielten Formen leichte oder stärkere Anschwellungen aufweisen, ohne dass sich dieselben zu Knoten individualisirt hätten. In diese Gruppe gehören die Formen mit tiefliegendem Sipho.

Pleuronautilus ampezzanus Loretz sp.

.rrysisozics. Cephalop. Medit. 'Triaspr,, pag. 277, Taf. Lxxxiv, Fig. I.

Pleuronautilus semicostatus Mojs.

Mojsisorice, Cephalop. Medit. 'Triaspre, pag. 27 S, Taf, LXXX'I, Fig. I, 2.

Pleuronautilus Ramsaueri Hauer sp.

Ilumer, Beitrïge zur kenntniss der Cephalopodenfauna der H.llstätter Sch., pag. I 44, Taf. I, Fig. 5, 6. Denkschriften k. Ak, d. Wiss. mat.-nat, Cl. Bd. IX. Wien IS55.

Pleuronautilus distinctus Mojs.

Mossisorics, Cephalop. Medit. T'riaspr., pag. 27S, Taf. LxxxV, Fig. 4.

Pleuronautilus Rollieri Art.

Cephalopodenf, der Reiflinger kalke, pag. 28, Taf. I, I’ig. 3. 4

P'leuronautilus scabiosus Art

Cephalopodenf. der Reiflinger Kalke, pag. 3 I, Taf. II, I*ig. 6

1) Mojsisozics It. ₹'.. Cephalop. Medit. 'Triaspr. 
Pleuronautilus esinensis Mojs.

Mojsisorics, Cephalop. Medit. Triaspr., pag. 276, Taf. LXXXVI, Fig. 5, 6.

Pleuronautilus Pichleri Hauer sp.

Inuer, Cephalop. bosnisch. Muschelk., pag 15, Taf. III, Fig. I.

Pleuronautilus superbus Mojs.

Moojisovics, Gebirge um Hallstatt, pag. I8, Taf. IV, Fig. x.

Pleuronautilus striatus Hauer.

Haucr, Cephalop. der Trias von Bosnien, pag. 7, Taf. II, Fig. 2; Taf. XIV, Fig. 2.

Pleuronautilus Marmolatae Mojs.

Mojsisovics, Cephalop. Medit. Triaspr., pag. 276, Taf. LxxxvI, Iig. 4.

Letztere Form schliesst sich mit ihrex wechselnden Sculptur gut an die Formen der Sub. gemmatusgruppe an.

\section{Formengruppe des Pleuronautilus Mosis Mojs.}

Der Querschnitt der hiehergehörigen Formen ist trapezoïdal oder rechteckig, je nachdem sie entweder der Ampezzanusgruppe, verkehrt trapezoïdal, wenn sie der Gattung Temnocheilus, oder mehr gerundet, wenn sie der Gattung Nautilus nahestehen. Die Flanken tragen Rippen nit deutlich entwickelten Knoten.

Hieher rechne ich:

a) Temnocheilus nahestehend:

Pleuronautilus oenanus Mojs.

Mrojsisovics, Cephalop. Medit. Triaspr., pag. 279, Taf. LxxxvII, Fig. 2.

b) Nautilus nahestehend:

Pleuronautilus Kellneri Hauer.

Ihauer, Cephalop. bosnisch. Muschells, pag. If, Taf. II, Fig. 2.

Pleuronautilus subaratus Keys. sp.

Mrijsisovics, Arktische Triasformen, pag. 97, Taf. XVI, Fig. I.

c) Der Ampezzanusgruppe nahestehend:

Pleuronautilus Cornalize Stopp. sp.

Mojsisovics, Cephalop. Medit. Triaspr, pag. 275, Taf, LXXXIV, Fig. 2, 3.

Pleuronautilus seminodosus Art.

Cephalopodenf, der Reiflinger kalke, mag. 32, Taf, I, Fig. 5; 'Taf. II, Fig. I, 2.

Pleuronautilus Mosis Mojs.

Mejsisorics, Cephalop. Medit, Triaspr, pag. 274, Taf. I.xxxV, İig. 3.

Pleuronautilus trinodosus Mojs.

Mojsisovies, Cephalop. Medit. Triaspr., pag. 27+, Tar. LXXXV, Mïg. I,

I'leuronautilus furcatus Art.

Cephalopodenf, der Reiflinger Kalke, pag. 34 , Taf. II, Fig. 3.

Pleuronautilus ptychoïdes Art.

Cephalopodenf, der keiflinger kalke, pag. 35, Taf. 11, Fig. 4 .

Pleuronautilus Wulfeni Mojs.

Wejsisovics, Gebirge um Hallstalt, pag. I0, Taf, VII, Iivg. 3. 
Pleuronautilus auriculatus Hauer.

Hexucr, Cephalop, 'Trias von Bosnien, pag. 9, Taf. II, Iig. I.

Pleuronautilus ornatus Haucr.

Hauer, Cephalop. bosnisch. Muschelk., pag. 17, 'Taf. III, Irig. 2.

Pleuronautilus perarmatus Mojs.

Nojissovics, Gebirge um Hallstatt, pag. 9, 'Taf. II, Fig. 2.

Pleuronautilus quadrangulus Hauer sp.

Ilauy, Cephalop. 'Irias von Bosnien, pag. 9, Taf. II, Iig. 3.

Pleuronautilus Fischeri Mojs.

Mojsisorics, Gebirge um Hallstatt, pas, Io, Taf. IV, Irig. 4.

\section{Formengruppe des Pleuronatilus subgemmatus Mojs.}

Die Formen dieser Gruppe sind klein, haben trapezoïdalen Querschnitt, auf den Flanken Spiralberippung oder, wie bei den drei letztgenannten Arten, ausserdem noch mehr oder weniger starke Radialberippung, welche somit auf nahe Verwandtschaft mit den Formen der Ampezzanusgruppe hinweist. Auffallend ist bei eben diesen drei Arten der Wechsel der Sculptur auf der Wohnliammer.

Ich rechne hieher:

Pleuronautilus subgemmatus Mojs.

Mrojsisovics, Cephalop. Medit. Triaspr., pag. 277, Taf. LXXXV, Fig. 2.

Pleuronautilus nodulosus Art.

Cephalopodenf. der Reiflinger Kalke, pag. 36, Taf. II, Fig. 7.

Pleuronautilus crassescens Art.

Cephalopodenf, der Reiflinger Kalke, pag. 37, Taf, III, Fig. I.

Pleuronautilus crassescens var. jugulatus Art.

Cephalopodenf, der Reiflinger Kalke, pag. 38, Taf. III, Fig. 2.

Pleuronautilus ambiguus Art.

Cephalopodenf. der Reiflinger Kalke, pag. 38, Taf. III, Fig. 3 .

Pleuronautilus planilateratus Hauer sp.

Haue, Nachträge zur Kenntniss der Cephalopodenfauna der Hallstätter Sch. Sitzungsber, k. Akad. d. Wiss, mat.-nat. Cl. 13d. X'LI. Wien IS60.

\section{Formengruppe des Pleuronautilus ampezzanus Loretz $\mathrm{sp}$.}

\section{Pleuronautilus Rollieri Art.}

Taf, I, Fig. $3 a, b, c$, Fig. $4 a, b$.

Das besterhaltene der vorliegenden Exemplare (Fig. 3) weist folgende Maasse auf:

Inurchmesser . . . . . . . . . . circal gi mm

Nabelweite (von Naht zu Naht)..... . $35=$

Höhe der letzten Windung. . . . . . . 40

Breite " * * (Marginaltheil) . . 38

(Umbilicaltheil) . . 40

Perforation des Nabels.......... Io " 
Pleuronautilus Rollieri hat einen flach gewölbten und auf der Mittellinie leicht eingekerbten Externtheil, die Flanken sind flach, die Nabelwand hoch und senkrecht, nur auf dem Ende der Wohnkammer schief gestellt, der Querschnitt derselben ist annähernd trapezoildal, wobei die Höhe gleich der grösseren Breite ist, deren Linie durch die Umbilicalknoten läuft. Die Sculptur besteht in kräftigen, rundlichen Radialrippen, welche auf der Umbilicalwand mit einem kurzen, nach rückwärts gerichteten Rippenstück beginnen, jedoch auf der Flanke selbst streng radial bis zur gerundeten Marginalkante verlaufen. Ihnen sind bei dem abgebildeten Stücke (Fig. $3 a$ ) auf der Wohnkammer je ein stumpfer Umbilical- und ebensolcher Marginalknoten aufgesetzt. Am Beginne der Wohnkammer sehen wir aber noch einen kleinen dritten Knoten in der oberen Hälfte der Radialrippe auftreten, der bei der ersten und zweiten vorhergehenden Rippe noch stärker entwickelt ist. Ebenso tritt - aber nur an einer

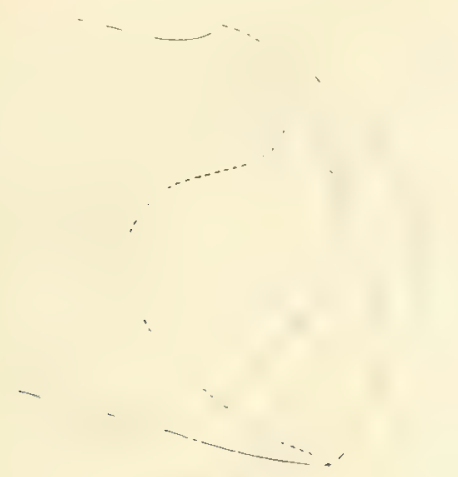

Iin i.

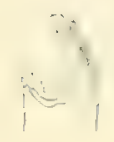

Fig. 8 .

Glossoceras gracile Barr

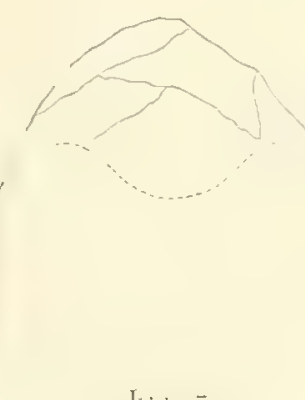

I.t. - .

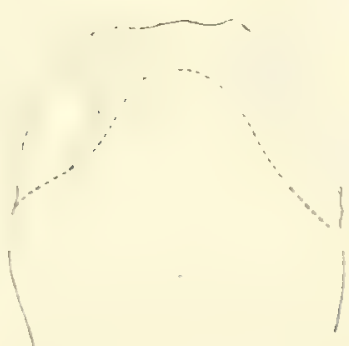

Fig. 6.

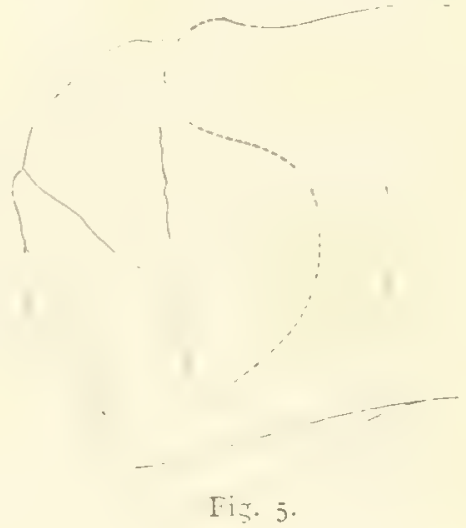

Fig. 9.

Ophidioceras simplex Barr.

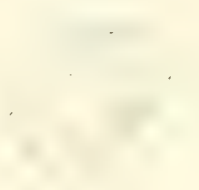

Mundrandformen triadischer und paliozoischer Nautiliden.

Stelle sichtbar - ein kleiner stumpfer Knoten im Intercostalfeld der Marginalkante auf. Leider lässt der Erhaltungszustand der Stücke nicht den Ursprung dieser beiden Kinotenelemente auf den jüngeren Windungen sehen, von welchen es den Anschein hat, als wenn dieselben nur mit knotenlosen Rippen versehen wären, was immerhin ein sonderbarer Sculpturwechsel wäre.

Die Kammerscheidewände (Fig. 3 c) zeigen auf dem Externtheil eine flache 13ucht; der Laterallobus ist gross und weit unter den marginalen Vorsprung zurückweichend; über die Umbilicalwand reicht die Kammerscheidewand senkrecht hinab; ihr weiterer Terlauf ist nicht zu crmitteln. Der Sipho scheint tief unter der Kammermitte zu liegen.

Die Schale ist mit feinen, den Radiahrippen fast parallel verlaufenden Anwachsstreifen bedeckt, welche auf dem Externtheil sich in kurzem Bogen nach rückwärts wenden und dann eine Bucht von ungefähr zwei Rippenbreiten Tiefe bilden.

Pleuronautilus Rollieri ist wenig involut, indem knapp der Externtheil umhüllt wird, und weitnabelig ist. 
Sehr schön erhalten ist bei einem der Exemplare der Mundrand, welcher im 'lexte zut Abbildung gebracht wird.

Beginnend am Interntheile der Windung, sehen wir einen weit vorspringenden Internlappen (Fig. 4, 5, 6), der um circa $12 \mathrm{~mm}$ über den Bogen des Externtheiles vorragt; von hier verläuft der Mundrand geradlinig rück- und schräg aufwïrts (Fig. 4,5) und bildet auf der Flanke cine etwas mehr gegen den Marginalrand gehobene Lateralbucht; wendet sich dann mit einem flacheren Convexstück über die Marginalkante und bildet auf dem Externtheil cine kleinere halbrunde Externbucht (Fig. 7), welche ungefähr 1/4 der Breite des Externtheiles einnimmt. Was aber als das Auffallendste an der Form dieses Mundrandes erscheint, ist die Thatsache, dass der Rand dieser Externbucht, im Profil betrachtet (Fig. 4 und 5), aufgestülpt ist und vor dieser Aufstülpung cine schwache I:inschnürung liegt.

Diese sonderbare Aufstiilpung des Mundrandes auf dem Externtheil ist bei mesozoischen Nautiliden noch nicht beobachtet oder - wenigstens soweit ich in Erfahrung bringen konnte - je bcschrieben und zur Abbildung gebracht worden. Auch Arojsisowics, welcher dic Gattung Pleuronautilus ${ }^{1}$, (pag. 273) aufstellte, scheint sie unbekannt gewesen zu sein, denn sie wird in der Charakteristik nicht erwähnt. Diese Aufstuilpung wird übrigens bei fortschreitendem Wachsthum wieder vollständig resorbirt, so dass man sich die Frage stellen muss, ob sie überhaupt auch auf dem äusseren Theile der Schale sichtbar war - meine Exemplare sind nur Steinkerne - oder ob sie nur eine Einkerbung auf der Innenseite der Schale darstellte. Wie dem aber auch sei, bleibt dieser Mundrand immerhin interessant genug, weil er ein weiteres Moment bezüglich der Abstammung der l'leuronautilen bildet.

Hält man nun Umschau nach anderen I'ormen, welche dieselbe Aufstülpung und annähernd dieselbe Form des Mundrandes aufweisen, so finden wir die ähnlichste Entwicklung unter den Ascoceratiden, und zwar bei Glossoceras gracile Barr. ${ }^{2}$ ) (Fig. 8). Hier finden wir ebenfalls einen weit vorspringenden Internlappen, eine stark zurückweichende Lateralbucht sowie ein convexes Verbindungsstück zwischen dieser und der Externbucht mit aufgestülptem Rande und vor diesem ebenfalls eine flache Einschnürung (im Profil).

Andere Formen mit aufgestülptem Rande finden wir bei den Cyrtoceratiden, z. 13. bei Phragmo. ceras Broderipi Barr.

Unter den Nautiliden tritt eine ähnliche Erscheinung nur bei Oplidioceras, der verengten Nebenform von Lituites, auf, z. B. (Fig. 9) Ophidioceras simplex Barr. (Vol. II, Pl. 478, case I.)

Noch bei einem anderen Pleuronautilus meines Materiales, dem Pleuronaut. seminodosus Art., welcher in Folgenden beschrieben werden wird (pag. 32, Taf. I, Fig. $5 a, b, c$, $d$, Taf. II, Fig. I $a, b$, Fig. 2), gelang es mir, dieselbe Frorm und Aufstülpung des Mundrandes blosszulegen.

Bei ausgewachsenen Exemplaren, wie die vorliegenden es sind, verlässt der letzte Theil der Wohnkammer, die Spirale, wodurch die Internseite frei sichtbar wird, so dass man deutlich das Vorspringen des Internlappens des Mundrandes sieht und dass die Wohnkammer, wenn auch etwas flacher, die Ausbuchtung der Unterseite beibehält.

Eben dieses Verlassen der Spirale sowie der auffallende Mundrand bilden Merkmale, die man sonst nur bei pal̈̈ozoischen Formen zu sehen gewohnt war. Besonders ersteres tritt markant bei der paläozoischen Nautilidengattung Ophidioceras Barr. auf. Jedoch sind dort die Windungen nur sich berührend, während sie bei P'leuronaut. Rollieri, wenn auch wenig, so doch umfassend sind.

Es ist natürlich nicht möglich, aus den beiden Pleuronautilenfunden mit aufgestülptem Mundrande und Internlappen, welche in ausowewachsenem Zustande die Spirale verlassen (Pleuronaut. Rollieri Art. und Pleuronaut. seminodosus Art.), derzeit irgend eine Consequenz zu ziehen über die systematische 
Stellung, sowie weitere Muthmassungen über die Verwandtschaft von Pleuronatililus überhaupt mit älteren Formengruppen zu äussern.

Vielleicht werden dies spätere, glücklichere Funde zulassen.

\section{Pleuronautilus scabiosus Art.}

Taf. II, Fig. $6 a, b, c, d$.

Ursprünglich mit Pl. striatus Hauer (Cephalop. bosn. Muschelk., pag. 7, Taf. II, Fig. 2, Tá. XIV, Fig. 2) identificirt, stellte sich doch bei genauerem Vergleiche mit dem Originale Hauer's heraus, dass diese Identificirung nicht aufrecht erhalten werden kann.

Nach Ergänzung des fehlenden Stückes des letzten Umganges erhält man folgende Maasse:

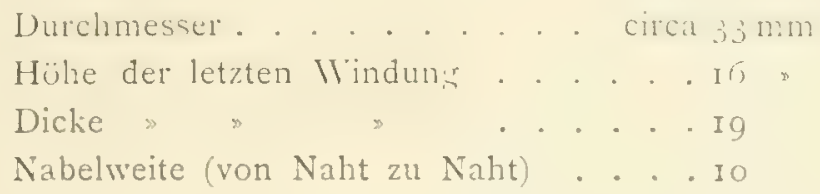

Der Externtheil ist bei jüngeren Exemplaren etwas stärker, bei älteren flacher gewölbt; die Flanken sind sanft gerundet und erreichen die grösste Dicke etwas unterhalb der halben Höhe; anfangs ist der Marginalrand wenig, bei grösseren Stücken auf der Wohnkammer hingegen stark abgerundet: die Umbilicalkante ist ebenso anfangs stärker, später jedoch weniger markirt, so dass die Flanke dann ohne deutliche Grenzen in die steile Nabelwand übergeht. Der Nabel ist weit, die Involution bedeckt den Externtheil und die Marginalwand.

Die Berippung besteht aus enggestellten gerundeten Rippen, welche erst in der Umbilicalregion der Flanke beginnen, dann kräftiger anschwellen und auf dem Externtheil selber verschwinden. Sie beginnen zuerst radial und wenden sich dann in halber Flankenhöhe bogenförmig nach rückwärts.

Bei weiterem Wachsthum scheint die Radialberippung sich derart zu reduciren, dass zuerst der umbilicale Rippentheil verschwindet, später auch der marginale und schliesslich haben wir glatte Flanken, welche nur mehr die feinen spiralen Längsstreifen alusser den Anwachslinien zeigen.

Die Schale, welche stellenweise sehr gut erhalten ist, zeigt analog den Rippen bogenförmigen Verlauf feiner Anwachsstreifen, welche auf dem Externtheil eine seichte Bucht bilden. Ausserdem tritt, schon mit freiem Auge gut sichtbar, eine feine spirale Längsstreifung auf, ähnlich der bei Pl, Pichleri Hauer sp. (pag. 3 r, Taf. II, Fig. $5(q)$ zu erwähnenden; der Steinkern zeigt eine Normallinie.

Die Kammerscheidewand weist eine fiache Externbucht und etwas stärkeren Lateralsinus auf, von dem aus die Scheidewand sich senkrecht über die Umbilicahwand hinab fortsetzt. Der Sipho liegt tief unter der halben, Mündungshöhe. Fig. 6 a zeigt die naturgetreue Abbildung des Stückes, bei welchem die Wohnkammer theilweise längs der Mittellinie des Externtheiles eingebrochen und gegen die Nabelkante der vorhergehenden Windung über dieselbe hinübergeschoben ist, diese zu Dreiviertel bedeckend. Fig. $6 \mathrm{c}$ zeigt ein reconstruirtes Bild dieser Species. Pl. scabiosus unterscheidet sich von Pl. stratus Hauer dadurch, dass bei ersterem die grösste Dicke der Windung etras unterhalb der halben Flankenhöhe, dort in der Nabelregion liegt; der Querschnitt zeigt hier grössere Dicke wie Höhe, dort überwiegt eher die Höhe. Der Nabel ist dort treppenförmig abgesetzt, was hier nicht der Fall ist. Ferner sind die Rippen bei Pl. scabiosus ohne knotenfömige Terdickung und auf dem oberen Flanken. theil stark nach rückwärts gebogen. Auch die Kammerscheidewände zeigen deutliche Unterschiede. Pleuronautilus scabiosus gehört zu dem Formentypus des Pleuronautilus Pichleri Hauer sp.

\section{Pleuronautilus Pichleri Hauer sp.}

laf. II, lig. $5 a$,

1865. Nautilus l'ichleri Hauer, Cephalopoden d. unt. 'Trias der Alpen. Sitzungsber. k. Aliad. d. Wiss. mat.•nat. Cl., pay. (izI. Taf. I, Fig. I-3.

1865. Nautilus semicostatus Beyrich. Monatsberichte kgl. Akad. d. Wiss., pag. 6r7. Berlin. 
1867. Nautilus Pichleri Beyrich, Ueber einige Cephalopod, a. d. Muschelk, d. Alp. Abhandlg. kgl. Akad. d. WViss, paś. I3 Iaf. III, Fig. 4. Berlin $x 860$.

1882. Pleuronautilus Pichleri Hauer sp. Mojsisovics E. v., Cephalopod. d. Medit. Triaspr., pag. 279, Taf. I.XXXVI, I ih. 3. Abhandilg. k. k. geol. R.A., Bd. X. Wien.

1887. Pleuronatilus Pichleri Hauer sp.; Hauer, Cephalopod. d. bosnischen Muschelk, von Han 13ulog, pag. I5, Taf. III, Fig. I a, b, c. Denkschr. kais. Akad. d. Wiss, mat,-nat, Cl., Bd, LIV. Wien.

Das Stück stammt von der ersten Begehung des Reiflinger Gebietes durch Stur vom Jahre 1863, findet sich in dessen Geologie der Steiermark (pag. 219) angeführt und wurde mir von der Direction der k. k. geol. Reichsanstalt freundlichst zur Verfügung gestellt. Flantr ${ }^{1}$ ) erwähnt desselben Stückes im Jahre 1865 in seiner Arbeit über Cephalopod. der unt. Trias (pag. 62I) ebenfalls schon, sowic dieselbe Species auch I 882 von Alojsisovics ${ }^{2}$ ), bei Abbildung des Haucr'schen Originales, beschrieben wird.

Das Reiflinger Exemplar ist auffallend in lolge seiner geringen Grösse und hat besonders kräftige Radialrippen, welche sich über den Marginalrand nach rückwärts biegen. Die Schale ist sehr gut erhalten, zeigt aber nur unter der Loupe die Anwachsstreifen der Flanke, während sie auf dem Externtheil sehr scharf hervortreten. Sie werden von spiralen Längsstreifen gekreuzt, die wieder auf der Flanke, besonders im Intercostalfeld, stärker hervortreten und auf dem Externtheil feiner werden und näher zusammenrücken.

\section{Formengruppe des Pleuronautilus Mosis Mojs.}

Pleuronautilus seminodosus Art.

Taf. I, Fig. $5 a-t$; Taf. II, Fig. I $a, b$, Fig. 2 .

Das eine der vorliegenden Exemplare (Taf. I, Fig. 5) zeigt die unverdrückte Wohnkammer im Steinkern erhalten, mit einer Länge von $82 \mathrm{~mm}$ (längs der Mitte des Externtheiles gemessen). Am Beginne derselben erkennt man noch Reste der letzten Kammerscheidewand. Man sieht einen trapezoïdalen Umriss der Wohnkammer von oben $24 \mathrm{~mm}$, unten $27 \mathrm{~mm}$ Breite und $25 \mathrm{~mm}$ Höhe. Das Ende desselben hat rundovale Form mit einer grössten Breite von $35 \mathrm{~mm}$ und Höhe von $28 \mathrm{~mm}$.

Bei dem auf Taf. II, Fig. I $a, b$ abgebildeten Stück ist auf der einen Flanke und dem Externtheile die Schale noch sehr gut erhalten.

Taf. II, Fig. 2 wiederum zeigt ein Exemplar mit erhaltenen und theilweise unverdrückten inneren Windungen. Ergänzt man bei diesem Stücke das Fehlende, so erhält man annähernd folgende Maasse:

Durchmesser . . . . . . . circa $93 \mathrm{~mm}$
Höhe der letzten Windung
Nabelweite
Perforation

Pleuronaut. seminodosus Art. hat flach gevölbten, in der Mitte leicht eingesenkten, breiten Externtheil, flache und bei ausgewachsenen Exemplaren nur auf den letzten Theil der Wohnlammer stark gewölbte Flanken (Taf. I, Fig. $5 c, d$ ). Marginal- und Umbilicalkanten sind gerundet; die Nabelwand ist hoch und senkrecht, gegen Ende der Wohnkammer nur mehr steil gestellt; der Nabel ist gross. Die Species ist schwach involut, die Umgänge wenig umfassend, indem nur der Externtheil umhïillt wird.

Die Sculptur wird aus kräftigen Radialrippen und Knoten gebildet. Dieselben verlaufen geradlinig und leicht nach rückwärts von der Radiale abweichend; sie beginnen auf der Nabelwand, schwellen

1) Hauer, Sitzungsber, kais, Alsad, d. Wiss, $186_{5}$.

2) Alojisozics, Cephalop. Med. Triaspr., pag. 279, Taf. LXXXVI, Fig. 3. 
beim Erreichen der Flanke sofort an und erreichen bei immer stärkerer Verdickung die gerundete Marginalkante in einem stumpfen Knoten. Auf den älteren Windungen ist der Knoten nicht so kräftig entwicleelt, sondern flacher und mehr in die Länge gezogen.

Bei ausgewachsenen Individuen verlässt der letzte Theil der Wohnkammer die Spirale, Was auch mit einem Wechsel der Radialsculptur verbunden ist. Die Rippen erreichen dann nicht mehr die Nabelwand, sondern verlöschen schon ungefähr in der Mitte der Flanke. Dieser plötzlich und ohne merklichen Uebergang stattfindende Wechsel der Sculptur, der in engem Zusammenhang mit der Ausschnürung steht, ist ausserordentlich auffallend. Die Anwachsstreifen verlaufen wie bei Pleuronautilus Rollieri parallel der Radialsculptur und bilden auf dem Externtheil eine tiefe Bucht.

Die Kammerscheidewände zeigen einen kleinen und sehr flachen Lobus auf dem Externtheil, eine tiefe, gerundete Lateralbucht, deren aufsteigender Ast nicht wie bei der verwandten Form des Pleuronautilus Rollieri nur bis zur Umbilicalkante reicht und dann senkrecht über die Nabelwand herabsteigt, sondern sich gleichsinnig aufsteigend auch über die Umbilicalwand fortsetzt und den höchsten Punkt erst in der Berührungslinie der vorhergehenden und der folgenden Windung erreicht. Der weitere Verlauf der Scheidewand zeigt einen sehr kleinen und spitzen Internlobus. Der Sipho liegt unterhalb der Mitte der Kammer.

Der Mundrand von Pl. seminodosus hat dieselbe Form wie der von Pl. Rollieri Art. Wir sehen ebenfalls einen weit vorspringenden Internlappen (Taf. II, Fig. I $\alpha$, ferner Taf. I, Fig. $5 a$ ), eine stark zurückweichende und etwas gehobene Lateralbucht und auf dem Externtheil einen flacheren Ventralausschnitt mit aufgestülptem Rande und darunter liegender kleiner Einschnürung.

Es sei mir gestattet, bei dieser Gelegenheit auf den *Pleuronautilus semicostatus (Beyrich) Mojs. zu sprechen zu kommen, mit dem anfangs Pleuronautilus seminodosus von mir identificirt wurde.

Diese Species wurde als Nautilus semicostatus I865 von Bcy'ric/2 ${ }^{2}$ ) zum ersten Male beschrieben und: pmit breitem Externtheil, an den schmalen Seiten mit dicht nebeneinander liegenden Rippen bedeckt, die am Externrand plötzlich aufhören «, bezeichnet, jedoch keine Abbildung gregeben.

Ebenfalls im Jahre 1865 beschrieb Hauc $r^{2}$ ) Cephalopoden der unteren Trias und darunter auch pag. 62x, Taf. I, Fig. I-3, den Nautilus Pichleri Hauer. Derselbe zeigt einen sselir sanft gerundeten Rücken und ist durch eine abgerundete Kante mit den ganz flachen, ebenen Seiten verbunden. Die Seitenwände tragen regelmässig starke, gerade Radialrippen 。

IS66 nun veröfentlichte Bcyrich seine im Vorjahre im Auszug mitgetheilte Arbeit ${ }^{3}$ ) und in dieser erscheint Nautilus semicostatus Beyr. nicht mehr, sondern ist identificirt mit dem in Vorjahre abgebildeten Naut. Pichleri Hauer und existirt demzufolge nicht mehr (pag. I36).

Trotzdem beschreibt Mojsisovics ${ }^{4}$ ) im Jahre 1882 (pag. 278, Taf. 86, Fig. I, 2) wieder einen - Pleuronautilus semicostatus (Beyrich) Mojsisovics;, bildet ein Exemplar seines Materiales ab und sagt in der Beschreibung, dass er gewölbte Seiten und leicht gegen rückwärts gebogene Rippen hat, was der von Bcyrich in den "Monatsberichten gegebenen Beschreibung des Nautilus semicostatus und der in den A Abhandlungen * gelieferten Abbildung desselben Stückes (als * Naut. Pichleri *) vollkommen widerspricht. Daraus ergibt sich, dass der von Lhojsisovics beschriebene Pleuronautilus semicostatus (Beyrich) Mojs. nicht die von Beyrich beschriebene Species ist, sondern etwas ganz Neues, eine eben ron Mojsisorics neu aufgestellte Art ist und daher richtig

Pleuronautilus semicostatus Mojs.

geschrieben werden muss.

i) Liyrich, Monatsberichte der kgl. (preuss.) Akad. d. Wiss. If. Dec. IS65.

2) Hauer Fr. un, Sitzungsberichte der k, Akad. d. Wiss. mat.nat. Cl. Wien IS65.

3) Rigrich, Ceber einige Cephalop. a. d. Muschelk. der Alpen. Abhandung der kigl. Akad. d. Wiss. Merlin IEG6.

1) Wojsisozics E. Z. Cephalop. Medit. Triaspr. 


\section{Pleuronatilus furcatus $\Lambda \mathrm{rt}$.}

laf. II, liver. $3 a, b, c$

Das grösste der vorliegenden zahlreichen Stücke wurde abgebildet und einzelne hier fehlendc Details nach den anderen Stücken ergänzt.

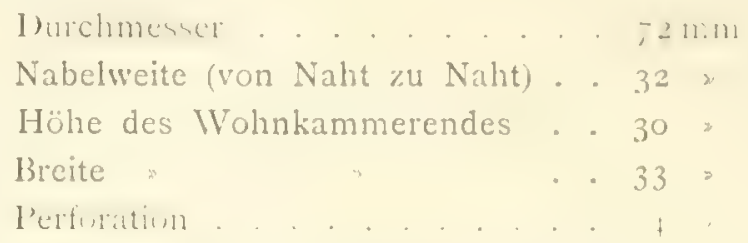

Der Externtheil ist flach gewölbt, die Flanken sind flach und nur auf der Anfangswindung leicht aufgetrieben. Die Marginalkante tritt ziemlich scharf heraus, ist mit Knoten besetzt und erscheint nur auf der Wohnkammer allein etwas gerundet; die Umbilicale ist durchaus gerundet, schwächer auf àlteren und stärker auf jüngeren Windungen.

Die Nabelwand ist hoch und steil gestellt; die Involution bedeckt den ganzen Externtheil.

Die Sculptur dieser Species wird aus Rippen und Knoten gebildet.

Erstere sind lräftig, beginnen am Nabelrand, verlaufen geradlinig und weichen gegen die Marginalkante nach rückwärts von der Radiale ab, so zwar, dass die Radiale die eine Rippe an der Nabelkante und die folgende an der Marginalkante trifft.

Auf dem letzten Theil der Wolnkammer ist die Berippung folgende: Die Rippen beginnen auf der Umbilicalkante ziemlich schwach, werden in ihrem weiteren Verlaufe nur um Weniges höher und kräftiger und enden verdickt am Marginalrand in einem rundlichen, stump̧en Kinoten. Rückschreitend von hier zu den früheren Windungspartien, ändert sich die Beknotung folgendermassen: Die Rippe findet nicht ihr Ende am Externrand in einem runden Knoten, sondern dieser erscheint etwas in die Länge gezogen und jene wendet sich bogenförmig über ihn hinaus noch ein klein wenig nach rückwärts. Später theilt sich dieser längliche Knoten in einen etwas kleineren intern- und kräftigeren externsitzenden Knoten, der analog dem Verlaufe der Rippe gegen den ersteren aus der Radiale gerückt erscheint. Der Internsitzende sinlit sodann immer weiter auf der Flanke hinab und erreicht seinen tiefsten Stand am Ende des zweiten Drittels (von der Nabel- gegen die Externkante gerechnet). Das Verbindungsstück der Rippe zwischen den beiden Knoten ist indessen immer schwächer geworden. Gleichzeitig mit dem Herabsinken des jetzt zum Lateralknoten gewordenen Externknotens schiebt sich erst ein kleiner Knoten zwischen je zwei externstehende ein, der bald dieselbe Stärke wie die primären erlangt, und schliesslich haben wir folgende Sculptur: Die Rippe beginnt am Umbilicalrand, verläuft geradlinig, allmälig anwachsend bis zum Lateralknoten, der kräftig entwickelt ist, und endet daselbst. Der Lateralknoten steht fast in der Mitte der ihm correspondirenden zwei Marginalknoten.

Zwischen je zwei solchen, aus einer Rippe und drei Inoten gebildeten Sculptureinheiten verläuft eine Radialrippe, deren Lateralknoten nur cinem marginalen entspricht. Auf älteren Windungen umhüllt die folgende Windung die Marginalknoten. Auf dem abgebildeten Stücle beginnt diese Art der Sculptur nach dem ersten Viertel des ersten Umganges. Bis dahin ist die Flanke schwach gewölbt und nur undeutlich sculpturirt. Diese Sculpturirung ist ausserordentlich auffallend. Erinnert der äussere Umriss der Schale durch seine umgekehrt trapezoïdale Form, die kräftigen Externknoten sowie der für Pleuronautilen relativ stark verengte Nabel an Trematodiscus, so ist doch noch viel auffallender die ceratitische Art der Beknotung, welche uns direct an trinodose Ceratitenformen erinnern.

Die Schale von Pleuronaut. furcatus zeigt den Rippen parallel verlaufende Anwachsstreifen, welche auf dem Externtheil eine tiefe Bucht bilden. Hier treten auch feine, die ersteren kreuzende Spiralstreifen auf, sowie auf Steinkernen eine kielartige Normallinie, die beiderseits ron je einer tiefen l'urche begleitet ist. 
Die Kammerscheidewand weist auf dem Externtheil eine grosse, flache Ventral-, auf den Flanken eine tiefere Lateral- und auf dem Interntheil eine kleine, sehr tiefe Internbucht auf, an dessen tiefster Stelle der kleine Internlobus liegt. Der Sipho wird knapp unter der halben Mündungshöhe sichtbar.

\section{Pleuronautilus ptychoides Art.}

Taf. II, Fig. $+a, b, c$.

Die Maasse des zur Abbildung gelangten Stückes sind:

Durchmesser . . . . . . circa $3 . \mathrm{mm}$
Nabelweite . . . . . . . . . I I
Höhe der Wohnkammer . . . . . IS
Breite

Der Externtheil ist flacher, die Flanken etwas stärker gewölbt. Der Ümbilicalrand ist leicht abgerundet und der marginale durch eine Knotenreihe bezeichnet. Die Nabelwand ist sehr hoch und fast senkrecht stehend; die Involution umhüllt die abgeflachte Partie des Externtheiles. Die Species ist rasch in die Höhe anwachsend und wird schnell dicker.

Die Sculptur wird aus Rippen und ihnen aufsitzenden Knötchen gebildet; erstere sind kräftig, radial gestellt, verlaufen geradlinig oder ein wenig convex nach vorne gebogen, beginnen auf der Flanke knapp neben dem abgerundeten Nabelrand sofort mit einer flachen, leichten Anschwellung, die im weiteren Verlaufe der Rippe verschwindet; etwas oberhalb der Flankenmitte sitzt ein kleiner, runder Knoten, auf welchen auf der Marginalkante ein ebenso grosser marginalgestellter folgt, der die Flanke vom Externtheil abtrennt. Zivischen beiden ist auf Schalenexemplaren die Rippe sehr stark reducirt, während sie auf den Steinkernen sich nur um Weniges verringert.

Die Schale zeigt ganz feine Anwachsstreifen, die parallel den Rippen auf der Flanke verlaufen und auf dem Externtheil einen tiefen Sinus von fast zwei Rippenbreiten Tiefe bilden. Hier heben sich in der Entfernung von I mm die Anwachsstreifen stärker hervor, wodurch eine Art flacher Bänderung entstelit, die auf dem Externtheil von feinen Spiralstreifen geschnitten werden. Auf Steinkernen kann man theils deutlicher, theils weniger deutlich zwei schwache Spirallinien ausnehmen, welche die Lateralund Marginalknoten verbinden.

Die Kammerscheidewände zeigen auf dem Externtheil einen flachen, auf den Flanken einen tieferen Sinus, eine steil eingesenkte Internbucht, deren Tiefe ein ganz kleiner Internlobus einnimmt.

Der Sipho steht tief unter der Kammermitte.

Pleuronautilus ptychoides steht dem im Folgenden beschriebenen Pl. ambiguus Art. (pag. 38 , Taf. III, Fig. $3 a, b)$ sehr nahe, unterscheidet sich jedoch von diesem dadurch, dass er nur zwei deutlich charakterisirte Knotenspiralen hat und dass der Sipho viel tieferstehend ist, während er dort fast in der Kammermitte liegt, ferner daselbst drei Ǩnotenspiralen vorkommen und die Wohnkammer bei gleicher Grösse fast ganz glatt wird. Ausserdem ist Pleuronautilus ambiguus rascher anwachsend. Pleuronautilus ptychoides stellt einen einfacheren Sculpturtypus dar als Pleuronautilus furcatus Art., da die hier noch ungespaltene Rippe sich dort, wenn auch undeutlich, gespalten hat.

\section{Formengruppe des Pleuronautilus subgemmatus Mlojs.}

Dieselbe umfasst kleine, rasch anwachsende Formen mit wenig involuten Windungen. Der Externtheil ist meist flach gewölbt, die Flanken flach oder nur wenig aufgebläht; Extern- und Lmbilicalkante stets deutlich entwickelt; die Nabelwand hoch und fast senkrecht stehend. Der Externtheil ist 
stets sculpturfrei; der Lateraltheil mit drci(?) bis fünf gekörnelten Längsspiralen, welche auf dem Wohnkammertheil meist fast ganz verschwinden. Bei Pl. crassescens (pag. 37, 'Taf. III, lïg. I a, ()) tritt auf der Schale der Wohnkammer starke Radialsculptur, auf dem Steinkerne der diesel vorangehenden Partie sowic bei Var. jugulatus (pag. 38, Taf. III, Iig. 2) erst beginnende Radialsculptur auf.

Pleuronautilus ambiguus (pag. 38 , Taf. III, Fig. $3 a, b$ ) bildet mit Pl. planilateratus Hauer sp. ') den Uebergang zu den Formen mit geknoteten Radialrippen, also der Gruppe des Pleuronaut. Mosis Mojs. Die Kammerscheidewände haben meist kleinen Extern-, relativ grossen Laterał, Intern- und Siphonillobus. Der Sipho steht etwas unterhalb der halben Mündungshöhc; Normallinie meist vorhanden.

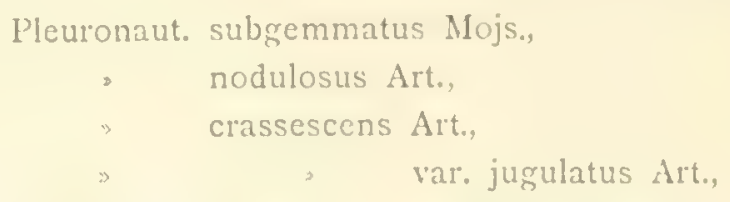

vermitteln den Uebergang von Trematodiscus Meek, u. Worth, zu Pleuronautilus Mojs., indem sie die jenen eigenthünliche Längssculptu1 in mehr oder weniger deutlicher Weise mit der für diese charakteristischen Quersculptur verbinden und bei Trematodiscus ähnlichen Formverhältnissen einen sculpturfreien Externtheil aufweisen.

Pleuronautilus subgemmatus Mojs.

IS52, Mojsiscrics E. \%, Cephalop. Medit. Triaspr, pas. 277, Taf. LxXXV, Iig. 2 a, h.

Ein einzelnes kleines Bruchstück, welches ein $9 \mathrm{~m}$ langes und $7 \mathrm{~mm}$ breites Windungsfragment darstellt, zeigt die fast senkrecht eingesenkte Nabelwand, auf deren scharfer Kante die erste Längsspirale aufsitzt. Dann folgen gegen die ebenfalls scharf markirte Marginalkante zunächst zwei näher und dann zwei weiter gestellte Längsspiralen, von denen die externer stehenden etwas gröber sind. Somit treten auf der Flanke fünf Längsrippen auf. Die Quersculptur wird von ganz niederen, flachen, ungefähr I mm breiten, rippenähnlichen Radialverdickungen gebildet; weiters bemerkt man feine, linienförmige Anwachsstreifen und ebenso feine, spiral verlaufende Linien; wo beide Systeme auf den Rippen sich treffen, bilden sie feine Knötchen; hiedurch entsteht eine feine Crenelirung der Schale.

Der Externtheil ist flach gewölbt.

Pl. subgenmatus Mojs. wird aus der Trinodosus-Zone von der Schreyeralm beschrieben.

Pleuronautilus nodulosus Art.

Taf. II, Fig. 7 a. $l$.

Das grösste der vorliegenden sechs Exemplare und Bruchstüclie hat einen

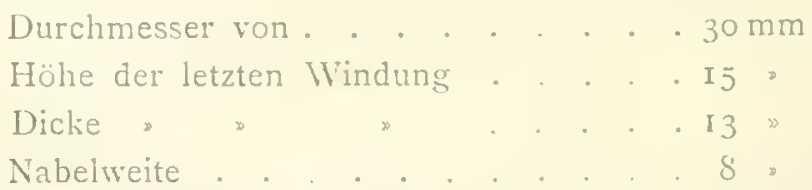

Der Externtheil ist flach gewölbt, die Flanken abgeplattet, der Nabel, anfangs senkrecht eingesenkt, erhält gegen Ende der Wïndung bei ausgewachsenen Stücken eine mehr oder weniger schräge Haltung. Sowohl Nabel- als Marginalkante sind deutlich entwickelt. Die grösste Breite der Windung liegt in der Linie der Marginalkante, in Folge dessen der Querschnitt verkehrt trapezoïdale Form zeigt. Pleuronautilus nodulosus ist eine rasch anwachsende Form und wenig involut, da der Externtheil durch die folgende Vindung knapp umhüilt wird.

Hauer Fr. z', Nachträge zur Kenntniss der Cephalopodenf. d. Hallstätt. Schichten. Sitzungsber. k. Akad. d. Wiss. mat.nat. Cl. Bad. XI.I. Wien 1560 . 
Die Flankensculptur wird aus vier starken Spirallinien gebildet, von denen die erste auf der Umbilicalkante und die vierte auf der Marginalen aufsitzt. Die zweite und dritte sind derart auf der Flanke vertheilt, dass die erstere der Umbilicalkante stärker genähert ist als die letztere der Externen. Die Quersculptur wird nur aus Anwachslinien gebildet, welche meist kräftig hervortreten und auf dem Kreuzungspunkte mit den Spirallinien stumpfe Knötchen bilden. Ihr Verlauf ist folgender: Sie steigen senkrecht über die Nabelwand herauf, wenden sich dann von der ersten zur zweiten Spirale in einem flach concaven Stück nach rückwärts; bis zur dritten verlaufen sie gerade und radial, und wenden sich sodann bis zur vierten Spirallinie, also bis zum Externrand, wieder nach rückwärts, jedoch geradlinig. Auf dem Externtheil bilden sie eine tiefe Bucht. Eine deutliche Normallinie ist besonders auf jüngeren Exemplaren zu sehen

Die Kammerscheidewände von Pl, nodulosus haben einen kleinen, seichten Extern- und breiteren, aber nur um wenig tieferen Laterallobus; dann sinkt die Kammerscheidewand senkrecht über die Umbilicalwand und bildet eine flache Internbucht, an deren tiefster Stelle ein relativ grosser runder Internlobus sichtbar wird.

Der Sipho liegt knapp unter der Kammermittellinie.

Pleuronautilus nodulosus steht dem Pl. subgemmatus Mojs., ${ }^{1}$ ) welcher sich ebenfalls in den Reiflinger Kalken findet (pag. 36), sehr nahe. Der Unterschied liegt nur darin, dass Pl. subgemmatus Mojs. etwas involuter ist und fünf Längslinien hat, während $\mathrm{Pl}$. nodulosus nur deren vier aufweist.

\section{Pleuronautilus crassescens Art. \\ Taf. III, Fig. I $a, b$.}

Die Maasse des abgebildeten Stückes sind:

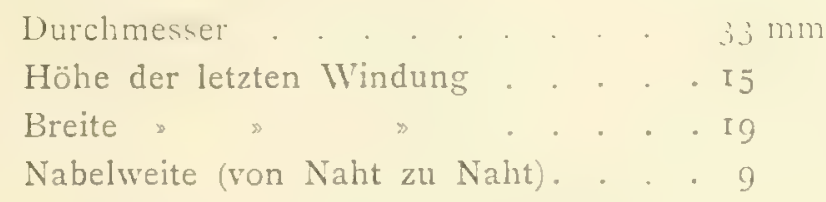

Der Externtheil ist anfangs stärker, auf der Wohnkammer selbst schwächer gerundet; ebenso sind die Flanken anfangs flach, später stärker gerundet. Die grösste Breite liegt in der Umbilicalregion. Die Nabelwand ist steil gestellt; die Nabelkante scharf entwickelt, ebenso die Marginalkante, welche sich jedoch auf der Wohnkammer abrundet. Die Involution bedeckt ungefähr ein Drittel der Flankenliöhe. Der Querschnitt der letzten Windung erscheint plump und ist breiter als hoch.

Die Sculptur wird aus Längs- und Radialrippen gebildet. Die ersteren treten in vier Reihen auf; die erste sitzt auf der Umbilicalkante, die vierte auf der Marginalkante auf und ist relativ am stärksten entwickelt; den übrigen freien Raum der Flanke nehmen die zweite und dritte Spirale ein, welche annähernd in gleicher Entfernung von den Randspiralen stehen; entsprechend der Umbilicalspirale ist auch die zunächststehende Zweite schwächer entwickelt.

Die radial verlaufenden Rippen beginnen schwach in der Umbilicalregion und behalten von der zweiten Längsspirale an bis zum Externtheil nahezu dieselbe Stärkc bei. Sie verlaufen geradlinig, wenden sich von der Umbilicalkante bis zur zweiten Spirale nach rück- und aufwärts und behalten von da ab die Radialrichtung bei. Annähernd kommt auf eine Luftkammer eine Querrippe zu stehen; wo beide Rippensysteme sich kreuzen, sitzen kleine runde linötchen auf, ron denen diejenigen der zwei Mittelspiralen die kräftigeren sind.

Auf der Wohnkammer ändert sich die Sculptur, indem die Querrippen vollständig überwiegen, und die Längsspiralen nur mehr als schwache Erhebungen auf den Kreuzungsstellen auftreten. Aut

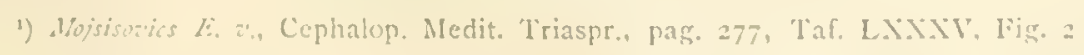


dem Umbilicalrand sitzen jetzt die kräftigsten Kinötchen nuf und von diesen aus wenden sich die Rippen, ganz allmälig und nur um Weniges grösser werdend, erst in einem flach concaven Stück bis zur zweiten knotenförmigen Erhebung, sodann geradlinig und etwas nach rückwärts von der Radiale abweichend bis zur schwächeren dritten und von hier leicht convex gebogen zum Marginalrand, der indessen seine frühere Schärfe verloren hat. Somit hat die Rippe im Allgemeinen einen flach convexen, nach rückwärts gerichteten Verlauf.

Die Schale ist nur theilweise erhalten; auf den lilanken lassen sich, auch mit der Lupe nur undeutlich, die Anwachsstreifen verfolgen, welche erst mit freiem Auge gut sichtbar auf dem Externtheile hervortreten. Sie wenden sich fast stumpfwinkelig über die Externkante und bilden auf dem Externtheil eine tiefe Bucht. Gekreuzt werden die Anwachsstreifen von stellenweise auftretenden Längslinien.

Auf dem Steinkern tritt eine zarte Normallinie hervor.

Die Kammerscheidewände haben einen lileinen, aber relativ tiefen Externlobus; der Externsattel liegt noch vollständig auf dem Externtheil und an diesen schliesst sich ein grosser; flacher Laterallobus an, der bis zur Umbilicalkante reicht; von hier senkt sich die Kammerscheidewand senkrecht über die Nabelwand hinab.

Die Luftkammern sind bei dem abgebildeten Stück kurz vor der Wohnkammer ausserordentlich eng gedrängt, was dafür spricht, dass das Individuum vollständig erwachsen war.

An Pleuronautilus crassescens schliesst sich sehr enge eine andere Form an, welche wohl am besten als Varietät der früheren aufzufassen ist.

Es ist dies

Pleuronautilus crassescens var. jugulatus Art., Taf. III, Fig. 2.

der in seinen Anfangswindungen vollständig mit P1. crassescens übereinstimmt. Der Unterschied liegt nur in der Sculptur der Wohnkammer. Hier sind die Radialrippen, die bei der Grundform so deutlich entwickelt waren, theils schwach und undeutlich nur zu sehen oder überhaupt nicht mehr sichtbar.

Etwas deutlicher treten die Längsrippen heraus. Die Anwachsstreifen, welche nur ausserordentlich schwach sichtbar auf der Flanke von Pl. crassescens waren, sind bei der Varietät kräftiger entwickelt und steigen in radialer Richtung über die hohe Nabelwand herauf, weichen sodann um Weniges nach rückwärts bis zur Verlängerung der zweiten Spirallinie, ron wo an sie leicht convex gekrümmt bis zur Marginalkante sich fortsetzen und sich dann fast stumpfwinkelig auf dem Externtheile nach rückwärts wenden, wo sie eine tiefe Bucht bilden. Bei Schalenexemplaren sind Umbilicalund Marginalkante auch auf der Wohnkammer noch kräftigst entwickelt.

\section{Pleuronautilus ambiguus Art.}

Taf. III, Fig. $3 a, l$.

Diese Species schliesst sich sehr enge an die beiden im Vorangehenden beschriebenen Formen an. Das abgebildete Stück hat einen

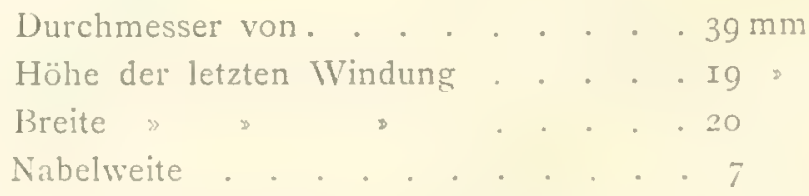

Die Externseite ist flach gewölbt auf der Wohnkammer, und etwas stärker auf älteren Windungspartien gerundet. 
Die Flanken sind fast ganz flach und erreichen die grösste Breite in der Úmbilicalregion. Die Nabelwand ist hoch, senkrecht stehend und auf der Wohnkammer ein wenig geneigt. Die Umbilicalkante ist sanft gerundet, die Marginale anfangs drahtähnlich entwickelt, behält auch auf der Wohnkammer - hier ungefähr ein Viertel des letzten Umganges - ihre Schärfe bei, verliert jedoch dort die drahtähnliche Gestalt.

Die Involution umfasst knapp ein Drittel der Flankenhöhe.

Die Sculptur wird aus radial gestellten Rippen gebildet. Sie beginnen mit einem kleinen Knötchen am Nabelrand und verlaufen in gleicher Stärke bis ungefähr drei Viertel der Flankenhöhe, wo sie ebenfalls in einem kleinen Knötchen enden. Die Rippen sind zart, aber doch kräftig entwickelt und zeigen eine fast unmerkliche Verdickung zwischen der Umbilical- und Lateralanschwellung. Auffallend ist, dass die Knötchen nicht rund sind, sondern länglich und senkrecht zur Rippenachse stehen, wo. durch der Anschein spiraler Knotenreihen erweckt wird; da aber zwischen den Knötchen keine directe Verbindung besteht, kann nur von Knoten der Radialrippen die Rede sein. Auf jede Luftliammer entfällt ungefähr eine Rippe.

Pleuronautilus ambiguus zeigt besonders auf dem Steinkerne eine auffallend tiefe Einschnürung zwischen dem oberen Radialknötchen und der Marginalkante; auf der Schale tritt diese nur als schwache Kerbe auf, bis zu welcher die Involution reicht.

Die Anwachsstreifen sind auf der Schale gut sichtbar, besonders im Intercostalfeld der Flanke; zwischen je zwei Linien liegt eine seichte Vertiefung, so dass die Schale wie fein gefurcht aussieht; die Streifen verlaufen parallel den Rippen und bilden auf dem Externtheil eine spitz gerundete, ziemlich tiefe Bucht.

Die Kammerscheidewände zeigen auf dem Externtheil einen ganz kleinen Externlobus, der von der Normallinie getheilt wird; die beiden Externsättel sind nieder und flach gerundet; die Lateralbucht gross und tief; dann senkt sich die Scheidewand schräg und ein wenig nach vorwärts gerichtet über die Nabelwand herab; hier schliesst sich eine tiefe, gerundete Internbucht an, deren tiefste Stelle ein relativ grosser, runder Internlobus einnimmt.

Das Sipho ist klein und liegt etwas unterhalb der halben Mündungshöhe.

Pl. ambiguus ähnelt auf den ersten Blick besonders dem Pl. crassescens var. jugulatus (pag. 38), von dem er sich jedoch bezüglich der Schalensculptur unterscheidet. Wohl haben beide Formen die glatte Wohnkammer, deren Sculptur fast allein nur mehr die Anwachsstreifen bilden, gemeinsam, sie zeigen jedoch den Unterschied auf den vorangehenden Mündungspartien. Bei der oben angeführten Varietät sehen wir vier deutlich entwickelte Spiralstreifen, während bei Pl. ambiguus keine mehr vorhanden sind und nur die zwei längsgestellten Knotenreihen den Anschein zweier Spiralstreifen herrorrufen, zu denen noch als dritte Linie die deutlich ausgebildete Marginallante tritt.

Es ist übrigens möglich, dass sich die Speciesdefinition für Pl. ambiguus, nach dem Funde eines Individuums mit vollständig erhaltener Schale, noch insofern ändere, dass sich auch auf der Marginalkante in der Verlängerung der Rippen knotenähnliche Anschwellungen constatiren lassen, was bei dem vorliegenden Stücke zu sehen nicht möglich ist. In jenem Falle hätten wir dann nicht zwei, sondern drei Reihen radial stehender Knötchen und eine Flankensculptur, die sehr an P1. ptychoides Art. (pag. 35 , Taf. II, Fig. 4) erinnern würde. Ein Unterschied zwischen Pl. ambiguus und Pl. crassescens var. jugulatus liegt jedoch in der Gestalt der Kammerscheidewände. Bei der oben angeführten Varietät, welche übrigens enggestellte Scheidewände hat, schen wir einen kleinen und tiefen Extern- und seichten Laterallobus, während ersterer bei Pleuronautilus ambiguus viel kleiner und scichter, letzterer gross und tief ist.

Als ähnliche Species, welche ihren Platz gut in dersclben Formengruppe findet, ist Pleuronautilus planilateratus Hawer sp.') (pag. II9, Taf. II, Fig. I- - zu erwähnen. Von annähernd gleicher

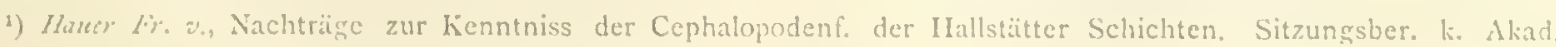
d. Wiss. mat.nat. Cl. Bd. XI. I. I860. 
Grösse, zeigt auch diese Form den Wechsel der Flankensculptur auf der Wolnkammer, welche fast ganz glatt wird. Auf den vorangehenden Windungspartien treten Radialrippen auf, welche drei Knotenreihen aufweisen, von denen die Marginale die grössten Individuen trägt. Die Anwachsstreifen sind deutlich entivickelt und werden von enggestellten Längslinien gekreuzt. Die Kammerscheidewände verlaufen auf dem Externtheil sbeinahe gerade*, was wohl gleichbedeutend mit einem flachen Extern. lobus ist.

Der Sipho liegt, wie bei Pleuronautilus ambiguus, unter der Kammermitte, Pleuronautilus planilateratus ist etwas evoluter. Beschrieben wird diese frorm vom l'eltschen bei Aussee aus den Hallstätter Schichten.

\title{
Unterfamilie: Nautilinae Mojs. Gattung: Nautilus Breyn.
}

\author{
Nautilus cfr. lilianus Mojs.
}

I882. Moisissovics E. v., Cephalop. Medit. Triaspr., pag. 286, Taf, LXXXII, Irig. 3, 4.

Das vorliegende Stück besteht zum grössten Theile aus einem Wohnkammerfragment, an welches sich drei Luftliammern anschliessen. Die Länge, über den Externtheil gemessen, betrügt $38 \mathrm{~mm}$; die grösste Dicke, etwas oberhalb der Seitenmitte, $20 \mathrm{~mm}$, Flankenhöhe ungefähr I7 mm.

Der Mündungsquerschnitt zeigt einen flachgewölbten Externtheil und Flanken, deren grösste Breite im oberen Drittel der Seitenhöhe liegt. Die Kammerscheidewände haben einen breiten und flachen Externlobus, kurzen und niedern Sattel, tiefen kleinen Laterallobus, der im oberen Drittel der Seitenhöhe liegt; der aufsteigende Ast des Nahtsattels springt nach vorne vor.

Die Anwachsstreifen, erst in der Radialrichtung ansetzend, wenden sich schon etwas oberhalb der Flankenmitte in weitem Bogen über den gewölbten Externtheil, auf dem sie eine tiefe, spitzgerundete Bucht bilden.

Ausser den Querstreifen ist die Schale noch mit bandförmig angeordneten, mikroskopisch. feinen Längsstreifen bedeckt, welche am stärksten in der Mitte des Externtheiles werden und deren Kreuzungsstellen unter der Lupe als feine Körnelung sichtbar sind.

Der äusseren Form nach, sowje bezüglich der feinen Schalensculptur stimmt das vorhandene Bruchstück nicht schlecht mit dem von . Mojsisorics abgebildeten Naut. lilianus überein. Jedoch wird in der Beschreibung der Durchschnitt als rechteckig angegeben, während er bei cfr. lilianus mehr gerundet und umgekehrt trapezoïdal erscheint. Auch ist der Verlauf der Kammerscheidewände etwas anders; sic werden als »entfernt stehend « beschrieben, während sie hier nahegerückt sind und zwei deutliche Loben zeigen, während Mojsisorics nur einen Laterallobus angibt.

Trotz dieser Unterschiede glaube ich nicht fehlzugehen, wenn ich das vorliegende Stück als cfr. lilianus bei Nautilus lilianus belasse, der aus der Trinodosus-Zone der Schreyeralm beschrieben wird.

\section{Nautilus nov. form. indet.}

Das einzige vorliegende Bruchstück weist folgende Maasse auf:

Durchmesser . . . . . circa $50 \mathrm{~mm}$
Höhe der letzten Windung . . . . . 24
Breite " $" .30$
Nabelweite (von Naht zu Naht). . circa 10

Der Querschnitt der Windung hat ungefäh trapezoildale Form; die Windung ist breiter als hoch: die Involution scheint die Hälfte der vorhergehenden Windung zu umhüllen. Der Externtheil 
ist schwach gewölbt, die Flanken sind fast flach zu nennen und erreichen die grösste Breite in der Nabelregion. Ein Marginalrand ist nicht entwickelt; der Umbilicale ist sehr kräftig, nur mit abgestumpfter Kantenlinie versehen; die Nabelwand ist hoch und steil gestellt. Die Anwachslinien sind in Folge des Erhaltungszustandes nicht zu sehen.

Die Kammerscheidewände sind relativ eng gestellt; sie setzen geradlinig über den Externtheil, zeigen eine flache, gegen den Externtheil gehobene Lateralbucht, einen kleinen umbilicalen Sattel, von wo aus die Scheidewand senkrecht über die Nabelwand herabsteigt; Internlobus und Lage des Sipho sind nicht bekannt.

Unser Bruchstück schliesst sich in seiner äusseren Form an den im Folgenden beschriebenen Nautilus pertumidus an. Er scheint in den späteren Wachsthumsstadien eine ähnlich aufgeblähte Form der Wohnkammer zu erlangen, ähnelt aber in dem vorliegenden Altersstadium noch mehr dem bei Oeberg ${ }^{-1}$ ) abgebildeten Nautilus Nordenskiöldi Lindstr. (pag. 4, Taf. V, Fig. I), der jedoch etwas involuter ist und noch rascher anwächst. Von jener Species ist jedoch die Suturlinie nicht bekannt.

\section{Nautilus efr. granulosostriatus Klipst. sp.}

1843. K7ipstein A. v., Beitrag zur geolog. Kenntniss der östl. Alpen, pag. 126, Taf. VII, Fig. 8, Giessen.

1870. Laube, Fauna der Schichten von St. Cassian, pag. 58, Taf. XXXVI, Fig. 3. Denkschr. k. Akad. d. Wiss. mat.-nat. Cl., Bd. XXX, Wien.

I882. Mojsisowics E. z., Cephalop. Medit. Triaspr., pag. 289, Taf. LXXXII, Fig. 7-9.

Erhalten ist ein kleines, verdrücktes Stück der- Wohnkammer und vier Luftkammern.

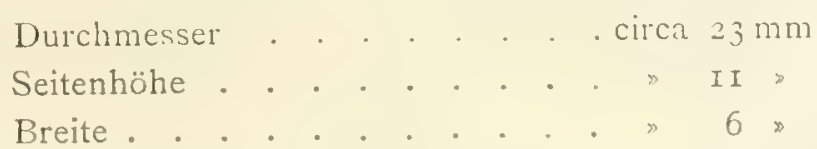

Die Form ist rasch anwachsend, hat kleinen Nabel, scheint schwach gekrümmte Seiten und höher gewölbten Externtheil zu haben. Die Kammerscheidewände verlaufen gerade über den Externtheil und zeigen auf den Flanken einen flachen Lobus.

Die Schale hat weitgestellte, deutlich sichtbare Querstreifen, die, radial am Nabelrand beginnend, sich in dem oberen Flankentheil in weitem Bogen nach rückwärts wenden und auf dem Externtheil eine spitzgerundete tiefe Bucht bilden. Eine Normallinie ist auf dem Steinkerne deutlich sichtbar, der besonders auf dem Externtheil noch gut die Querstreifen sehen lässt.

Die Vorliegenden sind mit den von Mojsisovics abgebildeten Exemplaren nicht vollständig übereinstimmend. Die Schalenstreifen sind hier deutlich mit freiem Auge sichtbar, sowie sie von Klipstein auch beschrieben wurden, während sie Mojsisovics als »mit freiem Auge kaum unterscheidbar * beschreibt. Klipstein schildert die durch die Kreuzung der Quer- und Längsstreifen entstandenen Feldchen als rhombisch, während sie hier eher rechteckig sind. Auch die Externbucht ist hier tief und schmal und nicht breit und nicht sehr tief «, wie sie Mrojsisovics beschreibt. Auffallend ist ferner hier" dic Normallinie, die bei keinem der oben angeführten Autoren erwähnt wird.

Aus all dem oben Angeführten scheint mir hervorzugehen, dass der hier als cfr. granulosostriatus bestimmte Nautilus doch nicht gut mit dieser Art specicll zu identificiren ist, dass aber das schlechte Exemplar die Aufstellung einer neuen Species nicht zulässt, welche sich mit Recht nach dem Funde eines guten Stïckes wird begründen lassen.

Nautilus granulosostriatus wird von Mojsisovics aus der Zone des Trachyceras Aon der Mergel der Stuoreswiesen bei St. Cassian angeführt.

Stockholm 1877 .

1) Oiverg Fi, Om Trias-fürsteningar frän Spetsbergen, kon. Somska Vetenskap.Akad. Handlingar, 13d. If, Nr. It, Deitrăge zur Pałontologie Oesterreich-Ungarns. Bd. X. 


\section{Nautilus pertumidus Art.}

laf. HI, Iig. A, 5, 6.

Eine ausserordentlich rasch in die Breite anwachsende Form. Das grüsste der vorliegenden Exemplare hat folgende Maasse:

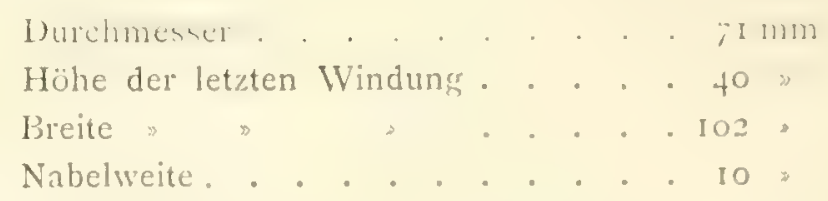

Der Externtheil, anfangs flach gerundeł, wölbt sich auf der Wohnkammer etwas höher. Die Flanken, anfangs stark gewölbt, flachen sich später immer mehr ab; die grösste Breite wird in der. Umbilicalregion erreicht. Eine Marginalkante ist eigentlich nicht entwickelt, sondern die Flanke geht allmälig in den Externtheil über; die Umbilicalkante ist stets deutlich sichtbar; die Nabelwand ist anfangs steil gestellt, beginnt jedoch beim starken Anwachsen der Windung in die Breite, also ungefähr bei Beginn des letzten Umganges, sich zu wölben; sie ist sehr hoch und der kleine Nabel tief eingesenkt. Bei dem abgebildeten Stück sind ungefähr 21/2 Umgänge zu sehen; auf der letzten Windung entfällt ungefähr ein Drittel auf die Wohnkammer. Eigentlich erst vom Beginn der letzten Wohnkammer an, und das nur bei ausgewachsenen Exemplaren, wie das in Fig. 6 abgebildete, beginnt die Windung sich plötzlich ausserordentlich zu verbreitern und erreicht, wenn man den einen abgebrochenen Flügel ergänzt, in der Umbilicalregion eine Breite von circa I $6 \mathrm{~mm}$.

Die Schale ist, besonders bei jüngeren Exemplaren, mit einem System von feinen, sich kreuzenden Linien bedeckt. Die radialgestellten steigen gerade über die Nabelwand auf, beginnen sodann gleich von der Nabelkante an sich leicht nach rückwärts zu wenden und biegen im oberen Theile der Flanke in grossem Bogen auf den Externtheil über, woselbst sie eine relativ kleine, spitz. gerundete Bucht bilden. Die Längsstreifen sind hauptsächlich auf der ersten Windung gut sichtbar; sie sind eng gestellt, treten besonders auf dem oberen Flanken- und Externtheil auf und bilden an den Kreuzungsstellen mit den Radiallinien mikroskopisch feine Knötchen. Auf dem letzten Umgang sind die Längslinien von der Schale verschwunden, bleiben aber stellenweise auf dem Steinkerne sichtbar.

Eine Normallinie ist deutlich entwickelt. Die Kammerscheidewände zeigen einen ganz kleinen, flachen Externlobus und niedern, sehr grossen Sattel; die Lateralbucht ist gross und sehr flach; dann senken sich die Kammerscheidewände über die Umbilicalwand herab und bilden eine verhältnissmässig grosse, gerundete Internbucht mit ganz kleinem Internlobus. Der Sipho liegt tief unter der halben Mündungshöhe.

Diese in ihren Anwachsverhältnissen exorbitante Form nimmt vorläufig einen isolirten Platz in der Triasfauna ein, und von den bekannten Formen stimmen nur zwei annähernd mit ihr überein. Es sind dies Nautilus Tintoretti Mojs. ${ }^{\text {) }}$ (pag. 283, Taf. XCI, Fig. I, 2) aus der Trinodosus-Zone der Schreyeralm und Nautilus Sibillae Mojs. ${ }^{2}$ ) (pag. Ioo, Taf. XVI, Fig. 2) aus dem schwarzen Daonellenkalke von Spitzbergen.

Ersterer wächst bei annähernd gleichem Durchmesser lange nicht zu so grosser Breite und Mündungshöhe an; hat abgeplatteten Externtheil, steile Nabelwand und ist bedeutend weniger involut; der Sipho ist grösser und steht in halber Höhe der Kammerwand. Letzterer hat wohl eine ähnliche lorm, ist aber viel kleiner und hat eine schräg gestellte Nabelwand. XXXIII. Nr. 0.

.Wojsisovics F. $\approx$, Cephàlop. Medit. 'Triaspr.

Mojsisouics F. \%. Arktische Triasfaunen, Mémoires Akad. Imp. des sciences St, Petersburg, VII. Sér. Tome 
Um Formen zu finden, denen Nautilus per'sumidus nahe steht, müssen wir zurück in permische Ablagerungen greifen. Dort haben wir z. B. den Nautilus cornutus, der von Golovinski') aus dem Perm des Kamo-Wolga-Bassins beschrieben wurde.

Es ist dies eine vollständig isolirt stehende Form, die zu grosser Dicke anwächst und bei welcher Intern- und Externtheil der letzten Windung in der Höhe des Nabelrandes sich vereinigen und eine Art von Horn oder Röhre bilden, deren Endpunkte (der Zeichnung nach) circa $193 \mathrm{~mm}$ weit von einander abstehen.

$\mathrm{Ob}$ eine ähnliche Ausbildung bei Nautilus pertumidus erfolgt, lässt sich an keinem der vorliegenden sechs Exemplare genau constatiren; nur bei einem ist am Nabelrand der Anfang einer derartig röhrenförmigen Krümmung der Flanke zu bemerken, welche auf ähnliche Entwicklung wie bei Nautilus cornutus hindeuten könnte, die aber ebenso gut auch durch irgend welche Zufälligkeiten entstanden sein kann. Die Lage des Sipho ist bei beiden Formen eine ähnliche, jedoch der Verlauf der Kammerscheidewände ganz verschieden. Auch zeigt die permische Form bei geringerer Grösse schon über drei Umgänge, während Nautilus pertumidus bei grösserem Durchmesser erst etwas über zwei aufweist.

Eine andere, nahestehende Form ist der von Koninck ${ }^{2}$ ) aus dem Carbon beschriebene Nautilus latiseptatus. Er zeigt dasselbe Anwachsverhältniss, dieselbe globose, an der Mündung stark aufgetriebene äussere Form, auch ähnlich gestaltete Kammerscheidewände, jedoch ist dieser Nautilus eigentlich ein Solenocheilus und hat als solcher einen knapp unter der Schale des Externtheils liegenden Sipho, während er bei Nautilus fertumidus unter der halben Mündungshöhe liegt, und eher dem Internrand genähert ist.

\title{
Sectio II. Ammonea.
}

\section{Ordnung: Trachyostraca Mojs. \\ Familie: Ceratitidae v, Buch. \\ Unterfamilie: Dinaritinae Mojs. \\ Gattung: Ceratites de Haan.}

\section{Formengruppe des Ceratites binodosus Hauer.}

1882. Mojsisovics E. v., Cephalop. Medit. Triaspr., pag. 19.

\author{
Ceratites semiornatus Art. \\ Tafel III, Fig. $7 a, b, c, a$. \\ Durchmesser . . . . . . . . $55 \mathrm{~mm}$ \\ Höhe der letzten Windung . . . . 27 \\ Dicke * . circa I5 \\ Nabelweite (von Naht zu Naht) . . s
}

Der Externtheil ist in letzten Viertel der letzten Windung voliständig thach, auf den vorangehenden Partien flach gewölbt. Die Seiten erreichen die grösste Dicke etwas unterhalb der Flanken.

1) Ciolorinski 1h, Materialien zur Geologie Russ'ands. Bd. I. Petersburg IE6g. Ueber das Perm im centralen Theile des liamo-IVolga-Bassins, pag. 38I, Taf. V, Irig. 15- I9.

2) De foninck, Faune du Calcaire Carbonif. de la Belgique. Ann. Mlus. Roy. d'Hist. nat. de I3elg. Bd. II, pag. IIo, Taf. XXII, lige $1-3$. 
mitte, von wo aus sie rasch gegen den Nabel und langsamer gegen den Marginalrand abfallen; der Umbilicalrand ist leicht abgerundet, die Wand fast senkrecht stehend; der Nabel ist eng; die Involution umfasst etwas über drei Viertel der vorletzten Windung.

Die Sculptur besteht auf der letzten Windung aus Radialstreifen, welche sich nur wenig aus der Schalenfläche erheben, erst im oberen Theil der Flanke rippenartig werden und an der Marginalkante in einen längsgestellten, scharfen, etwas in die Länge gezogenen linoten enden. Auf der vorletzten Windung jedoch sind die Schalenstreifen auch in der Nabelregion kräftiger entwickelt.

Die Suturlinie zeigt einen breiten Externlobus mit Medianhöcker, breiten, tiefen ersten und breitem zweiten Laterallobus, der von gleicher 'Tiefe wie der externe ist; dann folgt auf der Flanke ein breiter flacher erster und auf der Nabelwand ein etwas kleinerer zweiter Auxiliarlobus; alle Loben sind am Grunde reich geschlitzt; die Sättel sind breit gerundet und ganzrandign.

Ceratites semiornatus schliesst sich in gewissem Sinne an Ceratites aviticus Mojs. ${ }^{1}$ ) (pag. 2.4 , I'af. XII, Fig. 2-4) an. Dieser verliert bei zunehmendem Wachsthum erst die Lateraldornen, später die Umbilical- und Marginalknoten. Ob Ceratites semiornatus in der Jugend Lateraldornen besessen habe, lässt sich an dem einen Stücke nicht constatiren, wohl aber, dass er die Umbilicalknoten, welche er besass, auf der letzten Windung schon verloren hat, ebenso wie die Marginalknoten, welche auf dem letzten Theil der Wohnkammer verschwunden sind. Er wird dann ganz glatt wie Ceratites cordevolicus Mojs. (ibid., pag. 26, Taf. XII, Fig. 5, 6, 7), während bei Ceratites aviticus auch bei viel grösserem Durchmesser noch Marginal- und Umbilicalknoten fortbestehen.

Da wir vor Beginn der Wohnkammer die Kammerscheidewände keineswegs stark gedrängt sehen, also kein vollständig erwachsenes Individuum vor uns haben, die Form aber dennoch ihre Sculptur sehr vereinfacht, so ist dies nicht auf individuelle senile Beeinflussung zurückzuführen, sondern muss einen anderen Grund haben, den ich meinestheils nur in den senilen Einflüssen der Species selbst finde und daher den Ceratites semiornatus zu den rückgebildeten Formen der Binodosus Gruppe stelle. Er schliesst sich enger an Ceratites aviticus Mojs., Ceratites cordevolicus Mojs. an und endlich auch an Ceratites Fuchsi Mojs. (ibid., pag. 24, Taf. XII, Fig. I).

\section{Ceratites nov. spec. indet.}

Tat. IV, Fig. I $a, b$.

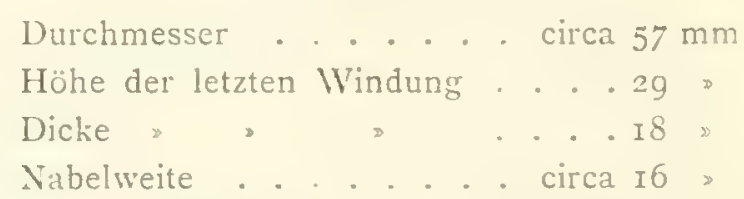

Der Externtheil ist flach gewölbt, ebenso die Flanken, welche die grösste Breite unterhalb der halben Höhe erlangen. Der Marginalrand ist deutlich entwickelt, der umbilicale leicht abgerundet. Die Nabelwand ist nieder und senkrecht stehend; der Nabel weit.

Die Inrolution dürfte zwei Drittel kaum erreicht haben.

Die Szulptur ist auf den früheren Umgängen kräftig entwickelt und besteht aus radial verlaufenden, enggesteliten Rippen, welche sich wohl ähnlich den Rippen auf der Wohnkammer bei Ceratites planus Art. (pag. 45, Taf. IV, Fig. $2 a, b, c$ ) verhalten haben mögen. Auf dem Theil der letzten Windung, welcher uns vorliegt, sind die Rippen sehr schwach geworden, besonders auf dem Steinkerne ${ }^{2}$ ) in der Umbilical- und Lateralregion, während sie auf der Schale als feine Rippenlinie sichtbar bleiben, welche von der Radiale nach vorn etwas abweichend als einfache Rippen die Flanke

1) Mojsisouits E. a., Cephalop. Medit. Triaspr.

) Die Zeichnung ist insoferne nicht ganz richtig, da eine Art von Umbilicalknoten angegeben wurde, welche thatsïchlich nicht vorhanden ist. 
übersetzen. In der Marginalregion schwellen die Rippen etwas mehr, kurz vor Erreichen des Randes, an und enden daselbst mit einer stumpfdornigen Verdickung, welche gegen Ende der Wohnkammer immer schwächer wird, sich etwas in die Länge zieht und schliesslich ganz verschwindet. Zwischen diesen, theilweise sehr undeutlichen Rippen, welche ziemlich weit von einander abstehen, treten noch feine Zwischenrippen auf, die den Intercostalraum ausfüllen, von denen sich aber nicht sagen lässt, ob sie ebenfalls als primäre oder schon als Secundärrippen aufzufassen sind. Ebenso undeutlich ist das Auftreten der schwachen Lateralknoten, deren unterhalb der halben Flankenhöhe beim vorliegenden Stücke zwei entwickelt sind.

Die Loben sind nicht bekannt.

Ceratites nov. spec. indet. schliesst sich vielleicht an Ceratites semiornatus Art. an.

\section{Ceratites planus Art.}

Taf. IV, Fig. $2 a, b, c$.

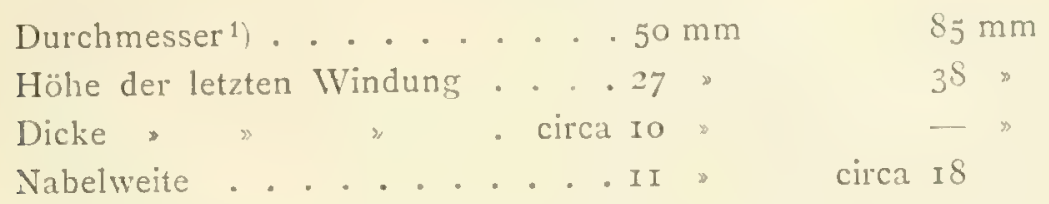

Der Externtheil ist anfangs schwächer und gegen Schluss des letzten Umganges etwas stärker gewölbt, die Flanken in der Mitte flach aufgetrieben. Der Marginalrand ist kantig entwickelt und auf der Wohnkammer des abgebildeten Exemplares schon stark abgerundet; der Umbilicalrand ist mit abgestumpfter Kante versehen. Die Nabelwand ist nieder und senkrecht stehend, der Nabel verhältnissmässig gross. Die Involution umfasst ungefähr zwei Drittel der Flankenhöhe des früheren Umganges.

Diese Species hat ein flach scheibenförmiges Aussehen.

Aehnlich dem Wechsel der Form des Externtheiles und Marginalrandes auf den vorhergehenden Windungstheilen und der Wohnkammer ändert sich auch die Ornamentirung der Flanke. Sie ist aus breiten, gerundeten und gedrängt stehenden Rippen gebildet, welche vom Umbilicalrand in einer Art von rundem Knoten beginnt. Von hier strahlen je zwei Rippen in radialer Richtung aus; sie tragen in ungefähr zwei Drittel der Flankenhöhe einen kleinen stumpfen Lateralknoten, der somit noch unterhalb der grössten lateralen Anschwellung liegt und in dem sich die Rippe gabelt. Die beiden Theile sind von gleicher Stärke, nur um sehr wenig schwächer als die gemeinsame Hauptrippe, biegen sich auf dem äusseren Flankentheil in sanftem Bogren etwas nach rückwärts und kehren sodann in einer knotigen marginalen Anschwellung, die sich ein klein wenig noch auf dem Externtheil fortsetzt wieder in die ursprüngliche Radialrichtung zurück.

Es entsprechen somit einer umbilicalen, knotigen Anschwellung zwei Lateralknoten und vies marginale, knotenförmige Verdickungen.

Bei weiterem Wachsthum ändert sich die Sculptur in dem Sinne, dass erst die knotige Verdickung am Nabel, später die des Marginalrandes verschwindet und die Lateralknoten sich immer mehr erniedrigen, bis auch sie vollständig verschwunden sind. In der Sculptur der Flanke ändert sich bezüglich der Rippen nichts. Sie verlaufen annähernd in gleicher Stärke, leicht sichelförmig geschwungen über den Lateraltheil und setzen aber, wenn auch bedeutend erniedrigt und gegen rorn convex gebogen, über den Externtheil hinüber auf die andere Flanke. Die Schale selbst ist mit feinen Linien parallel den Rippen bedeckt.

Die Suturlinie zeigt einen verhältnissmässig breiten Extern-, ungefähr doppelt so tiefen, breiten ersten Lateral-, kleinen breiten zweiten Lateral- und sehr breiten, aber seichten Auxiliarlobus auf de!

1) Die zweiten Maasszahlen entsprechen einem grösseren liruchstücli. 
Flanke, auf den gegen die Naht zu noch zwei kleine Auxiliarzacken folgen. Sämmtliche Loben sind am Grunde reich gezackt; der erste Laterallobus hat drei grosse Zacken, und kleine Spitzen ziehen sich bis zur halben Höhe hinauf. Die Sättel sind im Vergleich zu den Loben schmal, gerundet und ganzrandig. Der Extern- und erste Lateralsattel sind ein wenig nach aussen, respective innen verzoren, was die Einsenkung des Lobus noch breiter erscheinen lässt. Die Verbindungslinie der Sattelköpfe ist eine Gerade, welche mit der Radiallinie zusammenfällt, nur der erste Lateralsattel steigt etwas über dieselbe hernus.

Dem Ceratites planus stehen einige Formen der Binodosus.Gruppe Mojsisorics' sehr nahe. Ceratites Rothi Mojs. ${ }^{1}$ ) (pag. 25, Taf. IX, Fig. 7), der eine ähnliche Anordnung der Rippen und Knoten zeigt, ebenfalls die Sculptur wieder reducirt und dieselben feinen Schalenstreifen aufweist, welche convex über den Externtheil setzen. Jedoch ist diese Form viel dicker und plumper, von geringerer Grösse und hat nicht so gedrängt stehende Rippen. Der Nabel ist etwas enger, die Loben sind nicht bekannt.

Eine andere Form ist Ceratites Barrandei Mojs. (ibid., pag. 25, Taf. XII, Fig. 8), Die Aehnlichkeit liegt hier besonders im Anfang der letzten Windung, wo wir dieselben enggestellten starken Rippen wie auf der Wohnkammer von Ceratites planus Art. finden. Jedoch ist Ceratites Barrandei involuter, von grösserer Dicke und hat scharf entwickelte Marginalknoten, während Ceratites planus nur Anschwellungen hat. Die Loben sind nicht bekannt. Wir sehen aber bei Ceratites Barrandei ein Vorschreiten der Sculpturirung auf der letzten Windung, während hier das Gegentheil eintritt.

Eine dritte Species, die grosse Aehnlichkeit der äusseren Form aufweist, ist Ceratites aviticus Mojs. (ibid., pag. 24, 'Taf. XII, Fig. 2-4) und besonders das in Fig. 3 abgebildete Exemplar. Wir sehen dieselbe strahlige Anorđnung der Rippen am Nabelrand, denselben flach sichelförmigen Schwung auf dem äusseren Flankentheil. Jedoch ist auch diese Form involuter und dicker. Auch hier sind für weiteren Vergleich die Loben nicht bekannt.

Ceratites Fuchsi Mojs. (ibid., pag. 24, Taf. XII, Fig. I) hat eine ähnliche Art der Uebersetzung der Rippen über den Externtheil.

\section{Ceratites glaber Art}

Taf. III, Fig. $8 a, b, c$.

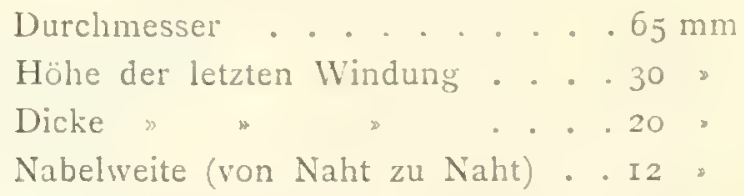

Der Externtheil ist anfangs der letzten Windung fast flach, auf der Wohnkammer hoch gewölbt; die Flanken sind flach gewölbt und erreichen die grösste Dicke etwas unterhalb der Mitte; Marginalund Umbilicalkante sind anfänglich scharf entwickelt, auf der Wohnkammer jedoch abgerundet. Die Involution ist gross und umfasst etwas mehr als drei Viertel der früheren Windung; der Nabel ist klein und die Nabelwand steil gestellt.

Die Sculptur ist bis zu ein Viertel der letzten Windung aus niedrigen Rippen gebildet, welche von der Radiale stark gegen vorn abweichen und gerade verlaufen. Sie beginnen am Nabelrand in einem länglichen stumpfen Knotenstücke, in dem sich zwei Rippen vereinigen, die sich dann getrennt bis zum Marginalrand fortsetzen, in der Flankenmitte sich erniedrigen und erst knapp vor Erreichen des Randes wieder stärker werden und am Marginalrand selbst einen scharfen und kleinen längsgrestellten Knoten bilden, von dem aus stellenweise sich die Rippe noch ein kleines Stück auf dem Externtheil in schräger Richtung fortsetzt. Später wird diese Sculptur immer undeutlicher und auf der

$$
\text { 1) Mojsisovics E. } \% \text {, Cephalop. Medit. Triaspr. }
$$


Wohnkammer, bei vollständig ausgewachsenen Formen, sehen wir nicht mehr gespaltene, sondern nur mehr einfache, flache Faltenstreifen, die weder Marginal- noch Umbilicalanschwellung aufweisen und geradlinig, von der Radiale gegen vorn abweichend, sich zum Externtheil fortsetzen, woselbst sie langsam verschwinden. Das Ende der Wohnkammer hat jegliche Sculptur verloren.

Die Suturlinie zeigt einen grossen breiten Externlobus, welcher zur Hälfte auf der Marginalkante liegt; der erste Laterallobus ist nur um wenig tiefer als der externe, ist gross, breit und besitzt vier Zacken; der zweite hat dieselbe Tiefe wie der externe, steht dem ersten nur wenig an Breite nach und hat auch wie dieser vier Zacken; ihm folgt noch auf der Flanke ein kleiner gezacliter Auxiliar, an den sich auf dem unteren Theil der Nabelwand ein zweiter, flacher anschliesst. Die Sättel sind ganzrandig und eher rund als spitz gewölbt.

Ceratites glaber schliesst sich mit Ceratites semiornatus Art. an die Formen der BinodosusGruppe: Ceratites aviticus Mojs. (pag. 24, Taf. XII, Fig. 2, 3, 4) und Ceratites cordevolicus Mlojs. (pag. 26, Taf. XII, Fig. 5, 6, 7) näher an.

Auch er zeigt in der Form der Sculptur bezüglich der T'endenz, die Ornamentirung bis auf vollständige Glätte zu reduciren, dieselbe Rückbildung wie die anderen Arten. Obgleich es hier nicht ganz klar ist, ob nicht individuelle senile Eigenschaften bei dem abgebildeten Exemplar eine so grosse Bedeutung haben, welche die speciellen überwiegen, denn es liegt ein vollständig ausgewachsenes Individuum vor.

\section{Ceratites simplex Art.}

Taf. IV, Iig. $+a, b$,

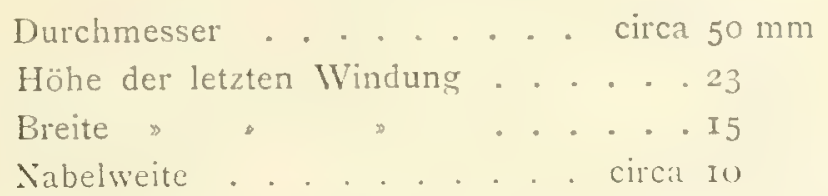

Der Externtheil ist hoch gewölbt; die Flanken sind schwach aufgebläht und erreichen ungefähr in der Flankenmitte die grösste Dicke; der Marginalrand ist als solcher fast unkenntlich, der umbilicale deutlich entwickelt und mit leicht abgestumpfter Kante versehen; die Nabelwand ist nieder und fast senkrecht stehend, der Nabel klein. Die Involution umfasst ungefähr drei Viertel der letzten Windung; die Form ist rasch anwachsend.

Die Sculptur ist sehr stark reducirt; auf der Schale haben wir in der Nabelregion schwach sichtbare flache Faltenrippen, welche theils radial als Hauptrippen gegen den Convextheil ziehen, theils sich-als Nebenrippe in einen am Ende der Wohnkammer reducirten Lateralknoten an die Primäre angliedern. Auf dem Steinkerne hingegen sind, wenigstens auf der Wohnkammer, überhaupt keine Falten oder Rippen sichtbar, ausser am stark abgeflachten Marginalrand ein kurzes Stück, das dem verdickten Rippenende mit schräggestellter, stumpfer, knotiger Verdickung wie wir sie bei Ceratites binodosus (pag. 48, Taf. IV, Fig. 3) sehen, entspricht. Bei Verlängerung dieser Rippenstücke gegen den Nabel zu treffen beide Linien in dem kleinen spitzen Lateralknoten zusammen.

Die Suturlinie zeigt einen breiten, aber kurzen und gezacliten Externlobus mit kleinem Sattel; der erste Laterallobus ist breit, tief, der zweite nur um wenig kürzer, beide sind am Grunde gezackt. Der erste Lateralsattel ist breiter als der Lobus, der zweite etwas schmäler; beide sind ganzrandig. Gegen den Nabel folgt undeutlich ein erster und ganz kleiner zweiter Auxiliarlobus auf der Flanke.

Die Reduction einzelner Sculpturelemente, wie wir sie auch hier wieder sehen, verweist diese Art in die Reihe jener rückgebildeten Formen, welche pag. 44 besprochen wurden. Hier bleibt aber die Marginalsculptur bestehen, Wenigstens noch in dem Altersstadium, welches das vorliegende Stïck von Ceratites simplex aufweist, während die Laterale verschwunden ist. Es scheint also die Marginalsculptur 
ein wichtigeres Sculpturelement zu repräsentiren, welches demzufolge länger persistirt und uns bei diesem typischen Ceratiten dieselbe Ausbildungsweise der Ornamentirung wieder zeigt, welche wir bei den Tirolitinen finden, nämlich: das Maximum der Flankensculptur auf dem Marginaltheile entwickelt. Wohl liennen wir Dinariten mit einer partiell entwickelten Marginalsculptur, z. 13. Dinarites circumplicatus Mojs. ') (pag. 8, 'Taf. III, Fig. 8, 9) und Dinarites liccanus Hauer (ibid, pag. 10, Taf. IV, Fig. I), die somit Tirolitinencharaktere zu ihren Dinariten-Eigenthümlichkeiten hinzuerworben haben, also vom einfacheren in ein höheres Ornamentirungsstadium eingetreten sind, was wir bei lirolites nie finden, der stets sein Maximum der Sculptur am Marginalrande beibehält. Diese Beobachtungen führten mich zu der Ansicht, dass ich die Marginalsculptur für bedeutsamer und somit die 'Tirolitinen selbst als älter und früher vertreten, respective entwickelt auffasse als die Umbilicalsculptur, respective die Dinaritinen selbst, ganz abgesehen davon, dass wir bis heute beide, Tiroliten und Dinariten, zum ersten Male in demselben Horizont gefunden haben.

Schliesslich muss noch auf die nahe Verwandtschaft hingewiesen werden, welche zwischen Ceratites simplex Art. und Ceratites binodosus Hauer besteht. Unterschiede finden wir in der engeren Berippung der letzteren Form, ferner in dem Aufhören der Lateralknoten und in der anderen Stellung der Marginalen, welche hier fast genau spiral und marginal, d. h. längsgestellt sind, während sie bei Ceratites simplex eher als verdicktes Rippenende aufzufassen sind.

\section{Ceratites binodosus Hauer.}

Taf. IV, Fig. $3 a, b, c$ 。

I850. Ammonites binodosus Hauer Fr. v., Ueber die von W. Fuchs in den Venetianer Alpen gesammelten Fossilien. Denkschr. k. Akad, d. Wiss. mat.-nat. Cl. Bd. II, pas Ix, Taf. XIX, Fig. I-4.

I865. Ceratites binodosus Hauer, partim, Cephalop. der unt. Trias d. Alpen. Sitzungsber. k. Akad. d. Wiss. mat.-nat. Cl. Bd. LII, pag. 623 .

I869. Ammonites binodosus Mojsisorics E. V., partim, Beitrag zur Kenntniss der Cephalop. Fauna des alp. MIuschelkalkes. Jahrbuch d. k. k. geol. R.-A., pag. 581 .

1879. Trachyceras binodosum Mojsisovics E. v., Dolomitriffe von Süd-Tirol und Venetien, pag. 40.

I882. Ceratites binodosus Hauer, Mojsisowics E. \%, Cephalcp. Medit. Triaspr., pag. I9, Taf. XI, Fig. I-5

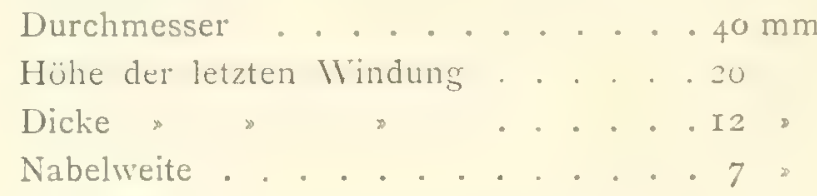

Der Externtheil, sowie die Flanken sind schwach gewölbt; Marginal- und Umbilicalkante sind deutlich sichtbar. Die Flanke erreicht, langsam anschwellend, etwas unterhalb der halben Seitenhöhe die grösste Dicke. Die Involution ist sehr gross und beträgt mehr als drei Viertel der Seitenhöhe, so dass nur mehr ein schmaler Streif der früheren Windung sichtbar bleibt und ein enger Nabel resultirt. Die Nabelwand ist nieder und senkrecht gestellt.

Die Ornamentirung ist aus radial verlaufenden Hauptrippen gebildet, welche auf älteren Windungen stärker, auf zuletzt gebildeten nur mehr schwach am Umbilicalrand beginnen, wenig gegen die Flankenmitte anschwellen und dort, wo die grösste Seitenanschwellung ist, einen spitzen Lateraldorn tragen; dann werden sie abermals schwächer und zeigen nur am Marginalrand eine Anschwellung der Rippe, die die Form eines stumpfen, quer gestellten Marginalknotens hat. Auswärts der Lateralknoten schieben sich Secundärrippen ein, welche am Marginalrand eine gleich starke Anschwellung wie die Hauptrippen zeigen und sich meist mehr oder weniger deutlich an je eine Primäre oberhalb der Flankenmitte angliedern. Auf dem abgebildeten Stücle sieht man neun Lateral- und neunzehn Marginalknoten. ${ }^{2}$ )

1) Mojsisovics Fi. z', Cephalop. Medit. Triaspr.

Die Zeichnung Irig. $3 a$ ist daher nicht ganz exact. 
Die Suturlinie ist leider nicht vollständig , bei den vorliegenden Stücken erhalten. Es fehlt der Externlobus, der wohl die ganze Breite des Externtheiles eingenommen hat; der Sattel liegt zum grössten Theile schon auf der Flanke. Der erste Laterallobus ist tief, der zweite ist kürzer und schmäler; nun folgt ein kleiner aber relativ breiter erster Auxiliarlobus, sodann ein kleinerer zweiter, der aber von der Nabelkante halbirt wird; die Zähnelung der Loben ist sehr reich und zieht sich hoch hinauf zum Beginn des Sattelbogens. Die Sättel sind ganzrandig und rund gewölbt; Extern-, erster und zweiter Lateralsattel liegen in gleicher Höhe, dann senken sich die Sättel ein wenig herab.

Die vorliegenden Exemplare gehören alle einer kleineren Varietät an; das grösste, ein IVohnkammerbruchstück, weist eine Seitenhöhe von $20 \mathrm{~mm}$ auf, hat also ungefähr dieselben Dimensionen wie das von Mrojsisovics abgebildete Stück. Das Reiflinger Exemplar ist jedoch stark verdrückt, lässt nur mangelhaft die Flankenbreite beobachten und gehört der loc. cit. Fig. 5 abgebildeten engnabeligen Varietät an.

Die Suturlinie stimmt, soweit sie sich beobachten lässt, gut mit der loc, cit. gegebenen Abbildung überein, wenn auch Mojsisovics zwei Auxiliarloben anführt, während hier nur anderthalb auf der Flanke zu sehen sind, was auf den Grössenunterschied der beiden Stücke zurückzuführen ist.

Der Nachweis des so charakteristischen Ceratites binodosus, der bis jetzt nur aus den Südalpen bekannt war, ist hier zum ersten Male auch für die Nordalpen gelungen, worin die besondere Bedeutung des Stückes liegt, da Ceratites binodosus als leitend für den unteren Muschelkalk (Zone des Ceratites binodosus) angesehen wird.

\section{Ceratites Waageni Art.}

Taf. IV, Fig. $5 a, b, c$.

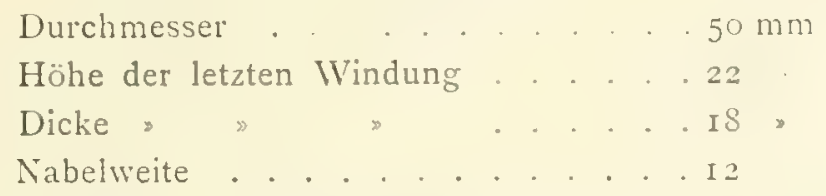

Der Externtheil ist gerundet, ebenso die Flanken, welche am Anfang der letzten Windung mehr umbilical, später mehr lateral die grösste Dicke erlangen. Die Marginalkante ist scharf entwickelt, der Umbilicalrand gerundet; die Nabelwand ist niedrig und anfangs fast senkrecht, später nur mehr steil gestellt. Der Nabel ist relativ gross und erhält durch den abgerundeten Nabelrand ein trichterförmiges Aussehen. Die Involution umfasst drei Viertel der früheren Windung.

Die Berippung besteht auf den älteren Windungen aus Spaltrippen; auf dem letzten Umgang schieben sich anfänglich nur einzelne einfache Rippen ein, später verschwinden die gespaltenen vollständig und ihre Stelle nehmen nur mehr einfache, spärlich gestellte Rippen ein, welche auf dem Steinkerne undeutlich hervortreten.

Auf dem ersten Viertel des letzten Umganges sehen wir die Rippe verdickt über die Umbilicalwand heraufsteigen und knapp neben dem Nabelrand, aber schon auf der Flanke selbst, einen stumpfen Knoten ansetzen. Hier endet der verdickte Theil der Rippe, welche sich nun spaltet; die beiden Rippentheile sind von gleicher Stärke, verlaufen annähernd radial und gerade zum Marginalrand, wo sie sich kurz vor Erreichen desselben etwas verdicken, sich gleichzeitig nach vorn wenden, dann auf der Kante selbst einen längsgestellten scharfen Knoten bilden und sich jenseits desselben noch ein ganz kleines Stück auf dem Externtheil fortsetzen und diesen dadurch etwas sculpturiren. Verfolgt man die Stellung der anscheinend umbilical stehenden Knoten, so sicht man, dass sie bei weiterem Wachsthum des Stückes immer weiter auf der Flanke vorrücken und auf der Wohnkammer in fast zwei Drittel der Seitenhöhe stehen. Nach dem ersten Viertel des letzten Umganges treten sic nicht mehr regelmässig, sondern nur mehr in weiten Abständen auf. Auf dem ersten Viertel zählt man vier solcher Knoten und auf dem ganzen übrigen Theil nur mehr drei. Der anfänglich am Umbilicalrand 
verdichte Rippentheil nimmt immer mehr an Stärke ab und auf dem letzten Theil der WVohnkammer ist keine Spur einer Berippung mehr zu sehen. Die Marginalknoten werden auf der Wohnkammer, soweit es sich hier constatiren lässt, nicht schwächer. Auf dem Externtheil tritt eine feine, kielartige Linie auf lem Steinkern hervor.

Die Suturlinie zeigt einen kleinen und schmalen Externlobus, breiten und tiefen ersten, sowic breiten und in gleicher Linie mit dem Externen stehenden zweiten Laterallobus, welche Loben sämmt. lich am Grunde gezähnt sind. Es folgt sodann noch auf der Flanke, aber schon am Umbilicalrande anstehend, ein breiter crster Auxiliar, dessen Lobengrund ebenfalls gezähnt ist, und auf der Nabelwand ein ganz kleiner, einspitziger Zweiter. Sämmtliche Sättel sind schr gross, breit und ganzrandig.

Ceratites Waageni erinnert in gewissen Beziehungen der äusseren I'orm im Anfang der letzten Windung an Ceratites binodosus Hauer') (pag. I9, Taf. XII, lFig. I-5), von dem er sich jedoch später beim Einfacherwerden der Rippen wieder ganz entfernt. Die Suturlinie hingegen ist ähnlich entwickelt wie bei Ceratites lennanus Mojs. (ibid., pag. 22, 'laf. XL, Fig. 15), von dem wieder die äussere Form vollständig abweicht.

\section{Formengruppe des Ceratites cimeganus Mojs.}

ISS2. Mojsisovics $E_{0} v$. Cephalop. Medit. Triaspr., pag. $2 S$

\section{Ceratites Mlojsvari Art. \\ Taf. IV, Fig. $6 a, b, c, d$.}

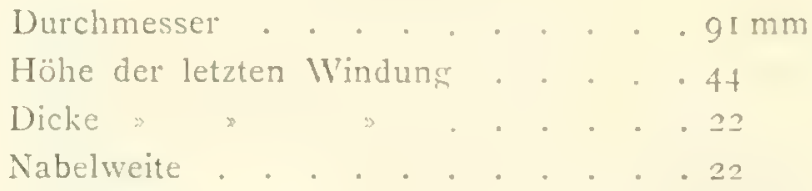

Der Externtheil ist anfänglich höher gewölbt, flacht sich aber auf der Wohnkammer selbst stärker ab. Die Flanke ist flach gekrümmt und zeigt die grösste Anschwellung um die Flankenmitte, knapp oberhalb der Lateralknoten. Marginal- und Umbilicalrand sind deutlich entwickelt; der Nabel ist gross; die Nabelwand sehr steil gestellt, auf der Wohnkammer selbst jedoch weniger, mit der das abgebildete Exemplar sich auszuschnüren beginnt. Die Involution reicht bis zu den Lateralknoten.

Die Sculptur wird aus drei Knotenspiralen von verschiedener Stärke und kräftigen, engstehenden, theils einfachen und theils inserirten Rippen gebildet. Diese beginnen am Umbilicalrand mit einem radial etwas in die Länge gezogenen stumpfen Knoten, die sich sodann stark bis zum lateralen Knoten erniedrigen, welcher in etwas mehr als dem Drittel der Flankenhöhe steht. Er ist klein, knopfförmig und stellenweise etwas longitudinal verlängert. Von hier setzen sich die Rippen leicht anschwellend, dann wieder sich verringernd ïber den Externrand bis auf den Marginaltheil fort, woselbst sie eine Sculpturirung desselben bedingen. Auf dem Externrand sitzt ein grösserer stumpfer Knoten auf, der nach aussen mit der Rundung des Marginaltheiles im Profil abschliesst. Diese Schilderung betrifft die Hauptrippen allein. Ausserdem schieben sich als Insertionsrippen noch, meist hinter der Hauptrippe, je eine Nebenrippe ein, die sich gegen die Flankenmitte an den Lateralknoten mehr oder weniger deutlich angliedern, von derselben Dicke wie die Hauptrippen sind und in einem Marginalknoten von gleicher Stärke, wie ihn jene haben, enden. Es entspricht also einem Umbilicalknoten ein Lateral- und zwei Marginalknoten (eventuell auch nur ein Marginalknoten); auf der Windung des abgebildeten Stückes ist das Verhältniss 20:2I:36.

Die Suturlinie ist gebildet aus einem breiten niedern Externlobus mit schmalem Medianhöcker, grossen, breiten und tiefen ersten Laterallobus, relativ schmalen und kurzen, an Tiefe dem externen gleichen zweiten Laterallobus und ganz kurzem ersten Auxiliallobus auf der Flanke, an den sich auf

$$
\text { Mojsisorics I: í.. Cephalop. Medit. Triaspr. }
$$


der Nabelwand noch ein kleiner Zacken als zweiter Auxiliar anschliesst. Die Lobengründe sind reich gezackt; bei dem ersten Lateralen, der besonders grobe Zacken aufweist, reichen feine Zähnchen bis hoch hinauf. Die Sättel sind rundbogig und ganzrandig; der breiteste ist der Externsattel; der erste und zweite Lateralsattel sind nur wenig verschieden. Die Verbindungslinie der Sättel macht vom externen zum ersten Lateral einen grossen Sprung und verläuft dann geradlinig und radial zu dem ersten Auxiliar, der wieder in gleicher Höhe mit dem Externen steht.

Ceratites Mojsvari schliesst sich bezüglich der Sculptur gut an folgende Glieder der'Formenreihe der Cimeganus-Gruppe Mojs') an: Ceratites trinodosus Mojs. (pag. 29, Taf. VIII, Fig. 5-7; 9, und Taf. XXXVII, Fig. 6, 7), C. elegans Mojs (pag. 3 I, Taf. IX, Fig. 5, 6, und Taf. XXVIII, Fig.9) und C. superbus Mojs. (pag. 32, Taf. XXVIII, Fig. 1o, und Taf. XXXIII, Fig. 5, 6). Mit C: superbus hat die neue Art das Verschwinden des Verbindungsstiickes zwischen Umbilical- und Lateralknoten ganz oder theilweise gemeinsam, während die beiden anderen Formen besser bezüglich der übrigen Sculpturelemente stimmen. Die Lobenlinie von C. elegans ist sehr ähnlich entwickelt, während diejenige von Ceratites trinodosus gewisse kleine Verschiedenheiten bezüglich der Begrenzungslinie der Sättel zeigt.

Ein sehr naher Verwandter ist auch der jüngst ${ }^{2}$ ) aus dem bosnischen Muschelkalk beschriebene Ceratites multinodosus Hauer (pag. I2, Taf. III, Fig. I). Ich möchte aber nicht den C. Mojsvari mit dieser Form direct identificiren, wie Hautr, pag. I3, vermuthet, dem damals nur ein Gypsabguss zum Vergleiche vorlag.

C. multinodosus ist bei geringerer Grösse evoluter, hat stärker abgeflachten Externtheil, breitere Windungen, höhere und kräftigere Rippen, welche zwischen Lateral- und Marginalknoten fast zu einer vierten Knotenreihe anschwellen, und hat die Verbindung zwischen Umbilical- und Lateralknoten stets deutlich entwickelt. Die Lobenlinie zeigt eher eine spitzbogige Entwicklung der Sättel, die Berührungslinie derselben ist radial und geradlinig verlaufend und zeigt nicht die grosse Höhendifferenz zwischen Extern- und ersten Lateralsattel, wie bei C. Mojsvari. Abgesehen davon besitzt C. multinodosus auf der Flanke keinen Auxiliarlobus, den er erst auf der Nabelwand entwickelt.

\section{Ceratites nov. spec. ex aff. multinodosi Hauer.}

Taf. IV, Fig. $8 a, b, i$

1892. Ceratites multinodosus Hauer; Cephalop. a. d. Trias v. Bosnien, pag. I2, Taf. III, Fig. I.

Es liegt nur ein Bruchstück von $54 \mathrm{~mm}$ Länge vor, welches einem Exemplar mit der Höhe der letzten Windung von $24 \mathrm{~mm}$ entspricht; der Sculpturtypus entspricht vollständig dem C. multinodosus. Die Radialrippen sind geradlinig, kräftig und treten auf dem Steinkern scharf hervor; sie beginnen am Umbilicalrand, dessen Kante abgestumpft ist, mit einem kräftigen Umbilicalknoten, dem grössten Knotenindividuum der Flanke. Diesem, stärker genährt als es bei C. multinodosus der Fall ist, folgt der kleine Lateralknoten und diesem auf dem gerundeten Marginalrande der relativ kleine Marginale. Zwischen diesem und dem Lateralen schwillt die Rippe knotenähnlich an, so dass wir bei dieser Species, ähnlich der bosnischen Form, eigentlich fast vier Knotenspiralen unterscheiden können. Die Flanke hat flach gewölbte Form, deren grösste Dicke ungefähr in der halben Höhe liegt. Die Nabelwand der Hauser'schen Art scheint höher zu sein.

Achnlich wie beide Arten in ihrer äusseren Gestalt sind auch die beiden Lobenlinien. 'Taf. IV, Fig. 76, stellt die Lobenlinie des Ceratites multinodosus vor, welche hier vom Original selbst und direct durch Abpausen gewonnen wurde, weil die Abbildung in den Cephalopoden der Trias von Bosnien * nicht ganz gelungen ist. Wir sehen einen niederen, breiten Externlobus mit niederen Medianhöcker, tiefen und breiten ersten Lateral- und schr kurzen, breiten zweiten Laterallobus, der an 'liefe

1) Mojsisorics E. $z$, Cephalop. Medit. Triaspr.

3) Haucy Fr. v., Cephalop. a. d. Trias v. Bosnien, 1892. 
etwa nur bis zur Hälfte des Externen herabreicht; die Loben sind am Grunde mit wenigen Zacken besetzt. Die Sättel sind unverhältnissmässig breit und rundbogig; der Externsattel ist der breiteste, erreicht aber nicht die Höhe des ersten Lateralen; der zweite Lateralsattel ist nieder, breit und erreicht fast die Spannweite des Externen; er steigt über die Umbilicalkante herab und erst knapp an der Naht schliesst sich ein kleiner, an Tiefe dem zweiten Laterallobus gleichender Auxiliarlobus an. Die Sattel. stämme verbreiten sich gegen die Sattelköpfe zu sehr rasch, so dass die Loben etwas zugespitzt aussehen. Die Berührungslinie der Sättel bildet einen flachen Bogen, dessen Scheitel der erste Lateral. sattel bildet.

Man könnte wohl einigermassen mit Recht sagen, dass der Hinwcis auf die Beschreibung des Suturlinie bei Howor genügend gewesen und die wiederholte Schilderung überflüssig sei; allein sie erfolgte hier nur aus dem Grunde, um die Unterschiede der Suturlinien beider in Rede stehenden Formen besser hervorheben zu können.

Taf. IV, Fig. 8c, stellt sodann die Lobenlinie der neuen Species dar. Wir sehen auf ihr sofort die viel grössere Tiefe und Breite des Externlobus, der einen ähnlichen breiten und niederen Medianhöcker besitzt wie die bosnische Species; sodann den viel breiteren, aber nur wenig unter den Externen herabreichenden ersten Laterallobus und einen nur halb so tiefen zweiten, dem auf der Nabelwand ein niederer, aber breiter Auxiliarlobus folgt.

Die Loben sind am Grunde mit feineren Zacken besetzt als bei C. multinodosus; während aber dort die Sattelstämme ganzrandig sind, ziehen sich hier feine Zähnchen etwa bis zu halber Höhe der beiden Lateralen hinauf; der Auxiliarlobus ferner ist hier nieder und breit und liegt knapp unterhalb des Nabelrandes, während er dort an Tiefe dem zweiten Lateralen gleicht und knapp an der Naht steht. Die Sättel sind ganzrandig, ebenfalls rundbogig, aber kleiner als bei der Houcr'schcn Form. Der Externe, zugleich der breiteste Sattel, ist bedeutend niedriger als der erste Laterale, der auch hier im Scheitel des flachen Bogens steht, welcher die Sattelköpfe verbindet. Die Sattelstämme sind breit und zeigen nicht jene Verengung gegen den Lobengrund.

Fassen wir die Merkmale beider Suturlinien zusammen, so haben wir whl wieder denselben Typus, der aber doch deutlich durch verschiedene Loben- und Sattelgrösse, verschiedene Form der Zähnelung und andere Vertheilung der Suturelemente bei beiden Arten variirt ist.

Ich kann nicht unterlassen, im Anhang an die eben beschriebene Art auch einer Form Erwähnung zu thun, welche vor nicht langer Zeit beschrieben wurde und die unser Interesse in regster. Weise wachruft durch die grossen Analogien, welche sie mit den eben behandelten Formen aufweist, denn sie stammt nicht aus der alpinen Trias, sondern aus der Schaumkalkschicht, der oberen Abtheilung des unteren Muschelkalkes der Hahnleite bei Sondershausen. Es ist dies

\section{Ceratites sondershusanus Picard sp.}

Taf. V, Fig. I $a, b, c, d$.

1892. Balatonites sondershusanus Picard, Zeitschrift d. deutsch. geol. Ges., Bd. 44, pag. 483, Taf. XXIV, Fig. I-4, 8.

Es ist vorauszuschicken, dass ausser einer kleinen Partie des Steinkernes nur der beiderseitige Abdruck erhalten ist, und dass Herr Picard durch Ausguss des Hohlraumes das Stück selbst erst auf diese Art reconstruirte. Die Lobenlinie ist nur stellenweise auf dem einen Theile des Abdruckes, d. h. der Innenseite der Schale, zu sehen und habe ich versucht, nach der Abbildung Fig. 8 und nach Analogien auch diese zu reconstruiren (Fig. I $d$ ). Herr Picard hatte die Gefälligkeit, meiner Bitte um Einsendung eines solchen Abgusses in der freundlichsten Weise zu willfahren und setzte mich hiedurch in den Stand, obige Bestimmung auszuführen. Ich spreche ihm daher meinen besten Dank dafuir aus,

Die Bestimmung dieser Art als Balatonites ist wohl zweifelsohne eine irrthümliche. Eines der Hauptunterscheidungsmerkmale zwischen Balatonites und Ceratites ist die bei jenem auf dem 
Externtheil auftretende mediane Dornenreihe, manchmal auch nur ein Kiel allein; da aber dieses Merkmal entschieden fehlt, wir nur einen glatten Externtheil haben, so geht schon daraus hervor, dass diese Species kein Balatonit sei.

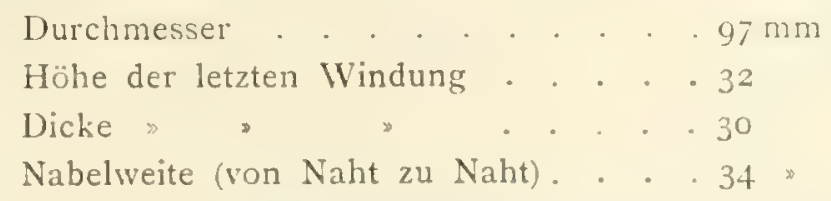

Der Externtheil ist sehr flach gewölbt; die Flanken erlangen unterhalb der halben Höhe ihre grösste Breite; der Marginalrand ist nur wenig abgestumpft und mit plumpen Dornen besetzt, ebenso der Umbilicale, der die viel kleineren Umbilicalknoten trägt. Die Nabelwand ist nieder und steil gestellt; der Nabel sehr gross; die Involution reicht kaum bis zur Hälfte der vorhergehenden Windung.

Die Sculptur wird aus sehr groben, gerundeten, geradlinig über die Flanke ziehenden Rippen gebildet, welche im ersten Viertel der letzten Windung radial verlaufen, später von der Radiale nach vorne abweichen.

Sie beginnen am Nabelrand und haben einen stumpfen, relativ kleinen Umbilicalknoten aufgesetzt, tragen in ungefähr ein Viertel der Flankenhöhe einen sehr grossen, plumpen, im Anfange der letzten Windung zugespitzten, später abgestumpften Lateralknoten, dem auf dem Marginalrande ein grosser, plumper, ebenfalls anfangs spitzer, später mehr abgestumpfter Marginaldorn folgt. Ausser diesen so beschaffenen primären Rippen treten secundäre auf, von denen je eine im Intercostalfeld entwickelt ist. Sie sind als inserirt $z u$ betrachten, sind im oberen Flankentheil, vom Marginalrand abwärts, nur selten unter den Lateralknoten der Hauptrippe herabreichend eingeschoben und gliedern, sich nur im ersten Theile der letzten Windung deutlicher an die Primärrippe an. Sie erlangen schnell nach ihrem Auftauchen aus der Lateralwand dieselbe Stärke wie die Hauptrippen, schwellen dann ebenfalls zu einer knotenförmigen Verdickung unterhalb des Marginaldornes so wie jene an und enden ebenfalls in einem gleichstarken Marginaldorn, der sich bei weiterem Wachsthum immer stärker abstumpft. Auf dem Esterntheil kann man noch ein kleines Stück weit eine Fortsetzung der Flankenberippung verfolgen, wodurch dieser eine Art von Sculptur, ähnlich wie Ceratites multinodosus und Mojsvari, erhält.

Die Suturlinie (Fig. I $d$ ), welche ich aus den erhaltenen Resten derselben (vide Picard, Fig 8 ), die aber nicht ganz richtig gezeichnet sein können, zu reconstruiren versucht habe, würde, falls diese Reconstruction richtig ist, einen breiten, niederen Externlobus mit breitem, niederem Medianhöcker zeigen und schon theilweise auf de $1^{\circ}$ Flanke liegen. Der erste Laterallobus ist sehr breit und reicht nur um wenig unter den Externen herab, der Zweite ist an Breite dem Externen gleichend und halb so tief wie der Erste, dann schliesst sich auf der Flanke noch ein breiter, sehr niederer Auxiliarlobus an. Die Art der Zähnelung ist nicht bekannt, jedoch muss sie sich auf den Lobengrund beschränkt haben, denn auf den Sattelstämmen ist keine Spur mehr zu sehen. Die Sattelköpfe sind breit, rundbogig, der Externe viel niederer und breiter als der erste Laterale, der am höchsten hinaufreicht; der zweite ist sehr klein und der Auxiliarsattel wird vom Umbilicalrand getheilt. Die Begrenzungslinie der Sättel zeigt einen vom Marginalrand zum ersten Lateralsattel rasch aufsteigenden Bogen, der sich dann langsam, fast geradlinig, zur Naht hinabsenkt. Wie wir sehen, würde diese Lobenlinie gut den. selben Typus repräsentiren, wie jene von C. multinodosus Hauer, C. nov. spec. ex aff. multinodosi Hauer und C. Mojsvari Art., und besonders mit dieser harmoniren, von der sie sich nur durch die 'Tiefe des Externlobus, sowie Höhe und Breite des Externsattels unterscheiden würde. Andererseits stimmen die Sculptur der Flanken und die Anwachsverhältnisse besser mit C. multinodosus Hauer überein.

Betrachten wir im Zusammenhang die Ceratiten des ausseralpinen Muschelkalkes, so finden wir, dass in der ganzen lormenmenge sich drei Sculpturstadien ausscheiden lassen, welche vertreten sind durch: 
I. Den einfachsten Sculplurtypus finden wir merkwürdiger Weise erst im Hauptmuschelkalk, woselbst er durch Ceratites nodosus de Haan vertreten ist. Es sind einfache Rippen, dic einen stumpfen Externlinoten tragen und die beginnende Entwicklung eines Umbilicalen angedeutet haben. Entsprechend der hohen Lage dieser Species sind die Loben hoch entwickelt, zeigen cinen kleinen Externlobus, einen grossen ersten, kleineren zweiten Laterallobus und $2-3$ Auxiliare.

Nachdem wir in tieferen Niveaux schon höher sculpturirte Formen finden, bleiben uns als Ausweg die beiden Annahmen, entweder eine, vielleicht sehr selten auftretende Form, die wir eben noch nicht kennen, im unteren Wellenkalk anzunehmen, oder für die germanischen Ceratiten einen rücklaufenden Sculpturtypus bei fortschreitender Suturentwicklung zu acceptiren, was immerhin cine etwas kühne Annahme wäre.

\section{Ceratites antecedens Beyrich.}

I\$5 S. Zeitschrift d. deutsch. geol. Gesellschaft, pag. 2II, Taf. IV, Iig. 4.

Hier gabelt sich die Rippe, zeigt an der Gabelstelle einen Lateralknoten und zwei Externstehende.

Ein kleiner Externlobus, ein grosser erster, kleiner zweiter Laterallobus und I-3 Auxiliate.

\section{Ceratites sondershusanus Picard sp.}

Mit einfachen und inserirten Rippen, welche drei deutliche und eine nur angedeutete Knotenspirale zeigen.

Ein kleiner Externlobus, ein grosser erster, kleinerer zweiter Laterallobus und ein Auxiliar auf der Flanke.

Dieser Entwicklungsreihe der ausseralpinen Ceratitenformen entspricht eine ganz analoge in den alpinen Muschelkalkbildungen, welche hier vertreten ist durch:

\section{Ceratites Výása Dicner.}

IS95. Pal. Indica Ser. XV., Himal. Foss. Vol. II, Part 2, pag. 19, Taf. V'l, Fig. I, 2.

Wir finden hier wieder einfache Rippen mit hervorragender Beknotung am Marginalrand.

Ein kurzer Externlobus, ein grosser erster Lateral, kleinerer zweiter, ein Auxiliar auf der Flanke und ein zweiter, breiter auf der Nabelwand, der bei weiterer Entwicklung sich in zwei kleinere auflösen dürfte.

\section{Ceratites binodosus Haucr,}

vergl. I882. Mojsisozics, Cephalop. Medit. Triaspr., pag. I9, Taf. II, Fig. 2.

Zeigt wieder die spärlichen Gabelrippen, welche an der Gabelungsstelle den Lateralen und am Marginalrande die Marginalknoten tragen.

Ein kurzer Externlobus, grosser erster, kleiner zweiter, und bis zum Nabelrand zwei kleine Auxiliarloben auf der Flanke.

\section{Ceratites multinodosus Hauer.}

1892. Haue, Cephalop. a. d. Trias von Bosnien, pag. 12, Taf, III, Fig. I.

Auch hier finden wir wieder einfache und inserirte Kippen, welche drei ausgesprochene Knotenspiralen tragen.

Ein kurzer Externlobus, grosser erster und kleiner zweiter Laterallobus, dem erst auf dem Nabelrand ein Auxiliarlobus folgt.

Aus alledem geht hervor, dass wir eine ähnliche Art der Entwicklung der Schalenornamentirung sowohl bei den Formen des ausseralpinen wie alpinen Muschelkalkes wiederfinden, und dass man sich fast versucht fühlen könnte, die germanischen Formen in die Formengruppen der alpinen einzureihen, wenn nicht die Suturlinien sich ganz anders charakterisiren würden. Bei den germanischen sehen wir die bei alpinen Formen unbekannte Entwicklung zahlreicher Auxiliarloben und eine Zähnelung 
der Loben, welche nur auf den Lobengrund beschränlit bleibt, während bei den alpinen Formen sich in geringerer Zahl die Auxiliarelemente entwickeln und die Zerschlitzung der Loben oft bis hoch hinauf zu den Sattelknöpfen greift. Eine Ausnahme macht allerdings Ceratites sondershusanus, der sich diesbezüglich schon bedeutend dem alpinen Charakter nähert.

\section{Ceratites anceps Art.}

Taf, V, Fig. $2 a, b, a$

Durchmesser des grössten Stückes . . . circa $73 \mathrm{~mm}$
Hïhe der letzten Windung. . . . . . . . . . . . . . . . . . . . 35
Dicke " 30 "
Nabelweite (von Naht zu Naht) . . . . .

Der Externtheil ist flach gewölbt, ebenso die Flanken, welche die grösste Dicke nahe am Umbilicalrand erlangen; Nabel- und Marginalrand sind deutlich entwickelt, jedoch mit abgestumpfter Kante. Der Nabel ist sehr gross, die Nabelwand nieder und senkrecht gestellt; die Involution bedeckt kaum $1 / 3$ der vorhergehenden Windung.

Die Berippung besteht aus auf dem ersten Umgang enggestellten, später immer weiter auseinander tretenden Rippen; sie verlaufen fast geradlinig und sind nur sehr wenig nach rückwärts schwach convex gebogen, wobei der umbilicale und marginale Anfangs- und Endpunkt in der Radialrichtung stehen. Sie sind drahtförmig - auf dem Steinkern -, zeigen in ihrem Verlaufe nur im oberen Flankentheil eine schwache Anschwellung und haben auf dem Umbilicalrand, über den sie nicht hinabreichen, einen dicken und stumpfen Nabelknoten aufgesetzt, der meist noch etwas radial auf der Flanke verlängert ist, aber dann rasch seine Höhe reducirt; in weniger als $1 / 4$ der Seitenhöhe tritt ein kleiner Lateralknoten auf, der noch kräftiger auf der vorletzten Windung entwickelt ist, dann aber immer undeutlicher wird. Auf dem Marginalrand findet die Rippe ohne eigentliche Anschwellung mit einer Wendung nach vorn ihr Ende. Ausser diesen so beschaffenen Hauptrippen treten noch inserirte Nebenrippen auf, welche am Marginalrand von gleicher Stärke wie jene sind und bis hinab zum Umbilicalknoten, auf älteren Windungstheilen jedoch nur in die Höhe des Lateralen reichen. Sie gliedern sich theils mehr, theils weniger deutlich an die Hauptrippe an, stellenweise hat es auch den Anschein, als wenn ein verdicktes Rippenstück sich im Umbilicalknoten gabeln würde.

Die Suturlinie zeigt einen breiten, niederen Externlobus mit niederem und breitem Median. höcker; der erste Laterale ist der grösste, der zweite kürzer und viel kleiner; auf der Nabelwand folgt ein sehr flacher, an Breite dem zweiten Lateralen gleichender Auxiliarlobus. Die Loben sind am Grunde gezähnt, der erste Laterallobus hat aùsser seiner Zähnelung zwei grössere Zacken.

Von den Sätteln ist der Externsattel nieder, sehr breit und wird von de1 Marginalkante getheilt; der erste Laterale ist viel kleiner, der zweite flach und sehr kurz und findet sein Ende jenseits der Umbilicalkante. Sie sind alle ganzrandig; verbindet man die Scheitelpunkte der Sattelköpfe, so crhält man eine sehr flach gekrümmte Linie.

Ceratites anceps erinnert in seinem Sculpturtypus bezüglich der weitgestellten und relativ schwach entwickelten Rippen eher an die Formen der Cimeganus-Gruppe Alojsisovics, nimmt aber einen gesonderten Platz in Folge der Stellung des Lateralknotens und der Involutionsverhältnisse ein. Besonders letztere bringen diese Form wieder der Zoldianus-Gruppe näher, mit der sie auch fast die Form der Suturlinie gemeinsam hat. Nur die Suturlinie von C. multinodosus Hauer (pag. 5 I, Taf. IV, Fig. 7 b) zeigt gewisse Aehnlichkeiten, und zwar die 13reite des Externsattels im Verhältniss zum ersten Lateralen und das Auftreten eines Auxiliaren unterhalb der Nabelkantc. Gänzlich verschieden ist jedoch das Höhenverhältniss dieser Sättel bei beiden Formen. 
Aus der 'Zoldianus-Gruppe Mojsisovics' stehen bezüglich der Suturlinie und der Involutionsverhältnisse wohl Ceratites gosaviensis Mojs.") (pag. 30, Taf. X, Fig. 8) und Ceratites Reiflingensis Art. (pag. 56, Taf. V, Fig. 3) am nächsten.

\section{Formengruppe des Ceratites Zoldianus Mojs.}

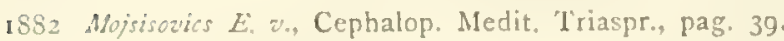

\section{Ceratites Reiflingensis Art.}

Taf. $\mathrm{V}, \mathrm{Iig} .3 \mathrm{k}, \mathrm{h}$

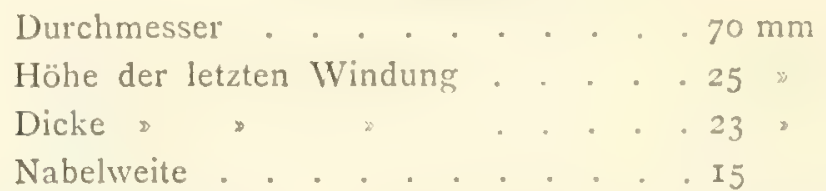

Der Externtheil ist flach gewölbt; die Flanken zeigen eine flache Wölbung, welche die grösste Breite unterhalb der Flankenmitte erlangt; Marginal- und Umbilicalrand ist kantig entwickelt und mit je einer Knotenspirale besetzt; die Nabelwand ist hoch, besonders im letzten Theile, und sehr steil gestellt. Diese Form ist wenig involut, indem weniger als die Hälfte der früheren Windung involvirt wird.

Die Sculptur wird aus dicken, knotentragenden, eng gestellten Rippen gebildet, die im Allgemeinen einen radialen Verlauf haben, jedoch ein flach convexes Mittelstück zeigen. Sie werden auf dem oberen Theil der Umbilicalwand erst sichtbar und tragen auf dem Nabelrand einen stumpfen Knoten, welcher gegen das Ende der Wohnkammer zu fast ganz verschwindet, so dass die Rippe ohne Anschwellung mit ihrer normalen Stärke plötzlich daselbst ihr Ende findet. Zwischen dem umbilicalen und lateralen Knoten, der ungefähr in ersten Viertel der Flankenhöhe liegt, verringert sicl die Rippe nicht und setzt sich in gleicher Stärke bis zum Marginalrand fort, wo sie, sich nach vorwärts wendend; noch ein klein wenig auf den Externtheil übertritt und auf der Flankenseite eine knotenförnige Anschwellung zeigt, welche auf dem Knie der Rippe, also direct auf der Kante aufsitzt.

Ausser den Primärrippen, deren Verlauf der eben geschilderte ist, treten noch secundäre auf, welche als inserirt $\mathrm{zu}$ betrachten sind, am Marginalrand dieselbe Beknotung wie jene haben, parallel denselben verlaufend sich auswärts des Lateralknotens mit einem schwachen, bogenförmigen Rippenstück an die Hauptrippe angliedern und eine schwache Anschwellung im oberen Drittel der Flankenhöhe haben, sonst aber an Stärke den primären gleichen.

Auf der Wohnkammer wird die Berippung viel plumper.

Die Suturlinie zeigt einen kurzen, relativ breiten Externlobus, etwas tieferen, breiten ersten Lateral- und kurzen, an Breite dem externen fast gleichenden zweiten, sowie einen die ganze Nabelwand einnehmenden Auxiliarlobus. Die Lobengründe sind fein gezähnt, nur der erste Laterale zeigt zwei grössere Zacken am Grunde. Der Externsattel ist sehr breit und liegt zum grösseren Theile schon auf der Flanke, der erste Laterale ist kleiner, jedoch etwas höher als der Externe, der zweite ist sehr nieder, breit und reicht bis zur Nabelkante. Die Sättel sind ganzrandig und bilden im Ganzen einen ausserordentlich flachen Bogen.

Ceratites Reiflingensis ist ein Vertreter der Formengruppe des C. Zoldianus Mojs. ${ }^{1}$ ) (pag. 39) und schliesst sich an den Ceratites gosaviensis Mojs. (ibid., pag. 39, Taf. X, Fig. 8) an. Ersterer hat, wie die meisten Formen dieser Gruppe, sehr enggestellte massive Rippen, welche etwas stärker gekrümmt sind als bei Ceratites gosaviensis und Ceratites zoldianus (ibid., Taf. X, Fig. 5, 6).

1) Mojsisovics $E_{0}$ v., Cephalop. Medit. Triaspr. 
Die Art der Involution nähert ihn dem Ceratites gosaviensis, der jedoch bei fortschreitendem Wachsthum die Beknotung der Flanke fast vollständig verliert, während hier wenigstens der Lateralknoten bestehen bleibt; auch besitzt Ceratites Reiflingensis keinen faden-oder drahtförmigen Kiel wie der Letztverglichene, der sich auch durch etwas geänderte Lobenform auszeichnet: die Loben sind nur wenig gezähnt, während die Reiflinger Species reichere Zähnelung aufweist.

Ein anderes vorhandenes Exemplar scheint eine etwas flachere Varietät vorzustellen.

\section{Ceratites Reiflingensis var. exiguus Art.}

Taf. V. Fis. 5 a, $i$.

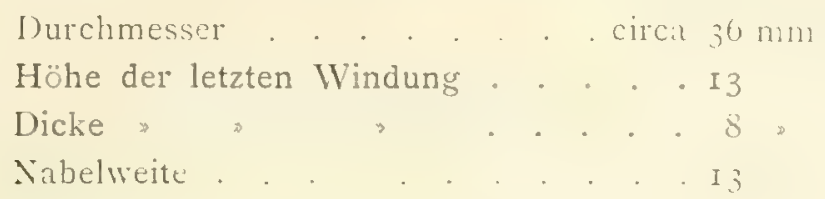

Diese Form wurde wegen den etwas weiter gestellten, auch massiveren Rippen, ferner wegen der etwas stärker entwickelten Umbilical- und Marginalknoten von der Species selbst abgetrennt.

Die Suturlinie zeigt kleine Verschiedenheiten, so ist z. B. der zweite Laterallobus kleiner, schmäler und auch weniger gezackt.

\section{Ceratites pseudovindelicus Art.}

Taf. V, Fig. $4 a, b, c$

Durchmesser . . . . . circa $43 \mathrm{~mm}$
Höhe der letzten Windung . . . . . 22
Dicke 2 . . . . . . . . . . . . . . . 9
Nabelweite

Die Externseite ist noch etwas flacher wie bei Ceratites Reiflingensis (ibid., pag. 56), die Flanken fast ebenflächig entwickelt; Marginal- und Umbilicalwand sind deutlich ausgebildet und tragen je eine Knotenspirale; die Umbilicalwand ist mässig hoch und fast senkrecht stehend; die Involution umfasst ungefähr zwei Drittel der Flankenhöhe, was einen relativ engen Nabel bedingt.

Die Sculptur besteht aus denselben Elementen wie bei Ceratites Reiflingensis; die Rippen sind stark und massiv, mit einer schwachen Anschwellung zwischen Lateral- und Marginalknoten versehen und daselbst schwach concav nach vorn gebogen; die Hauptrippen tragen auf dem Nabelrand sehr kräftige, runde Umbilicalknoten und kleine Laterale in kaum ein Drittel der Flankenhöhe und kräftige dornenähnliche Marginalknoten. Es besteht also der Unterschied zwischen Ceratites psendovindelicus und Ceratites Reiflingensis bezüglich der Knoten in den hier kräftig ausgebildeten Umbilical- und Marginalknoten, welche dort zurücktreten gegen den stärker ausgebildeten Lateralen.

Auch die Suturlinie ist ähnlich entwickelt; nur ist hier der Externlobus grösser und breiter, der zweite Laterale am Grunde zweispitzig und hat ausserdem jederseits noch zwei klcine Zähne; der Auxiliarlobus ist hier viel kleiner und liegt auf der Nabelkante. Der Externsattel liegt schon fast ganz auf der Flanke und der Grössenunterschied zwischen ihm und dem ersten Lateralsattel ist nicht so bedeutend wie bei Ceratites Reiflingensis.

Der Name wurde wegen der grossen Aehnlichkeit dieser Species mit Ceratites vindelicus Mojs. ${ }^{1}$ ) (pag. 40, Taf. X, Fig. 7) gewählt, ron dem er sich nur durch die etwas enger gestellten, kräftigeren Rippen und durch das Fehlen der Externfurche mit den sie begleitenden Kiellinien auszeichnet, und auch flachere Ilanken als jener hat. Die Suturlinie ist bei Ceratites vindelicus nicht bekannt.

1) Mojsisozics I: a's, Cephalop. Medit. 'Triaspr

Beiträge zur Palåontologie Uesterreich-Ungarns, Bd, $\mathrm{x}$. 


\section{Formengruppe der Circumplicati.}

1882. Mojsisorics L., z', Cephalop. Medit. 'Trjaspr., pag. 43.

\section{Ceratites tuberosus $\Lambda$ rt.}

Taf, V, lig. $6 a, b, c, d, c$.

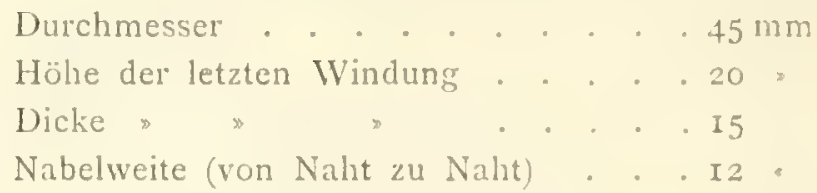

Der schmale Externtheil ist flach gewölbt; die Flanken schwellen gegen die Nabelregion zu an; Marginal- und Umbilicalrand sind gerundet, und zwar tritt jener in der Form einer abgestumpften Marginalkante auf, während dieser besonders auf der Wohnkammer mit breiter Rundung in die Nabelwand übergeht. Letztere ist anfangs senkrecht stehend, später nur mehr steil gestellt.

Die Sculptur ist aus einfachen, circumplicaten Rippen gebildet; sie beginnen auf der Flanke, nahe dem Umbilicalrand, mit einem stumpfen Knoten, sind nicht scharf individualisirt, sondern treten nur als radial verlaufende Anschwellung auf, welche sich gegen den Marginalrand immer mehr vermindert und noch vor Erreichen desselben verschwindet. Auf der letzten Windung zählt man sieben solcher Rippen, auf der vorhergehenden fast die doppelte Anzahl; gleichzeitig ist die umbilicale Anschwellung mehr an den Nabelrand vorgerückt, der hier auch weniger gerundet erscheint.

Ausserdem treten feine Radiallinien auf der Schale auf.

Die Involution ist sehr gross, indem die Flanke der vorhergehenden Windung bis zu den Umbilicalknoten umhüllt wird.

Die Suturlinie hat flach-bogenförmigen Verlauf; der Scheitel des Bogens wird vom ersten Lateralsattel gebildet, der oberhalb der Flankenmitte liegt; der Externlobus ist breit, kurz; der erste Laterale ist fast doppelt so tief wie der Externe, viel kleiner ist der zweite; sie sind alle sehr reich gezackt, so zwar, dass die Zacken bis hoch zu den Sattelbögen hinaufreichen; an den zweiten Lateralen schliesst sich noch auf der Flanke ein kleiner Auxiliarlobus an. Der Auxiliarsattel liegt anfangs der letzten Windung auf dem Umbilicalrand und zeigt eine spitzzackige Einkerbung; dann schliesst sich auf der Nabelwand ein breiter, niederer zweiter Auxiliarlobus an. In etwas mehr als der Hälfte der Windung hat sich die Einkerbung im ersten Auxiliarsattel schon zu einem kleinen secundären, deutlich abgetrennten Auxiliarlobus entwickelt, der auch gleichzeitig auf die Flanke selbst vorgerückt ist. Wir haben also drei Auxiliarloben bei einem ausgewachsenen Individuum. Der Extern-, sowie der erste und zweite Lateralsattel haben rundbogenförmigen Verlauf; die Sattelstämme sind durch die reiche Zackung ziemlich stark verengt. Der höchste und grösste Sattel ist der erste Laterale, der niederste der Externe.

Ceratites tuberosus schliesst sich enge an Ceratites aster Hauer ${ }^{1}$ ) (pag. I4, Taf. III, Fig. 3) und Ceratites Erasmi Mojs. ${ }^{2}$ ) (pag. 43, Taf. XL, Fig. 13) an. Alle drei Formen haben die circumplicate, an Dinarites dalmatinus Hauer (pag. 8, Taf. I, Fig. 7, 8) erinnernde äussere Form, unterscheiden sich aber von einander durch die Anzahl der Knoten, respective Rippen. Ceratites tuberosus hat nur sieben, während Ceratites Erasmi und Ceratites aster deren je neun aufweisen; auch hat ersterer die Knoten mehr lateral stehend, was mit der weiter abgeflachten Nabelwand zusammenhängt, während letzterer sich wieder von Ceratites tuberosus durch den etwas engeren Nabel unterscheidet.

Auch die Lobenlinie zeigt bei diesen drei Formen einen gewissen Grad ron Verschiedenheit; z. B. bezüglich des Externlobus, der wieder in Zusammenhang mit der verschiedenen Breite des

1) Hazer, Cephalop. Trias v. Bosnien. 1892.

2) Mojsisovics E. $\%$, Cephalop. Medit. Triaspr. 
Externtheiles steht. Bei Ceratites tuberosus, der den schmalsten Externtheil hat, liegt jener, ähnlich wie bei Ceratites Erasmi, fast ganz auf der Flanke, während er bei Ceratites aster noch vollständig auf dem Marginaltheil liegt. Der bogenförmige Verlauf der Sättel ist wieder bei Ceratites aster und tuberosus derselbe, während bei Ceratites Erasmi der Externsattel dieselbe Höhe wie der erste Laterale hat. Bezüglich der Auxiliare haben wir wieder eine Aehnlichkeit mit Ceratites Erasmi, der zwei, fast gleich grosse, ausserhalb des Nabelrandes und einen kleinen auf der Nabelwand hat, während Ceratites tuberosus bei viel kleinerer Gestalt erst einen grossen, dann kleineren Auxiliar auf der Flanke und einen wieder etwas grösseren auf der Nabelwand hat. Ceratites aster hingegen hat bei kleinerer Gestalt als das Reiflinger Exemplar nur zwei Auxiliare, von denen der erste schon zur Hälfte auf der Nabelwand liegt.

\section{Ceratites (Danubites?) spec. indet.}

Es liegt ein Bruchstück von allerdings sehr grossen Dimensionen vor und diese sind auch die einzige Ursache der Erwähnung, da sonst mit dem Stück nichts anzufangen ist.

Der Durchmesser beträgt . . circa $350 \mathrm{~mm}$
Höhe der letzten Windung. . . . . 92,
Nabelweite. . . . . . circa 7.8

Man erkennt eine im Marginaltheile am meisten aufgetriebene Flanke, die sich đann flacher gegen den Nabelrand zu senkt. Die Umbilicalwand ist anfangs hoch, erniedrigt sich aber gegen Ende der letzten Windung. Die Nabelweite ist relativ gering für den grossen Durchmesser. Die Rippen haben einen den Danubiten ähnlichen circumplicaten Charakter; an einer Stelle jedoch schiebt sich am Marginaltheile eine Zwischenrippe ein; auch lassen sich gegen Ende des Vindungstheiles zwei längliche Anschwellungen beobachten: eine in der Umbilical-, und eine in der Marginalregion.

Ceratites (Danubites引) spec. indet.

Taf. VI, Fig. I $a, b$.

Ein vorliegendes Bruchstück hat annähernd folgende Maasse:

Durchmesser. . . circa I I $\mathrm{mm}$
Höhe der letzten Windung. . . . 43 "
Nabelweite . . . . . circa I6

Die Form ist schlank und hochmündig, mit hochgewölbtem Externtheil, fast flachen Flanken, mit niederer schräggestellter Nabelwand und abgerundetem Umbilicalrand. Sie ist weitnabelig und die Umgänge sind sehr schwach umhüllend. Die Berippung ist eine den Danubiten ähnliche und besteht aus einfachen dicken, auf dem vorletzten Umgang engstehenden, später weiter auseinander tretenden Rippen.

\section{Isolirter Typus.}

\section{Ceratites altecostatus Art.}

Taf. V., Fig. $7 a, b, c$,

Durchmesser . . . . . circa 3 I mm
Höhe der letzten Windung . . . . . II
Dicke
Nibelwcite. . . . . . . . . . . . Io

Der Externtheil ist flach; die llanken sind flach gewölbt und erreichen die grösste Dicke unterhalb der halben Flankenhöhe; die Marginalkante ist deutlich entwickelt und gibt besonders dem letzten Windungstheile ein eckiges Aussehen; der Umbilicalrand ist weniger deutlich markirt und die Kante 
abgestumpft; die Nabelwand ist relativ nieder und schief stehend; die Involution ist gering und wird etwa ein Drittel der vorhergehenden Windung umhüllt.

Das zur Abbildung gelangte Stück ist bis zum Ende gekammert, jedoch drängen sich dic Kammern aúch dort noch nicht so, dass man annehmen könnte, dass hier der Beginn der Wohnkammer sei, weshalb man für ein ausgewachsenes, vollständig erhaltenes Stück dieser Species wohl einen Durchmesser von circa $55 \mathrm{~mm}$ annehmen kann. Wir haben also bei dem abgebildeten Stück grösstentheils noch Jugendwindungen, bei welchen sich die Sculptur ziemlich bedeutend ändert. Bis zur letzten Hälfte des letzten Umganges ist der Externtheil noch flach gerundet und bekommt erst dann sein flaches, eckiges Aussehen. Auch die Flanken sind stärker gekrümmt und werden erst späterhin flacher, behalten aber doch eine gewisse IVölbung bei.

In derselben Art ändert sich auch die Berippung. Sie besteht wohl durchgehends aus sehr hohen, schlanken Rippen, welche bei zunehmendem Alter ihr Aussehen derart veründern, dass sie anfangs theils als einfache Rippen, theils als einfache mit inserirten Zwischenrippen, theils als deutliche Spaltrippen entwickelt sind, während später nur mehr Haupt- und inserinte Zwischenrippen auftraten. Erstere beginnen dann hart am Nabelrand mit einer kleinen, länglichen Verdickung, tragen in circa ein Drittel der Flankenhöhe einen kleinen knopfförmigen Knoten und enden am Marginalrand mit einer stumpfen, knotenförmigen Verdickung. Zwischen dem Lateral- und Marginalknoten schwillt die Rippe wieder ein wenig an. Die inserirte Rippe reicht nicht bis zum Lateralknoten und erlangt am Marginalrand dieselbe Stärke wie die Primäre. Beide halten die Radialrichtung ziemlich genau ein. Stellenweise folgen zwei Hauptrippen auf einander, wodurch eine Art von Einschnürung sich entwickelt, welche undeutlich auch auf dem Externtheil zu sehen ist.

Hier setzen die beiderseitigen Rippen über denselben hinüber, fallen aber in der Mitte mit dem Scheitel des flachen Externtheiles fast zusammen, so dass gegen Ende der Windung in radialer Richtung deutlich die Kerbung hervortritt, während am Anfange derselben noch ein schmaler, glatter Mediantheil sichtbar ist. Nur an einer Stelle, hinter der eben erwähnten Einschnürung, setzt die Rippe massiv und erhaben über den Externtheil hinüber.

Die Suturlinie zeigt einen niederen, breiten Externlobus mit schmalem und niederem Medianhöcker: ein relativ schmaler sehr tiefer erster Lateral, schmaler, an Tiefe dem Externen gleichender zweiter und auf dem Nabelrande ein kurzer Auxiliarlobus. Die Loben sind nur am Grunde gezähnt. Die Sättel sind flach gerundet, der Extern- und erste Lateralsattel fast von gleicher Breite, der zweite sehr klein, und gegen die Naht zu ist auch noch der Auxiliarsattel sichtbar. Die Sattelköpfe stehen an einer geraden Linie.

Ceratites altecostatus stellt einen isolirten Typus unter den bis jetzt bekannten Ceratiten vor, auf welchen das Charakteristicum: "Radialsculptur auf dem Externtheil stets unterbrochen , keine rechte Anwendung mehr findet. Es ähnelt diese Form schon in gewisser Beziehung den, in der Folge beschriebenen Reiflingiten, und hat auch, so wie diese, weit abstehende Kammerscheidewände.

\section{Unterfamilie: Tirolitinae Mojs.}

\section{Gattung: Balatonites Mojs.}

\section{Gruppe der Balatonites gemmati Mojs.}

1882. Mojsisovics E. v., Cephalop. Medit. Triaspr., pag. 78

Balatonites balatonicus Mojs.

Taf. VI, Fig. $2 a, b, c, d$, Fig. $3 a, b, c, d$.

1872. Ammonites balatonicus Mojsisovics, Ueber ein erst kürzlich aufgefundenes unteres Cephalopoden-Niveau im Muschelkalk der Alpen. Verhandlg. k. k. geol. K.-A., pag. igo.

1873. Ammonites balatonicus Boeckh, Die geologischen Verhältnisse des südlichen Theiles des Bakony. Mittheilungen aus dem Jahrbuche der kgl. ungar. geol. Anstalt, Bd. II, pag. 6I. 
1873. Trachyceras balatonicum Mojsisovics, Ueber einige Triasversteinerungen aus den Südalpen. Jahrbuch der $k$. $k$. geol. R. A., pag. 426, Taf. XIII, Fig. 3, 4 .

1882. Balatonites balatonicus Mojsisovics, Cephalop. Medit. Triaspr., pag. 78, Taf. IV, Fig. 2-6.

Diese von Mojsisorics aufgestellte Gattung und Art wird auf Taf. IV seines eben citirten Cephalopodenwerkes in fünf verschiedenen Exemplaren abgebildet und im Texte die grosse Variationsfähigkeit der Species betont. Die angegebenen Dimensionen passen auf das loc. cit. Fig. 2 abgebildete Stück, folglich ist wohl dieses als Typus aufzufassen. Das in der vorliegenden Arbeit auf Taf. VI, Fig. $3 a, b, c$ abgebildete Bruchstück schliesst sich gut an das oben citirte MIojsisovics' an, zeigt aber ebenfalls wieder gewisse geringere Unterschiede.

Der Externtheil ist, abgesehen von den Mediandornen, ziemlich hoch, die Flanken ausserordentlich flach gewölbt; der Marginalrand ist scharf hervortretend, der Umbilicale stark abgerundet und lässt nur eine niedere, senkrecht gestellte Nabelwand offen; die Involution ist gering, ungefähr ein Drittel der früheren Windung bedeckend, der Nabel sehr weit.

Sculpturirt ist diese Variation mit dornen- und knotentragenden Rippen. Wir bemerken auf dem Umbilicaltheil, jedoch schon auf der Flanke selbst, enggestellte, grosse, spitz-gerundete Umbilicalknoten, zugleich die grössten Knotenindividuen der Windung. Hier strahlen zwei Primärrippen aus, welche aber nur als flache Anschwellung bis zur halben Flankenhöhe entwickelt sind, und je einen kleineren, spitzgerundeten Lateralknoten tragen, sich dann etwas verstärlit bis zum Marginalrand fortsetzen und daselbst randlich längsgestellte scharfe Marginaldornen ansetzen. Auf dem Externtheil selbst ist die Rippe nur mehr undeutlich entwickelt; sie erscheint vom Narginaldorn aus knieförmig nach vorn gebogen und trägt dort, wo sie mit dem Rippenfortsatz der anderen Seite zusammentrifft, einen hohen, scharfen, längsgestellten Externdorn, der die Mitte des.Externtheiles einnimmt. Die Schale erscheint hier wie von unten durch den scharfen Dorn emporgehoben, was dem Externtheil ein scharfes, schneidendes Aussehen im Profile verleiht.

Die Rippen selbst verlaufen auf der Flanke geradlinig und radial, sind sehr eng gestellt und tragen zwischen Lateral- und Marginaldorn noch einen kleinen accessorischen Knoten, stellenweise nur eine kleine Anschwellung der Rippe.

Wie man sieht, zeigt sich die Variationsfähigkeit dieser Species hier wieder. Das bei Mlojsisovics abgebildete Stück (Fig. 2) ist involuter. Ferner sieht man wohl auch das Ausstrahlen zweier Rippen vom Umbilicalknoten, jedoch meist in der Art, dass eine stärkere und eine sehr viel zartere von hier aus sich entwickeln; ausserdem treten aber auch einfache Rippen auf, die vorne etwas stärker sind und weiter von einander abstehen als bei dem Reillinger Exemplar, bei dem auch die Externdornen viel schärfer entwiclielt sind, was übrigens mit dem verschiedenen Alter der Individuen zusammenhängen mag. Die Dimensionen des Fig. $3 a, b, c$ abgebildeten Stückes sind:

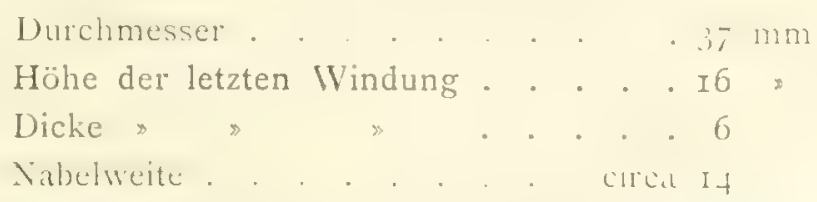

Die Suturlinie von Balatonites balatonicus war bis jetzt noch nicht belannt. Fig. 3 c zeigt die. jenige des oben besprochenen Stückes. Wir sehen eine flach gespannte Suturlinie, bei welcher der erste Lateralsattel die grösste Höhe erreicht und, analog der geringen Involution, erst am Unbilicalrande den Auxiliarlobus.

Der Lxternlobus ist tief, mit zwei schmalen Flügeln, welche von einem schmalen, hohen Medianhöeker getheilt sind, der fast die Höhe des Externsattels erreicht; der erste Laterallobus ist nur um wenig tiefer als der Externe, und breit; der Zweite hat dieselbe form wie der Erste, dic 'liefe des Externen und, der geringeren Tiefe entsprechend, auch etwas geringere Breite wie der Erste: cin breiter Auxiliantobus folgt auf der Nabelwand. Die Loben-liefon sind rejeh gezälnt. Die Sättel 
sind rundbogig; der Externe, etwas abgeflacht auf der äusseren Seite, ist der Grösste, liegt fast gan\% auf der Flanke und hat etwas geringere Höhe wie der erste Laterale, welcher kleiner und höher ist; sein Sattelstamm ist etwas verjüngt; der zweite Laterale ist viel kleiner und niederer und reicht bis zum Umbilicalrand. Die Sättel sind ganzrandig.

Eine andere Variationsrichtung repräsentirt das in Fig. $2 a, b, c, d$ abgebildete Fragment. Wir haben ungefähr die Hälfte des letzten und die Hälfte des vorletzten Umganges noch gut erhalten und sehen, dass auch diese, ähnlich dem oben besprochenen Stücke, zu der weiter genabelten Varietät gehören. Ich möchte dieses Stück noch am ehesten dem Balatoniten von Köveskálla aus dem BakonyVValde gleichstellen, welches MIojsisovics loc. cit. Taf. IV, Fig. 5, abbildet. Es ist jenes Stück zwar sehr schlecht erhalten, jedoch sieht man immerhin genügend viel, um die grobrippige Varietät zu erkennen, gegenüber der feinrippigen auf Fig. 2, und sieht die groben, einfachen, bedornten Rippen, zwischen denen eingeschaltete Zwischenrippen auf der oberen Flankenhälfte auftreten. Der Externtheil trägt scharfe, im Alter abgestumpfte Kieldornen.

Ganz dasselbe finden wir bei dem Reiflinger Exemplar wieder. Der Externtheil ist schmal, relativ schmäler als bei dem Stück von Köveskálla, die Flanken sind flach gewölbt und erreichen die

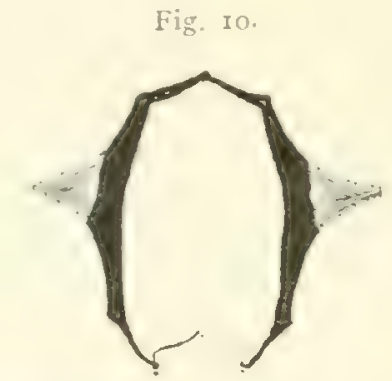

Balatonites efr. Ottonis Buch. sp.

Reconstruction nach E. v. Mojsisozics: Cephalopod. Medit. Triaspr. Taf. VI, Fig. I $\dot{o}$.

grösste Breite im oberen Theil; der Marginalrand ist schärfer als der Umbilicale entwickelt, der abgestumpft ist und in eine schräg gestellte Nabelwand übergeht.

Die Berippung besteht aus groben primären Rippen, welche nach rückwärts flach convex gekrümmt sind und mit knieförmiger Knickung vom Marginalrand aus auf den Convextheil übertreten; sie beginnen am Nabelrand mit einem spitzen, dornartigen Knoten, verschwinden fast vollständig und treten erst im Lateraldorn wieder auf, der etwas unterhalb der Flankenmitte liegt. Derselbe erscheint an allen Stellen gebrochen und ist es wohl schon bei Lebzeiten des Thieres grösstentheils gewesen, ode1 er war mindestens stark abgestumpft. An einer Stelle ist er jedoch noch in der Gesteinsdecke erhalten gewesen und hier sehen wir einen circa $5 \mathrm{~mm}$ langen dornigen Stachel, der auf der Flanke aufsitzt. Es ist selbstverständlich, dass sie nur in den allerseltensten Fällen erhalten bleiben können. Stellen wir uns einen solchen Balatoniten mit seinen Stacheln vor, so müsste er ein ähnliches Aussehen gehabt haben, wie etwa Margarites circumspinatus Mojs') (pag. 299, Taf. CXVII, Fig. 6). Am Marginalrand sitzt sodann ein grösserer abgestumpfter Marginalknoten, über den hinaus sich die Rippe mit gleicher Breite und Höhe stumpfwinklig gegen rückwärts gewendet bis zur Medianlinie fortsetzt, daselbst mit der Rippe der anderen Flanke zusammenstösst und einen dicken, meist abgestumpften längsgestellten Externknoten bildet. Zwischen Marginal- und Lateraldorn tritt ein accessorischer kleiner Dorn oder Knoten auf. Die eingeschobene Zwischenrippe ist auf dem Extern- und Marginaltheil gleich stark wie die Primäre entwickelt, reicht nicht bis zum Lateraldorn hinab und verjüngt sich sehr schnell.

$$
\text { i) Wojsisovics E. v, Cephalop. Hallst. Kalke, Bd. VI, 2. IS93. }
$$


Die Suturlinie dieser Varietät ist ganz ähnlich entwickelt wie bei der oben Beschriebenen (Taf. VI, Fig. 5 c). Hier sehen wir (Taf. VI, Fig. 5 c) ähnliche Verhältnisse, jedoch ist der Externlobus durch einen noch höheren und schmäleren Medianhöcker getheilt; das grösste Sattelelement ist der erste Lateralsattel und sämmtliche Sättel bilden nicht einen flach gespannten Bogen, sondern reichen an eine Radiallinie hinan.

So auffallend wohl bei dieser Varietät der lange Lateralstachel erscheinen mag, so ist er doch keineswegs als etwas ganz Neues aufzufassen; nur der zufällige Erhaltungszustand verhinderte die Kenntniss derselben bis jetzt. Betrachten wir z. B. den von Mojsisovics ${ }^{1}$ ) gegebenen Durchschnitt der letzten Windung von Balatonites cfr. Ottonis Buch. sp. (pag. 78) auf Taf. VI, Fig. I b, so sehen wir dort im Profil die Sockeln zu den mehr oder weniger langen Stacheln, welche, Fig. I $\alpha$, sämmtlich gebrochen sind. Reconstruirt man sich diese Dornen oder Stacheln, so erhält man ein Profil, das demjenigen der obigen Varietät entschieden ähnelt (Fig. Io).

\section{Balatonites hystrix Art.}

Taf. VI, Fig. $4 a, b$, Fig. 5 .

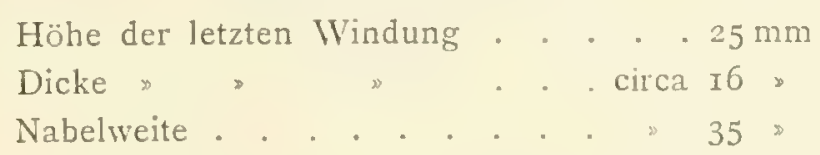

Der Convextheil ist, abgesehen vom Externdorn, abgeflacht; die Flanken sind flach, schwellen nur mässig gegen die Lateralknoten zu an und senken sich, wenigstens auf der letzten Windung, ohne ausgesprochene Umbilicalkante mit abgeschrägter Nabelwand zur Naht hinab; die Marginalkante ist durch eine Dornenreihe markirt; die Mitte des Externtheiles trägt scharfe Kieldornen; die Involution ist gering, die Species weitgenabelt.

Die Radialsculptur besteht aus massiven, hohen Hauptrippen, welche vom Nabelrand bis zum Externdorn reichen und kürzeren, parallel zu diesen verlaufenden Nebenrippen, welche, sowie die Hauptrippen, einen starken Externdorn tragen. Erstere steigen mehr oder weniger deutlich von der Naht aus über die Nabelwand hinauf, tragen auf dem Nabelrand einen hohen, spitzen Umbilicaldorn, etwas unter halb der Flankenmitte einen spitzen und grossen, radial etwas in die Länge gezogenen Lateraldorn und auf dem Marginalrand einen etwas kleineren Marginalen; zwischen Marginal- und Lateraldorn sitzt ausserdem noch ein wohl relativ grosser, aber im Verhältniss zu den beiden Dornen nur kleiner accessorischer Flankenknoten; vom Marginaldorn aus behält die Rippe fast genau die Richtung und Stärke desselben auf den Flanken bei und bildet dort, wo sie in der Mitte des Convextheiles mit der correspondirenden Rippe der anderen Flanke zusammentrifft, einen ungefähr $2 \frac{1}{2} \mathrm{~mm}$ hohen, längs gestellten und schneidenden Externknoten; zwischen den einzelnen Externknoten tritt auf dem Steinkern deutlich eine feine Mittellinie auf.

$\mathrm{Zu}$ jeder Hautrippe gehören, wenigstens in dem Altersstadium, dem die vorliegenden Stücka angehören, je zwei Nebenrippen. Dieselben haben parallelen Verlauf mit jenen, zeigen denselben hohen Externdorn, dieselbe Rippenstärke auf den oberen Flankenpartien, mit gleichstarkem Marginaldorn und accessorischen Flankenknoten; jedoch erlischt die Eine in der Höhe des Lateraldorns, die Andere schon etwas früher, zeigt aber auch dann noch analog diesem ein kleines Lateralknötchen. In der unteren Flankenhälfte haben wir sodann nur mehr die Hauptrippen allein und am Umbilicalrand einen kleinen, etwas mehr flankenwärts stehenden Umbilicalknoten, der, zu den Nebenrippen gehörend, meist in der Verlängerung der grösseren liegt.

Die Rippen haben im Ganzen einen leicht bogenförmigen Verlauf und sind gegen vorn Hach concav.

1) Mojsisozics E. z", Cephalop. Medit. Triaspr. 
Fig. 5 zeigt den Durchschnitt eines zweiten Bruchstückes, welches zweifelsohne einem jüngeren Exemplare angehört und flacher gewölbte Flanken hat. Es gelang die nicht abgewitterte, aber leider etwas verdrückte Schalenhälfte blosszulegen, welche einen kleineren Externdorn zeigte, wie $\mathrm{Fig} \cdot 4 b$, hingegen einen spitzen Marginaldorn, ausserordentlich grossen ovalen Lateraldorn, der in $2 \mathrm{~mm}$ Höle leider gebrochen ist, aber dann noch eine grosse ovale Bruchfläche zeigt, weshalb wohl der Schluss nicht zu gewagt erscheint, dass er bedeutend grösser gewesen ist, vielleicht ein langer Latcralstachel war. Auch der Umbilicaldorn zeigt noch eine grosse Bruchfläche und dürfte ebenfalls stachelähnlich gewesen sein. Ich habe daher in Fig. 5 ein reconstruirtes Bild dieser Stacheln gegeben, wobei dic schwarz gehaltenen 'Theile die erhaltenen Sockeln derselben darstellen.

Die Suturlinie ist nicht bekannt.

Balatonites hystrix ähnelt auf den ersten Blick vollständig dem Balatonites balatonicus Mojs. ') (pag. 78, Taf. IV, Fig. 2-6), von dem er sich nur durch das regelmässige Auftreten zweier statt einer Nebenrippe und durch die hiedurch bedingte weitere Entfernung der Hauptrippen von einander, sowie durch die in der Regel viel höheren Mediandornen auf dem Externtheil unterscheidet. Ist die Annahme des Auftretens von Stacheln richtig, so ist das Vorhandensein dieser ein weiterer Unterscheidungsgrund.

Bezüglich des Auftretens eines kleinen Umbilicalknotens im Zwischenfeld zwischen den Hauptrippen muss auf die Aehnlichkeit des Balatonites hystrix mit Balatonites cfr. Ottonis Buch sp. ${ }^{1}$ ) (pag. 78, Taf. V, Fig. I, Taf. VI, Fig. I) hingerviesen werden. Bei beiden Formen finden sich dic Nebenrippen hiedurch schon am Nabelrand angedeutet.

\section{Balatonites nov. spec. indet. ex aff. gemmati Mojs.}

Taf. VI, Fig. $6 a, b$.

1882. Balatonites gemmatus sojsisorics E. 2', Cephalop. Medit. Triaspr., pag. 8I, Taf. VI, Fig. 3.

Leider ist das Bruchstück doch zu unvollständig, um darauf eine neue Species sicher begründen zu können. Wir sehen einen flach gewölbten Externtheil, dessen Mitte von einer stark hervortretenden Mittellinie eingenommen wird, welche hier an Stelle der Kieldornen tritt. Die Flanken sind flach gewölbt; die Marginalkante scharf durch eine Dornenspirale bezeichnet, die Umbilicale ist weniger deutlich ausgesprochen und dient den grossen Umbilicaldornen als Ansatz; die Nabelwand ist schrägstehend und nieder; die Involution gering, besonders die inneren Vindungen sind kaum umfassend. Die Flankensculptur besteht aus kräftigen Radialrippen, welche über die Nabelwand schwach herauf steigen und auf der Flanke selbst sofort einen sehr grossen Umbilicaldorn bilden. Ungefähr in der Flankenmitte sitzt ein grosser Lateraldorn auf, dem auf der Marginalkante ein etwas kleinerer Marginaldorn folgt.

Zwischen diesem und dem Lateralen sitzt in ungefähr dem ersten Drittel ein kleiner und in dem zweiten Drittel der Entfernung beider von einander ein grösserer accessorischer spitzer Knoten auf, so dass wir auf der Flanke vier respective fünf Knoten-oder Dornenspiralen haben. Die Hauptrippe, welche breiter als hoch ist, verläuft in der unteren Flankenhälfte radial, in der oberen leicht concav nach vorn gekrümmt, so zwar, dass der Marginaldorn wieder in der Radiallinie liegt.

Die Vermehrung der Rippen erfolgt, wenigstens auf der letzten Windung, durch Theilung und Insertion. Von der Hauptrippe spaltet sich auswärts des Lateraldornes eine Nebenrippe ab, welche aber erst knapp unter dem Marginaldorn die gleiche Stärke wie die primäre erlangt, einen gleich starken Dorn trägt und auch bezüglich der accessorischen Dornen sich nicht unterscheidet. Nächst dieser ist noch eine grössere Nebenrippe von gleichem Verlauf unđ Stärke wie die primäre inserirt, welche ebenfalls einen Lateraldorn trägt und erst unterhalb dieser erlischt. Sie wäre vielleicht bei weiterem Verlauf auf den Umbilicaldorn zu beziehen und wir hätten dann eine ähnliche Anordnung,

$$
\text { Moisisorics F. ve. Cephalop. Medit. Triaspr. }
$$


wie wir sie bei Balatonites balatonicus Mojs. (Taf. VI, Fig. $6 a, b$ ) finden. Die Rippen setzen nur undeutlich auf den Externtheil über, der, wie schon erwähnt, keine Kieldornen aufweist, sondern nur eine stark hervortretende Mittellinie, welche im Zwischenfeld zwischen je zwei Rippen stark zurücktritt. Besonders stark auf den innersten Windungen, aber auch auf der letzten und vorletzten treten kräftige Einschnürungen auf; auf einem inneren Umgang, der — nebenbei bemerkt — nur schwache Berippung zeigt, treten sieben solcher Einschnürungen auf.

Die Suturlinie ist nur undeutlich zu sehen; man bemerkt einen niederen, aber grossen ersten Laterallobus mit reichgezacktem Grunde und einen relativ kürzeren und kleineren Zweiten, welcher ebenfalls reichgezackt erscheint. Auf der Nabelwand ist ein Auxiliarlobus schwach angedeutet. Die Sättel scheinen breit und flach gewölbt zu sein.

Die im Obigen beschriebene Species schliesst sich gut an zwei Formen der Gemmati-Gruppe Mrojsisovics' an, und zwar an Balatonites balatonicus Mojs., dessen Aehnlichkeit schon oben ervähnt wurde, und an Balatonites gemmatus Mojs. (pag. 8I, Taf. VI, Fig. 3). Auf der andern Seite weist die Art dex Rippentheilung, ferner die Reduction der Kieldornen wieder sehr auf gewisse, wenig involute Trachy. ceras-Arten hin, z. B. Trachyceras (Anolcites) amicum Mojs. (pag. Io6, Taf. LXXXI, Fig. 9) aus den Wengenerschichten. Die Aehnlichkeit dürfte sich noch vermehren, wenn bei einem älteren Individuum die accessorischen Knötchen zwischen Lateral- und Umbilicaldorn, die hier nur stellenweise und nut mit der Lupe wahrnehmbar sind, stärker entwickelt sein sollten.

\section{Balatonites constrictus Art.}

Taf. VI, Fig. $7 a, b, c$.

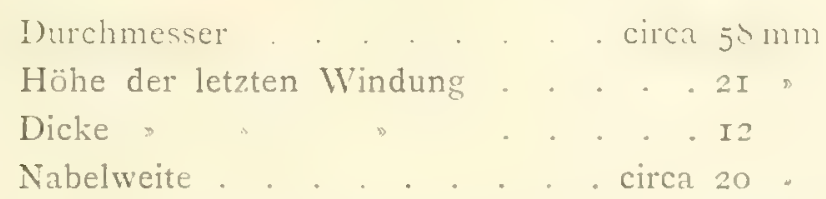

Der Externtheil ist spitz-dachförmig, nicht gerundet; die Flanken flach gewölbt, mit scharf entwickelter Marginalkante, auf welcher längsgestellte Knoten aufsitzen, und leicht abgestumpfter Umbilicaler mit stumpfen Umbilicalknoten; die Nabelwand ist schräg gestellt und nieder. Die Species ist sehr weitnabelig; die letzte Windung umfasst ungefähr ein Drittel der früheren.

Die Flanken sind mit einer undeutlichen Radialsculptur bedeckt, bestehend aus flachen, nach vor'n bogenförmig und concav gekrümmten Rippen. Die Berippung besteht aus Hauptrippen und Nebenrippen; erstere lassen sich deutlich in ihrem Verlauf vom Nabel zum Marginalrand verfolgen; sie beginnen mit einer kleinen, stumpf-knotenförmigen Anschwellung am Ümbilicalrand, tragen in etwas weniger als der halben Flankenhöhe einen grösseren, spitz-knotenförmigen Ansatz und auf der Marginalkante einen, die ganze Rippenbreite einnehmenden, längsgestellten und scharfen Marginalknoten. Nun setzt die Rippe, sich immer mehr erniedrigend, im Sinne des Verlaufes auf der I'lanke - also ohne besondere Schwenkung nach vorne - auf den Externtheil über und bildet dort, wo sie mit der Rippe der anderen Flanke zusammentrifft, einen ebenfalls längsgestellten und scharfen Externknoten, welcher dem Marginalen an Grösse nachsteht. Die anderen Rippen, welche sich nicht bis zum Nabelrand verfolgen lassen, wären als Nebenrippen aufzufassen. Sie treten nur deutlich auf dem Externund oberen Flankentheil hervor und tragen daselbst den Primären gleiche Extern- und Marginalknoten. Ausserdem sehen wir knapp unterhalb der letzteren, sowohl auf den Primär- wie Secundärrippen, schwache Anschwellungen in linienförmiger Anordnung, welche einer unausgebildeten oder reducirten Knotenspirale, ähnlich der marginalen, entsprechen.

Wenigstens auf der letzten Windung sehen wir zahlreiche Contractionen, welche in kleineren Zwischenräumen auf einander folgen. Auf dem erhaltenen Stück finden wir vier solcher Einschnürungen. 
welche den Verlatuf der Rippen in der Art beeinflussen, dass -- gegen vorn gerechnet - stets wor denselben eine stärker ausgebildete und hintor derselben eine schwächer entwickclte Hauptrippe auf. tritt. Das /wischenfeld zwischen zweien dieser Contractionen ist mit drei Nebenrippen ausgefült, so dass zwei Ümbilical- und Lateralknoten dann fünf marginalen und externen Kinoten entsprechen.

bie Suturlinie ist nicht bekannt.

Die Zeichnung IFig. $7 a$ ist insoferne nicht ganz genau, weil der Unterschied in der Stärke der vor und nach der Linschnürung stehenden Hauptrippen zu weng markirt ist und das Verschwinden der Nebenrippen vor Erreichen des Nabelrandes nicht deutlich zu sehen ist.

Interessant ist das Auftreten dieser Einschnürungen, die sonst seltener beobachtet werden. Bekannt waren sie bis jetzt nur bei folgenden Formen: Balatonites balatonicus Mojs. ${ }^{1}$ ) (pag. 79 , Taf. IV, Fig. 2-6) auf den inneren Windungen; bei Balatonites bragsensis Loretz. sp. (pag. 8o, 'laf. VI, Fig. 2), wo sie sowohl auf den inneren als äusseren Windungen sich finden, und ferner bei I3alatonites Zitteli Mojs. (pag. 80, Taf. V, Fig. 2, und Taf. XIX, Fig. 3), und zwar besonders bei dem Taf. XIX, Fig. 2 abgebildeten Stück auf inneren und äusseren Windungen. Allerdings finden sie sich nicht im Texte erwähnt, wohl aber zeigt sie deutlich die Abbildung auf laf. XIX, Fig. 3. Man liann übrigens auch einen Zweifel nicht unterdrücken, ob nicht Balatonites bragsensis und Balatonites Zitteli von Taf. XIX, Fig. 3 idente und nur im Alter beträchtlich varïrende Individuen seien. Somit kämen diese Erscheinungen bei frormen aus der Binodosus-Zone vor, von denen Balatonites Zitteli aus der Trinodosus-Zone eine Ausnahme machen würde.

In dem Reiflinger Material finden sich zahlreiche Formen, welche diese Einschnürungen ebenfalls zeigen, so z. B. Balatonites nov. spec. indet. ex aff. gemmati Mojs. (pag. 64, Taf. VI, Iïg. 9) und den im Folgenden beschriebenen Formen.

Balatonites constrictus schliesst sich bezüglich der Involutionsverhältnisse und der zarten Art der Berippung wohl am ehesten an die beiden Formen der Gemmati-Gruppe: Balatonites bragsensis Loretz sp. (siehe oben) und Balatonites Zitteli Mojs. (Taf. XIX, Fig. 3) an, unterscheidet sich aber von diesen theilweise durch die dachförmige Gestalt des Convextheiles. Diesbezüglich zeigt er eine Annäherung an die Formen der Balatonites acuti Mojs. ${ }^{2}$ ) (pag. 87) (Dorycranites Hyatt ${ }^{3}$ ), bei welchen sich der Externtheil bei Verschwinden der Marginal- und Externdornen zur Schneide abändert.

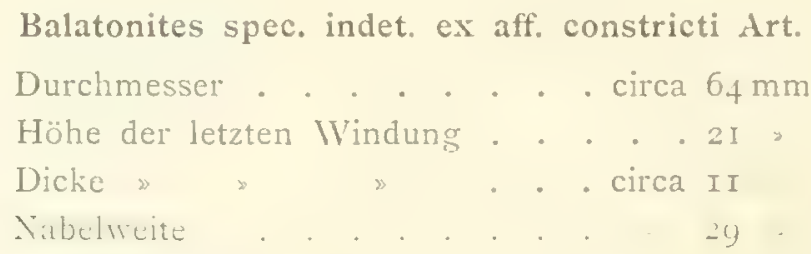

Das vorliegrende Stück ist im Steinkern erhalten und zeigt ein Segment der letzten, vorletzten und drittletzten Windung.

Der Externtheil ist nicht deutlich sichtbar, die Flanken sind flach gewölbt, höher im oberen Theil und rascher absinkend im unteren. Die Nabelwand ist nieder und schiefstehend; der Umbilicalrand leicht abgestumpft, der marginale schärfer durch längsgestellte Knoten entwickelt. Die Involution ist sehr gering, indem nur wenig mehr als die Marginalkante verdeckt wird; die Form ist weitnabelig.

Die Radialsculptur besteht aus einfachen, enggestellten Rippen, von denen jedoch nicht alle die Nabelwand erreichen und daher als inserirt aufzufassen sind. Sie haben flach-bogenförmigen, nach vorn concav gerichteten Verlauf. Die Primären beginnen mit einer stumpf-knotenförmigen

\footnotetext{
1) Mojisovics $E$. $z^{\prime}$, Cephalop. Medit. Triaspr.

2) Mrojsisouics E. v. Cephalop. Medit. Triaspr.

3) Whiteaves, Contributions to Canadian Palaeontlogy Vol. I, pag. I45, Montreal I8S9.
} 
Anschwellung am Nabelrand, tragen im oberen Drittel der Flankenhöhe einen Lateralknoten, am Marginalrand einen längsgestellten Marginalen und auf dem Externtheil wohl auch einen ebensolchen Externen. Dazwischen treten accessorisch und nicht immer gut sichtbar in dem unteren 'Theile der Flanke, dem Lateralen mehr als dem Umbilicalen genähert, im oberen Drittel dem Marginalen mehr genähert, zwei schwache Knötchen auf.

Die inserirten Rippen haben denselben Verlauf wie die primären, tragen keinen oder nur einen ganz undeutlichen Lateralknoten und erlöschen knapp unterhalb diesem.

Auch hier treten, so wie bei Balatonites constrictus und anderen Formen, häufig Einschnürungen auf. Sie beeinflussen den Verlauf der Berippung in der Art, dass stets wor der Contraction eine schwächere primäre Rippe mit schwächerem Lateral- und Umbilicalknoten sich entwickelt und stets nach derselben eine stärkere mit grossem Umbilicalen und Lateralen folgt. Das Zwischenfeld erfüllen Nebenrippen. Von der Mündung nach rückwärts zählend, zeigt das Feld zwischen zwei Einschnürungen eine starke primäre, drei inserirte und eine schwache primäre Rippe.

Die Suturlinie ist nicht bekannt.

Diese Art erinnert ausserordentlich an Balatonites constrictus, von dem sie sich durch die geringere Involution, die höhere Stellung der Lateralknoten und das Auftreten der accessorischen Knötchen unterscheidet. Sie stellt höchstwahrscheinlich eine Varietät jener vor und würde auch hier so aufgefasst worden sein, wenn das vorliegende Stück besser erhalten wäre.

\section{Balatonites contractus Art.}

Taf. VI, Fig. $8 a, b$,

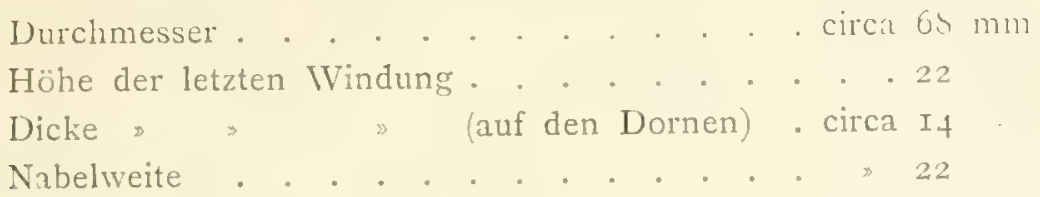

Der Externtheil ist ähnlich wie bei Balatonites constrictus, d. h. dachförmig entwickelt; die Flanker sind flach gewölbt und erreichen im oberen Theil die grösste Dicke; die Marginalwand ist durch eine längsgestellte Knotenspirale scharf entwickelt, der Umbilicale leicht abgerundet; die Nabelwand ist. relativ nieder und schräg gestellt; die Involution umfasst ungefähr ein Drittel der früheren Windung; die Form ist sehr weitnabelig.

Die Radialsculptur besteht aus Haupt- und Nebenrippen, welche breit, jedoch flach entwickelt sind. Erstere beginnen am Nabelrand in einem stumpfen, niedern Umbilicalknoten und zeigen einen nach vorne. concaven flachen Bogen, der im Externknoten wieder zur Radiallinie zurückkehrt. In ungefähr zwei Drittel der Flankenhöhe sitzt ein grosser, spitzer Lateraldorn auf, und auf der Marginalkante ein die ganze Rippenbreite einnehmender, längsgestellter scharfer Marginalknoten; von hier setzt sich die Rippe nur mehr undeutlich, im Sinne des oben erwähnten Rippenbogens, auf dem Externtheil fort, wo in der Mitte ein ebenfalls längsgestellter scharfer Externknoten von gleicher Grösse wie der Marginale aufsitzt; zwischen Lateraldorn und Marginalknoten tritt meist schwächer und nur stellenweise stärker eine leichte Anschwellung der Rippe auf. Im oberen Drittel der Flankenhöhe gliedert sich eine Nebenrippe an, welche schnell dieselbe Breite wie die Hauptrippe erlangt und Marginal- und Externknoten trägt wie jene.

Achnlich wie bei Balatonites constrictus treten auch hier zahlrciche Einschnürungen auf, und zwar stark entwickelte, welche vom Nabelrand über Flanke und Externtheil ziehen, und geringere, welche die Nabelwand nicht erreichen, deutlicher auf der Flanke und undeutlicher auf dem Externtheil entwickelt sind und nur Depressionen des Steinkernes oder IVülste auf dem Schaleninnern darstellen. Diese, ich möchte sie l'scudo-Einschnürungen nennen, treten fast regelmässig nach einem Rippenpaar, 
bestehend aus Haupt- und Nebenrippe, auf und wären daher nicht einmal als Pseudo.Contractionen aufzufassen, würden sie nicht auch - wenn auch weniger deutlich - über den Externtheil streichen, während jene in weiten Abständen nach je 3-4 Rippenparen auftreten. Sie bedingen dann bei der nach rückwärts folgenden ersten Hauptrippe die dornartige Entwicklung des Lateralknotens, wie sie Fig. 8 b zeigt, der sonst nur durch eine leichte Anschwellung markirt ist.

Die Suturlinie ist nicht bekannt.

Balatonites contractus schliesst sich enge an den oben beschriebenen Balatonites constrictus an, ist jedoch weniger involut als dieser und auf den Flanken bedeutend gröber berippt, wodurch auch die weitere Stellung der Rippen erklärlich wird.

\section{Balatonites gracilis Art.}

Taf. VI, lïg. $9 a, b, c$.

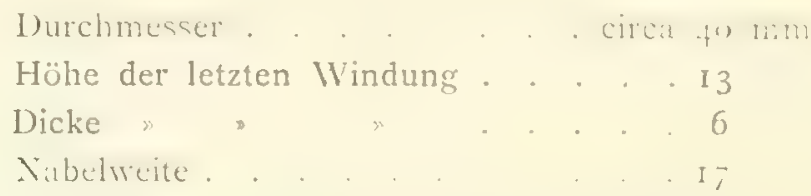

Der Externtheil ist dachförmig, in der Medianlinie mit scharfen und spitzen Kieldornen besetzt; die Seiten sind flach gewölbt, Marginal- und Umbilicalrand deutlich entwickelt und ersterer mit einer Dornenspirale, letzterer nur mit stumpfen Knoten besetzt; die Nabelwand ist nieder und schiefstehend. Die Windungen sind weitnabelig, wenig übergreifend und bedecken eben noch die Marginalkante des früheren Umganges.

Die Flanken sind mit einer zarten Radialsculptur bedeckt. Dieselbe besteht aus, nach vorne leicht concaven, flachen Hauptrippen, welche sich deutlich vom Nabelrand bis zum Externdorn verfolgen lassen und aus inserirten Nebenrippen, die nur im oberen Flankentheile sichtbar sind. Erstere steigen schwach sichtbar über die Nabelwand herauf, haben auf dem Rande einen stumpfen Umbilicalknoten aufgesetzt, tragen auf dem Marginalrande einen spitzen Marginaldorn, treten dann, etwas kräftiger werdend, auf den Externtheil über und enden in der Mittellinie mit einem längsgestellten, zugeschärften und spitzen Externdorn. Auf dem Externtheil correspondiren die beiderseitigen Rippen und der Externdorn selbst bildet den Endpunkt des flachen Rippenbogens, der radial in derselben Linie liegt wie der Umbilicale. Die eingeschalteten Nebenrippen zeigen dieselbe Extern- und Marginalentwicklung wie die Hauptrippen und verschwinden ungefähr in der halben Flankenhöhe. Die zahlreich auftretenden Einschnürungen, welche denselben Verlauf wie die Rippe haben, scheiden gewisse Sculptureinheiten auf der Flanke ab; von vorn gerechnet, folgt jeder Contraction eine Hauptrippe mit kräftiger Beknotung, welche ausserdem noch in drei Viertel der Flankenhöhe ein kleines Lateralknötchen trägt. Ihr folgt eine Inserirte, dann eine Hauptrippe mit schwachem Umibilicalknoten, wieder eine Inserirte und schliesslich wieder eine Hauptrippe mit kräftigem Umbilicalknoten. Dann folgt eine Einschnürung nach der sich dieselbe Folge wiederholt. W'ir haben somit in einer solchen Sculptureinheit fünf Rippen mit: drei Umbilicalknoten, fünf Marginal-, fünf Externdornen und einem Lateralknötchen.

Die Suturlinie zeigt einen niederen, breiten Externlobus, dessen beide Flügel ron einem niedern, breiten Medianhücker getheilt sind und auf der Innen-, Unter- und Aussenseite je eine zackige kleine Spitze aufweisen; der erste Laterale ist gerundet, ausserordentlich breit, fast dreimal so tief als der Externe und am Grunde mit drei deutlicheren und zahlreichen kleineren Spitzchen besetzt; der zweite Iaterale ist klein, etwas tiefer als der Externe, mit spitzgerundetem Grunde, in deren Mitte ein Zacken, ähnlich wie bei Popanoceras, herabhängt; gegen die Naht zu folgt ein kleiner Auxiliarlobus. Die Sättel sind klein, ganzrandig und rundbogig; der Externsattel ist am breitesten und liegt fast ganz auf der Ilanke, der zweite Laterale wird rom Umbilicalrand halbirt. Die Verbindungslinie ihrer Scheitel ist eine radialstehende Gerade. 
Balatonites gracilis ähnelt in der Form und Vertheilung der Rippen dem Balatơnites Zitteli Mojs. ${ }^{1}$ ) (pag. So, Taf. XIX, Fig. 3). Wir finden auch hier wieder die zahlreichen Einschnürungen, welche Sculptureinheiten abscheiden, die aus ähnlich vertheilten Rippen sich zusammensetzen. Jedoch ist Balatonites Zitteli viel involuter, hat kräftigere Umbilical- und schwächere Marginalbeknotung und tiefer sitzende, auch stärker entwickelte Lateralknoten. Die grössten Unterschiede zeigen jedoch die Suturlinien, insbesondere durch den bei Balatonites gracilis so ausserordentlich stark entwickelten ersten Laterallobus.

Als verwandte Form ist weiterhin Balatonites bragsensis Loretz sp. $^{1}$ ) (pag. So, Taf. VI, Fig. 2) anzuführen und der im Folgenden beschriebene Balatonites lineatus (pag. 69, Taf. VI, Fig. Io $a, b, c$ ).

\section{Balatonites lineatus Art.}

Taf. VI, Fig. Io $a, b, c$.

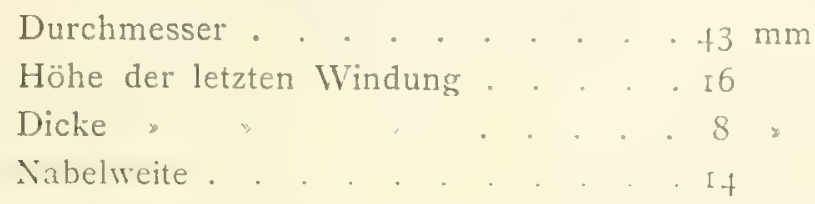

Der Externtheil ist schmal, dachförmig, mit zugeschärftem Medianknoten; die Flanken sind flach gewölbt und erreichen ungefähr in der Flankenmitte die grösste Dicke; die Marginalkante ist scharf markirt durch längsgestellte Marginalknoten, die Umbilicale leicht gerundet, dient zur Ansatzstelle für kräftige, spitze Dornen; die Nabelwand ist nieder uud steil gestellt; die Involution umhüllt kaum ein Drittel der vorhergehenden Windung und wird gegen Ende des letzten Umganges noch bedeutend geringer.

Die Quersculptur wird aus radialen, fast geradlinig verlaufenden, zarten Rippen gebildet; sie zerfallen in Primäre, welche mit dem Umbilicaldorn beginnen, ungefähr in der halben Flankenhöhe ein kleines Lateralknötchen, und vom Marginalrand den längsgestellten Marginaldorn tragen, sich von diesem aus stumpfwinklig nach vorne wenden, und in der Medianlinie des Externtheiles mit einem länglichen, flachgedrückten Kieldorn enden - und in secundäre, inserirte Zwischenrippen, die sich nur in einzelnen Fällen bis gegen den Umbilicaldorn verfolgen lassen, jedoch in der Marginal. region mit derselben Stärke auftreten wie die Primären. Zwischen je zivei Hauptrippen lassen sich je drei Zwischenrippen unterscheiden, von denen die dritte (von der Mündung an gerechnet) sich im Umbilicaldorn an die Hauptrippe mehr oder weniger deutlich anschliesst, während die zweite und erste sich stellenweise zu einem flachen Knötchen am Umbilicalrand vereinigen, welches zwischen den Nabeldornen der Hauptrippen zu stehen lommt. Keine đer Zwischenrippen trägt einen Lateralknoten. Zu zwei Umbilicaldornen eines Sculpturfeldes gehören somit zwei Lateralknoten, fünf Marginale und fünf Externknoten. Ausser dieser Radialsculptur tritt auf Schalenexemplaren noch eine ziemlich deutliche Spiralstreifung auf, in der Form dreier Linien: die unterste ist am undeutlichsten zwischen Umbilicalund Lateralknoten nur stellenweise schwach zu sehen, die mittlere ist selir gut, fast überall zu verfolgen und tritt in der Höhe des Lateralknotens auf, während die Obere wieder undeutlicher wird und sich ungefähr in der Mitte zwischen Lateral- und Marginalknoten hinzieht. Die Schale zeigt ferner ausscrordentlich feine Radialstreifung, welche parallel den Hauptrippen verläuft und auf den Extern. theile sich analog diesen nach vorne wendet.

Auch hier treten sowohl auf den inneren als wie auf der letzten Windung kräftige Einschnürungen auf, die Tlanke und Externtheil, gleichmässig und gleichsinnig den Hauptrippen, übersetzen; meist sind sie von einander durch ein Hauptrippenpar getrennt.

\footnotetext{
1) Mojsisovics Li. v., Cephalop. Medit. Triaspr.
} 
Die Suturlinie durchsetzt in etwas schräger Richtung nach Aussen zu dic Berippung. Wir finden einen breiten, niederen Externlobus, der von einem breiten, niedern Medianlä̈cker halbirt wird und dessen Flügel je drei lileine Zäckchen am Grunde aufweisen; der erste Laterale ist breit und reicht tiefer herab áls der externe; der zweite ist schmal und etwas kürzer als ersterer; beide sind am Grunde gezackt; von der Nabelkante wird ein breiter, ganzrandiger Auxiliarlobus halbirt, dessen Scheitel radial in derselben Höhe liegt wie der Externsattel. Dieser ist sehr breit, liegt vollständigr auf der Flanke und reicht ungefähr bis zur halben Höhe des ersten Lateralsattels hinauf; der zweite Laterale ist nur um wenig schmäler als der Erste. Sämmtliche Sättel sind ganzrandig.

Balatonites lineatus schliesst sich bezüglich der Sculptur eng an Balatonites gracilis an, während die Suturlinien total von einander verschieden sind, so dass es den Anschein hat, als ob beide ganz andern genetischen Reihen angehören würden.

Balatonites transfuga Art. Taf. VII, Tig. $1 a$, b, Irig. 2 .

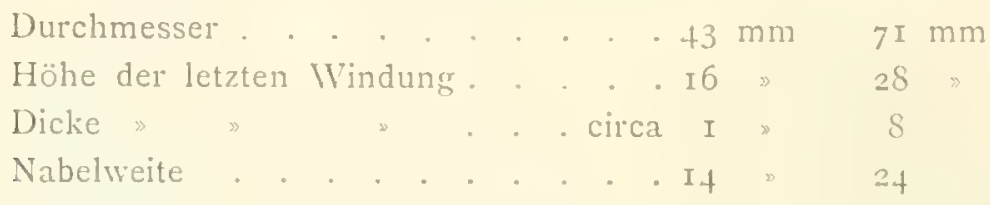

Von den zwei vorliegenden Exemplaren ist das kleinere nach der Medianfläche zu verschiedenen Malen gebrochen, so dass sich bei der flachen Scheibe eine Seite nicht ganz freilegen liess, weshalb die Abbildung Taf. VII, Fig. I $a, b$ in gewissem Sinne als reconstruirt $z$ u betrachten ist. Fig. 2 zeigt das grössere Exemplar, das leider nur in Steinkern enthalten ist.

Der Externtheil ist, abgesehen von den Extern- und Marginaldornen flach gewölbt und ihm sind auf dem Marginalrande die grossen ohrförmigen Marginaldornen aufgesetzt, zwischen denen eine scharf prononcirte, und folglich als kleiner Kiel entwickelte Medianlinie auftritt; die Flanken sind sehr flach gewölbt und erlangen ungefähr in der Flankenmitte die grösste Dicke; der Marginalrand ist deutlich entwickelt, der umbilicale erscheint in Folge der stumpfen Knoten leicht gerundet; die Nabelwand ist nieder und fast senkrecht stehend. Die Involution der weitnabeligen Windungen ist gering und beträgt kaum ein Viertel des früheren Umganges.

Die Flankensculptur wird aus schnurförmigen, enggestellten Rippen gebildet und besteht aus einfachen Haupt- und inserirten Zwischenrippen; sie setzen radial am Nabelrande an und wenden sich, ungefähr von der Flankenmitte an, mit einem flachen Bogen nach vorn; die Hauptrippen tragen auf der Nabelwand die stumpfen, grossen Umbilicalknoten, welche zunächst den Marginalen die grössten Knotenindividuen sind; dann folgt in geringer Entfernung eine Spirale, bestehend aus spitzen Knötchen, ungefähr in der Flankenmitte eine dritte aus gleichstarken, spitzen Knötchen, und nahe unter den starken, leicht abgeflachten und längsgestellten Marginaldornen eine vierte Spirale, bestehend aus hleineren, spitzen Knötchen. Ausserdem schiebt sich zwischen die zweite und dritte eine accessorische Spirale, aus feinen Knötchen gebildet, ein und zwischen die dritte und vierte zwei weitere accessorische Spiralen, welche ebenfalls aus kleinen Knötchen bestehen. Somit haben wir auf den letzten Theilen der Flanken acht Knotenspiralen. Die Zwischenrippe reicht in der Regel bis etwas unterhalb der Flankenmitte herab, trägt dieselben Knotenspiralen, welche aber, mit Ausnahme des Marginaldornes, aus etwas kleineren Knötchen gebildet sind, die dieselbe Breite wie die Rippe, der sie aufsitzen, haben. Letztere bildet, auf dem Externtheile stark verflachend und in der Medianlinie mit der Rippe der anderen Flanke zusammenstossend, daselbst die oben erwähnte niedere aber scharfe Kiellinie.

Dieselben Verhältnisse zeigt auch das grosse Exemplar, nur ist hier die genaue Aufeinanderfolge ron Hatupt- und inserirten Rippen nicht mehr so deutlich eingehalten, indem stellenweise auch 
zwei Zwischenrippen aufeinander folgen, von denen die eine punktförmig am Nabelrande schon ange. deutet ist. Ausserdem schalten sich - genau nach dem schon anderweitig vielfach beobachteten Gesetz auf dem äusseren Flankentheil zwischen die dritte und vierte Hauptspirale statt zweier, drei accessorische Knotenspiralen ein, so dass wir bei der grësseren Winđungshöhe neun Knotenspiralen haben. Je kleiner im Gegentheile die Höhe der Windung wird, desto geringer wird die Anzahl der Spiralen, indem eine um die andere accessorische Reihe ausbleibt und schliesslich auch die anderen Spiralen reducirt werden.

Die Suturlinie liess sich nicht beobachten, was bei dem ungünstigen Erhaltungszustande des kleineren Exemplares nicht Wunder nimmt, während das grössere Stück, das doch im Steinkerne erhalten ist, gerade im Anfange der letzten Windung stark abgewittert ist.

Dieser auffallend sculpturirte Balatonit hat schon ganz den 'Trachycerastypus und schien auch anfangs zweifellos den Trachyceraten, speciell Anolcites Mojs. $\left.{ }^{1}\right)($ pag. 692) zugezählt werden zu müssen. Nebst dem mangelhaften Erhaltungszustand trug hieran der Umstand Schuld, dass der Mediankiel, der sich bei allen Balatoniten erst später entwickelt, hier besonders spät erworben wird. Bei den anderen Formen dieser Gattung findet sich dieser Kiel oder diese Dornenspirale schon vollständig auf der letzten Windung, während sie hier erst im letzten Viertel derselben auftritt, was immerhin für Stücke eines ähnlichen Durchmessers, wie ihn Fig. I hat, ein merkwürdiges und deutliches Charakteristicum wäre.

Balatonites transfuga schliesst sich unter den Balatoniten am ehesten an Bal. gemmatus Mojs. ${ }^{2}$, (pag. 8 I, 'Taf. VI, Fig. $3 a, b$ ) an. Freilich hat Balatonites transfuga eine weit flachere Scheibe, während Balatonites gemmatus bedeutendere Dicke erlangt, jedoch ist der Sculpturtypus ganz derselbe; schnurförmige, enggestellte Rippen mit scharfen Marginal- und abgestumpften Umbilicalknoten und dazwischen zahlreiche Knotenspiralen. Nur der Externtheil differirt, der hier lange und hohe, abgestumpfte Kieldornen hat. Die Suturlinie ist bei beiden Formen unbekannt. Die Aehnlichkeit der Ornamentirung der Trachyceraten verlangt unbedingt auch, dass man unter diesen nach möglicherweise verwandten Formen sucht. Es ist naheliegend, dass hier die von Mlojsisovics als Anolcites ausgeschiedene Formen in erster Linie in Betracht kommen müssen, da sie über den Externtheil setzende Rippen aufweisen, also ein niedereres Ausbildungsstadium der Trachyceras-Entwicklung darstellen. Auffallend ist nur, dass die von Mojsisovics aus der Zone des Ceratites trinodosus beschriebenen Anolciten gar keine Analogien bieten. Die grösste Aehnlichkeit finden wir erst bei Trachyceras (Anolcites) ju dicaricum Mojs. ${ }^{2}$ ) (pag. Io8, Taf. XIV, Fig. 3), der aus der Zone des Protrachyceras Archelaus, das heisst dem oberen Theile der Wengener Schichten Stur's oder den Aon-Schiefern Hertle's (Trachyceras Schf. Mlojsisowics) beschrieben wurde. Beachtet man, dass die Aon-Schiefer der Voralpen die Reiflinger Kalke direct und concordant überlagern, was auch bei Reifling der Fall ist (Profil pag. S) und somit den nächst höheren Horizont darstellen, so fällt diese Analogie beider Formen weniger auf. Die Involution ist bei Anolcites etwas grösser; zwei Hauptrippen vereinigen sich in je einem Umbilicalknoten und theilen sich dann jede wieder, was eine gedrängtere Radialsculptur bedingt, über welcher, ähnlich wie bei Balatonites transfuga, je sieben Knotenspiralen liegen. Der Externtheil ist schlecht zu sehen und scheint von den Rippen schwach übersetzt zu werden. Auch von dieser Art ist die Suturlinie nicht behannt.

\section{Balatonites efr. semilaevis Hauer.}

2887. Ifuner fi, v., Cephalop, bosnisch. Muschelk. pag. 29, Taf. VII, Fig. 6.

Das kleine, vorliegende Bruchstück hat über den Externtheil gemessen eine Länge von 19 mm, die Flankenhöhe beträgr $9 \mathrm{~mm}$, die Dicke $7 \mathrm{~mm}$.

Der Externtheil ist breit, dachförmig und ebenflächig begrenzt, die Flanken sehr flach gewölbt. mit deutlich entwickelter Marginalkante, während die Umbilicale leicht gerundet ist. Die Berippung

1) Mojsisorics, Cephalop. Hallstädt. Kalke. I, Abtheilung. (2. IHälfte.) I\$93.

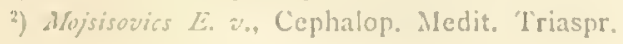


besteht aus kräftigen, nicht gedrängt stehenden Rippen, welche nach vorne schwach concav gebogen sind. Sie bestehen aus Haupt- und inserirten Zwischenrippen; erstere beginnen am Nabel in einem kleinen Knötchen und tragen auf dem Marginalrand einen kleinen stumpfen Marginalknoten, von dem aus die Rippen sich auf dem Externtheil mit gleicher Stärke nach vorn wendend in der stumpfen, dicken Medianlinie mit der correspondirenden Rippe der andern Flanke zusammentreffen, ohne einen Knoten oder dergleichen zu bilden; die Nebenrippen haben denselben Verlauf und gleiche Stärke und reichen etwas über dic Flankenmitte hinab.

Balatonites cfr, semilaevis unterscheidet sich von dem Hancr'schen Original nur durch die, wenn auch schwache Ausbildung einer Marginalkante, die vielleicht auf grössere Jugend des vorliegenden Stückes zurückzuführen ist.

\section{Familie: Tropitidae Mojs. \\ Unterfamilie: Celtitinae Mojs. \\ Gattung: Reiflingites Art.}

Seitdem E. v. Mojsisovics in den * Cephalopoden der Hallstätter Kalke (I. Abtheilung, 2. Hälfte, pag. 398) den Vorschlag gemacht hat, die Formen der Gruppe des Celtites Floriani1) (pag. 145) von den Celtiten abzutrennen und mit den Formen der "Untergruppe der Ceratites absoleti «2) (pág. 28) zu einer neuen Untergattung von Ceratites zu vereinigen, der er den Namen „Danubites gibt, verblieb von den Muschelkalkformen nur die „Formengruppe des Celtites epolensis (pag. 149) mehr bei Celtites im engeren Sinne.

In dem eben erscheinenden Theile des grossen Werkes von W. Waagen, Serie XIII der Palaeontologia indica ${ }^{3}$ ), finden wir (pag. 69) eine Anzahl von Celtiten, welche sich in der äusseren Form mehr oder weniger an die beiden von Mojsisovics früher aufgestellten Formengruppen an. schliessen, und deren Erhaltungszustand derartig ist, dass jeder Zweifel ausgeschlossen ist, ob diese Formen den Ceratitiden oder Tropitiden zuzuweisen wären. Es lässt sich vielmehr stets die lange Wohnkammer von fast einem ganzen Umgang deutlich constatiren, ihre Zugehörigkeit zu den Tropitiden ist folglich erwiesen. Fällt aber jetzt das eine Vergleichsmoment (Gruppe des Celtites Floriani Mojs.) Weg, so verbleiben diese neu aufgestellten Gruppen der Salt-Range Formen als selbstständige Formengruppen der Gattung Celtites neben der jetzt sfüheren : Formengruppe des Celtites epolensis Mojs. bestehen.

In seinem neuesten Werke löst aber Mojsisovics diese Gruppe ebenfalls auf, indem er die beiden Formen, welche sie bildeten, trennt und in zwei verschiedenen Gruppen unterbringt. Hier werden die sümmtlichen Celtiten-Formen — da IInjsisovics die Salt-Range Celtiten noch nicht kannte - in einer *Unterfamilie: Celtitinae zusammengefasst, die wieder in die Gattungen

Celtites,

Tropiceltites,

Haidingerites

zerfällt.

Erstere setzt sich aus folgenden Formengruppen zusammen:

Gruppe der Celtites multispirati,

acutoplicati,

annulati

und ein isolirter 'Typus.

1) Mojsisovics E. v, Cephalop. Medit. Triaspr.

2) Mojsisovics E. v., Arktische T'riasfaunen.

3) Whagen IV., Salt-Range fossils: Ceratite formation. 
Für den Muschelkalk kommen gegenwärtig nur die beiden Gruppen der

a) Celtites multispirati mit

Celt. epolensis Mojs.') (pag. I49, Taf. XXIX, Fig. I, 2, 'Taf. XXXVII, Fig. I3),

"Neumayri Mojs. ${ }^{2}$ ) (pag. 348 , Taf. CC, Fig. 5, 6),

- Edithae Mojs. (ibid., pag. 349, Taf. CC, Fig. 7);

b) Celtites acutoplicati mit

Celt. Buchii Klipst. sp.') (pag. I50, Taf. XXX, Fig. 7-ro)

in Betracht. Die beiden anderen Gattungen: Tropiceltites und Haidingerites wurden bis jetzt noch nicht in so tiefen Lagern gefunden.

Die Charakteristik der Celtitinen (pag. 346) gibt an: Ganzrandige, ungezähnte (clydonitische) Loben, eine lange, mindestens einen ganzen Umgang umfassende Wohnkammer, zahlreiche niedrige, annähernd rechteckige, evolute Umgänge, eine einfache, plikate Flankensculptur, und einen meist glatten Externtheil.

Die indischen Formen schliessen sich im Sculpturtypus enge an beide Gruppen an; sie haben ähnliche Involution, stets glatten Externtheil und theils rechteckige Umgänge: Gruppe der Quadrangulares (pag. 72), theils höher gewölbte: Gruppe der Ovales. Die Aehnlichkeit verschwindet aber bedeutend, wenn man die Suturlinien rergleicht. Wir finden nämlich bei-beiden Gruppen, und zwar bei den geologisch älteren Quadrangulares wie bei den geologisch jüngeren Ovales, Formen mit und olne Zackung der Loben.

Celtites multiplicatus Waag. (pag. 78, Taf. VII, Fig. 2) aus der ersten Gruppe hat Zacken, welche dem

Celtites trapezoïdalis Waag. (pag. 76, Taf. XXI, Fig. 3) fehlen, wobei allerdings ins Gewicht fällt, dass das abgebildete Stück ein kleines, anscheinend junges Individuum war. Bei der anderen Gruppe finden wir in Celtites acuteplicatus Waag. (pag. 82, Taf. VII, Fig. 5, 6, 7) ein Stück, bei dem man in Folge starker Abwitterung nur mehr feine Spuren einer Lobenzackung sieht.

Ausserdem zeigen die isolirten und hier angeschlossenen Formen theilweise Zackung:

Celtites laevigatus Waag. (pag. 86, Taf. VII $a$, Fig. 3 ),

theilweise clydonitische Lobenform:

Celtites teres Waag. (pag. 88, Taf, VII $a$, Fig. 4).

Die geologisch ältere Form hat hier gezackte Loben, während die jüngere, aus dem Dolomit des obersten Ceratite Limestone, ganzrandige Suturglieder hat.

Bei allen, und zwar insbesondere bei den geologisch älteren Formen, welche aus Aequivalenten des oberen Buntsandsteinniveau stammen, liegt der zweite Laterallobus noch nicht gänzlich ausserhalb der Involutionsspirale, wird vielmehr von ihr in verschiedenem Masse getroffen, so dass streng genommen nur von einem Laterallobus gesprochen werden dürfte. Setzt man diese Thatsache auch auf Rechnung des individuellen Alters und behält die Annahme zweier Lateralloben bei, so muss auf jeden Fall die Diagnose bezüglich der clydonitischen Loben der Celtiten geändert werden.

Ein neuer Typus tritt nun zu den eben besprochenen Formen aus dem Reiflinger Muschelkalk hinzu, der in gewissem Sinne wieder vollständig von den gegenwärtig als Celtitinen zusammengefassten Gruppen abweicht, aber doch hier seine natürlichste Angliederung findet. Diese Formenreihe, welche im Verhältniss zu Celtites, Tropiceltites und Haidingerites ebenfalls als selbstständige Gattung zu gelten hat, für welche ich den Namen

\section{Reiflingites}

vorschlage, zeichnet sich durch wenig involute, kaum umfassende Umgänge aus, mit leicht sichelförmig gebogener Radialsculptur, bestehend aus einfachen und inserirten Rippen, seltener deutlichen Spalt-

1) Mojsisozics E. V., Cephalop. Medit. Triaspr.

$\left.{ }^{3}\right)$ Mojsisorics E. $\approx$, Cephalop. d. Hallstätt. Kalke. I. Abtheilung, 2. Hälfte. 
rippen mit ein bis zwei deutlichen Knotenspiralen auf der Flanke der erwachsenen Individuen. Bei Steinkernen ist der flachgewölbte Externtheil entweder glatt, zeigt eine deutlich differenzirte Mittellinie oder besitzt einen drahtförmigen Kiel; stets findet sich die Lateralsculptur aber auf dem Externtheil unterbrochen; Marginal- und Umbilicalrand sind mehr oder weniger deutlich entwickelt; die Nabelwand ist meist nieder und stets sehr steil gestellt.

Die Suturlinie zeigt schmale, gezackte Loben und relativ breite, ganzrandige Süttel; der Externlobus ist breit, gezackt; ein grosser erster und kleiner zweiter Laterallobus, welcher noch auf der Flanke liegt und an den sich auf der Nabelwand ein Auxiliar anschliesst; auf der Internseite folgt sodann ein kleiner zweiter Auxiliar und ein zweispitziger Internlobus. Die Kammerscheidewände stehen auch bei erwachsenen Individuen theilweise in grösserer als normaler Distanz von einander (Reiflingites Eugeniae, Reiflingites torosus), theilweise in normaler. (Reiflingites rota, Reiflingites fortis). Die Länge der Wohnkammer beträgt mindestens mehr als $3 / 1$ Umgang.

Wir finden in dieser Gattung Merkmale wieder, die wir früher bei Formen der Gruppe des Celtites Floriani Mojs, kennen lernten. Z. B. die Wenig involuten Ümgänge, die bald drahtförmige Kiellinie bei

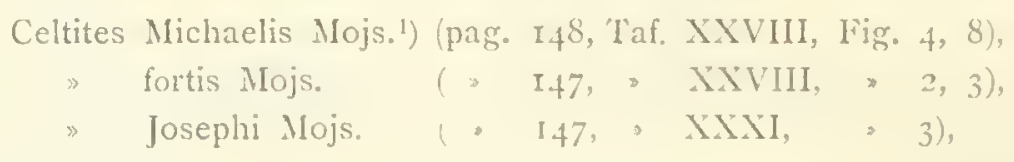

bald deutliche Medianlinie bei

Celtites Floriani Mojs. (pag. 145, Taf. XXVIII, Fig. 5, 6, 7, Taf. XXXI, Fig. 4).

Wir finden auch die Spalt- oder inserirten Rippen und die Beknotung, bei

Celtites fortis Mojs.,

den zweispitzigen Internlobus und den grösseren als normalen Abstand der Kammerscheidewände. Es wäre daher wohl möglich, dass der Fund eines echten Celtiten der früheren Floriani-Gruppe mit vollständig erhaltener langer Wohnkammer wieder zur Zurückweisung derselben zu den Celtitinen führen könnte.

Nach all dem fühle ich mich gezwungen, jetzt den Danubites (Celtites) fortis Mojs., der zweifelsohne in die allernächste Verwandtschaft ron Reiflingites (Reifl. torosus, pag. 76, Taf. VII, Fig. 4, 5) gehört, von den Danubiten abzutrennen und Reiflingites zuzuweisen.

Es scheint auch, dass Ceratites celtitiformis Hauer2) (pag. I3, Taf. III, Fig. 2), der freilich eine über den Externtheil setzende Flankensculptur hat, hier anzugliedern wäre. Allerdings ist in Fig. 2 c die Lobenlinie schlecht reproducirt, die vielmehr ganz ähnlich derjenigen von Reiflingites Eugeniae ist und auch in ähnlich weiten Distanzen auftritt.

Sollten neuere Funde ähnliche Formen zu Tage fördern, dann wird sich die Richtigkeit der Vermuthung der Zugehörigkeit zu Reiflingites besser beurtheilen lassen. Wir müssten dann, bei Erweiterung der Gattungsdiagnose, zwei Formengruppen unterscheiden, die eine mit furcater Flankensculptur, welche auf dem Externtheil unterbrochen ist, die andere mit plikater Sculptur, die sich über den Externtheil fortsetzt.

Die Familie der Tropitiden, für welche fast gleichzeitig E. $v_{0}$ Mojsisovics und W. Waagen die Eintheilung in Subfamilien aufstellten, erfährt, wenn wir das Hallstätter Material zusammenhalten, mit dem permischen von Sicilien, Salt-Range und Reiflinger Materiale insofern eine Vermehrung, dass zur zweiten Subfamilie: Tropitinae, die Gattung Pseudharpoceras Waagen hinzutritt; die vierte Subfamilie: Celtitinae umfasst dann folgende Gattungen:

\section{Paraceltites Gemm.,}

Yenodiscus WVaag.,

i) Mojsisovics E. ข., Cephalop. Medit. Triaspr.

$\left.{ }^{2}\right)$ Hauer Fr. 2 , Cephalop. Trias von Bosnien. I892. 
Celtites Mojs.,

Tropiceltites Mojs.,

Haidingerites Mojs.,

Reif lingites Art.

Die Gattungen Stephanites Waag. und Acrochordiceras Hyatt liessen sich in eine fünfte Subfamilie zusammenfassen, für die der Name:

\section{Stephanitinae}

aus phonetischen Rücksichten der berechtigteren Bezeichnung Acrochordiceratinae vorzuziehen wäre. Die Diagnose für diese Subfamilie der Celtitinae würde dann lauten:

»Sehr wenig umfassende, weitnabelige Ümgänge mit groben Lateralfalten, einfach plikater Flankensculptur oder furcater Berippung mit Knoten. Die Suturlinie ist nach dinaritischem oder ceratitischem Typus gebaut, oder von clydonitischer Form.

Die verschiedenen Elemente, besonders bei den Suturlinien, die wir in der Subfamilie der Tropitinae finden, erklärt sich daraus, dass es den Anschein hat, als wenn wir hier die verschiedenen Entwicklungsstađien eines Cephalopodenzweiges zusammengefasst hätten, der wohl in tiefen permischen Schichten beginnt, dessen einer Trieb (Paraceltites) nach kurzer Dauer schon erlischt, während Xenodiscus mit seinen hochentwickelten Loben gleichzeitig đas lebensfähige Element repräsentirt. Wir hätten dann in Reiflingites ein Maximum der Entwicklung und in den Hallstätter Kalken nur mehr Zwergformen mit sehr vereinfachten Lobenelementen.

Betrachtet man die Formenmenge der Ceratitiden und Tropitiden, also die beiden Hauptstämme der Trachyostraca, so wird man finden, dass bei den Suturen und Sculpturen gewisse Stadien wiederkehren, die für eine parallele Entwicklung bei gleichen Gesetzen für beide Familien sprechen wiirde. Greifen wir die Celtitinen heraus, so finden wir bei Paraceltites Gemm. ein ähnliches Stadium der Suturentwicklung wie bei Dinarites oder Triolites; bei Xenodiscus ein ähnliches Stadium wie bei Ceratites Sturi (Gruppe der Nudi), bei Stephanites dann die ähnliche Entwicklung wie bei der Gruppe der Ceratites Circumplicati; fasst man ferner die Gruppen des Ceratites binodosus, cimeganus und zoldianus zusammen als Ganzes unter dem Namen der Gruppe der Ceratites nodosoplicati, so finden wir dieser entsprechend bei den Celtitinen die Entwicklungsform der Reiflingiten.

\section{Reiflingites Eugeniae Art.}

Taf. VII, Fig. $3 a, b, c, i$.

Durchmesser . . . . . . . . $55 \mathrm{~mm}$
Höhe der letzten Windung. . . . 19 "
Dicke » * . . . . . . . . . . . 24 "
Nabelweite. . . . . .

Der Externtheil ist flach gewölbt, der Mediantheil etwas aufgetrieben und der Scheitel mit einer kielartigen Linie versehen; die Flanken sind fast flach und nur sehr schwach gegen die Nabelregion zu gewölbt; die Marginal- und Umbilicalknoten deutlich entwickelt; die Windung hat einen trapezoïdalen Querschnitt, mit ziemlich hoher, senkrecht gestellter Nabelwand. Dic Involution ist gering und bedeckt Convextheil und Marginalkante der früheren Windung.

Die Radialsculptur besteht (auf dem Steinkern) aus enggestellten, dünnen Haupt- mit je einer inserirten Zwischenrippe, die stellenweise in deutliche Spaltrippen übergehen. Sie sind flach-sichelförmig gebogen, steigen mehr oder weniger deutlich über die Nabelwand herauf, entwickeln auf dem Nabelrand selbst einen mehr oder weniger deutlich differenzirten kleinen, stumpfen Umbilicalknoten, dem in kaum 1/4 der Flankenhöhe ein grösserer Lateraler folgt, in dem die Flanke ihre grösste Dicke erreicht. Zwischen beiden ist die Rippe etwas verdickt, ebenso am Marginalrande, ohne dass im Quer- 
schnitt die Verdickung nur knotenähnlich aussähe.') Auf dem Externtheile set»t sich die Rippe gegen vorne gewendet fort und findet verflachend an der feinen kichartigen Mittellinie ihr Ende; von beiden Seiten stossen die Rippen stumpfwinklig dort zusammen. Ganz denselben Verlauf, wie die Hauptrippen, haben auch die inserirten Zwischenrippen, die aber nur bis zur Höhe des Lateralknotens herabreichen. Auf der ziveiten Windung (von aussen gerechnet) haben wir noch annähernd dieselben Verhältnisse wie auf der Letzten, und erst auf der Drittletzten ändert sich die Sculptur derartig, dass die Umbilicalknoten vollständig verschwinden und die inserirten Rippen tiefer herabreichen, gleichzeitig mit einer stärkeren Wölbung der Flanken. Da der Abdruck der Schale theilweise erhalten ist, sn erkennt man, dass auf derselben die Rippen sehr kräftig und massiv heraustraten.

Die Suturlinie wird zum letzten Male in ungefähr drei Viertel der letzten Windung sichtbar und steht von der vorhergehenden weit ab, ebenso wie die übrigen von einander. Sie besteht aus einem tiefliegenden breiten Externlobus, der von einem breiten, niedern Medianhöcker getheilt ist, wodurch zwei kleine Seitenäste resultiren; der erste Laterale reicht nur um wenig tiefer herab, ist relativ schmal, mit gerundetem Lobengrund; der Zweite ist ein klein wenig kürzer als der Externe und schmal; von der Nabelkante abwärts zieht sich über die Umbilicalwand ein grosser, llacher Auxiliar. Die Loben sind am Grunde fein gezackt und im ersten Lateralen scheiden sich zwei grössere Zacken aus. Die Sättel sind rundbogig und relativ gross; der Externe ist der grösste, wird von der Marginalkante halbirt und erreicht nicht ganz die Höhe des ersten Lateralen, der an Breite hinter diesem zurücksteht. Der erste und zweite Laterale reichen mit ihren Scheiteln an eine Gerade heran, welche einer Radiallinie entspricht.

\section{Reiflingites torosus Art.}

Taf, VII, Fig. $+a_{\text {: }} b, c, d$, Fig. 5 .

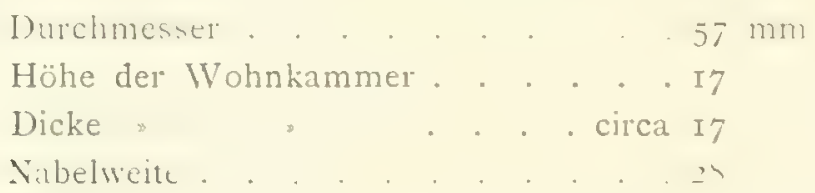

Der Externtheil ist ganz flach gewölbt, fast abgeplattet zu nennen und hat eine auf dem Anfang der letzten Windung schwächer, später stärker hervortretende Mittellinie. Die Seiten sind flach gewölbt und erreichen in der Umbilicalregion die grösste Dicke; der Marginalrand ist schwächer, der umbilicale stärker abgerundet, wodurch sich eine sehr schräggestellte niedere Nabelwand ergibt. Die Involution ist sehr gering und umfasst den Convextheil und eben noch die Marginalkante der früheren Windung.

Die Flanken sind mit einer Radialsculptur, bestehend aus Haupt- und inserirten Nebenrippen, bedeckt. Sie sind auf der Flanke schwach sichelförmig gebogen, weit von einander abstehend und treten auf dem Steinkern scharf und ziemlich schlank heraus, während sie auf Schalenexemplaren kräftiger, massiv und daher enger gestellt erscheinen; sie steigen sehr flach über die Nabelwand herauf, werden, so wie sie die Flanke erreicht haben, sofort bedeutend höher, ohne einen deutlich differenzirten Umbilicalknoten zu entwickeln, schwellen immer mehr an, bis zu einem Punkt, der ungefähr im ersten Viertel der Flankenhöhe liegt und der stellenweise als deutlicher Lateralknoten auftritt. Mit dieser knotenförmigen Verdickung fällt auch die grösste Breite der Windung zusammen. Von hier ab wird die Rippe sofort niedriger, schwillt erst auf dem Marginalrand etwas stärker an und setzt sich in gleicher Breite, jedoch schnell verflachend, bis zu der kielartigen Mittellinie beziehungsweise Medianlinie fort; die beiderseitigen Rippenenden treffen somit in ihrer Fortsetzung stumpfwinklig in der-

Die Zeichnung Iig. $3 c$ ist nicht ganz genau, weil die Marginalanschwellung der Rippen zu stark und die Verdickung derselben zwischen dem Lateralknoten und der Marginalanschwellung gar nicht angegeben ist. 
selben aufeinander; von gleicher Höhe und Stärke wie diese Hauptrippen sind auch die Nebenrippen, die aber, rom Convextheile aus, nicht ganz bis zur Lateralanschwellung der Hauptrippen herabreichen.

Auf der letzten Windung tritt an zwei Stellen eine Art von Einschnürung auf, auf der vorletzten - wohl nur in Folge des Erhaltungszustandes - ist sie nur an einer Stelle zu beobachten. Sie erfolgt in der Weise, dass eine Nebenrippe hier nicht entwickelt ist, wodurch ein breites Feld, jederseits von zwei Hauptrippen flankirt und analog dem Verlauf dieser, über die Flanke zieht. Die weitere Fortsetzung über den Externtheil lässt sich nicht verfolgen, da gerade an diesen beiden Stellen das beste Exemplar gebrochen ođer abgesplittert ist und die anderen diese Erscheinung nicht mit wünschenswerther Deutlichkeit zeigen. Daher bleibt auch die Möglichleit offen, dass diese Einschnürungen, die die anderen Species nicht zeigen, nur individuelle und vielleicht krankhafte seien.

Die Suturlinie ist sehr ähnlich derjenigen von Reiflingites Eugeniae entwickelt. Der Externlobus ist etwas schmäler und weniger tief, der Medianhöcker schmäler und höher; der erste Lateral ist relativ breiter, der Zweite schmal, aber tiefer als derjenige der früheren Art; vor der Naht folgt ein kleiner Auxiliar. Die Loben sind reich geschlitzt, jedoch sind die Zacken und Zähnchen nicht nur auf den Grund beschränkt, sondern reichen etwas höher hinauf. Die Form der Sättel ist eine ähnliche wie bei Reiflingites Eugeniae, nur ist der erste Lateralsattel hier der höchste, von wo aus die Lobenlinie sich sehr wenig gegen den Externtheil und rascher gegen den Nabel zu senkt.

Bei einem jüngeren Exemplar gelang es, die Internseite der Windung blosszulegen, und hier zeigte sich auf der Internwand zunächst der Naht ein zweiter, spitzer und kleiner Auxiliar, ein ziemlich hoher Sattel und ein zweispitziger, relativ grosser Internlobus.

Reiflingites torosus steht dem Reiflingites fortis Mojs. sp. ') (pag. I47, Taf. XXVIII, Fig. 2, 3) sehr nahe. Die Unterschiede beider Formen liegen darin, dass Reiflingites fortis flache Flanken mit gröberen Rippen und auf dem Externtheile einen »dickfadenförmigen Kiel hat, während Reiflingites torosus stärker gewölbte Flanken mit schlankeren Rippen und einer sehr schwach hervortretenden Medianlinie oder Auftreibung hat. Bei Reiflingites fortis sind von dem abgebildeten grossen Exemplare keine Loben bekannt, weshalb weitere Analogien fehlen.

Von Reiflingites Eugeniae unterscheidet sich Reiflingites torosus durch seine stärker gewölbten und niedrigeren Windungen, sowie durch seine gröbere und spärlichere Berippung; auch sind hier die Lateralknoten nicht so deutlich differenzirt, wie dort.

\section{Reiflingites spec. indet.}

Zwei kleine Bruchstücke liegen vor, deren Erhaltungszustand so mangelhaft ist, dass er keine nähere Bestimmung derselben zulässt.

Das eine Stück zeigt die enggestellten gröberen Rippen mit dem undeutlich entwickelten Lateralund Umbilicalknoten, wie wir sie bei Reiflingites fortis kennen lernten, ohne indessen die dicke, drahtförmige Mittellinie des Convextheiles zu zeigen. Die Suturlinie zeigt einen grösseren ersten Laterallobus und kleinen zweiten auf der Flanke mit relativ weitgehender Bezahnung, zeigt also ungefähr den Lobentypus von Reiflingites torosus Art. und wäre in Ganzen wohl noch am ehesten an Reiflingites fortis Mojs. sp. (pag. I47, 'Taf. XXVIII, Fig. 2, 3) anzuschliessen.

Das andere kleine Stück, das nur eine Partie der Flanke ohne Externtheil aufweist, hat gröbere Rippen als das erste Bruchstück, welche enger gestellt sind und deutlich entwickelte Lateralknoten aufweisen. Die Umbilicalen sind nicht so deutlich differenzirt, jedoch besser als bei dem oben angeführten Bruchstücke.

Auch dieses Stück glaube ich noch am ehesten an Reiflingites fortis Mojs. sp. anschliessen zu können.

I) Mojsisosics E. ข., Cephalop. Medit. Triaspr. 
Reiflingites rota Art.

'Taf, VII, Fic. $6 a, b, c, d$.

Durchmesser . . . . . . . $60 \mathrm{~mm}$
Höhe der letzten Windung . . . . . $16=$
Dicke
Nabelweite. . . . . . . . $27=$

Der Externtheil ist flach gewölbt, zcigt aber eine etwas deutlicher ausgesprochene Scheitelpartie; die Flanken sind fast flach und erreichen in der Umbilicalpartie die grösste Dicke, was cinen annähernd trapezoildalen Querschnitt der Windung zur liolge hat; Marginal- und Umbilicalrand sind leicht abgestumpft, die Nabelwand nieder und senkrecht stehend; die Involution sehr gering und bedeckt nur den Convextheil und die Marginallinoten der früheren Windung, was einen sehr weiten Nabel bedingt.

Die Radialberippung besteht aus Haupt- mit inserirten Zwischenrippen; sie sind - auf dem Steinkern - eng gestellt, so wie bei Reiflingites Eugeniae, jedoch etwas massiver. Die Hauptrippen steigen flach, aber gut unterscheidbar über die Nabelwand herauf und schwellen stellenweise zu einem deutlichen Umbilicalknoten, meist aber nur zu einer undeutlichen knotenartigen Verdickung an, sobald sie die Flanke selbst erreicht haben. Diese verdickte Rippenstelle reicht nur bis zu $1 / 3$ der Flankenhöhe, wo ein kleiner, knopfähnlicher, stets deutlich entwickelter Lateralknoten aufsitzt. Hinter demselben verjüngt sich die Rippe abermals, erhöht und verdickt sich wieder ein wenig, verringert abermals đie Dicke, um auf dem Marginalrand selbst knotenähnlich in Breite und Höhe anzuschwellen, ähnlich wie auf dem Nabelrand, ohne einen entwickelten Knoten zu bilden. Die Rippe setzt sich sodann noch ein Stück auf dem Convextheil fort, verlischt aber noch vor Erreichen des Scheitels. Der Convextheil erscheint durch die von der Flanke dick herüberreichenden Rippen am Rande gekerbt, jedoch beiderseits in nicht ganz regelmässiger Weise, weil die Rippen nicht ganz genau correspondiren. Neben den Hauptrippen sind auf Extern- und oberem Flankentheile die Nebenrippen gleich stark entwickelt, verschwinden jedoch bald unterhalb der Anschwellung zwischer Marginalrandverdickung und Lateralknoten und erreichen nur in einzelnen Fällen die Höhe desselben.

Die Suturlinie steht in ihrer Entwicklung zwischen derjenigen von Reiflingites Eugeniae und Reiflingites torosus. Der Externlobus ist breit, jedoch niederer als bei beiden Formen und ist von einem niederen, ziemlich breiten Medianhöcker getheilt. Der erste Laterale ist bezüglich Höhe und Breite zwischen beiden Arten stehend, der zweite Laterale ist klein, so wie derjenige bei Reiflingites torosus; direct unterhalb des Nabelrandes folgt ein grosser flacher Auxiliar, der, wie es den Anschein hat, bis zur Naht reicht. Die Loben sind nur am Grunde gezähnt und zeigt der erste Laterale zwei etwas grössere Zacken. Die Sättel sind rundbogig und ganzrandig; der Externsattel ist der grösste, aber um eine Kleinigkeit niederer als der erste Laterale und liegt zum grösseren Theile auf der Flanke; der zweite Laterale ist viel kleiner als der erste und sein absteigender Ast reicht bis zur Nábelkante.

Reiflingites rota hat eine flach scheibenförmige Gestalt und ähnelt in vieler Beziehung sehr dem Ceratites celtitiformis Hauer $^{1}$ ) sp. (pag. I3, Taf. III, Fig. $2 a, b$ ). Jedoch hat dieser noch flachere Flanken, wenigstens das zur Abbildung gelangte Stück, das als Typus aufzufassen ist, hat gröbere und viel enger gestellte Rippen mit bedeutend höherem Lateralknoten. Die Zwischenrippen reichen meist in die Höhe des Lateralknotens, der hier umbilicaler gestellt ist, stellenweise auch noch darüber hinaus.

1) Hazer fr. $v$, Cephalop. Trias von Bosnien. 1892. 


\section{Unterfamilie: Stephanitinae Art.}

\section{Gattung: Acrochordiceras Hyatt.}

\section{Acrochordiceras nov. spec. indet.}

Das grösste der vorliegenden Bruchstücke besteht aus ungefälı einer Hälfte der letzten Windung und ist in der Mitte des Externtheiles gebrochen. Ueber denselben gemessen beträgt die Länge $72 \mathrm{~mm}$, die Windungshöhe circa $30 \mathrm{~mm}$. Der Externtheil ist breit gewölbt, ohne dass sich eine Marginalregion ausscheidet; der Nabel ist eng, der Nabelrand leicht gerundet und mit entfernt stehenden grossen Kinoten besetzt; die Nabelwand ist nicht sichtbar.

Die Berippung besteht aus groben, gegen den Externtheil zu anschwellenden Rippen, welche enggestellt sind und von denen zwei sich am Nabelrand vereinigen und einen dicken, stumpfen, horizontal gestellten Knoten bilden. Zwischen je zwei dieser vereinigten Rippen folgen drei Zwischenrippen, die, jede gesondert, über die Nabelwand hinabziehen.

Die Suturlinie ist nicht sichtbar.

Von den bekannten Arten erscheint als die nächststehende Acrochordiceras Damesi Nötling 1) (pag. 334, Taf. XV, Fig. I), der auch kürzlich von Hancr aus dem bosnischen Muschelkalk beschrieben worden ist (pag. 22, Taf. V, Fig. 2). Die neue Species hat eine ebensolche dick aufgeblähte Form, jedoch vereinigen sich bei Acrochordiceras Damesi regelmässig drei Radialrippen in einem Knoten, der in die Länge gezogen erscheint, und zwischen je zwei dieser vereinigten Rippen befinden sich ein bis zwei knotenlose Zwischenrippen, während bei der Reiflinger Species das Entgegengesetzte der Fall ist: drei Zwischenrippen und je zwei in einem Knoten vereinigte Hauptrippen.

\section{Acrochordiceras undatus Art.}

Taf. VII, Fig. $7 a, b, c$, Fig. 8

Von den zahlreich vorliegenden Bruchstücken entspricht das Grösste einem Exemplar mit ungefähr folgenden Maassen:

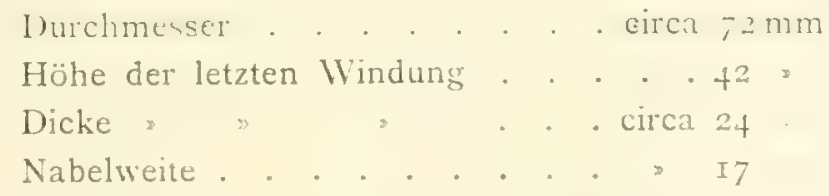

während das Kleinste einen Durchmesser von nur circa $15 \mathrm{~mm}$ hat.

Acrochordiceras undatus zeigt bei ausgewachsenen Stücken eine schlanke, hochmündige, rasch anwachsende Form der letzten Windung, kleinere Stücke haben mehr globose Gestalt. Bei Ersteren ist dementsprechend der Externtheil schmäler, bei Letzteren weiter gerundet und die Flanken weniger, respective stärker gewölbt. Ein Marginalrand scheidet sich in keinem Falle ab, der Umbilicale ist sehr deutlich entwickelt und nur die Kante leicht abgestumpft. Die Nabelwand ist hoch, flach convex gekrümmt; die Involution umfasst mehr als $1 / 2$ der früheren Windung; die Species ist überhaupt relativ engnabelig.

Die Radialberippung besteht aus gedrängt stehenden, spitzgerundeten groben Falten, welche schwach am Nabelrande beginnen, dann allmälig anschwellen und erst knapp vor Erreichen des Convextheiles die grösste Dicke erlangen. Sie sind vollständig knotenlos und vermehren sich gegen aussen durch Insertion; die inserirten Rippen unterscheiden sich durch nichts von den Primären, als dass sie nicht bis zum Nabelrand hinabreichen. Auf kleineren Stücken erfolgt diese Insertion nur 
in selteneren Fällen; meistens findet ein Zusammentliessen zweier Rippen am Nabelrand statt. Sie steigen, sehr schwach sichtbar, über die Nabelwand hinauf, weichen dann sofort, mit der 'l'enden\% nach vorne, stark von der lRadialrichtung ab, bilden auf der Flanke einen flachen concaven und auf dem Externtheil einen mässig starken convexen Bogen. Die Intercostalräume sind im Verhältniss zur Stärke der Rippen schmal.

Die Suturlinic ist bei einem kleinen Stücke vollständig und bei dem grossen, abgebildeten, nur stellenweise zu sehen. Fig. 7 c zeigt daher eine Suturlinie, bei welcher die Verhältnisse der kleinen Form auf die Flankenbreite der grossen übertragen sind.

Der Externlobus ist breit und von einem breiten, niedern Medianhöcker getheilt. Jeder Flügel zeigt einen grossen Zacken in der l'iefe und zwei kleine, lateral gestellte; der erste Laterallobus ist ausserordentlich tief, breit, am Grunde mit drei grossen Zacken und zwei kleineren Zähnen besetzt; der zweite ist sehr kurz, breit, und von der Basis mit zwei grösseren und zwei kleineren Zacken versehen. Die Sättel sind ganzrandig und ihre Scheitel reichen an eine radialstehende Linie heran; der Externe ist der grösste, an schmalsten der erste Laterale; der absteigende Sattelstamm des Externen und der aufsteigende des ersten Lateralen sind mit feinen Zähnen bis hoch hinauf besetzt; der zweite Lateralsattel liegt schon ganz auf der Nabelwand. Die Süttel uberhaupt sind flachbogig und im lerhältniss zu den Loben klein.

Auch hier scheint es, dass wir wieder eine Ausnahme von der Regel haben, dass die projicirte Involutionsspirale stets die Trennungslinie zwischen Lateral- und Auxiliarloben abgibt, und zwar im entgegengesetzten Sinne, wie bei Balatonites lineatus Art. (pag. 69), denn hier scheint eben diese Trennungslinie den grösseren Theil des zweiten Laterallobus abzutrennen. Ein anderer Schluss lässt sich aber noch aus der Stellung des zweiten Laterallobus ziehen, dass nämlich diese neue Species einen alten Typus repräsentirt, bei welchem der Lobus erst über die Nabelwand heraufgerückt ist und noch eine so tiefe Stellung auf der llanke bewahrt, dass er in Folge des Alters der Form nach grösstentheils innerhalb der Projectionsspirale fällt.

Acrochordiceras undatus schliesst sich an die beiden bis jetzt bekannten knotenlosen Formen aus der unteren Trias an: Acrochordiceras pustericum Mojs. ${ }^{1}$ ) (pag. I43, Taf. VII, Fig. 4) und Acrochordiceras enode Hauer $^{2}$ ) (pag. 24, Taf. VII, Fig. I) von Han Bulog; unterscheidet sich aber durch Verlauf und Vermehrung der Rippen und speciell von Acrochordiceras enode durch die Form der Suturlinie (vide Hancr, Taf. VII, Fig. I c), da diejenige von Acrochordiceras pustericum nicht bekannt ist. Acrochordiceras undatus ist ausserdem weitnabeliger als beide Formen.

\section{Acrochordiceras pustericum Mojs.}

I878. Trachyceras pustericun Mojsisozics E. \%, Dolomitriffe von Süd.Tirol und Venetien, pag. 27 S. 1882. Acrochordiceras pustericum Mojsisovics E. v, Cephalop. Medit. Triaspr., pag. I43, Taf. VI, Fig. 4

Obgleich nur ein kleines Bruchstück vorliegt, so genügt dasselbe doch, um diese Species bestimmen zu können. Wir sehen eine rasch anwachsende Form mit kleinem Nabel, flachem Lateralund gekrümmtem Externtheil.

Die Radialsculptur besteht aus ziemlich flachen Rippen, welche geradlinig und genau radial über Flanken und Externtheil ziehen und sich entweder knotenlos am Umbilicalrand vereinigen oder im unteren Flankentheil dichotomiren.

Die Suturlinie ist nicht sichtbar.

Unter den bis jetzt bekannt gewordenen Acrochordiceras-Arten sind, wie schon früher erwähnt, nur zwei Arten knotenlos, und nur diese kommen bei der Bestimmung des vorliegenden Bruchstückes,

1) Mojsisovics E. $\nu_{0}$, Cephalop. Medit. Triaspr.

Hlater Fr. z., Cephalop. Trias von Bosnien. I892. 
das zu einem Individuum von circa $45 \mathrm{~mm}$ Durchmesser gehört, in Betracht: Acrochordiceras enode Hauer $^{1}$ ) (pag. 24, Taf. VII, Fig. I) und Acrochordiceras pustericum Mojs., mit dem das Stück identificirt wurde.

Beide Formen ähneln sich, nur ist Erstere stärker aufgebläht und etwas evoluter. Ich entschied mich für die Identificirung mit Letzterer, weil das Reiflinger Stück der engnabeligen und flacheren Form angehören dürfte und ausserdem die feine Radialstreifung der Schale zcigt, welche die Abbildung von Acrochordiceras pustericum aufweist, deren jedoch der T'ext nicht Erwähnung thut.

\section{Acrochordiceras enode Hauer.}

1892. Acrochordiceras enode Haucr Fr. v., Cephalop. Trias von Bosnien, pag. 24, Taf. Vril, Fig. I.

Die vorliegenden Stücke sind bedeutend kleiner als die von Hantr beschriebenen Exemplare; das Grösste hat einen Durchmesser von $32 \mathrm{~mm}$; sie scheinen daher Jugendformen dieser Species vorzustellen; sie sind hochmündig, stark involut und engnabelig. Im Gegensatze zur Beschreibung von Acrochordiceras enode ist die Nabelkante hier nicht sehr scharf markirt, sondern der Rand leicht abgestumpft.

Die enggestellten Rippen schwellen ebenfalls gegen den Externtheil zu an, wo sie sich leicht convex nach vorne wenden; das Flacherwerden derselben auf der Aussenseite ist charakteristisch für die ausgewachsene Form.

Die Suturlinie zeigt ebenfalls gewisse Differenzen mit der in Fig. I $c$ gegebenen, die wohl nur auf theilweise Fehlerhaftigkeit der Zeichnung zurückzuführen sind. Der Externlobus ist von einem schmalen, steilen Medianhöcker getheilt und zeigt nicht einen langen, sondern zwei grössere Zacken und zahlreiche Zäckchen, die sich aber auf die Flankentheile (nicht auch die Medianseite) beschränken. Der erste Laterale ist sehr gross, tief und breit, der zweite bedeutend kleiner, jedoch relativ gross, breit und von etwas grösserer Tiefe wie der Externe. Beide sind mit je zwei grösseren Zacken am Grunde und zahlreichen grösseren und kleineren Zäckchen auf den Sattelstämmen besetzt; rom Nabelrand halbirt, folgt ein niederer, grosser Auxiliar mit gezacktem Grunde, und über die Umbilicalwand hinab folgen weitere Auxiliarelemente. Die Sättel sind fast von gleicher Höhe; am niedersten steht der zweite Lateralsattel. Der breiteste ist der Externe, die beiden Lateralen fast gleich schmal. Die Sattelstämme sind, wie schon erwähnt, reich geschlitzt, jedoch steigen die Zacken nicht bis zum Scheitel hinauf, der ganzrandig bleibt.

\section{Acrochordiceras nov. spec. indet}

Taf. VII, Fig. Io $a, b$.

Ein Bruchstück der äusseren Windung. Ueber den Externtheil gemessen beträgt die

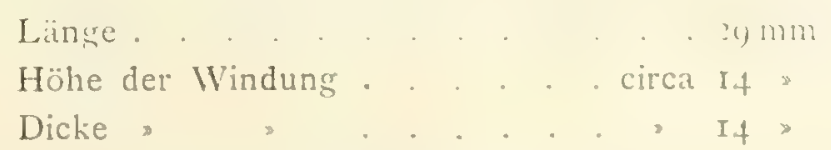

Der Durchmesser dieşer Form dürfte daher ungefäh $28 \mathrm{~mm}$, die Nabelweite circa $6 \mathrm{~mm}$ betragen.

Der Externtheil ist flach gewölbt; die Flanken schwellen erst gegen die Umbilicalregion an und enden in einem leicht gerundeten Nabelrand; die Umbilicalwand ist hoch und leicht convex gewölbt; ein Marginalrand scheidet sich nicht ab. Die Involution der engnabeligen Form beträgt ungefähr $1 / 2$ des früheren Umganges; die Windungen wachsen langsam an.

1) Hhuer fir. $y$, Cephalop. 'Trias yon Bosnien. ISgz. 
Die Radiaberippung besteht aus enggestellten, gegen den Externtheil zu anschwellenden kräftigen Rippen, welche radial auf der Illanke und leicht convex nach vorne gebogen auf dem Iiterntheil verlaufen; sie beginnen am Nabeliand und je zwei vereinigen sich in einem grossen, stumpfen und ungefäh $3 \mathrm{~mm}$ hohen Umbilicalknoten; zwischen zwei solchen Rippenpaaren treten zwei Zwischenrippen auf, von denen die eine am Nabelrand beginnt, die andere noch vor Erreichen desselben erlischt.

Die Suturlinie ist nicht bekannt.

Diese kleine Art differirt schon durch ihre Grösse vollständig von den bis jetzt bekannten Formen, denn bei der kräftigen Berippung und dem scharf ausgeprägten Habitus dieser Species ist doch wohl die Möglichkeit ausgeschlossen, dass wir es nur mit ciner Jugendform zu thun hätten.

\section{Acrochordiceras erucosum $\mathbf{\Lambda}$ t.}

T'af. VII, Fig。 $9 a, b, c$.

Durchmenser . . . . . . . 15 17
Höhe der letzten Windung
Dicke
Nabelweite. . . . . . . . . $5=$

Diese kleine, rasch anwachsende Form hat einen rundlichen, seitlich etwas zusammengedrückten Querschnitt, an welchem man einen grossen, flach gewölbten Convextheil, eine Art von niederer, flacher Flanke, mit meist undeutlich markirtem Marginal- und besser entwickeltem Umbilicalrand mit schwach convex gekrümmter Nabelwand ausscheiden kann. Die enggenabelte Form ist sehr stark involut, so dass ein kleiner, sehr steil eingesenkter Nabel resultirt.

Die Berippung wird aus, über die Nabelwand fein heraufziehenden, später immer mehr anschwellenden, enggestellten Rippen gebildet; sie verlaufen anfangs radial, dann sind sie - besonders auf dem Convextheile - leicht convex nach vorn gebogen und tragen zwei Knotenspiralen, was eben als eine Art von Umbilical- und Marginalknotenbildung zu bezeichnen ist. Auf der letzten Windung finden sich bei dem abgebildeten Stücke drei solcher radial übereinander stehender Knotenpaare. Jedoch liess sich bei sämmtlichen vorliegenden vier Exemplaren keine Gesetzmässigkeit, bezüglich der Vereinigung der Rippen in den Knoten mit Sicherheit feststellen, indem stets gewisse Variationen vorwalten. Aus diesen Gründen ergibt sich ungefähr folgende Regel: eine etwas verdickte Rippe steigt über die Nabelwand hinauf und trägt auf dem Nabelrande einen kleinen, stumpfen Knoten, in welchem sie sich in zwei Theile spaltet. Beide Theile tragen in der Höhe der Marginalkante Anschwellungen; die eine ist schwach, die andere grösser und sogar bedeutender als der umbilicale Knoten; in ihm gliedert sich eine weitere Rippe an, welche sofort die Stärke der Primären erlangt; es ist stets die gegen vorn folgende Rippe, welche sich angliedert. Wir haben somit drei Rippen, welche zwei grosse und einen ganz kleinen flachen Knoten tragen; zwischen je zwei solcher knotentragenden Rippenpaare verlaufen vier Zwischenrippen, die in der Höhe der beiden Knoten ganz schwache Anschwellungen aufweisen.

Die Suturlinie zeigt flach bogenförmigen Terlauf, indem Extern-und zweiter Lateralsattel auf gleicher Höhe stehen und der erste Laterale am weitesten hinaufreicht. Der Externlobus ist breit und tief und ist von einem niederen, kegelförmigen Medianhöcker getheilt; von den beiden Flügeln des Lobus trägt jeder ein feines, lateral gestelltes Zäckchen und einen schräg herabhängenden Zacken. Der erste Laterallobus ist breit, gross, viel tiefer als der Externe und zeigt am Grunde zwei grosse Zacken und zwei lateral gestellte Zähnchen; der zweite Laterale ist breiter als der erste, jedoch sehr kurz, ungefähr nur $1 / 2$ so tief als jener und hat dieselbe Vertheilung der Zacken. Von den Sütteln ist der Externsattel der grösste; der erste Lateralsattel wird von der Marginallinie halbirt und der 
zweite liegt schon fast ganz auf der Nabelwand; sie sind ganzrandig und auch den Sattelstämmen fehlt jede Spur der Bezahnung.

Diese neue Species, die sich durch ihre dicke, raupenförmige Gestalt auszeichnet, unterscheidet sich sehr scharf von den bis jetzt bekannten Formen, die gar keine Analogien bilden, durch die Ausscheidung einer Art von Flanke, begrenzt durch zwei mehr oder weniger deutliche Spiralen, welche stellenweise als zwei grosse, stumpfe Knoten übereinander stehen. Die Vertheilung und Form der Suturglieder erinnert in gewissem Sinne an den von Mojsisovics aus der Trinodosus-Zone beschriebenen und abgebildeten Acrochordiceras Carolinae Mojs.') (pag. I4I, Taf. XXVIII, Fig. I4, Taf. XXXVI, IFig. 3).

\title{
II. Ordnung: Leiostraca Mojs. \\ I. Unterordnung: Arcestidea Waag.
}

\author{
Familie: Arcestidae Waag.
}

Unterfamilie: Arcestinae Mojs.

Gattung: Arcestes Suess.

Arcestes ventricosus Hauer.

ISg2. Arcestes ventricosus flaur Fr. v., Cephalop. a. d. Trias von Bosnien, pag. 29, Taf. VII, Fig. 4, Taf. VIII, Fig.3, Taf. IX, Fig. I $a-d$.

Durchmesser . . . . . . . . . . . . . 4 $4 \mathrm{~m}$
Höhe der letzten Windung . . . . . . . . . . . . . 43
Dicke 4
Nabelweite 4

Der Externtheil ist relativ hochgerundet, die Flanken, gegen die Unbilicalregion aufgebläht, erlangen knapp oberhalb des Nabelrandes die grösste Dicke; der Nabelrand ist gerundet, die Umbilicalwand hoch und fast senkrecht stehend. Die Involution ist sehr gross und lässt nur einen ganz kleinen Nabel offen, der bei zunehmendem Alter sich immer mehr zu schliessen scheint.

Die Schale ist mit inneren Schalenleisten versehen, welche auf dem Steinkern als tiefe, breite Furchen hervortreten. Solche Labien finden sich - wohl nur in Folge des Erhaltungszustandes - vier auf dem letzten Umgang; sie zeigen vom Nabelrande auslaufend bis in circa $3 / 4$ der Flankenhöhe zuerst ein nach vorne flach concaves Stück, wenden sich dann knieförmig nach rückwärts und ziehen in einem stärkeren concaven Stück über den Externtheil. Die Labien sind in der Umgebung der knieförmigen Biegung am tiefsten und zeigen in ihrem ganzen Verlauf einen leicht wulstförmig-verdickten Vorderrand. Die Schale hat feine Radialstreifung, bestehend aus feinen Linien, welche am Nabelrand sehr enggestellt sind, in einem flachen Bogen über die Flanke ziehen und den Externtheil, woselbst sie ungefähr $2 \mathrm{~mm}$ von einander abstehen, gerade übersetzen.

Die Suturlinie ist bei dem vorliegenden Stücke in Iolge Ausfüllung der Luftkammer mit grobem Kalkspath nicht besonders deutlich zu sehen, entspricht aber der von Haucr abgebildeten: Ein breiter Externsattel, spitzgerundete Lateralsättel, alle reichgeschlitzt so wie die Loben.

Dic feine Schalenstreifung, welche sich auch - obgleich nicht besonders erwähnt - auf den bosnischen Originalien finden, kommt sonst bei mediterranen Arcesten wie es scheint nicht häufig

1) Mojsisorites LE. 2 , Cephalop. Medit. Triaspr. 
vor: Sie sind nur bei Arcestes subtridentinus Mojs.') (pag. 156, 'laf. XLIII, Iig.g. I-3, und 'Taf, XLIV Fig. I-3) erwähnt und finden sich dann erst wieder bei Ioannites trilabiatus Mojs. (ibid., pag. I67, Taf. XLII, Fig. 2) und Ioannites tridentinus Mojs. (ibid., pag. I68, Taf. XLVII); bei ersterer Form sind diese Radialstreifen auf dem Externtheil ausserdem noch von enggestellten Spiralstreifen übersetz.

\section{Anhang.}

Nov, gen. indet.

Taf. VIII, Fig. 10 a, $b$.

Durchmesser . . . . . . . $34 \mathrm{~mm}$
Höhe der letzten Windung
Dicke

Die Gestalt ist dick scheibenförmig; der Externtheil stumpfgerundet; die Flanken sind nur wenig gewölbt und erlangen ungefähr in der Seitenmitte die grösste lBreite; ein Marginalrand ist nicht entwickelt, ebenso wie der Umbilicale nur auf den früheren Umgängen in undeutlicher Form auftritt; auf der letzten Windung ist der Nabel callös verschlossen. Die Schale ist glatt und nur mit zahlreichen, sehr feinen, annähernd radial verlaufenden Anwachsstreifen bedeckt, welche jedoch auf der Flanke einen, gegen vorne leicht concaven Verlauf zeigen, der auf dem Externtheil sich in einen leicht convexen umsetzt.

Auf dem Steinkern treten bei dem vorliegenden Bruchstücle drei lurchen auf, welche inneren Schalenleisten - Varices - entsprechen. Sie haben denselben Verlauf wie die Zuwachsstreifen; die Ränder dieser Steinkernfurchen sind leicht verdickt und auf der äusseren Schale werden die innerlichen Leisten durch stärkere Entwicklung der beiderseitigen Zuwachsstreifen kenntlich.

Die Länge der Wohnkammer beträgt wenigstens einen Umgang, scheint dieses Maass jedoch zu überschreiten.

Der ungünstige Erhaltungszustand des vorliegenden Stückes lässt leider keine genaue Bestimmung der Suturelemente zu. Durch Entfernung eines T'heiles des letzten Umganges war es möglich, gekammerte Partien der vorletzten Windung blosszulegen. Leider sind dieselben mit so grobkörnigem Spathe erfüllt, dass die Lobenzeichnung hiedurch voliständig undeutlich wird. Man kann nur eben so viel constatiren, dass die Sättel ganzrandig, die rundlichen Loben ebenfalls ungezackt sind und in eine mediangestellte Spitze auslaufen. Es scheinen zwei Lateralloben und drei Auxiliare aufzutreten; der Externlobus war gar nicht sichtbar.

Die Frage, warum ein so ungenügend charakterisirtes Exemplar überhaupt zur Beschreibung gelangt, hat hier allerdings eine scheinbare Berechtigung. Bedenkt man hingegen, dass schon zwei ähnlich schlecht erhaltene und ähnlich aberrante Formen, wie die vorliegenden, in die Literatur Eingang gefunden haben, so hat auch die Anführung des vorliegenden Stüches ilıre Erklärung und Begründung theilweise gefunden.

Die oben beschriebene Form erinnert im Lobentypus nicht unbedeutend an die Lobitinen, und in der That finden wir bei dem aus der Archelaus-Zone durch E. $\%$. Iojsisoutics') beschriebenen Stücke, das er als Lobites nov. fo indet (pag. I 79, Taf. XXXIX, Fig. 3) anführt, eine sehr ähnliche Suturlinie wieder. Auch von dieser Art ist nur ein Bruchstück erhalten, das eine ähnliche Gestalt wie das Reiflinger Exemplar hat, jedoch enggenabelt ist, auch keine Furche aufweist, was sich freilich leicht damit erklären lässt, dass die Schale noch vollständig erhalten ist und daher die eventuell vorhandenen Varices unmöglich zeigen konnte.

Noch eine andere Form lässt sich hier zum Vergleiche heranziehen: die von E. w. Hojsisovics loc. cit. aus der Trinodosus-Zone der Schreyeralm angeführt und als „Cyclolobus? indet « (pag. I fI, 
Taf. XXXVI, Fig. 4) beschrieben und abgebildet wird. Auch hier finden wir dieselbe äussere frorm wieder, auch die Steinkernfurchen treten wieder auf und so wie bei dem Lobiten aus den Wengener Schichten ein enger Nabel. Jedoch scheint die Lobenlinie des, allerdings auch sehr schlecht erhaltenen Stückes zu differiren, denn sie zeigt wohl ähnlich ganzrandige Sättel, scheint jedoch zahlreichere Auxiliarelemente zu besitzen, die in dieser Anzahl sowohl dem Reiflinger Lxemplare als dem oben angeführten Lobiten fehlen. In keinem der drei angeführten Fälle erlaubt es jedoch đer Erhaltungszustand, die systematische Stellung genau zu fixiren.

Ich stelle das Reiflinger Exemplar nur deshalb in die Nähe von Arcestes, weil erstens die Steinkernfurchen einen ähnlichen Verlauf wie die bei Arcestes auftretenden haben: weil ferner der callös verschlossene Nabel sich ebenfalls dort findet, z. B. bei Arcestes Escheri Mojs. (ibid., pag. I62, Taf. XLVI, Fig. 7-9), während er anderen Arcesten wieder fehlt, und drittens, weil die Suturlinie ganzrandige Sättel zeigt, während dieselben bei den Ioannitinen gespalten sind. Diese Form wäre dann vielleicht als Vorläufer von Arcestes aufzufassen, bei welcher die Lobenelemente noch ganzrandig sind, während sie bei Arcestes selbst schon gegliedert sind; auch wäre ihr die oben erwähnte Lobitesform vielleicht als Form mit offenem Nabel anzuschliessen.

\section{Familie: Cladiscitidae Zitt.}

\section{Gattung: Procladiscites Mojs.}

\section{Procladiscites Brancoi Mojs.}

1882. Procladiscites Brancoi Mojsisozics $E$ : :, Cephalop. Medit. Triaspr., pag. I7I, 'Taf. XILVIII, Fig. I, 2.

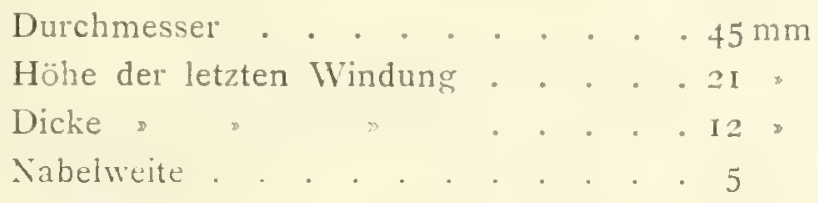

Wir haben es hier zweifelsohne mit einem jüngeren Individuum $z u$ thun, das bis zum Ende gekammert erhalten ist. Es hat noch schlankere Form als die bei Mojsisorics abgebildeten Exemplare, was wohl auf die grössere Jugend zurückzuführen ist, wenigstens hat ein kleineres Exemplar meines Materiales, das nur einen Durchmesser von $30 \mathrm{~mm}$ aufweist, noch geringere Dicke, als sie relativ das grössere Stück von Mnjsisorics besitzt. Dass Procladiscites Brancoi in der Jugend eine schmälere Scheibe als im Alter bildet, geht übrigens schon aus der Abbildung Fig. $2 b$ hervor, auf welcher wir sehen, dass der Anfang der letzten Windung einen höher gewölbten Externtheil besitzt als das Ende desselben. Andererseits haben jüngere Exemplare einen relativ weiteren Nabel, der sich bei zunehmendem Alter immer mehr und mehr verengt. Das abgebildete Exemplar hat einen Durchmesser von $69 \mathrm{~mm}$ und eine Nabelweite von $5 \mathrm{~mm}$; das grössere Reiflinger Exemplar hat bei einem Durchmesser von $45 \mathrm{~mm}$ dieselbe Nabelweite, und das kleinere Stück von $30 \mathrm{~mm}$ hat fast $41 / 2 \mathrm{~mm}$ Nabel. weite. Somit scheint sich die Vermuthung E. Mojsisovics' zu bestätigen, dass bei vollständig ausgewachsenen Individuen der Nabel verschlossen wird, ähnlich wie es die Cladisciten thun.

Die Suturlinie, welche bei beiden Exemplaren gut sichtbar ist, hat nur den einzigen Unterschied aufgewiesen, dass der Externlobus etwas tiefer als bei Procladiscites Brancoi (Fig. $2 i^{\circ}$ ) ist, jedoch nicht die Tiefe desjenigen von Procladiscites Griesbachi Mojs. (ibid,, pag. 172, Taf. XLVIII, lig. 3 und 4 ) erreicht. Ausserdem treten nicht acht, sondern nur sieben Auxiliarloben auf; bei dem kleineren Stïcke scheinen nicht einmal sieben vorzukommen.

Procladiscites Brancoi Mojs. fand sich ausser auf der. Schreyeralm (Trinodosus-Zone) auch im bosnischen Muschelkalk. ${ }^{1}$ )

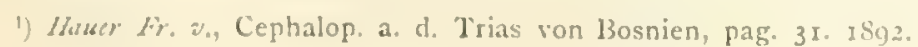




\title{
2. Unterordnung: Pinacoceratidea Waag.
}

\section{Familie: Pinacoceratidae lischer.}

\section{Gattung: Pinacoceras Mojs.}

\author{
P'inacoceras cfr, Damesi Mojs.
}

1882. Pinacoceras Damesi Mojsisovics $E$, v., Cephalop. Medit. Triaspr, pag. I95, Taf. III, I'ig. 9.

Durchmesser . . . . . . . . $15 \mathrm{~mm}$
Höhe der ersten Windung . . . . . . . . . . . . . . . . . .

Der Externtheil des stark verdrückten und grösstentheils als Steinkern erhaltenen Stückes zeigt einen abgestutzten Externtheil, flach gewölbte Flanken, welche die grösste Dicke im unteren Theile erlangen; die Narginalkante ist deutlicher entwickelt, während die Umbilicale fast gerundet erscheint; die Nabelwand ist sehr nieder. Die Involution umfasst etwas über $1 / 2$ der letzten Windung; der Nabel ist gross; die Umgänge bilden eine sehr flache Scheibe.

Die Schale ist faltenlos, scheint aber mit feinen Schalenstreifen besetzt zu sein.

Die Suturlinie ist nur wenigr sichtbar; ihr Gesammtverlauf unterscheidet sich aber insoferne von Pinacoceras Damesi, dass keine herabhängenden Nahtloben sich finden, sondern die Suturlinie in einem flachen Bogen die Flanke übersetzt.

\section{Gattung: Sageceras Mojs.}

\section{Sageceras Walteri Mlojs.}

1874. Sageceras Walteri Mojsisovics; C. .7\%. Panl, Die Trias in der Butowina, Verhandlg. k. k, geol. 12.A., pag. 363.

I879. Sageceras carpathicum Mojsisovics, Ueber einige neue Funde von Fossilien in den Ost.Karpathen, Verhandlg. $k$. k. geolog. R.-A., pag. 189 .

IS82. Sageceras Walteri Mojsisovics, Cephalop. Medit. Triaspr., pag. IS7, Taf. LIII, Fig. 9, II-I3.

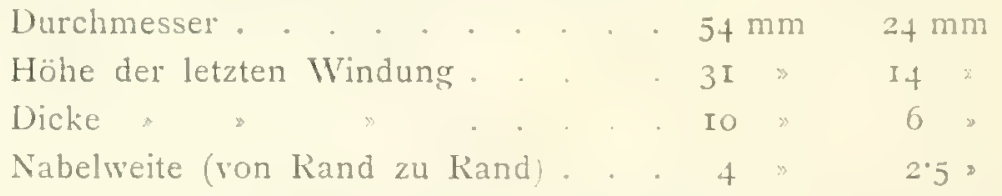

Das grösste und kleinste der vorliegenden Exemplare hat die oben angefühnten Maasse, welche ungefähr mit den von Mojsisovics angeführten Dimensionen der dickeren Varietät übereinstimmen.

Die Exemplare sind als Steinkerne erhalten, zeigen einen auffallend schmalen, gerundeten Externtheil ohne Randleisten, welche somit nur der Schale zukommen. Die Seiten sind flach und haben in der Umbilicalregion die grösste Dicke, wodurch sich um den Nabel herum eine Art ron IVulst bildet, der jedoch nicht bis zur Nabelkante selbst reicht, sondern sich vor dieser, die randlich etwas verdiclit ist, deprimirt.

Die Lobenlinie ist sehr schön zu sehen, zeigt im Ganzen einen leicht bogenförmigen Verlauf, der sich gegen den Nabel zu fast gerade streckt und die grösste Convexität in der Flankenmitte aufweist.

Der Externlobus ist sehr klein und durch einen relativ grossen Medianhöcker in zwei niedere, kleine Spitzen getheilt; hieran schliesst sich eine Serie von Adventivloben, beim grossen Exemplar in der Siebenzahl, beim kleinen jedoch nur fünf; sie nehmen gegen die Mitte an Grösse zu, ihr Grund ist zweispitzig; nun folgen vier Haupt-Lateralloben, von denen der erste wohl die grösste Tiefe 
erreicht, jedoch an Breite dem vierten entspricht; an Breite folgt sodann der zweite, und der dritte Laterallobus erst ist der breiteste. Ihr Lobengrund ist in der Weise gezackt, dass die Mitte des Lobus einen hohen Spitzbogen aufweist, dessen Fuss nach aussen abgeschrägt ist, wodurch zwei Zacken entstehen; die Auxiliarloben sind von ähnlicher Form wie die Adventivelemente, nur kürzer und beim grossen Exemplar in der Fünfzahl entwickelt.

Wir sehen die beiden von Mojsisovics abgebildeten Typen der dickeren und schmäleren Varietät insoferne variirt, dass bei annähernd gleicher Flankendicke der ersteren Varietät der Externtheil so schmal wie bei der zweiten erscheint, und dass bei einem Durchmesser von $54 \mathrm{~mm}$ die Ausschnürung des bis dahin sehr engen Nabẹls erst beginnt.

\section{Gattung: Megaphyllites Mojs.}

\section{Mlegaphyllites procerus Art.}

Taf. VII, Iijg. II $a, b, c, d$.

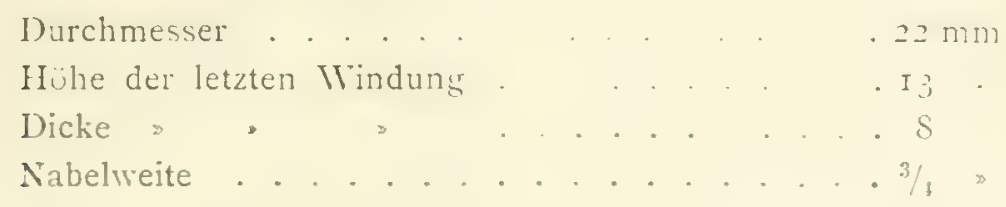

Der Externtheil ist ziemlich flach gewölbt, die Flanken, aufgebläht, erlangen in der Umbilical. region die grösste Dicke, von wo aus sie etwas flacher gegen den Externtheil und rascher gegen den Nabel abfallen; weder eine Marginal- noch Umbilicalkante sind vorhanden; der Nabel selbst ist callös verschlossen.

Auf der Flanke sieht man sehr feine Schalenstreifen, welche vom Nabelrand ausgehend auf der Flanke ein flach concaves Stück bilden und den Externtheil in einem kurzen, ziemlich flachen Converstück übersetzen. Auf dem Steinkern treten, so wie bei den anderen Megaphylliten, Ringfurchen auf, welche inneren Schalenwülsten entsprechen und sich äusserlich durch schwache Verdickung der Schale mehr oder weniger deutlich charakterisiren. Sie haben einen ähnlichen Verlauf wie die Schalenstreifen und scheinen mir im Gegensatze zu Arojsisorics ${ }^{1}$ ) (pag. Igo) eher auf dieselben Ursachen wie die Labien bei Arcestes zurückzuführen zu sein. Auch finden sie sich, bei vier von sechs Exemplaren, deutlich wahrnehmbar schon auf Luftkammertheilen und treten somit nicht erst auf der Wohnkammer selbst auf, denn eben jene vier Exemplare sind bis zum Ende noch gekammert.

Die Suturlinie ist radial verlaufend und zeigt nur eine minimale convexe Wölbung im oberen Theile der Flanke. Der Externlobus ist breit, nieder und ist von einem Medianhöcker getheilt, dessen Kopf eingesenkt ist; die beiden Flügel enden in je eine Spitze und haben auf der Lateralseite zwei grosse und einen kleinen Zacken. Die projicirte Windungsspirale trifft den dritten Laterallobus, weshalb drei Lateralloben anzunehmen sind. Sie haben so ziemlich dieselbe Gestalt, sind rundlich und mit kräftigen Zacken besetzt; der erste Laterale ist der" grösste, reicht tiefer hinab wie der Externe und trägt einen grossen mittleren und je zwei seitliche Zacken; der zweite und dritte Laterale haben dieselbe, jedoch verjüngte Gestalt und am Grunde zwei kleinere und höher seitlich gestellt je einen Zacken. Dann folgen gegen den Nabelrand zu drei kleinere zweizackige und fünf winzige einspitzige Auxiliarloben. Wir haben somit bei einem Exemplar von der Grösse des abgebildeten elf laterale Lobeneinheiten. Die Sättel sind ganzrandig, kugelförmig; am höchsten und breitesten ist der Externe, die anderen in abnehmender Grösse; die Sattelköpfe sitzen auf sich verjüngenden Stielen auf.

Megaphyllites procerus unterscheidet sich von den anderen Arten erstens durch die bedeutendere Schlankheit der Form, die ihre grüsste Dicke nicht in der oberen, sondern in der Umbilicialregion 
erlangt; ferner durch die feine linienförmige Streifung der Schale, welche sonst nicht vorkommt, ausser bei Megaphyllites Jarbas Münster sp. ${ }^{1}$ ) (pag. I93, 'Taf. LIII, Fig. 7, 8), wo sie aber im 'Texte nicht erwähnt und daher wohl fraglich ist. Nach Mrojsisozics (pag. 190) sind fünf Lateralloben anzunehmen, welche auswärts der Projectionsspirale fallen. Vergleicht man aber die Abbildungen, so findet man stets, dass die Spirale den dritten Laterallobus trifft, was sich auch bei der Reiflinger Species wiederholt.

An Schlankheit ähnelt diese neuc Art dem, von Hener aus der T'rias von Bosnien (pag. 32, Taf. X, Fig. 3) abgebildeten Megaphyllites sandalinus Mojs., der aber einen relativ sehr grossen Nabel aufweist.

\section{Familie: Noritidae Waag. \\ Gattung: Norites Mojs.}

Die von Mojsiswics aufgestellte Gattungsdiagnose erfährt durch die im Folgenden gegebenen Resultate insoferne einige Abänderungen, dass der Zacken im Medianhöcker nicht als Charakteristicum aller Noriten gelten kann, da er sich nicht bei allen Reiflinger liormen fand. Dem in der Folge beschriebenen Norites cfi: gondola Mojs. fehlt derselbe, und zwar nicht nur bei einem grossen, sondern auch bei einem kleinen Exemplar. Er scheint daher kein ausnahmsloses generelles Merkmal zu sein, sondern eher nur individuelle Bedeutung zu haben und besonders bei jenen Formen aufzutreten, welche in sehr naher Verwandtschaft mit Pronorites stehen.

Ferner ist auch die Gabelstellung der Zacken des ersten Laterallobus nicht generell zu verwerthen. Sie findet sich bei einzelnen Species und fehlt anderen. Bei dem als Norites apioìdes (Taf. VIII, Fig. 3) abgebildeten Exemplar ist sie auf der einen, zu stark abgefeilten Flanke zu sehen, und fehit der anderen, diesbezüglich mit Sorgfalt nur sehr wenig abgeschliffenen Seite. Sie ist also nur ein nebensächliches Merkmal.

Von grösserer Wichtigkeit ist aber das Auftreten ron nur zwei Lateralloben statt drei, welche sich gleichmässig bei allen Noriten finden, die bis jetzt bekannt geworden sind, und zwar nicht nur bei den neuen Reiflinger Arten, sondern auch bei der von Han Bulog beschriebenen Form ebenso wie - der Zeichnung nach — auch beim Originale von der Schreyeralm.

\section{Norites gondola Mojs.}

I882. Ammonites gondola Mojsisorics. Beiträge zur Ľenntniss der Cephalopodenf. des alpinen Muschelkalkes. Jahrbuch k. k. geolog. R.A.. pag. 58 , Taf. XV, Fig. 3 .

1882. Norites gondola Mojsisorics, Cephalop. MIed. Triaspr, pag. 202, Taf. LII, Fig. 5-S.

Durchmesser . . . . . . . . . $39 \mathrm{~mm}$
Höhe der letzten Windung . . . . . 22 ,
Dicke $\$$. . . . I

Das vorliegende Stück ist als Steinkern erhalten, bis zum Ende gekammert und zeigt sehr schön die Suturlinie. Es gehört der von Mojsisovics erwähnten flacheren Varietät an und zeigt nur kleine Reste der Schalenbedechung, was auch die Ursache ist, dass keine Spur der Randkiele oder der erwähnten Mittellinie des Externtheiles mehr sichtbar ist.

Die Suturlinie weist gewisse Differenzen auf; der kleine herabhängende Zacken am Kopfe des Medianhöckers im Externlobus ist so reducirt, dass er nur mehr als feine, seitwärtsgerückte Spitze auftritt. Die beiden Flügel des Externlobus sind an ihrem äusseren lateralen Ende mit zwei bis drei feinen Zähnen besetzt.

1) Mcisisozics E. Z., Cephaiop. Medit. Iriaspr. 
Bei Norites gondola Mojs. sowohl wie bei sämmtlichen anderen Noriten meines Materiales finden sich lieineswegs drei, sondern nie mehr als zwei Lateralloben, da in jedem Falle die Projectionslinie der vorletzten Windung den zweiten Lateralsattel trifft und nur in einem Falle - Norites cfr. gondola Mojs. - ein kleines Stück des dritten lateralen Lobenelementes abtrennt. Von diesen zwei Lateralloben zeigt der erste deutlich, der zweite undeutlicher die Gabelstellung der Lobenzacken; gegen den Nabel zu folgen fünf immer kleiner werdende Auxiliarloben; der Externsattel ist nieder und breit; der erste Laterale schmal und hoch; die Sättel sind alle ganzrandig und sitzen auf verjüngten Stielen auf. Der Verlauf der ganzen Lobenlinie zeigt eine bedeutende Höhendifferenz zwischen Extern und erstem Lateralsattel, während die anderen Sättel an einer geraden, rasch zum Nabel absinkenden Linie stehen.

\section{Norites cfr. gondola Mojs.}

Taf. VII, Fig. I2 $a, b$.

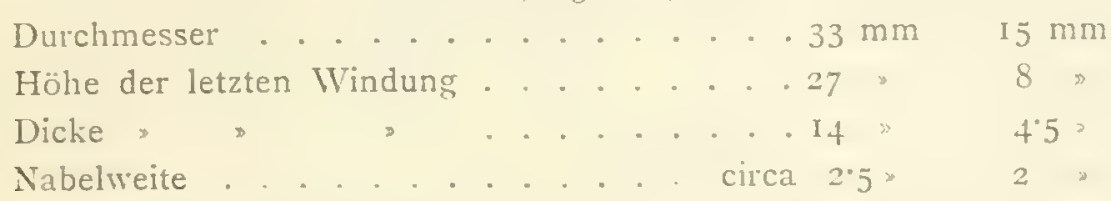

Diese Form, die ihren nächsten Anschluss an Norites gondola ${ }^{1}$ ) findet, steht der dort citirten dickeren Varjetät sehr nahe. Die Stücke sind als Steinkern erhalten und bis zum Ende gekammert. Die Aufblähung im umbilicalen Theile der Flanke ist hier noch stärker wie dort, was schon aus den Maass. zahlen hervorgeht, indem bei dem grössten der vorliegenden Stücke dem Durchmesser von $33 \mathrm{~mm}$ eine grösste Dicke von I 4 mm entspricht, während das Verhältniss dieser Maasszahlen bei dem von Mojsisovics beschriebenen Stücke gleich $36^{\circ} 5$ : I 2 ist.

Einen anderen Unterschied finder wir in der Grösse des Nabels, der bei der Schreyeralm-Form ungleich grösser ist, während wir hier bei bedeutend grösserer Flankenhöhe einen viel kleineren Nabel finden.

Das kleinste Stück von $15 \mathrm{~mm}$ Durchmesser hat einen um $0^{\circ} 5 \mathrm{~mm}$ kleineren Nabel, was dafür sprechen würde, dass Norites cfr. gondola bei weiterem Wachsthum seinen Nabel wieder zu verengen beginnt.

Bezüglich der Lobenelemente finden wir wieder einige weitere Variationen. Aehnlich der Reiflinger Form des Norites gondola erreicht auch hier der Externlobus fast die Tiefe des ersten Lateralen, zeigt aber keine Spur mehr einer Zackung des Medianhöckers oder der beiden Lateraltheile. Auch hier können, streng genommen, nur zwei Lateralloben angenommen werden, da die projicirte Spirale den Aussenrand des dritten Lobenelementes triff. Die Loben sind breiter als bei der eben beschriebenen Art und die gespreizte Zackenstellung ist weniger deutlich zu sehen; gegen den Nabelrand schliessen sich ein grosses erstes und drei kleinere Auxiliarelemente an. Die Sattelform ist die gleiche wie bei Norites gondola, nur sind die Sattelstämme weniger stark an der Basis verjüngt. Die ganze Lobenlinie sinkt nicht wie bei Norites gondola geradlinig vom ersten Lateralsattel an herab, sondern verläuft schwach bogenförmig zum Nabelrand.

Falls die vorliegenden Stücke einen tadelloseren Erhaltungszustand hätten, liesse sich auf Grund der Abweichungen von dem aufgestellten Typus mit Recht eine eigene Varietät aufstellen, was so unterbleiben muss.

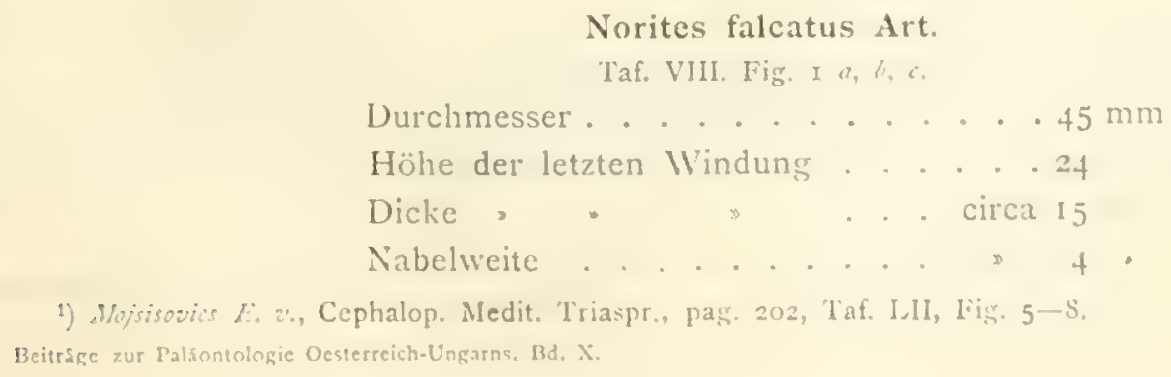


Der Externtheil ist ziemlich breit und anfangs der letzten Windung flacher, später etwas stärker gewölbt; die Flanken erreichen in der umbilicalen Hälfte die grösste Dicke und haben cinen annähernd birnförmigen Querschnitt; die Marginalkante ist deutlich in Form einer aufgesetzten feinen Leiste entwickelt, während sich auf dem Externtheil keine Spur eines Kieles findet; am Umbilicalrand fehlt cine Kielleiste, und wir sehen ihn ganz leicht abgestumpft entwickelt. Die Nabelwand ist senkrecht gestellt und hoch, der Nabel sehr eng, die Involution sehr gross und lässt nur einen schmalen Rand der früheren Windung frei.

Die Schale ist mit feinen, sichelförmig gebogenen Schalenstreifen oder Linien bedeckt, welche enggestellt und mit freiem Auge gut wahrnehmbar sind. Sie erinnern in ihrem Verlaufe vollkommen an diese Art der Schalenzeichnung bei Harpoceras opalinum Reir. Sie steigen über die Nabelwand herauf, verlaufen ein Stück in radialer Richtung, zeigen in der lilankenmitte cin rundes, convexes Lateralstück, an das sich unterhalb der Marginalkante eine concave kleinere Partie anschliesst, von der aus die Streifen den Externtheil bogenförmig übersetzen.

Die Suturlinie hat im Allgemeinen den Charakter, den wir bei Norites gondola Mojs. kennen lernten, jedoch zeigt sich abermals, dass wir hier nur mit zwei und nicht mit drei Lateralloben zu rechnen haben, indem die projicirte Involutionsspirale knapp auswärts des, als erster Auxiliarlobus zu deutenden Lobenelementes verläuft.

Der Externlobus reicht am tiefsten hinab und hat annähernd dieselbe liefe wie der erste Laterale, dessen tiefster Zacken erst in gleicher Höhe mit der Mitte des Externen steht. Die beiden Arme desselben werden durch einen ziemlich breiten, konischen, oben abgestumpften Medianhöcker getrennt, an dessen Scheitel wir einen kleinen Medianzacken beobachten. Aus den Längenverhältnissen des Externen und des ersten Laterallobus ergibt sich eine einseitige und etwas schräg auswärts gerichtete Stellung des Letzteren, der am Grunde zwei grössere und darüber zwei kleinere Zacken aufweist. Die gabelförmige Anordnung derselben, wie sie bei Norites gondola sich findet, ist aber hier schon sehr verwischt; der zweite Laterallobus ist ungefähr halb so tief als der erste und steht ihm an Breite nur wenig nach; sein Grund ist mit fünf grösseren und kleineren Zähnchen besetzt; dann schliesst sich ein grösserer gezackter Auxiliarlobus und drei successive kleiner werdende Auxiliarelemente bis zum Nabelrande an.

Extern- und erster Lateralsattel sind ungefähr von derselben Breite; ersterer ist sehr kurz und wird von der Marginalkante derart getheilt, dass der grössere Theil noch auf den Externtheil zu liegen kommt; der erste Laterale ist der zu höchst stehende; sie sind sämmtlich ganzrandig und von rundbogenförmigem Verlauf; die Sattelstämme sind an der Basis leicht verjüngt; der erste und zweite Lateralsattel, sowie die vier Auxiliare bilden mit ihren Scheiteln keine bogenförmige, zum Nabel herabhängende Linie, sondern stehen an einer Radiallinie an.

Norites falcatus unterscheidet sich von den bisher bekannten Formen durch die etwas stärker aufgeblähte Form; von Norites gondola \lojs. speciell durch das Fehlen der stumpfen, kielartigen Linie auf dem Externtheil, das Fehlen der Leisten auf dem Nabelrand, und die scharfen, sichelförmig verlaufenden I inien auf der Schale, die dort radial verlaufen. Die Suturlinie unterscheidet sich durch den ausserordentlich tief herabreichenden Externlobus und niederen Externsattel, ferner durch die geradlinige Anordnung der Lateralsattel und Lobenglieder.

Norites subcarinatus Hauer ${ }^{1}$ ) (pag. 3I, Taf. VII, Fig. 7) ist eine weitnabeligere lorm, welche lange nicht so hochmündig ist, aber auf dem Externtheil die stumpfe, kielartige Anschwellung und die Marginal- und Umbilicalleisten zeigt. Wir finden hier dieselben sichelförmigen Schalenstreifen mit identem Verlaufe wieder. Die Suturlinie ist aber sehr verschieden, und zwar durch die Stellung, Form und grosse Breite des Externlobus, welcher den ganzen Externtheil einnimmt. Auf der Flanke 
erst folgt ein, dem ersten Lateral an Breite gleichender Externsattel, der an Höhe nur ein wenig von jenem differirt.

Dass F\%. $v$. Hater von 4 Lateralloben spricht, dürfte wohl auf einen Druckfehler zurückzuführen sein, indem es vvier Laterallobenelemente heissen dürfte. Vergleiche mit dem Originale aus dem k. k. Naturhistorischen Hofmuseum ergaben auch hier wieder zwei Lateralloben, an die sich ein grosser Auxiliar und ein kleiner zweiter, stumpfzackenförmiger auf dem Nabelrand anschliesst. Die (loc. cit., Taf. VII, Fig. 7 c) gegebene Abbildung der Suturlinie entspricht aber sehr wenig dem Originale, weshalb ich (Taf. VIII, Fig. 2) dieselbe, direct von jenem abgepaust, zur Neuabbildung bringe.

Die Frage liesse sich allerdings aufwerfen, ob nämlich Norites subcarinatus Hauer wirklich ein Norit sei?

Dagegen spricht die starke Ausschnürung der Form, der sehr stark heraustretende stumpfe Mediankiel, und bei der Lobenlinie die Form und Stellung des Externlobus, sowie die geringe Anzahl der Flankenelemente. Der dicke Mediankiel ähnelt vielmehr der Ausbildung desselben bei Hungarites, dem auch die Anzahl der Lobenelemente entsprechen würde. Vergleicht man z. B. den Hungarites Elsae Mojs. ${ }^{1}$ ) (pag. 224, 'Taf. XXIV, Fig. 6, und 'Taf. XXXIII, Fig. 3, 4), so haben wir in dieser eine ausserordentlich nahestehende Form gefunden. Zwar ist die Suturlinie dort nicht vollständig erhalten, was aber bekannt ist, sieht sehr ähnlich derjenigen von Norites subcarinatus Hauer aus. Nur die hier auftretenden leichten Marginalkantenleisten sind bei Hungarites noch nicht bekannt, dem sonst die starke Ausschnürung und Art der Anwachsstreifen entsprechen würde.

\section{Norites apioïdes Art.}

Taf. VIII, Fig. $3 a, b, c$.

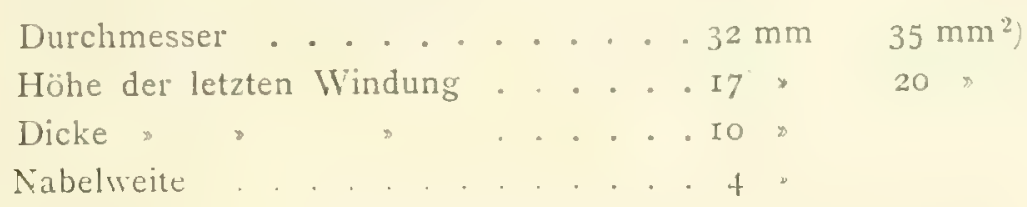

Der Externtheil ist ausserordentlich flach gerundet, die Flanken sind wenig autgetrieben und erreichen etwas unterhalb der Flankenmitte die grösste Dicke; die Marginalkante ist als zarte, drahtförmige Leiste entwickelt, der Umbilicalrand leicht abgestumpft; die Nabelwand ist hoch und senkrechtstehend, der Nabel selbst enge; die Involution lässt nur einen minimalen Theil des früheren Umganges frei.

Die Schale ist mit feinen, sichelförmigen Anwachsstreifen bedeckt, welche in derselben Stärke und ähnlich eng gestellt wie bei Norites falcatus Art. auftreten. Der Externlobus ist nieder, breit und nimmt fast den ganzen Externtheil ein; der Medianhöcker ist sehr breit und zeigt einen herabhängenđen Zacken, die Arme selbst sind relativ schmal und leicht nach innen gebogen. Der erste Laterallobus ist breit, erreicht ungefähr die doppelte Tiefe des Externen und ist am Grunde mit drei grossen Zacken und seitlich mit je einem kleinen Zähnchen besetzt; erstere zeigen keine Spur einer gespreizten Stellung; der zweite Lateral hat dieselbe Breite wie der erste, seitlich zwei kleine Zähnchen und im Grunde zwei grosse Zacken; dann folgen bis zum Nabelrand fünf Auxiliarloben, von denen die drei ersten schmal, fast von gleicher Grösse und mit je zwei kleinen Zacken besetzt sind, während die letıten in Form stumpfer Zacken auftreten.

Der Externsattel ist von annähernd gleicher Grösse wie die beiden Lateralen und liegt fast granz auf der Flanke. Der erste Laterale reicht am höchsten hinauf; von hier senken sich die Sättel, mit den Scheiteln an einer geraden Linie anstehend, welche sehr rasch zum Nabelrand abfält. Ver-

1) Mojsisoz'ics E. $z^{\prime}$, Cephalop. Medit. 'l'riaspr.

2) Die zweite Maasszahl entspricht einem grösseren Bruchstücl. 
bindet man den letzten Auxiliarsattel mit der Medianlinie des Externtheiles mittelst einer auf dieser senkrecht stehenden Geraden, so ergibt sich - bis zum Externsattel gemessen - bei den abgebildeten Stück eine Höhendifferenz von $8 \mathrm{~mm}$, während dieselbe bei Norites gondola Mojs. nur etwa $3 \mathrm{~mm}$ beträgt. Die Sättel sind gerundet und ganzrandig, die Sättelstämme an der Basis leicht verjüngt.

Norites apiödes ähnelt in seiner äusseren Gestalt bedeutend dem Norites gondola Mojs. ${ }^{1}$ ) (pag. 202, Taf. LII, Fig. 5-8). Jedoch bestimmten folgende Unterschiede die Abtrennung: Norites apioïdes ist hochmündiger und hat bei fast gleichem Durchmesser einen etwas schlankeren Externtheil, dem die dicke Medianlinie zu fehlen scheint; der Nabel ist viel enger, dem am Rande auch die feine Nabel. leiste fehlt. Die Suturlinie zeigt ausser dem differirenden allgemeinen Verlauf mit den stark herabhängenden Auxiliarelementen nur geringfügige Unterschiede.

Norites falcatus ist noch hochmündiger als Norites apiö̈des und hat im Vergleich zur Grösse einen noch engeren Nabel, aber eine fast vollständig radial verlaufende Suturlinie.

\section{Norites psilodiscus Art.}

Taf. VIII, Fig. $4 a, b, c$.

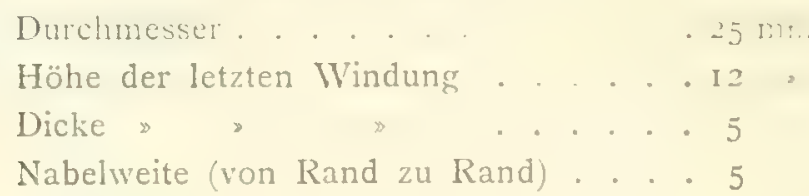

Der Externtheil ist fast flach, die Flanken flach gewölbt, erlangen ausserhalb der Flankenmitte die grösste Dicke und senken sich dann rasch zum Nabelrand hinab. Die Narginalkante ist als feine Schalenleiste, der Umbilicalrand als rundlicher, leichter Wulst entwickelt, so dass es den Anschein hat, als ob die Flanke rund um den Nabelrand herum eine Depression erfahren hätte. Die Involution ist sehr stark und lässt nur einen schmalen Rand der früheren Windung frei. Der Nabel ist weit und treppenförmig abgesetzt, die Nabelwand sehr steil stehend.

Die Schale ist mit feinen sichelförmigen Anwachsstreifen besetzt, welche als enggestellte, zarte Linien auftreten und den Externtheil mit einem flach convexen Stück übersetzen, kurz, wir haben hier wieder denselben Verlauf dieser Linien, wie wir ihn bei Norites falcatus, Norites apioides etc. schon kennen gelernt haben.

Die Suturlinie zeigt einen ziemlich tiefen und breiten Externlobus, welcher jedoch nicht den ganzen Externtheil einnimmt. Er ist von einem breiten, niederen Medianhöcker getheilt, von dessen Spitze ein kleiner Zacken herabhängt. Die beiden Arme sind einspitzig; der erste Laterallobus ist ungefähr um 1/. tiefer als der Externe, ist breit und zeigt an seiner Basis drei kleine Zacken; der zweite Laterallobus ist gegen den ersten zu schräg gestellt, von annähernd derselben Gestalt wie der erste und an der Basis ebenfalls mit drei Zähnchen besetzt; dann folgen gegen den Nabelrand zu noch drei kleine, gerundete Auxiliare.

Die Sättel sind rundbogig und ganzrandig, mit an der Basis leicht verjüngten Stielen; der Externlobus wird von der Marginalkante halbirt und ist von derselben Breite, jedoch geringerer Höhe wie der erste Laterale, welcher an höchsten hinaufreicht; die Scheitel der Sättel stehen an einer Geraden, welche rom ersten Lateralsattel an sehr rasch zum Nabel absinkt.

Norites psilodiscus hat noch die grösste Aehnlichkeit mit Norites apioïdes Art., obgleich die aussere Form nicht unbedeutend differirt. Norites apiö̈des ist dicker, viel engnabeliger und hat daner einen senkrecht abgesetzten Nabel; die grösste Dicke der Flanke liegt etwas unterhalb der Flankenmitte, während sie bei Norites psilodiscus oberhalb liegt, auch fällt die Flanke dort leicht gerundet, 
hier fast flach zum Nabelrand ab, der dort abgestumpft, hier wulstförmig entwickelt ist. Grosse Aehnlichkeiten haben aber die Suturlinien in beiden Fällen, wobei die vier Auxiliare bei der grösseren Form den drei Auxiliaren der kleineren Form bei Norites psilodiscus entsprechen.

\section{Familie: Ptychitidae Waag. Unterfamilie: Proptychitinae Waag. \\ Gattung: Beyrichites Waag.}

Beyrichites cfr. maturus Mojs. sp.

I8S2. Meekoceras maturum Mojs., E. O. Mojsisooics, Cephalop. Medit. Triaspr, pag. 2I9, Taf. L, Fig. 3.

W. Waagen spricht in dem eben erscheinenden Theile der Salt-Range Fossils, ${ }^{1}$ ) Vol. II, pag. I6o, die Vermuthung aus, dass

Meekoceras maturum Mojs.,

Meekoceras reuttense Beyr. sp. (Bcyrich, Cephalop. a. d. Muschelk. der Alpen, pag. II3, Taf. I, Fig. 4) und

Meekoceras K'hanikoffi Opp.sp. (Oppcl, Ostindische Fossilreste, pag. 275, Taf. LXXVI, Fig. 4), weil sie sich von den ursprünglichen Typus der Gattung Meekoceras Hyatt weit entfernen, deshalb von Meekoceras abzutrennen und in eine neue Gattung Beyrichites zusammenzufassen seien, deren nächste Verwandtschaft bei seiner neuen Gattung Proptychites (loc. cit., pag. I62) und bei Ptychites Mojs. zu finden ist, welche Gattungen gemeinsam mit Sturia Mojs. die Unterfamilie der Proptychitinen in der Familie der Ptychitiden bilden. Das mir vorliegende Materiale ist keineswegs so beschaffen, um eine selbstständige Stellungnahme in dieser Frage zu ermöglichen; ich beschrünke mich daher nur darauf, die Ansicht meines verehrten Lehrers hier kurz angedeutet zu haben.

Das vorliegende Stück hat folgende Maasse:

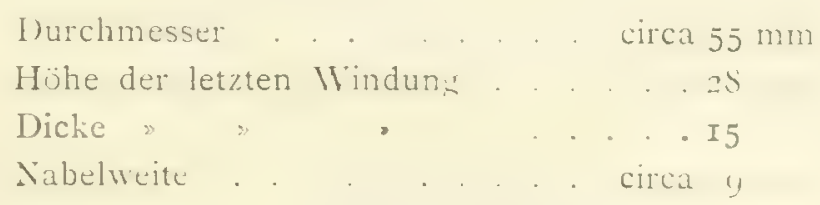

Der Externtheil ist relativ schmal, die Seiten, gegen die Umbilicalregion flach anschwellend, senken sich dann rasch zum Nabelrand hinab; derselbe ist leicht abgestumpft, während sich keine Spur einer Marginalkante findet; die Nabelwand ist nieder und fast vertical stehend: die Involution sehr gross.

Die Flanken sind mit Radialfalten versehen, von denen auf dem vorliegenden Fragmente vier auf den halben Umfang entfallen. Sie verlaufen gerade, nicht leicht gekrümmt, und erlangen in der unteren Flankenhälfte die grösste Dicke, welche somit auch ungefähr mit der grössten Flankenbreite zusammenfällt.

Die Suturlinie lässt zwei Lateralloben und einen grossen Auxiliarlobus erkennen, auf den bis zum Nabelrand wohl noch zwei kleinere Auxiliarelemente folgen dürften, jedoch ist an dieser Stelle das Stück gebrochen. Der Externlobus hat bedeutende Breite und ist von einem breiten, jedoch relativ hohen und schlanken Medianhöcker getheilt; er hat ungefähr die halbe Tiefe des ersten Lateralen und ist besonders an Basis und Innenseite mit gröberen Zacken und feineren Zähnchen besetzt; der erste Laterallobus hat fast die doppelte Tiefe des Externen, ist im oberen Theile etwas verjüngt, an der Basis leicht zugespitzt und daselbst mit srossen Zacken versehen, von denen kleinere bis zum Sattel auf-

5) Palacontolog. indica, Serie Xill. 
steigen; an Grösse ragt besonders ein basal- und medianstehender Lacken hervor; der zweite Laterallobus ist breiter als der erste und an 'liefe grleich dem Externen; auch er ist mit zahleichen, aber kleineren Zacken besetzt; der erste Auxiliar ist breit, nicder und mit gezahnter 13asis. Die Sättel haben im Allgemeinen cinen bogenförmigen Verlauf und der Scheitel des Bogens wird rom ersten Lateralsattel eingenommen. Sie sind schmal, die Bezahnung reicht bis fast zu ihrem Scheitel hinauf, der dadurch ein blattförmiges Aussehen erhält; an Grösse folgt auf den ersten Lateralsattel der zweite, während der Externsattel erst an dritter Stelle folgt.

Mannigfaltig sind die Unterschiede zwischen der von L. 2\%.Mojsisovics aufgestellten Art und dem vorliegenden Stück. Der schmäleren Ausbildung des Externtheiles der Keiflinger Species ist wohl kein grosses Gewicht beizulegen, denn wir haben es hier mit einem jüngeren Individuum zu thun, und auch bei der Schreyeralm-Form wird der breitere Lxterntheil erst gegen Ende der Windung erlangt. Sehr verschieden hingegen ist die Berippung, welche bei lieyrichites maturus aus schwachen, nicht sehr zahlreichen Falten bestehen, die erst in der äusseren Hälfte der Windung deutlich hervortreten und daselbst eine leichte Krümmung erkennen lassen. Hier hingegren stehen die Falten noch spärlicher, sind ebenfalls flach, verlaufen aber radial und zeigen in der unteren Hälfte die grösste Anschwellung. Auch der Nabel ist hier entschieden weiter wie dort. Die Suturlinie zeigt cbenfalls gevisse Variationen: der Medianhöcker ist schmäler, der Externlobus niederer, der Externsattel kleiner und der erste Laterallobus hat eine schlankere Form wie Beyrichites maturus.

\section{Gattung: Ptychites Mojs.}

\section{Formengruppe der Ptychites rugiferi llojs.}

1882. Mujsisozics E. v., Cephalop. Medit. Triaspr., pag. 246, Fig. I, 2.

\section{Ptychites Oppeli Mojs.}

I882. Ptychites Oppeli Mojsisovics E. ש., Cephalop. Medit. Triaspr., pag. 24S, Taf. LxXI, Fig. I, 3, Taf. LxxII.

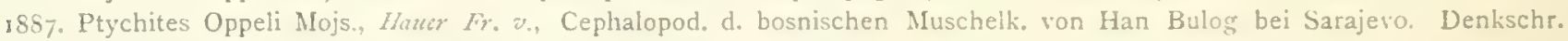
k. Akad. d. Wiss. mat.-nat. Cl., Bd. LIV, pag. 39.

ISgz. Ptychites Oppeli Mojs., Hauer Fr. v., Cephalopoden a. d. Trias von Bosnien. Denkschr. k. Akad. d. Wiss. mat.-nat. Cl., Bd. LIX, pag. 37.

In dieser Species werden von Mojsisovics zwei Varietäten ausgeschieden, von denen die eine schmälere zugleich einen kleineren Nabel aufweist, während die dickere Form weitnabeliger ist.

In meinem Reiflinger Material ist nur die schmälere Varietät vertreten, welche sich aber insoferne wieder von dieser unterscheidet, dass sie nicht so hochmündig ist, sondern bei geringerer Breite bezüglich der Windungshöhe der dickeren Varietät näher steht.

Bei einem Durchmesser von $69 \mathrm{~mm}$ zeigen sich jeđoch die kräftigen Falten schon leicht convex nach vorne gekrümmt und verschwimmen sodann in $3 / 4$ der Flankenhöhe. Sie erscheinen dann - auf dem Steinkerne - in feine, linienförmige Fältchen aufgelöst, welche enggeschaart den Externtheil übersetzen. Auch zwischen den groben Falten treten, meist zu zwei oder drei, derartige feine Fältchen auf.

Auf der Schale sind die Falten und Zwischenräume zwischen denselben von feinen Zuwachsstreifen überdeckt, welche gleichförmig wie diese verlaufen.

\section{Ptychites dontianus Hauer sp.}

1850. Ammonites dontianus Hauk F\%. $\%$, Ueber die von Bergrath Fuchs in den Venetianer-Alpen gesammelten Fossilien, pag. Ir6, Taf. XIX, Fig. 6. Denkschr. t. Akad. d. Wiss. mat.-nat. Cl, Bd, II. Wien I85I.

IS82. 1'tychites dontianus Hauer sp., Mojsisozics E. v., Cephalop. Medit. Triaspr, pag. 249, Taf. LXX, Fig. I.

Diese für den unteren Muschelkalk charakteristische Form ist durch ein Bruchstück vertreten, welches ein Windungsfragment von fast $87 \mathrm{~mm}$ Flankenhöhe darstellt. Die Suturlinie ist trefflich 
erhalten, leider aber nur bis zum ersten Auxiliarlotus, hinter welchem durch Verdrückung und Bruch die Fortsetzung desselben zerstört worden ist.

Der Externtheil ist etwas schmäler als die Beschreibung und Abbildung ihn angeben; dies übt auch seinen Einfluss auf den Medianhöcker aus, der hier etwas höher und schmäler erscheint, sonst aber dieselbe Zackung der Seitenwände und Spitze enthält. Der Externlobus ist stark gezackt, besonders an der Basis durch grössere Elemente zerschlitzt und erreicht ungefähr die halbe Tiefe des ersten Laterals.

Der erste Laterallobus hat bei breitem Lobenstamme eine stark zertheilte Basis, deren Mitte von einem central stehenden grossen, zerschlitzten Zacken eingenommen wird; bis zum Sattelansatz folgen jederseits drei grössere Zacken, welche sich gegen oben successive verkleinern; der ziveite Lobus hat ähnliche Gestalt wie der erste, ist jedoch etwas kürzer und von plumper Form; hierauf folgt ein um wenig schmälerer Auxiliar, welcher jedoch den zweiten Lateral etwas an Tiefe übertrifft.

Der Externsattel hat fast dieselbe Höhe und Breite wie der erste Laterale, beide sind einblätterig und nur durch kleinere Zäckchen gegliedert; der zweite Lateralsattel ist flacher, wodurch er grösser erscheint, und wird durch den von innen vorrückenden Zacken zweiblätterig getheilt. Aus der Grösse der Windung lässt sich auf das Vorhandensein von drei Auxiliarloben bei dem vorliegenden Durchmesser schliessen. Auch bei diesem grösseren Exemplare erscheint die Zerschlitzung nicht fein, sondern ist als einfach, eventuell als grob zu bezeichnen.

\section{Ptychites Seebachi Mlojs.}

1852. Ptychites Seebachi Mrojsisorics E. 2', Cephalop. Medit. Triaspr., pag. 249, Taf. LXVII, Fig. 7, Taf. LXX, Fig. 2.

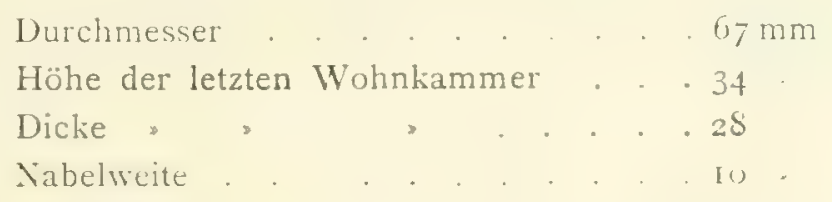

Es liegt ein Stück vor, das den vollständig erhaltenen letzten Umgang, nur aus der Wohnkammer bestehend, zeigt und grösstentheils als Steinkern erhalten ist. Da keine Loben $2 u$ sehen sind, steht man wirklich vor der Alternative, ob man sich betreffs der äusseren Form für Ptychites Oppeli oder die eben angeführten Species entscheiden soll. Mojsisovics gibt bezüglich der Unterscheidung beider keine Anleitung, was auch Fr. $\%_{0}$ Hau ${ }^{1}$ ) veranlasste (pag. 39), Ptychites Seebachi Mojs. und Ptychites Breunigi Mojs. direct als Synonima des Ptychites Oppeli Mojs, anzuführen. Die Unterschiede sind aber beim Fehlen der Suturlinie wirklich recht minimale, und ich vermag nur herauszubringen, dass Ptychites Oppeli vielleicht noch etwas hochmündiger ist und Ptychites Seebachi etwas stärker gewölbte Flanken hat, weshalb die Umbilicalkante nicht so stark heraustritt, auch leicht abgestumpft ist, und dass die Nabelwand hier schräger gestellt ist und der Nabel - wenigstens bei der vorliegenden Form - um Weniges kleiner erscheint. Die Berippung erfolgt durch etwas flachere, enger gestellte Falten, die jedoch auch nur bis $3 / 4$ der Flankenhöhe reichen, hier aber, im Gegensatze zu Ptychites Oppeli, geradlinig verlaufen. Auch die feinen Fältchen auf dem Steinkerne und kräftigen Zuwachslinien auf der Schale finden sich wieder. Alle diese Unterschiede sind aber, wie gesagt, so minimale, dass sie durch Variationen der einen oder anderen Form leicht aufgehoben werden können.

\section{Ptychites cfr. intermedius Hauer.}

i892. Nuucer Fr. v., Cephalop. a. d. Trias von Bosnien, pag. 4 , Taf. XIV, Fig. I $a$, b, Taf. XV, liig. 3.

Es liegt ein grosses Bruchstück einer Wohnkammer vor, dessen Steinkern eine ähnliche Sculptur aufweist, wie sie F\%. Haw bei seiner neuen Art schildert. Da jedoch nur ein Exemplar mit Schale

1) Hawer fir. v., Cephalop. bosn. Muschelk. I857. 
abgebildet ist und über die Beschaffenheit des Steinkerns nichts gesagt wird, so lässt sich das Reiflinger Bruchstück mit der bosnischen liorm nur vergleichen, nicht identificiren.

Es gehörte auch zu einem viel grösscren lixemplar, wodurch vielleicht der schmälerc Convextheil sich von selbst erklärt. Die lilanke, welche die grösste Breite in der Umbilicalregion erlangt, ist mit fachen Walten bedeckt, welche eben dort am stärksten hervortreten und in $2 / 3$ der Höhe verschwimmen; dann treten aber kräftige, flache lraltenstreifen, meist in der Dreizahl angeordnet, hervor, welche dic Lateralsculptur bis zum Convextheil fortsetzen, den sic, immer undeutlicher werdend, überziehen. I)ie Sculpturirung verläuft anfangs radial, in $2 / 3$ der Höhe wendet sie sich mit einem flachen Concavtheil nach rückwärts, der auf dem Externtheil in ein viel flacheres convexes Bogenstück übergeht.

\section{Formengruppe der Ptychites megalodisci Mlojs.}

1882. Mojsisovics E. v, Cephalop. Medit. Triaspr., pag. 250.

\section{Ptychites Suttneri Mojs.}

I882. 1'tychites Suttneri Mojsisozics E. v., Cephalop. Medit. Triaspr., pas. 25I, Taf. LXXIV und Taf. LXXV, Irig. 2, 3. 1887. P'tychites Suttneri Mojs., Hhuer Fr. a', Cephalopod, d. bosnischen Muschelk, von Han Bulor bei Sarajevo. Denkschr. k. Akad. d. Wiss, mat.-nat. Cl., Bd. LIV, pag. 4 I.

In dem zahlreichen Materiale, welches aus dem Reiflinger Kalke hier vorliegt, finden wir dic ganze Formenmannigfaltigleit dieser Species wieder. Vergleicht man die Suturlinie, welche wir aus Taf. LXXIV und LXXV bei E. Mojsisovics finden, dann fallen uns zwei derselben auf, welche wohl die Extreme der Variationen dieser Art ausdrücken.

Taf. LXXIV, Fig. 2c, und Taf. LXXV, Fig. a zeigen denselben Typus durch breite Sattelstämme und relativ kurze Loben.

Taf. LXXV, Fig. 36 stellt das andere Extrem dar, mit relativ tiefen und schmalen, regelmässig und spärlicher zerschlitzten, baumförmigen Loben, deren Sättel an einer viel Hacher gespannten Bogen. linie anstehen als beim anderen Typus. Reducirt man Taf. LXXT, Fig. $3 a$ auf denselben Durclmesser wie Taf. LXXIV, Fig. $2 a$, so ergibt sich, dass diese Form weitnabeliger als jene ist, wodurch sich bei Ersterer die schmäleren Sattelstämme durch die geringere Flankenbreite erklären.

Zwischen beiden Extremen gibt es entsprechend der Variationsfähigkeit der Art zahlreiche Uebergänge, welche die Suturlinie und äussere Form zeigen; allen gemeinsam bleibt nur die Art der Flankensculptur durch flache Falten. Ich finde aber nicht, dass diese Schalenfalten bei alteren Individuen ssehr zahlreiche, das heisst wohl: zahlreicher als bei jüngeren Individuen werden. Bei meinem grössten Stücke von circa Ioo mm Durchmesser treten nicht mehr Falten als bei Formen der Mittelgrösse auf, wohl aber sind sie bedeutend flacher geworden, nehmen daher mehr Raum ein und erscheinen gedrängter. $\mathrm{Ob}$ diese Verhältnisse sich bei weiterem Fortwachsen ändern, darüber gestattet dieses Material kein Urtheil, es ist aber anzunehmen, dass diese immer flacher werdenden Falten schliesslich ganz verschwinden. Ausser den Radialfalten treten noch gedrängt stehende, ziemlich kräftige Anwachsstreifen auf Schale und Steinkern auf, welche geradlinig-radial verlaufen und den Externtheil übersetzen.

Ptychites Suttneri Mojs. bildet den bedeutendsten Bestandtheil der Ptychitenfauna des Reiflinger Kalkes unserer Localität.

\section{Ptychites cfr. megalodiscus Beyr. sp.}

1867. Ammonites megalodiscus Beyrich, Cephalopoden a. d. Muschelk. d. Alpen. Abhandlungen kgl. Akad. d. Wiss. Berlin 1866, pag. I35, Taf. II.

1882. P'tychites megalodiscus Beyr. sp., Mrojsisovics E. v., Cephalop. Medit. Triaspr., Abhandlungen k. l.. geol. R.A., Bd. X, pag. 253, laf. LXXVII, Fig. I, Taf, LXXVIII, Fig. I, 2.

I887. I'tychites megalodiscus Beyr. sp., Ilauer Fir. a', Cephalopoden d, bosnischen Muschelk. von Han Bulog bei Sarajevo. Denkschr. k. Akad. d. Wiss. mat.-nat. Cl., Bd. LIV, pag. 42. 
Von dieser Species liegen nur zwei Windungsbruchstücke vor, welche sich am besten hier anschliessen lassen. Die, soweit die erhaltenen Theile es gestatten, trefflich sichtbare Suturlinie zeigt den kräftig entwickelten Externlobus mit weitgehender Zerschlitzung der Basis und inneren Seitenwand, den tiefen ersten Laterallobus, weIcher fast die doppelte Tiefe des Externen erlangt, und den zweiten Laterallobus, welcher nur wenig dem Ersten an Tiefe nachsteht. Der Externsattel ist auffallend gross, eintheilig, beim ersten Lateralsattel wird schon bei dieser Grösse die spätere Zweilappigkeit durch einen grossen, von Aussen gegen Innen vorrückenden Zacken angedeutet; die Sattelstiele sind relativ schmal und zeigen reiche Zerschlitzung; der Externsattel hat die Höhe des ersten Lateralsattels.

Die sonst Ptychites megalodiscus sehr ähnliche Species unterscheidet sich von diesem selbst nur durch den relativ kürzeren Externlobus, hohen breiten Externsattel und den im Verhältnisse zum Externen tiefen ersten und zweiten Laterallobus.

\section{Ptychites domatus Hauer.}

1850. Ammonites domatus Houtr Fr. $v$, Ueber die von Bergrath Fuchs in den Venetianer Alpen gesammelten Fossilien. Denlsschr. k. Akad. d. Wiss. mat.-nat. Cl., Bd. II, pag. II5, Taf. XVIII, Fig. I2. Wien IS弓̆x.

I882. Ptychites domatus Hauer sp., liojsisozics E. $\%$, Cephalop. Medit. Triaspr., pag. 250, Taf. LXII, Fig. 4, 5.

Unter den zahlreichen vorliegenden Stücken, welche fast ebenso viele Entwicklungsstadien dieser Form repräsentiren, ragt ein sehr schön erhaltenes Exemplar hervor, welches noch bedeutendere Grösse erreicht als das bei MTojsisovics (loc. cit.) Fig. 4 abgebildete Stück. Aus der äusseren Form desselben ergibt sich, dass Ptychites domatus beim weiteren Wachsen die Tendenz verfolgt, seine Windung zu erhöhen, was in der Weise geschieht, dass nicht der Nabelrand sich abplattet und die Form zu egrediren beginnt, sondern dass der Externtheil sich höher wölbt und schärfer wird. Die Flanlien bleiben flach gewölbt, die grösste Lateralbreite wird auf dem Nabelrand erreicht, welcher leicht ab. gestumpft ist, während die Umbilicalwand anfangs schräg, tiefer gegen die Naht zu hingegen senkrecht abfällt.

Die Involution ist eine vollständige, indem die vorhergehende Windung bis auf die Nabelkante umbüllt wird, ja bei dem letzten Umgang erscheint der letzte Theil der Umbilicalpartie sogar ein wenig überhängend. Der Nabel ist relativ gross, tief und trichterförmig. Die Radialfalten sind sehr stark reducirt und nur hie und da tritt noch die eine oder andere stellenweise stärker hervor. Ausserdem treten auf der Schale sehr feine radial und fast geradlinig verlaufende Zuwachsstreifen auf, welche den Externtheil übersetzen. Auf dem Steinkerne sieht man, ähnlich wie bei Ptychites globus Hauer (pag. 99, Taf. VIII, Fig. 8), schwache Spirallinien oder Fältchen auftreten.

Ptychites maximus Art.

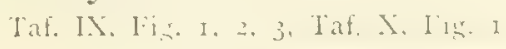

\begin{tabular}{|c|c|c|c|c|c|c|c|c|}
\hline \multirow[b]{3}{*}{ Durchmesser } & & \multirow[b]{3}{*}{. } & \multicolumn{3}{|c|}{ Engnabelige Varietät } & \multicolumn{3}{|c|}{ Weitnabelige Varietät } \\
\hline & & & & & & & & \\
\hline & . . . . . & & 172 & $\mathrm{~mm}(400 \mathrm{~mm})$ & $\mathrm{I} 30 \mathrm{~mm}$ & $160 \mathrm{~mm}$ & I7I & $\mathrm{mm}$ ? \\
\hline Höhe der letzten & Wohnkammer & - & $9^{6}$ & $\star$ & $68 \gg$ & $9 I \gg$ & 95 & \\
\hline Dicke » " & , & - & - & & - & 49 & 50 & , ? \\
\hline Nabelweite . . & . . . . . . & . . & 15 & » & I 5 & IS & 29 & $\$$ ? \\
\hline
\end{tabular}

Unter den vier vorliegenden Exemplaren, deren Maasse obenstehendes Verzeichniss bietet, scheiden sich zwei ab, von denen nur die eine Seite erhalten ist und den angewitterten Steinkern zeigen, wodurch die Kammerscheidewände schön im Relief sogar heraustreten; und zwei, von denen das eine Exemplar ein grosses Fragment der Wohnkanmer mit schön erhaltener Schale darstellt, während das andere vollständig ist und Wohn- und Luftkammern aufweist.

beitráge zur Paliontologie Oesterreich-Ungarns. Bd. X. 
Die eng- und weitnabelige Varietät scheinen auch bezïglich der Dicke insoferne zu variien, dass erstere viel geringere Dicke erlangt, verbunden mit schmaler Ėntwicklung des Convextheiles, wodurch eine flache, scheibenförmige Gestalt im Gegensatze zur anderen Varietät resultirt, dic sich durch breiteren Externtheil und bedeutendere Flankenbreite auszeichnet, welche etwas oberhalls der Flankenmitte erlangt wird, während das Maximum der Lateralanschwellung bei der schmäleren Varietät sich unterhaib der Flankenmitte findet. Die Schale ist am Umbilicalrande stark verdickl; die Nabelwand fällt senkrecht $a b$ und scheint erst gegen Schluss der Wohnkammer bei vollkommen erwachsenen Individuen sich etwas schräger zu stellen. Der Nabel selbst ist steil treppen-, fast trichterförmig eingesenkt, indem die Involution knapp neben dem Nabelrande der früheren Windung erfolgt.

Die Flanke ist mit Radialfalten bedeckt, welche besonders bei Formen der Mittelgrüsse kräftig heraustreten; sie sind gerade verlaufend, zeigen wulstige, eher breite als hohe liorm und sind relativ eng gestellt. Ausserdem ist die Schale mit gedrängten, auch über den Externtheil ziehenden, kräftigen Zuwachsstreifen bedeckt, welche auf der unteren lilankenhälfte radialen Verlauf zeigen, im oberen Theile leicht gegen rückwärts geschwungen sind und den Externtheil mit einem flach-convexen Stück übersetzen. Gegen Ende des letzten Umganges, oder überhaupt auf der Wohnkammer erwachsener Individuen, verflachen die Radialrippen immer mehr und hören schliesslich ganz auf.

'Taf. IX, Fig. 2, zeigt einen 'Theil des erhaltenen grossen Wohnkammerstückes, dem die sub $d$ oben gegebenen Maasse entsprechen. Man bemerkt darauf, dass die falten schon ganz verflacht sinu, sieht die ausserordentlich schön erhaltenen Zuwachsstreifen der Schale und ein schmales, spiral verlaufendes Band, längs welchem die Zuwachsstreifen schärfer heraustreten. Wir haben es hier vielleicht mit einem Haftband zu thun, das hervorgerufen wird durch das Umfassen der Schale mit einem festaufliegenden Arme des Thieres, wodurch längs desselben die Feinheiten der Sculptur mehr als auf den freien Stellen der Schale erhalten blieb. Gegen rückwärts verschwimmt dieses l3and allmälig.

Abgesehen von dem sub d erwähnten grossen Bruchstücke ist bei sämmtlichen anderen Stücken die Suturlinie schön erhalten. Taf. IX, Fig. 3, stellt dieselbe der grossen engnabeligen Varietät dar. Wir finden einen relativ tiefen, etwa bis $3 / \frac{1}{4}$ der Tiefe des ersten Laterallobus herabreichenden Externlobus mit schmalem und steilwandigem Medianhöcker; der Lobus zeigt grobe Zerschlitzung, in der besonders ein dreizackiger Arm von der Innenseite und ein plumper, etwas unterhalb des Sattelkopfes stehender hervorragen. Der erste Laterallobus ist sehr breit angelegt, symmetrisch mit grossen Zacken zerschlitzt und endet an der Basis in eine mediangestellte Spitze; der zweite Laterale ist ebenfalls breit, ähnlich symmetrisch zerschlitzt wie der erste und wird von dem Externlobus an Tiefe übertroffen; zunächst schliesst sich nun ein erster Auxiliar an, welcher in Folge Absinkens der Suturlinie zum Nabel eine leicht gegen den zweiten Lateralen convergirende Stellung einnimmt und in Form und Bezackung demselben ähnelt; der weitere Raum bis zum Nabelrande ist mit vier grösseren, zapfenförmigen Auxiliargliedern erfüllt, deren Deutung als ein unentwickelter zweiter Auxiliarlobus denkbar ist.

Die Sättel haben alle flachbogige Form; der Externsattel ist noch deutlich einlappig und nur mit drei grösseren und zwei kleineren Secundärzacken besetzt; er steht an Höhe nur um wenig dem ersten Lateralen nach, bei welchem der eingangs erwähnte grosse Zacken des Externlobus schon bis zur Sattelmitte vorgerückt ist und ihn hiedurch zur zweilappigen Entwicklung zwingt; im zweiten Lateralsattel ist dieser Zacken noch kräftiger geworden und reicht bis $3 / 4$ der Tiefe des Lobus herab; auch im ersten Auxiliarlobus findet sich dieser starke Zacken wieder.

Im Allgemeinen hat die Suturlinie einen, von der Höhe des ersten Lateralsattels flach absinlienden Verlauf, und der letzte Auxiliarzacken auf dem Nabelrande steht radial in der Höhe des tiefsten Zackens des Externlobus. Auffallend bei der Suturlinie ist die Leere und Breite der Sattelfelder, welche nur relativ wenig durch Zerschlitzung der Loben- und Sattelstiele reducirt wird. Jedoch gerade dieses Merlimal verringert sich bei der oben angeführten weitnabeligen Varietät. Hier tritt das Gegentheil ron dem auf, auf das oben, gelegentlich der Beschreibung des Ptychites Suttneri, hingewiesen wurde. Dort 
wurden die Loben bei der weiter genabelten Form betreffs der Breite reducirt, während hier die Sattelbreite abnimmt, so dass die Leere der Felder verschwindet und die Loben ein gedrängteres Aussehen haben.

Ptychites maximus gehört zweifelsohne in die Gruppe der Megalodisci E. \% Mojsisovics', und zwar schliesst er sich hier zunächst an Ptychites Suttneri Mojs. ${ }^{1}$ ) (pag. 25r, Taf. LXXIV und LXXV, Fig. 2, 3) und Ptychites megalodiscus Beyr. sp. (ibid., pag. 253, Taf. LXXYII) an, während ein Vergleich mit Ptychites reductus Mojs. (ibid., pag. 252, Taf. LXVIII) wegen der drei Lateralloben desselben hier nicht gezogen werden kann.

\section{Formengruppe der Ptychites opulenti Mojs.}

I8S2. Mfisisories E. *., Cephalop. Medit. Triaspr., pag. 259.

\section{Ptychites globus Hauer.}

Taf. VIII, Fig. $S a, b$ :

IS92. Ftychites (Arcestes?) globus Hutur Fr. w, Cephalop. a. d. Trias von Bosnien, pag. 39, Taf. XV, Fig. $2 a, u, c$.

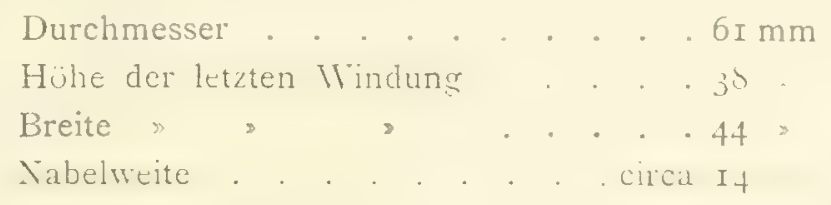

Externtheil und Flanken haben anfangs der letzten Windung einen halblugelförmigen Querschnitt, welcher sich gegen Ende der Windung etwas höher wölbt; die grösste Dicke wird in der Umbilicalregion erreicht; der Umbilicalrand ist gegen die Flanke zu abgerundet und geht dann in eine hohe, senkrecht stehende Nabelwand über. Die Involution ist bedeutend, so dass nur ein schmaler Streifen der vorhergehenden Windung sichtbar bleibt, wodurch ein steil (treppenförmig) abgesetzter, tiefer Nabel sich ergibt. Bei höherem Alter des Individuums zeigt die Flanke die Tendenz, den Nabel zu verengen.

Die vorliegenden, fast gänzlich als Steinkern erhaltenen Stücke zeigen auf demselben, und zwar auf den gehammerten Theilen zwei parallele, median gestellte feine Linien, die auch auf der Wohnkammer sichtbar bleiben, jedoch gesellen sich beiderseits zu diesen je drei annähernd in gleichen Distanzen auftretende flache Spiralstreifen, welche den Raum bis zum Nabelrand einnehmen. Gekreuzt werden diese Longitudinalstreifen von feinen, dicht gestellten — nur auf dem Steinkerne sichtbaren Radialstreifen, welche die Windung geradlinig übersetzen.

Die Suturlinie zeigt vom Externsattel ein rasches Aufsteigen zum ersten Lateral, von wo die Linie sich langsam bis zum Nabelrande senkt, den sie ungefähr in gleicher Radialhöhe mit der Spitze des Externlobus erreicht.

Der Externlobus ist schmal und sehr kurz und wird von einem schmalen Medianhöcker getheilt, wodurch sich zwei kleine seitliche Arme entwickeln, deren Basis zwei mikroskopisch feine Zähnchen aufweist; von den drei Lateralloben ist der erste zugleich der breiteste und tiefste, der mehr als die dreifache Länge des Externen erlangt; er ist asymmetrisch ausgebildet, indem die Zähnchen und Zacken, die fast bis zur Sattelhöhe des Externsattels reichen, auf der Aussenseite des Lobus wolnl in Folge Platzmangels auffallend gegen die Innenseite verkürzt erscheinen. Gleichzeitig ist der Lobus schwach schräg gegen aussen gestellt; die Basis ist mit zwei grösseren und seitlich je einem kleineren Zacken besetzt. Der zweite Laterale ist schmäler als der erste, seitlich symmetrisch entwickelt, reicht nicht ganz bis zur Tiefe des Ersten herab und zeigt eine annähernd gleiche Zerschlitzung der Basis wic dieser; der Dritte erlangt dieselbe 'Tiefe wie der Zweite, ist jedoch von Oben durch das Absinken der

') Mojsisorics EE a'.. Cephalop. Medit. 'Triaspr. 
I obenlinie gegen den Nabel verkïrt. Dann folgt ein kurzer erster Auxiliar von gleicher Irorm wic der dritte Laterale und auf der Nabelkante beginnt ein zweiter kurzer Auxiliarlobus.

Der Externsattel ist ausserordentlich klein und weist ein rundes ganzrandiges Blatt am Scheitel auf; neben kleineren Zähnchen greifen grössere Zacken an den anderen Sätteln so ein, dass der erste Lateralsattel einblätterig, die beiden anderen zweiblätterig getheilt werden; ausserdem bemerkt man im zweiten Lateralsattel einen Zacken besonders kräftig entwickelt, der auch beim Auxiliarsattel wiederkehrt; beim zweiten und dritten Lateral, sowie beim Auxiliarsattel sind die Sattelstiele leicht verjüngt.

Für Ptychites globus gibt F\%. Haucr als die nächsten Verwandten den Ptychites Pauli Mojs. 1) (pag. 25I, Taf. LXII, Fig. 2) und Ptychites domatus Hauer sp. (ibid., pag. 250, 'Taf. LXII, Fig. 4, 5) an. Ich kann mich dieser Auffassung nicht vollständig anschliessen, denn erstens differirt die bosnische von diesen beiden Arten nicht unbedeutend durch die äussere Form, zweitens durch die Gestalt der Loben. Nach der Eintheilung der Ptychiten in Formengruppen, wie sie Mlojsisowics pag. 244 Vorschlägt, gehören beide eben angeführten Formen der Gruppe der Megalodisci an, welche sich neben anderen Merkmalen durch das Auftreten nur zwe ier Lateralloben auszeichnen. Da aber, wie wir gesehen haben, Ptychites globus über drei Lateralloben verfügt, so spricht dies eher für seine Zugehörigkeit zur. Gruppe der Opulenti, wo wil ähnliche globose Formen in Ptychites opulentus Mojs. (ibid., pag. 259, 'Taf. LXXIII, Fig. I-4) und Ptychites progressus Mojs. (ibid., pag. 259, Taf. LXVII, Fig. 4, 6) finden, welche ebenfalls über drei Lateralloben verfügen; ja letztere Form zeigt so ausserordentliche Aehnlichkeit mit Ptychites globus, dass nur in der äusseren Form, welche einen etwas höher gewölbten Externtheil und weniger steil gestellte Nabelwand hat, deutlichere Unterschiede zu sehen sind, denn aucl die Suturlinien (Fig. $6 \mathrm{c}$ und vgl. ibid., Tafelerklärung!) sind fast ident.

Die Frage, ob Ptychites globus Hauer vielleicht den Arcesten zugehöre (Hauєr, pag. 70), glaube ich hiedurch der Lösung genähert zu haben.

\section{Ptychites opulentus IIojs. (Jugendform).}

laf. VIII, Fig. $9 a, b, c$.

r\$69. Arcesses cfr. Everesti Oppel, Mojsisovics E. i'., Beiträge zur Kenntniss des Cephalopodenfauna des alpinen Muschel. kalkes. Jahrbuch k. k. geol. R.A., pag. 575 .

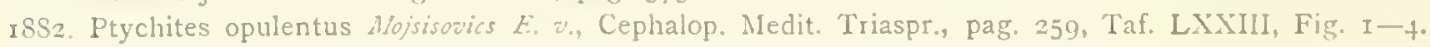

IS92. Ptychites opulentus Mojs., Hazir $\%$ \%, Cephalopoden a. d. Trias von Bosnien. Denkschr. k. Akad. d. Wiss. mat.-nat. Cl., i3d. LIX, pag. 4o.

Diese Form, welche in zahlreichen, gut erhaltenen Exemplaren vorliegt, weist die grösste Aehnlichkeit mit Ptychites opulentus auf, weshalb sie hier angeschlossen sein möge. Das kleinste von Mojsisovics abgebildete Exemplar hat einen Durchmesser von $32 \mathrm{~mm}$, während die grössten Stücke hier folgende Maasszahlen haben:

Durchmesser . . . . . . . . 2 I mm
Höhe der letzten Windung . . . . . 8 ,
Dicke $>$. . . . . . . . . . . . $7 \%$
Nabelweite . . . . . .

Analog der Beschreibung von Mlojsisovics bezüglich der Formen beim Durchmesser von I2 mm übertrifft auch hier die Dicke die Höhe, und die Form erlangt an der Nabelkante die grösste Breite. I)er Externtheil ist ziemlich hoch gerundet, die Flanke flach anschwellend gegen den Nabelrand; dieser selbst ist nur an der Kante leicht abgestumpft, während die Nabelwand fast senkrecht auf die frühere Windung abfällt. Darin liegt einer der geringfügigen Unterschiede dieser Form von Ptychites opulentus, indem hier der Nabelrand stärker gerundet, bei der Reiflinger Form hingegen nur eben die Kante abgestumpft ist.

$$
\text { 1) Mojsisoutics E. v. Cephalop. Medit. Triaspr. }
$$


Nach Mojsisorics treten, nur bis zu einem Durchmesser von $12 \mathrm{~mm}$, sich in weiten Abständen folgende Schaleneinschnürungen auf, welche bei fortschreitendem Wachsthume verschwinden und von engstehenden flachen Schalenfalten ersetzt werden. Loc. cit. Taf. LXXIII, Fig. 4 findet man aber bei dem abgebildeten Stücke von $32 \mathrm{~mm}$ noch Schalenfurchen und ausserdem Falten, was vollständig den Verhältnissen bei den Reiflinger Formen entspricht, wo bei der eben angegebenen Grösse sich ebenfalls beide Sculpturformen finden; die negative auf dem Steinkerne und die positive in Gestalt von engstehenden, geraden, radial verlaufenden Falten, welche den Externtheil nicht erreichen und sich in feine Linien auflösen. Die Involution ist ausserordentlich gross, indem der vorhergehende Umgang bis zum Rande bedeckt wird, so dass ein trichterförmiger Nabel entsteht. Er ist relativ gross im Verhältnisse zu Jugendformen von der Schreyeralpe, indem er dort beim Durchmesser von" $32 \mathrm{~mm}$ erst $7.5 \mathrm{~mm}$ beträgt und hier schon bei 2 I $\mathrm{mm}$ die Grösse von $7 \mathrm{~mm}$ erlangt.

Die Suturlinie ist sehr ähnlich der von Mlojsisozics abgebildeten Form: drei Lateralloben und auf dem Nabelrande ein kleiner Auxiliarlobus. Die Suturlinie steigt rasch zum ersten Lateralsattel an und senlit sich langsam zum Nabelrand herab. Der einzige Unterschied liegt in dem kleinen Auxiliarlobus, der hier schon auf dem Rande auftritt, was dort noch nicht der Fall ist.

\section{Unterfamilie: Gymnitinae Waag. \\ Gattung: Gymnites Mojs.}

Gymnites gibberulus Art.

Taf. VIII, Fig. $5 a, b, c$, Fig. $6 a, b, c, d$

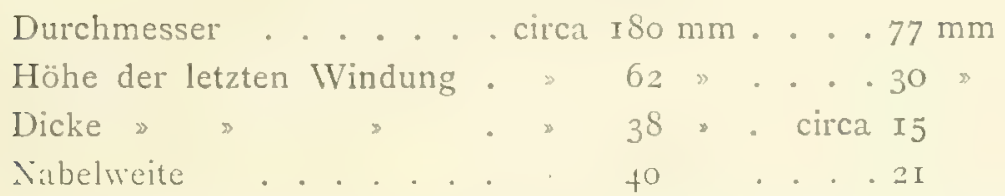

Der Externtheil ist hoch-gerundet, die flachen Flanken erreichen bei jüngeren Individuen in der oberen Lateralfäche, bei älteren etwas tiefer die grösste Breite und sind von dem Externtheil nicht abgegrenzt; der Umbilicalrand ist abgestumpft und geht in eine steilgestellte, anfangs niedere, bei weiterem Vachsthum höhere Nabelwand über. Der Nabel ist weit und vergrössert sich bei weiterem Wachsthum relativ, ebenso wie die Involution geringer wird, die bei dem kleineren Individuum (Fig. 6) mehr als die Hälfte, später weniger beträgt.

Bei den in Fig. 5 abgebildeten grösseren Individuen tritt - bei einem Durchmesser von circa r ro mm - auf der Flanke, etwas oberhalb der Flankenmitte ein spiraler, flacher Wulst oder niederer Lateralkiel auf, ähnlich demjenigen bei Gymnites obliquus Mojs. ${ }^{1}$ ) (pag. 236, Taf. LVI, Fig. I), Gymnites Credneri Mojs. (pag. 237, 'Taf. LIX, Fig. I $a$ ) und Gymnites Ecki Mojs. (pag. 238, Taf. LX, Fig. $3 a$ ), der aber bei diesen Formen meist in längliche Knoten aufgelöst ist, während er hier persistirt, auch relativ früher auftritt als dort. Immerhin scheint diese rudimentäre Flankensculptur nur eine Eigenthümlichkeit der Wohnkammer zu sein, welche bei Gymnites gibberulus noch etwas länger erhalten ist und jedenfalls länger als ein Umgang gewesen sein muss.

Die Suturlinie besteht aus reichzerschlitzten Loben- und Sattelelementen und ist in drei Entwicklungsstadien zu bcobachten. Bei Fig. $6 c$ zu Beginn des letzten Umganges, ferner Fig. $6 d$ am Ende desselben beim jüngeren Exemplar und Fig. $5 c$ die vorletzte Suturlinie vor Beginn der Wohnkammer beim grossen Fragmente.

Die jüngste Suturlinie zeigt einen breiten Externlobus, welcher ungefähr an ' liefe $3 / 4$ des ersten Lateralen entspricht; der Medianhöcker ist sehr breit, geht in eine stumpfe Spitze aus, welche durch

1) Mojsiscuics Li. V., Cephalop. Medit. Triaspr. 
je ein Zäckchen direct gekerbt ist, so dass sich ein vertiefter Centraltheil abscheidet. Aussen. und Innenwand des einen Armes des Lobus, der - wenn man so sagen darf — fast ganz auf der Flanke liegt, ist reich geschlitzt, und zwar die Aussenwand mit feineren, die Innenwand mit grösseren und secundär wieder mit feiner zugespitzten und getheilten Zacken. Insbesondere ragt einer daselbst stark hervor, der schon sehr hoch am Sattel situirt ist; der stark verengte Lobengrund ist mit zwei grösseren Zacken besetzt. Im zweiten Entwicklungsstadium sind die Verhältnisse fast dieselben geblieben; die beiden Zacken des Lobengrundes verschieben sich etwas, indem der äussere fast in die Mitte rückt, während von Aussen sich ein grössercr Zacken zu entwickeln beginnt, der eine symmetrische Stellung zu dem innern einzunehmen bestrebt ist. Beim dritten Stadium ist der zuletzt zugewachsene Zacken schon von gleicher Grösse wie die beiden älteren, und der Lobengrund ist jetzt durch drei Aeste, einen mittleren und zwei seitliche, getheilt.

Der Externsattel ist hoch gewölbt, niederer als der erste Laterale und durch Zähnchen und Zacken zerschnitten. Seine Form bleibt bei den zwei anderen Entwicklungsstadien diesclbe.

Der erste Laterallobus zeigt einen rundlichen Lobengrund, welcher durch einen längeren, median gestellten und zu beiden Seiten je zwei grössere und kleinere symmetrisch angeordnete Zacken getheilt ist. Die Sattelstiele sind an der Basis leicht verjüngt, zeigen wie beim Externsattel an der Innenseite grössere und reichere Zerschlitzung und beiderseits einen besonders hervorragenden Zacken. Der Sattel selbst ist von gleicher Form wie der Externe, reicht jedoch höher hinauf. Auch hier ändert sich in den beiden Entwicklungsstadien nichts Principielles, nur die Zacken werden grösser, ihre secundäre Zerspaltung feiner und in die Zackenzwischenräume schieben sich feine Zähnchen ein.

Der zweite Laterallobus ist schmäler als der erste, hat ungefähr die Tiefe des Externen und zeigt eine ähnliche dreitheilige Zerschlitzung des Grundes, jedoch an der Aussenseite grössere Zackenelemente. Der Sattel ist schmal, schmäler als der Externe, und reich geschlitzt.

An den zweiten Laterallobus schliesst sich eine Serie von kleinen Auxiliarloben an, welche zackenförmig entwickelt sind und deren Scheitel an einer Geraden stehen, welche vom hopf des zweiten Lateralsattels rasch zum Nabel absinkt und den Nabelrand in radialer Richtung unterhalb des Externlobus erreicht. Eine andere, ebenfalls richtige Auffassung wäre die, dass man von einem einzigen langen, flachen und reich geschlitzten Auxiliarlobus sprechen könnte.

Gymnites gibberulus unterscheidet sich von den oben angeführten Gymniten durch den erwähnten Unterschied im Auftreten des Lateralwulstes, ferner der Form des Flankenquerschnittes und der Involution; er unterscheidet sich von dem ihm am nächsten stehenden Gymnites incultus Beyrich sp. ${ }^{\prime}$ ) bezüglich der Suturlinie durch die Form des Externlobus. Dieser ist bei letzterer Form von fast derselben Tiefe wie der erste Lateral, ist aber oben breit angesetzt und dann in einen langen Ast ausgezogen, der wieder dreitheilig endet, während er bei Gymnites gibberulus von geringer Tiefe, im Ganzen breit, am Grunde nur verjüngt ist und erst bei ganz erwachsenen Individuen in drei kurze Arme endet.

Noch ist die Analogie des Gymnites gibberulus mit einer Form aus dem bosnischen Muschelkalk zu erwähnen, mit Gymnites Bosnensis Hauer²) (pag. 37, Taf. VIII, Fig. I). Der Unterschied besteht darin, dass die bosnische Form schlankere Umgänge von geringerer Höhe besitzt, was schon aus den Maasszahlen rgo mm Durchmesser zu $36 \mathrm{~mm}$ Windungshöhe gegen $180 \mathrm{~mm}$ zu $62 \mathrm{~mm}$ erhellt, bei einer relativen Dicke von $20 \mathrm{~mm}$ zu $80 \mathrm{~mm}$. Auch die Suturlinie hat, abgesehen davon, dass sie bei der Reiflinger Species einen gröberen Charakter trägt, bei der bosnischen feiner geschlitzt erscheint, gewisse, jedoch nur geringfügige Unterschiede.

Mojsisozics E. v., Cephalop. Medit. Triaspr., pag. 233, Taf. LIV, Fig. I-3.

Hhuer lir. á, Cephalop. bosn. Muschell. ISS7. 


\section{Familie: Meekoceratidae Waag. \\ Unterfamilie: Kymatitinae Waag.}

Im demnächst erscheinenden Theile der Salt-Range Fossils, Vol. II, pag. $240 \mathrm{ff}$, stellt Waagen die Familie der Meekoceratidae auf, deren ältere Glieder der früheren Familie der Pinacoceratidae, beziehungsweise den Unterfamilien der Lytoceratinae und Ptychitinae angehörten. Die Familie der Meekoceratidae zerfällt wieder in die Unterfamilien:
I. Kymatitinae,
II. Aspiditinae,
III. Meekoceratinae,
IV. Gyronitinae,

welche sich im Allgemeinen in zwei Gruppen trennen lassen, deren erste gänzlich unsculpturirte Formen mit goniatitischer Lobenentwicklung unfasst - Unterfamilie der Kymatitinae -, während die zweite grössere Gruppe, welcher die restirenden Unterfamilien zufallen, glatte und sculpturirte Formen enthält, bei denen die ceratitische Lobenform prävalirt.

Die Unterfamilie der Kymatitinae wird nur aus zwei Gattungen gebildet:

$$
\begin{aligned}
& \text { Kymatites WVaag., } \\
& \text { Parakymatites Waag., }
\end{aligned}
$$

welche sich von einander durch die Form des Externlobus und das Vorhandensein oder Fehlen einer Auxiliarserie unterscheiden. Im Allgemeinen wird die Verwandtschaft mit Lecanites Mojs. betont, jedoch als trennende Merkmale auf die Form der Loben, speciell des Externlobus sowie auf die Weit- oder Engnabeligkeit hingewiesen.

Als Charakteristica der. Unterfamilie führt Waggen an: Stets glatte, Hachgewölbte Flanken, Externtheil flach gerundet oder mit leicht abgestumpften Marginalkanten, über welchẹ dann ein flach gerundeter Mediantheil aufragt; die Umbilicalkante ist deutlich entwickelt, jedoch abgestumpft; die Umgänge sind weitumfassend, wodurch ein relativ enger Nabel offen bleibt.

Die Suturlinie besteht aus einem ausserordentlich breiten Externlobus, welcher durch einen breiten Medianhöcker getheilt ist, wodurch zwei Lateralflügel sich ergeben, welche schon gan\% auf die Flanke zu liegen kommen und den Anschein von Adventivloben erwecken; sodann finden sich zwei fast clydonitische Lateralloben, der erste gross, in seltenen Fällen einige kleine, unregelmässige Zäckchen aufweisend, der zweite klein. Bei den Kymatiten schliesst sich gegen den Nabel ein breiter, flacher Auxiliarlobus an, bei Parakymatites folgt eine Serie von drei successive kleiner werdenden Auxiliarloben; die Loben sind clydonitisch, die Sättel breit gerundet und ganzrandig.

Im Reiflinger Kalke fanden sich drei Formen, die durch Aehnlichkeit der äusseren Gestalt und Verlauf der Suturlinie sich als gemeinsam einer Gruppe angehörend erwiesen und welche ich in der Folge als

\section{Proavites}

behandeln werde. Sie unterscheiden sich vollständig von allen bis jetzt bekannten alpinen Formen und dürften wohl hier bei den Kymatitinen ihren natürlichsten Anschluss finden. Sie zeigen dieselbe ïussere Form wie jene, haben ebenfalls clydonitische Lobenelemente und flachgerundete, ganzrandige Sättel, unterscheiden sich jedoch vollständig durch die Gestalt des Externlobus. Derselbe ist nicht breit wie dort, sondern ist ausserordentlich schmal und wird von einem schmalen Medianlöcker in zwei schmale Arme getheilt, welche an der Basis spitz oler leicht abgestumpft endigen. Nachdem alle anderen Merkmale von Proavites mit den Formen der obigen Unterfamilie Wargen's übereinstimmen, ausserdem aber zwischen Kymatites und Parakymatites gewisse Lnterschiede in der Ausbildung des 
Externlobus schon bestehen, so schliesse ich Pronvites hier und insbesondere an kymatites selbst an, wodurch sich aber die Nothwendigkeit ergibt, die Diagnose der Unterfamilie der Kymatitinen um das oben angeführte Merkmal der Entwicklung des Externlobus bei Proavites zu erweitern.

\section{Gattung: Proavites Art.}

Die hieher gehörenden Formen haben flach-scheibenförmige Gestalt mit nur wenig gewölbten Flanken, welche die grösste Breite in der Umbilicalregion erlangen; der Externtheil ist flach, die Marginalkante scharfkantig entwickelt, der Umbilicalrand leicht abgerundet; die Involution ist gross und lässt nur einen kleinen, treppenförmig abgesetzten Nabel offen, mit relativ hoher, fast senkrechter Nabelwand; die Flanken sind sculpturfrei; die Schale wscheint sichelförmig gebogene Anwachslinien zu zeigen.

Die Länge der Wohnkammer liess sich nicht ermitteln.

Die Suturlinie hat den Typus der Kymatitinen: es treten zwei Lateralloben von clydonitischer Form mit flach-bogenförmigen Sätteln auf, an welche sich auf dem Nabelrande ein kleiner Auxiliar anschliesst; der Externlobus ist im Gegensatze zu Kymatites und Parakymatites schmal, wird ron einem schmalen Medianhöcker in zwei schmale Aeste getheilt, welche an der Basis abgestumpft oder spitz endigen; der Lxternsattel liegt auch zum grösseren Theile auf der lilanke.

Die von Waggcn ausgesprochene Ansicht, dass die Unterfamilie der Kymatitinen zunächst in Verwandtschaft zu Lecanites Mojs. steht, bestätigt sich auch hier insoferne, dass die Form des Ėxternlobus vollständig dieselbe Ausbildung hat wie bei Lecanites Mlojs.

\section{Proarites Hüffeli Art.}

Taf. X. Fig. $2 a, b, c, d$.

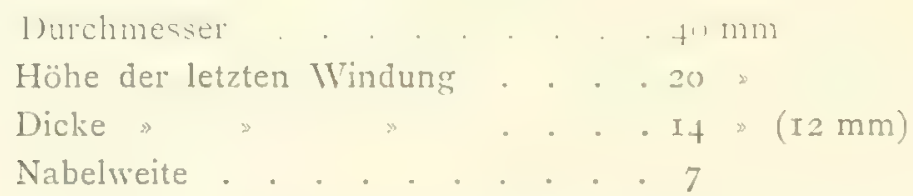

Der Externtheil ist breit und flach, die Flanken leicht gewölbt und erlangen die grösste Dicke in der Umbilicalregion; die Marginalkanten sind scharf entwickelt, der Umbilicalrand sanft abgerundet, die Nabelwand fast senkrecht stehend. Die Form hat weitumfassende Umgänge, so dass nur ein kleiner, țreppenförmig abgesetzter Nabel offen bleibt.

Die Suturlinie zeigt zwei Lateralloben und auf dem Nabelrande einen kleinen Auxiliarlobus; die Schcitel der Sättel stehen an einer Radiallinie; der Externlobus ist schmal, reicht ungefähr bis $2 / 3$ der Tiefe des ersten Lateralen herab und wird von einem schmal-konischen Medianhöcker in zwei Aeste getrennt, welche spitz enden; der erste Laterallobus erreicht die grösste Breite und Tiefe unter den Lobenelementen, endet rundbogig und ist ganzrandig; der zweite Laterale erlangt nur ungefähr die Hälfte der Tiefe des Externen, ist schmal, ebenfalls ron runder Form und ganzrandig; der Auxiliarlobus ist noch kleiner als der zweite Laterale, sonst aber von denselben Formverhältnissen. Die Sättel sind ron rundbogenförmiger Gestalt; der Externsattel erreicht die grösste Spannweite und liegt grösstentheils schon auf der Flanke; der zweite Lateralsattel ist von derselben Breite wie der erste, jedoch gegen den Nabelrand zu etwas verzogen; auf der Nabelwand schliesst sich an den Auxiliarlobus ein kleiner, flacher Sattel an. Sämmtliche Sättel sind ganzrandig.

Wahrend die äussere Form an gewisse Meekoceraten erinnert, ist die Suturlinie in ihrer goniatitischen Einfachheit doch gänzlich anders entwickelt, so dass es schwer ist, Proavites an andere alpine formen anzureihen. 
Beide vorliegende Stücke sind fast gänzlich als Steinkern erhalten, nur an einer Stelle ist auf der Marginal- und Extermpartie noch ein kleiner Rest der Schale zu sehen. Er zeigt einen nach vorne offenen Bogen, welchen die feinen Zuwachsstreifen bilden, die den Externtheil bogenförmig convex überspannen. Das wäre ein ähnlicher Verlauf, wie wir ihn bei Norites falcatus Art. (pag. 89 , Taf. VIII, Fig. I) kennen gelernt haben, weshalb wohl der Schluss gestattet ist, dass sich an den concaven Marginal. theil der Zuwachsstreifen ein convexer Theil ungefähr in der Flankenmitte anschliesst und ein gerades Radialstïck die Verbindung mit dem Nabelrand herstellt, also mit einem Worte ein sichelförmiger Verlauf der Zuwachsstreifen angenommen werden kann.

\section{Proavites marginatus Art.}

Taf, X, Fig. $4 a, b, c$

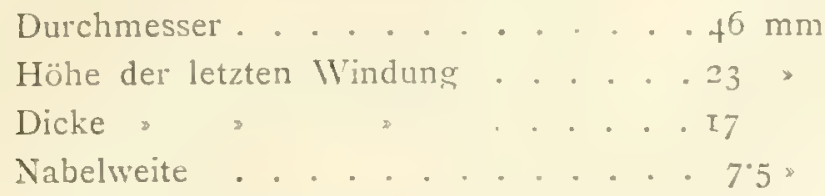

Der Externtheil ist flach, die Flanken schwellen gegen den Nabel zu an und erreichen, von dort gerechnet, ungefähr im ersten Drittel der Flanke die grösste Dicke; der Aussenrand ist scharfkantig entwickelt; der Nabelrand abgestumpft; die Nabelwand ist hoch und sehr steil gestellt; die Involution lässt nur einen schmalen Streifen der früheren Windung frei, so dass der Nabel klein und treppenförmig abgesetzt erscheint. Die Schale ist nicht erhalten.

Die Suturlinie ist von ähnlicher Form, wie wir sie bei Proavites Hüffeli kennen gelernt haben, nur zeigt sich der Unterschied, dass die Sattelscheitel nicht wie dort an einer geraden, sondern flach bogenförmig gekrümmten Linie anstehen, indem der erste Lateralsattel den Externen nur um wenig, der zweite um etwas mehr an Höhe überragt.

Der Externsattel reicht fast zur halben Tiefe wie der erste Lateral herab; er ist klein und von einem niederen Medianhöcker in zwei Aeste getheilt, welche beiderseits in je eine Spitze enden; der erste Lateralsattel ist breit und tief, der Zweite kurz und klein, beide an der Basis gerundet, von clydonitischer Form; auf dem Nabelrande schliesst sich ein kleiner, gerundeter Auxiliarlobus an, dem auf der Naht selbst ein zweiter, kleinerer folgt. Die Sättel sind ebenfalls ganzrandig und von flachbogenförmiger Gestalt; der Externsattel, welcher grösstentheils auf die Flanke zu liegen kommt, hat die weiteste Spannung, während der erste und zweite Lateralsattel von gleicher Weite sind und Letzterer noch flachere Form hat als Ersterer, auch gegen den Nabel etwas verzogen erscheint; der Auxiliarsattel, welcher auf der Nabelwand liegt, ist von älnnlicher Gestalt.

Der Unterschied zwischen Proavites Hüffeli und Proavites marginatus besteht darin, dass letzterer einen etwas schmäleren Externtheil besitzt, wodurch diese Art scheinbar grössere Dicke erlangt, sowie einen stärker abgerundeten Nabelrand aufweist; auch ist die Form des Externlobus im Verhältnisse zum ersten Lateralen eine etwas geänderte, die hier von srösserer, dort geringerer Tiefe ist.

\section{Proavites avitus Art.}

Taf. I, Fig. $3 a, i, c$

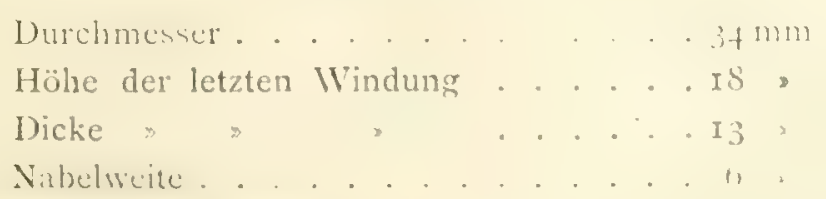

Der Externtheil ist flach, die Flanke leicht anschwellend gegen die Umbilicalregion, so dass sie im unteren Flankendrittel die grösste Breite erlangen; die Marginalkante ist scharf entwickelt, der 
Marginalrand leicht gerundet; die Nabelwand ist hoch und senkrecht stehend, der Nabel relativ weit im Verhältniss zu den anderen Arten dieser Gattung; die Involution ist gross und lïsst einen sclımalen Streifen der früheren Windung frei, so dass der Nabel treppenförmig abgesetzt erscheint. Dic Schale ist nicht erhalten.

Die Suturlinie ist sehr schwach gekrümmt, was dadurch hervorgerufen wird, dass der erste Lateralsattel etwas höher als der Zweite und der Externe emporragt; wir finden ebenfalls wieder zwei Lateralloben. Der Externlobus hat hier fast die Tiefe des ersten Lateralen, ist klein, von einem sehr kurzen, schmalen Medianhöcker getheilt, wodurch jederseits ein kleiner Ast entsteht, welcher an der Basis stumpf endet; der erste Laterallobus ist relativ kurz, breit und ganzrandig, sowie der Zweite, welcher sehr klein entwickelt ist; auf der Nabelwand schliesst sich ein gerundeter Auxiliarlobus an, welcher etwas tiefer hinabreicht und eher etwas grösser ist als der zweite Laterallobus. Die Sättel sind breit gerundet; der Externsattel crlangt die grösste Breite und wird von der Marginalkante halbirt; der zweite Lateralsattel ist fast ebenso breit, jedoch flacher und gegen den Nabel etwas verzogen; der erste Lateralsattel ist der kleinste; sämmtliche Sättel sind ganzrandig.

Der Unterschied zwischen Proavites avitus und Proavites marginatus und Proavites Hüffeli besteht darin, dass Ersterer etwas weitnabeliger als die anderen Formen ist, dass der Externlobus viel kleiner ist und fast zur Tiefe des, hier auch kürzeren, ersten Laterallobus herabreicht, dass der Externsattel von der Marginalkante halbirt wird und der erste Auxiliarlobus noch nicht auf den Nabelrand vorgerückt ist, wenn auch auf dieses letztere Merkmal kein grosses Gewicht zu legen ist, weil es vielleicht nur durch individuelles Alter bedingt ist.

\section{Anhang: Isolirte Form.}

\section{Nov. gen. Sphaerites Art.}

Als Genus Sphaerites, welches gegenwärtig erst in einer Species vorliegt (mit vier Exemplaren), bezeichne ich kleine, globose Gehäuse mit weitumfassenden Umgängen, deren letzter Theil sich bei erwachsenen Formen auszuschnüren beginnt. Die Schale ist glatt; auf dem Steinkerne treten in weiten Abständen Einschnürungen auf. Die Wohnkammer beträgt ungefähr $3 / \frac{1}{4}$ mgang. Die Suturlinie zeigt einen breiten, tiefen Externlobus, welcher von einem breiten, niederen Medianhöcker getheilt ist, einen breiten, noch etwas tiefer herabreichenden gezackten Laterallobus, zwischen beiden ein kleiner Adventivlobus, welcher einspitzig endet, und auswärts des Nabelrandes einen runden, breiten Auxiliarlobus. Die Sättel sind flach-bogenförmig und ganzrandig; die vorangehende Windung auf die folgende, Letzte projicirt, schneidet einen kleinen Theil des Lateralsattels ab.

Es ist ausserordentlich schwierig, diese so beschaffene Gattung in das bestehende System einzureihen oder anzuschliessen; ich muss diese Frage auch vorläufig noch offen lassen, weil es nach meiner Ansicht richtiger ist, derlei aberrante Formen eine Zeit lang als s isolirte Formen ohne Anschluss mitzuführen, bis sich durch glückliche weitere Funde von Aehnlichem die naturgemässe Stellung von selbst ergibt, als sie willkürlich, nur aus subjectiven Gründen, in das bestehenđe System einzuzwängen.

Die äussere Form von Sphaerites hat entschieden gewisse Analogien mit Nannites Mojs. ${ }^{1}$ ) (pas. 210), und zwar insbesondere mit Nannites Bittneri Mojs. (pag. 2Io, Taf. XXXIX, Fig. I I) gemein. Wir finden bei dieser Form dieselbe globose, engnabelige Gestalt wieder mit breitem Ventraltheil und xrösserer Breite der Windungen als Höhe, eine sich ähnlich einsenkende Umbilicalregion mit stei? grestellter niederer Nabelwand. Nur freilich ist die Suturlinie bei beiden Formen vollständig verschieden;

1) Mojsisovics E. 2 ., Cephalop. Medit. Triaspr. 
bei Nannites mit clydonitischen Lobenelementen, hier bei Sphaerites mit einem deutlich gezachten Laterallobus und als deutlichst trennendes Merkmal das Auftreten eines Adventivlobus.

Sonst kämen nur mehr Jugendformen von Arcestes oder Joannites in Betracht, die eine ähnliche globose Gestalt ja auch besitzen und Contractionen auf dem Steinkerne zeigen. Die Analogie ist jedoch nur eine zufällige, denn die Suturlinien sind eben ganz anders entwickelt. Jugendformen ron Ptychiten können hier nicht berücksichtigt werden, denn erstens sind sie stets viel weitnabeliger und zweitens überwiegt bei diesem Durchmesser ( $10 \mathrm{~mm}$ ) noch meist die Höhe die Breite.

Ueberhaupt darf ein Jugendstadium nicht zum Vergleiche herangezogen werden, denn in dem abgebildeten Stück haben wir, wenn auch vielleicht nicht ein vollständig erwachsenes Individuum vor uns, so doch zum Mindesten keine Jugendform mehr, denn die Suturlinien stehen schon ziemlich enge auf dem letzten Umgange.

Gewisse Kreideformen, z. B. Tissotia mit den tiefgespaltenen Sätteln der Suturlinie, dürfen in Folge der zahlreichen Lobenelemente hier auch nicht im Entferntesten in Betracht kommen.

Sphaerites globulus Art.

Taf. X. Fig. 5 a, $\therefore$.

Durchmesser . . . . . . 10 mm
Höhe der letzten Windung
Dicke
Nabelweite . . . . . . . . 62

Die Externseite ist breit gerundet und vereinigt sich mit der Flanke zu einer kugeligen Windungsform, bei welcher sich in Folge dessen keine Spur eines Marginalrandes abscheidet; die Flanke senkt sich in der Umbilicalregion zum eigentlichen Umbilicalrand sanft herab, der selbst deutlich, wenn auch leicht abgestumpft entwickelt ist und an den sich eine niedere, fast senkrecht stehende Nabelwand anschliesst. Dieser globosen Windungsform entspricht ein sehr kleiner Nabel; die Umgänge sind stark involut, indem die frühere Windung fast vollständig umhüllt wird, wodurch ein kleiner, trichterförmiger Nabel frei bleibt. Beim Durchmesser von $7 \mathrm{~mm}$ findet sich noch keine Spur einer beginnenden Ausschnürung, welche bei ro $\mathrm{mm}$ Durchmesser — wie das abgebildete Stück zeigt schon kräftigst entwickelt ist.

Die Schale ist glatt und mit ziemlich kräftigen, radialen Zuwachsstreifen bedeckt, welche gleichmässig Flanken- und Externtheil überziehen. Auf den Steinkernen treten Einschnürungen auf, die besonders kräftig auf der Ventralseite entwickelt sind und deren sich auf einem Umgange höchstens zwei constatiren lassen.

Die Suturlinie zeigt im Allgemeinen einen streng radialen Verlauf, indem die Scheitel der Sättel an einer Radiallinie anstehen; ein einziger Laterallobus ist vorhanden.

Der Externlobus reicht fast so tief herab, wie der Laterale, ist sehr breit und wird von einem breiten, niederen Medianhöcker in zwei Aeste gespalten, welche an der Basis stumpf enden; in dem breiten Raume zwischen Extern- und Laterallobus finden wir einen kleinen Adventivlobus, der wohl kräftig entwickelt ist, jedoch im Verhältniss zu den beiden anderen Lobenelementen als klein zu bezeichnen ist; er reicht ungefähr bis zu $3 / 4$ der Tiefe des Lateralen herab, ist ziemlich schmal und endet einspitzig, so dass er eine trigonale Form zeigt; der Laterale ist breit und seine Basis mit vier Spitzen versehen, von denen zwei grössere flach und gespreitzt am Grunde stehen und darüber jederseits ein kleines, lateral gestelltes Zäckchen sichtbar wird. Bis zum Nabelrande folgt cin Auxilias, der ungefüh die Tiefe des Adventivlobus hat; er ist gerundet und ganzrandig. 
Die Sättel sind sämmtlich flachbogenförmis; der lixternsattel ist am stärksten gerundet und zugleich der kleinste, während Adventiv und Lateralsattel annähernd von gheicher Form und Grösse sind und der Auxiliarsattel sich flach über die Nabelwand herabsenkt. Die Sättel sind ganzrandig und die Sattelstiele an der Basis leicht verjüngt. Die Projectionslinie der früheren Windung schneidet einen kleinen Theil noch vom Lateralsattel ab.

\section{VERTEBRA'TA.}

\section{Lepacanthus gracilis Art.}

Iange . . . . . . . . . . . . . . .

Der in mehreren theils besser, theils schlechter erhaltenen Exemplaren vorhandene I'lossen. stachel ist von schlanker Gestalt, hat im unteren Theile einen fast geradlinigen Verlauf, während der obere, grössere Theil eine flache Krümmung nach rückwärts aufweist.

Der Querschnitt des Stachels zeigt kein vollständiges Oval, sondern zwei vordere, flachgerundete Seiten, während der rückwärtige Theil gerundet ist und vier kleine Längsriefen zeigt. Die beiden vorderen Flächen, welche sich unter sehr stumpfem Winkel treffen, sind mit feilenartiger Qucrsculptur bedeckt, welche aus schräg von oben gegen abwärts laufenden Linien besteht, welche wieder ron längslaufenden, feineren gekreuzt werden. Die Kante selbst ist ein Stück weit mit feinen Spitzen oder Widerhaken besetzt. Die Schalensubstanz des Stachels ist relativ schwach entwickelt, wodurch ein grosser Hohlraum für die ebenfalls asymmetrisch entwickelte Alveole frei bleibt, welche sich bis in die Spitze fortsetzt und hier knapp unter derselben als feiner, oval geformter Canal endet.

Bezüglich der Orientirung dieses Stachels deutet sowohl die feilenartige Streifung und der Besatz der Schneide mit kleinen Widerhaken, als auch die Krümmung des Stachels selbst, sowie die Art der asymmetrischen Entwicklung desselben darauf hin, dass die mit Längsfurchung versehenen Seiten als die vorderen anzusehen ist. Die Deutung des Stückes, ob es als Flossen- oder Nackenstachel aufzufassen ist, fällt hier freilich schwer. Unter den triassischen Fischen ist keiner bekannt, der ähnliche Stacheln besessen hätte. Die Form vielmehr, sowie die Zeichnung und das weite Hinaufreichen der Alveole in die Spitze erinnert eher an die Nackenstacheln permischer Xenacanthiden, deren Nachkommen allerdings noch in triassischen Meeren gelebt haben können. Es würde somit der Nachweis ron Xenacanthiden in der Trias diesem Funde eines Nackenstachels interessante Bedeutung verleihen.

Mastodonsaurus spec. indet.

Länge des Schädels . . . . . circa $95 \mathrm{~cm}$
Breite , . . . . . . . 34 . 945
Approximative Länge des ganzen Thieres .

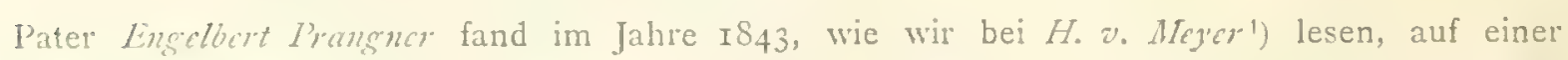
grossen Platte des oberen Reiflinger Kalkes - nach dem heutigen Stande unserer Kenntniss - im 
alten Steinbruche des Scheiblinggrabens, der am Westausgange der Ortschaft Gross-Reifling beginnt, die Reste eines gewaltigen "Saurus«, der wohl hundertfünfzig Jahre dem Einflusse der Atmosphärilien ausgesetzt gewesen sein mag. Im Sommer I $8+7$ sah W. Haidinger ${ }^{2}$ ) gelegentlich eines Besuches der nordsteirischen Gebirge jenes interessante Fossil noch in situ und gab die erste Anregung dazu, dass dieser überaus werthvolle Fund für die Wissenschaft gerettet werde.

Da Grund und Boden dem Stifte Admont gehörte, kam das Stück kurze Zeit darauf in das Stiftsmuseum, woselbst es leider bei dem Brande des Klosters (I863) fast vollständig zu Grunde ging. IVir müssen es wohl aufrichtigst beklagen, dass von diesem Unicum nie eine Abbildung angefertigt worden war, die den interessanten Fund der Wissenschaft erhalten hätte, ja auch nicht einmal eine ausreichende Beschreibung geboten worden ist. Die wenigen Bemerkungen, die W. Haidingcr darüber veröffentlichte und die kurze Motivirung H.v. Meyer's für seine Bestimmung als Ichthyesaurus platyodon Cony 6 . sind im Grunde genommen das Ganze, was wir als Beschreibung des Stückes besitzen. Der letzte Geologe, welcher dasselbe im Admonter Museum noch gesehen hatte, Dyonis Stur, beschränkte sich in seiner "Geologie der Steyermark* (pag. 218 und 219) auch nur darauf, seine Zweifel an der Mcyer'schen Bestimmung auszudrücken und gab kurz die oben angegebenen Maasse an. Somit schien der Reiflinger Fund vollständig für uns verloren zu sein!

D1. A. Bittner hatte nun schon vor Jahren gelegentlich seiner geologischen Aufnahmsarbeiten des Blattes Admont-Hieflau das Glück, bei dem Gastwirthe in Palfau (im Salzathale), Herrn Hinter . buclinger, eine allerdings etwas mangelhafte Zeichnung des Reiflinger „Saurus zu entdecken; leider wollte sich der Besitzer nicht ron dem Bilde trennen und erst im heurigen Sommer gelang es Dr. Bitther, die Einwilligung zu der Reproduction des Bildes zu erlangen, und übergab mir dasselbe in zuvorkommendster Weise zur Publication, wofür ich ihm hier meinen verbindlichsten Dank sage. Auf seinen Rath sandte ich nun einen Abzug des Bildes, das in der Einleitung zu der vorliegenden Arbeit auf pag. I4 seinen Platz gefunden hat, an Hern Prof. W. Deecke in Greifswald, der in bereitwilligster Weise die Beschreibung des alten Reiflinger Fundes übernahm. Ich benütze daher mit Freuden die Gelegenheit, Herrn Prof. Deccke meinen besten Dank für seine freundliche Mitarbeiterschaft auszusprechen.

Ich füge zum Schlusse noch hinzu, dass nach den oben citirten Angaben H. $\%$. HIy rr's $^{\prime}$ das Stück in einem sesten, schweren, grünlichgrauen Mergelkalke erhalten war, das wahrscheinlich ein Zwischenmittel in den besonders im Anschlusse des Scheiblinggrabens selu gleichmässig entwickelten knolligen Reiflinger Kalken repräsentirte.

Prof. Decke berichtet mir nun Folgendes: „Das Stück, dessen Abbildung Sie mir zusandten, hat schon früher einmal (I885) von meiner Seite Nachforschungen veranlasst. Bei der Abfassung meines Aufsatzes über Lariosaurus etc. wandte ich mich an den jetzt verstorbenen Director Stur mit der Bitte, um Aufschluss über dies interessante Vorkommen eines Ichthyosaurus im Reiflinger Kalke und erfulı1. nun, dass die Platte verbrannt sei, aber das Reptil schwerlich ein Ichthyosaurus gewesen sei. Diese Ansicht ist auch schon in der ${ }^{2}$ Geologie von Steyermark ausgesprochen (2IS-2I9). Ferner hat ja

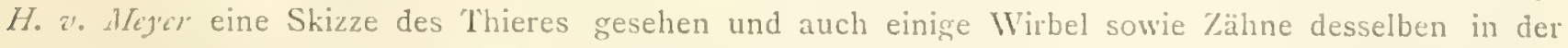
Hand gehabt. Vielleicht ist es nun mit Hilfe aller dieser Angaben und der von Herrn Bittncy wieder entdecliten Abbildung möglich, die ungefähre Stellung đes Thieres zu ermitteln.

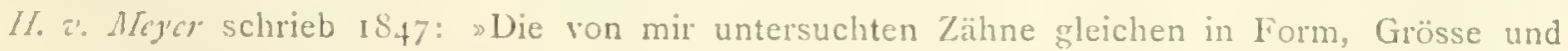
sonstiger Beschaffenheit dem Zahn, von welchem Cuvier Oss. foss., t. 226, f. 4, 5, Abbildung gibt, und der dem Ichthyosaurus platyodon beigelegt wird. Der gegen + Fuss lange Schädel wüirde in Grüsse und Form ebenfalls zu genannter Species passen, dessen Wirbel aber noch nicht so genau dargelegt sind, um mit den zu Reifling gefundenen verglichen werden zu können. Einen, letzterem ähnlichen Wirbel kenne ich von Littersberg bei Weinar. Das Reptil scheint daher Ichthyosaurus platyodon zu sein. 
Fasst man die Abbildung ins Auge, so erkennt man einen dreieckigen liopf, der nach Siu circa $95 \mathrm{~cm}$ lang und $3+\mathrm{cm}$ breit gewesen ist. Derselbe liegt auf der Oberseite, und es sind die beiden Unterkieferäste in der Symphyse auseinander gebrochen, sowie halb nach innen umgeklappt, so dass die Zahnreihen deutlich hervortreten. Die beiden Unterkiefer lassen sich ferner an den über die Schädelbasis hinausragenden Angularenden deutlich erkennen; sie dürften daher beiderseits die Contur des Schädels in der Figur bestimmen. Hinter dem Kopfe befinden sich theils zerstreut, theils im Zusammenhange 24-25 Wirbel, welche kurze Körper, stärker hervortretende Ränder haben und daher in der Mitte etwas eingeschnürt erscheinen. Die Gelenkflächen scheinen stark vertieft gewesen zu sein. Diese Eigenthümlichkeiten, die auch auf der liggur deutlich hervortreten, haben $1 \%$. W Her wahrscheinlich veranlasst, den ihm vorgelegten Wirbel für einen solchen von Ichthyosaurus zu halten; denn damals kannte man biconcave Wirbel nur von dieser Reptilienfamilie. Die andere Beobachtung in Betreff des Zahnes stimmt gleichfalls mit der Zeichnung insoferne als die Zühne nicht glatt gewesen sein können, sondern Längsfurchen gehabt zu haben scheinen, worauf die sternförmige Wicdergabe und der Vergleich mit dem Zahne des Ichthyosaurus platyodon hinzeigen. Solche stark geriefte Zähne kommen bei Ichthyosauriden häufiger vor, z. B. Ichthyosaurus communis (Lydckkr, Fossil Rept, and Amphib. in the Brit. Mus., II, pag. 42). Betrachtet man aber die Zeichnung genauer, so lässt sich die Zutheilung zu dieser Reptilienfamilie nicht aufrecht erhalten. Die Zähne dürften nämlich fest eingeleilt in Alveolen gesessen haben; ausserdem lassen sich die erhaltenen Theile des Brustgürtels schwer mit solchen eines Ichthyosaurus vereinigen.

An Plesiosauriden kann ich ebenfalls das Thier nicht anschliessen. Die Wirbel sind zu kurz

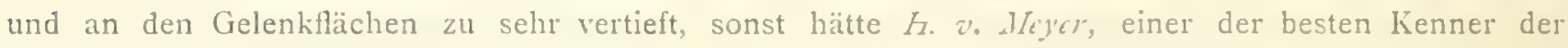
Nothosauriden, jedenfalls den hier vorgelegten Wirbel nicht der ersteren Familie zugeschrieben. Dazu kommt, dass die Theile des Brustgürtels auch zu den Plesiosauriden nicht recht stimmen. Meiner Meinung nach - wenn man auf solche unzureichende Zeugnisse eine solche überhaupt aussprechen darf - handelt es sich um ein Thier aus der Gruppi dir Hastodonsauricr. Unter diesen finden wir nämlich eine Reihe von Arten, die sich durch kurze Wirbelkörper mit verdickten Rändern und biconcaven Gelenkflïchen auszeichnen.

Es sind dies Gattungen mit sogenannten embolomeren (Zittch, Handbuch der Paläont., III, 394 ff., speciell die Abbildung $3 \delta_{4} C$ ) oder solche mit stereospondylen Wirbeln, bei denen eine gewisse Aehnlichkeit mit Ichthyosaurus hervortritt. Die Form des Schädels und die Bezahnung widersprechen dieser Deutung keineswegs, ja es passt der sternartige Querschnitt der Zähne noch besser zu Labyrinthodonten als zu den Reptilien (vgl. Qucnstcdt, Die Mastodonsaurier, Taf. III, Fig. 3b). Der grosse flache, hinter dem Schädel gelegene Knochen könnte die mittlere Kehlbrustplatte darstellen. Er ist eigenthümlich vierlappig mit wahrscheinlich etwas abgebrochenem proximalen Ende. Seine Gestalt erinnert an die von Metopias diagnosticus Mey, aus dem Keupersandsteine (Zittcl, Handbuch der Paläont., III, 492). Den darüber befindlichen längeren und an einem Ende verbreiterten Knochen kann ich nur mit dem Ilium von Mastodonsaurus giganteus vergleichen. Dieser ist ganz ähnlich gestaltet, hat die gleiche schräge Abstutzung an dem einen und eine Verbreiterung am anderen Ende (Zittel, ibid., 406-407). Am hinteren rechten Ende des zusammenhängenden Halswirbels sieht man zwei lragmente, die annähernd parallel liegen und gegliedert sind. Theile von Hand und Fuss können es kaum sein, da die Glieder zu kurz und zahlreich sind. Dagegen können sie als Reste des Bauchpanzers aufgefasst werden, der ja häufig aus solchen bogenförmig angeordneten Hautknochenstücken besteht. Ob dazu auch die drei bis vier parallel liegenden Knöchelchen unten links an der Ecke gehören, möchte ich dahingestellt sein lassen; für Fingerglieder sind sie zu dünn. An der anderen Seite des Halses liegen einige Rippenstücke und an deren Ende ein eigenthümlich durchbrochener Knochen, der möglicherweise von der Schädeldecke herstammt. Der grosse Knochen auf der linken Seite der \%eichnung liesse sich als rechte seitliche Kehlbrustplatte deuten. Die ganz unten rechts 
gelegenen Knochen mögen Fingerglieder und Fragmente von einer der vier Gliedmassen sein. Die anderen Knochen sind nach der Figur kaum zu bestimmen.

Mastodonsaurier kennt man ausser aus dem Buntsandsteine und Keuper aus dem schlesischen Mfuschelkalke (Z. d. D. g. G., 37, ISS5, 52S-532, und ibid., 36, I884, I4I-I 42). Auch würde die Grösse des Thieres wohl zu dieser Gruppe passen, da die schwäbischen Keuperformen ebenfalls gegen I $m$ Schädellänge besitzen. Der einzige Ichthyosaurus aus der Trias ist von Besano erwähnt und von Bassani beschrieben, leider nicht abgebildet. Es ist dies eine kleine Form, die nur $90 \mathrm{~cm}$ lang wird, die also mit diesem grossen Thiere nichts zu thun hat (Bassani, Sui fossili e sull' eta degli scisti bituminosi di Besano in Lombardia. Atti Soc. Ital. d. sc. nat., XXIX, I886, 6-7).

Reste grösserer Individuen von Ichthyosaurus werden dagegen von Hulke aus den Halobia und Daonella führenden triadischen Schichten Spitzbergens beschrieben und zwei Arten, Ichthyosaurus polaris und Ichthyosaurus Nordenskiöldii, aufgestellt. Eine Revision dieser Formen wäre wünschenswerth (Bihang till $\mathrm{kgl}$. Svenska Vetensk. Handl., I, I872/73, Nr.9, und ibid., Handlinger, N. F., XIV, t. I875, Nr. 5, p. II 2). 


\section{O R R I G E N D A.}

Auf pag. II, Zeile I3, von unten soll es statt Cephalopoden heissen: Cephalopodenarten.

Auf pag. I2, Zeile 8 von oben, soll es statt granulatostriatus heissen: granulosostriatus.

Als Erklärung des scheinbaren Widerspruches auf pag. II unten ist zu bemerken, dass von den 85 Cephalopoden. arten des Verzeichnisses die Nummern 36 und 37 (zwei Ceratites [Danubites?] spec, indet.), sowie Nr.60 (Nov. gen. indet . al, zu undeutlich oder als systematisch zu wenig brauchbar vernachlässigt wurden und dass auch von den verbleibsnicn 82 Arten noch Nr. 30: Ceratites sondershusanus Picard sp, als dem germanischen Muschelkalk angehörig, ausgeschieden werden muss, so dass thatsächlich und zweifellos dem Reiflinger Fundorte SI Arten verbleiben, er somit um 9 Forn.e: mehr geliefert hat als der bisher reichste Fundort .Schreyeralms aus dem oberen Muschelkalk der Nordostalpen. 
TAFEL I (I).

Orthoceras, Pleuronautilus. 
TAFEL I II.

Fis. 1. Orthoceras nov. spec. indet., pas. 25.

Bruchstück mit theilweise erhaltener Schale.

Fis. 2.

Orthoceras nov. spec. indet., pag. 25.

Bruchstück mit erhaltener Schale.

Fig. $312, \therefore c$ Pleuronautilus Rollieri Art., pag. 28 ,

Bruchstück mit theilweise erhaltener Schale; c Lobenlinie von demselben Stücke.

Fis. +2. 2 .

Pleuronautilus Rollieri Art., pag. 29.

Ein zweites, als Steinkern erhaltenes Stück mit vollständig erhaltenem Murdıund

Fig. $5 a, i, c, d$. Pleuronautilus seminodosus Art., pag. 32.

Als Steinkern erhaltenes Bruchstück; d der Querschnitt der letzten Windung in der Hohe der let/ten Kammerscheidewand, $c$ der Querschnitt am Ende der Wohnkammer. 

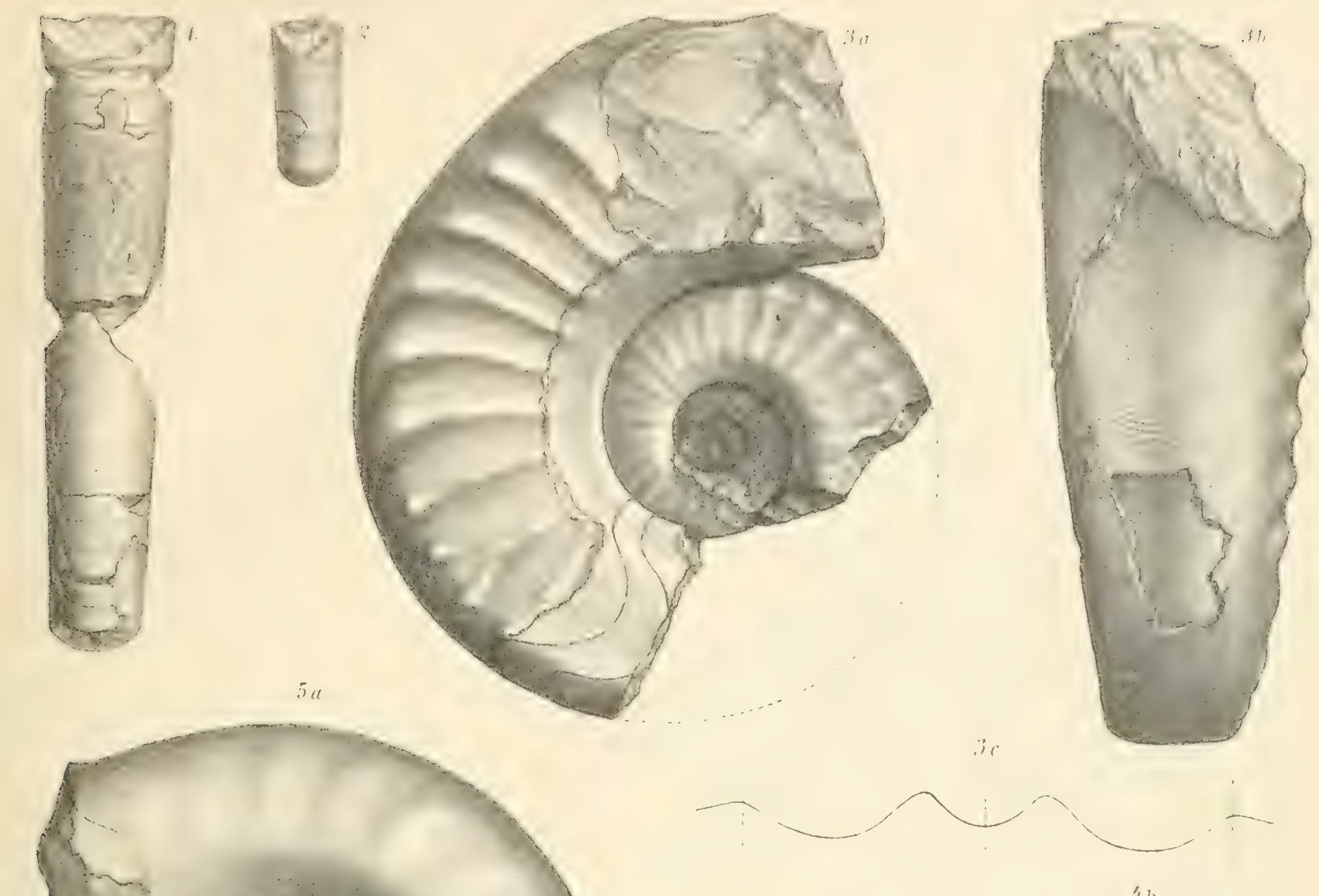

$\because 6$
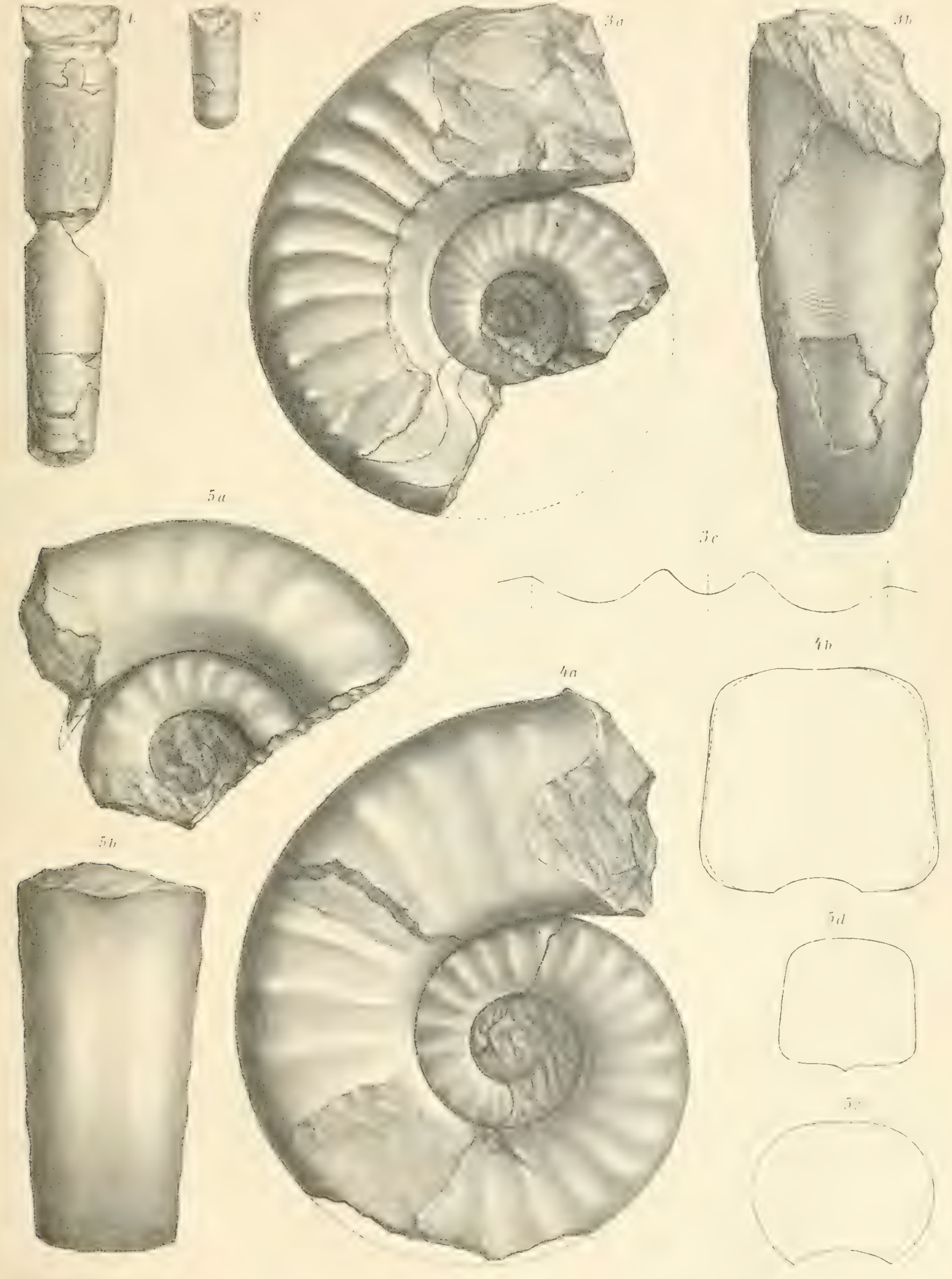

A.Swobeds nd.Nas nez u.lith

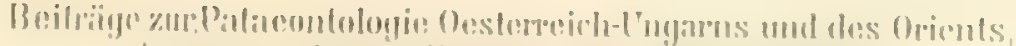

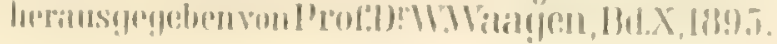



TAFEI, II III.

Pleuronantilus. 
TAFEL II (II).

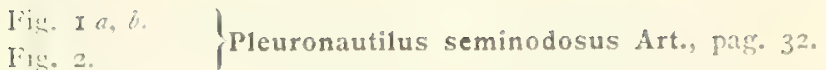

Das in Fig. I abgebildete Stük hat theilweise Schalenbedechung, wilhrend Fig. 2 nur als Stuni.rt. erhalten ist.

lik. 3.... Pleuronautilus furcatus Art., pas. 34.

Exemplar mit theilweiser Schalenbedeckung.

lik. 4 "l, b,c. Pleuronautilus ptychoïdes Art., pag. 35.

Exemplar mit theilweiser Schalenbedeckung; c Querschnitt desselben Stückes.

lili $5 \ldots$ Pleuronautilus Pichleri Hauer sp. pag. 3 ?.

Das von D. Stur gefundene Stück, aus dem Besitze der k. k. geolog. Reichs-Anstalt.

Iig. $6 a, b, c, d$. Pleuronautilus scabiosus Art., pag. 3 I

Exemplar mit theilweise erhaltener Schale. Fig. c ein reconstruirtes Bild nach dem stark verdrucliten Originale Fig. $a, b$

lijg. $7 a, b$. Pleuronautilus nodulosus Art., pag. 36.

Exemplar mit grossentheils erhaltener Schale 

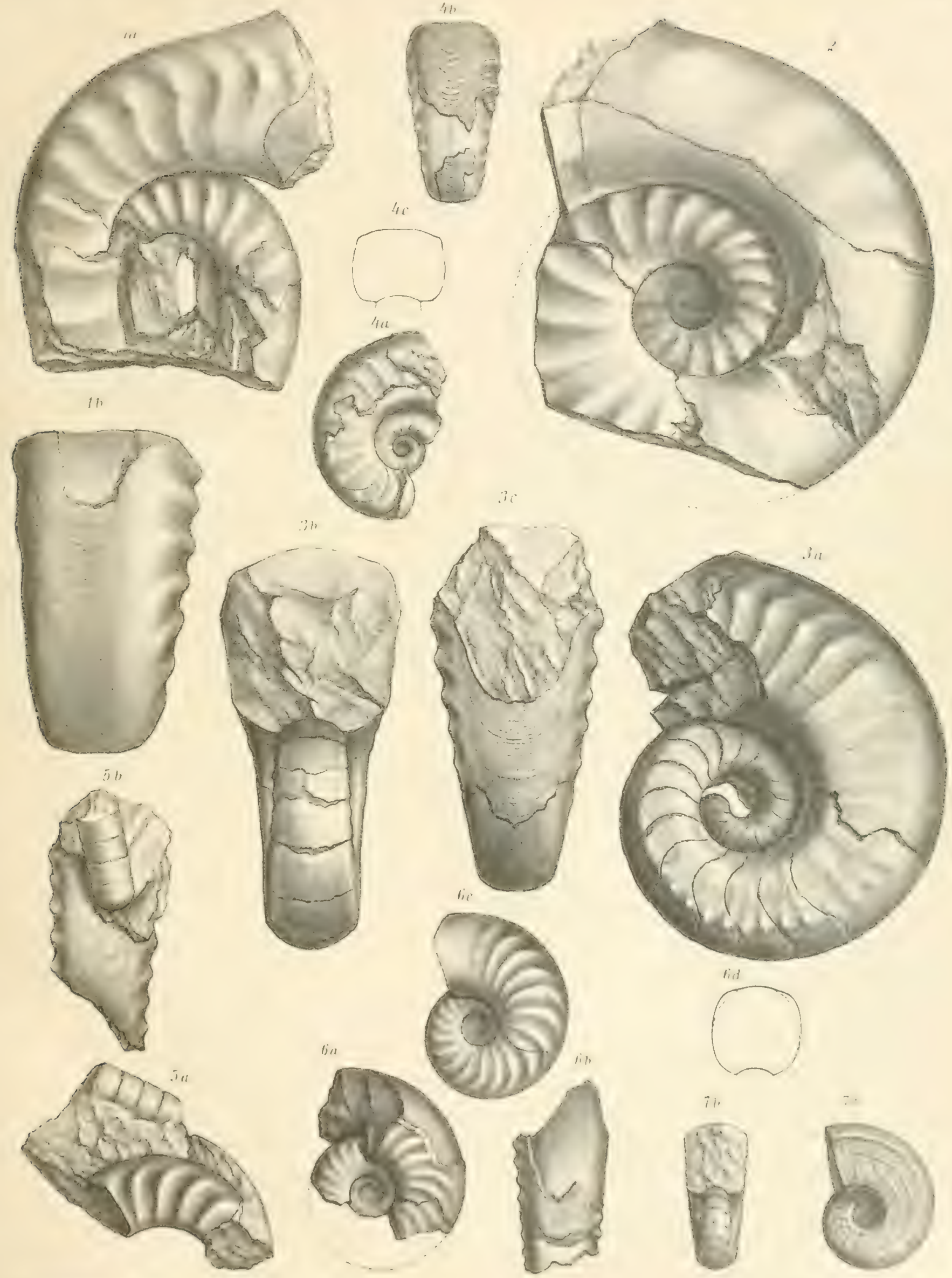

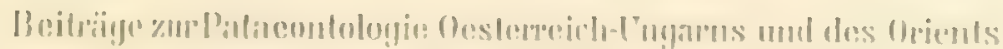

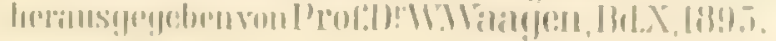



TAFEL III (III)。

Pleuronutilus, Nautilus, Ceratites. 
TAFEL III (III).

Vis. I $\therefore$ Pleuronautilus crassescens Art., pag. 37.

Exemplar mit theilweiser Schalenbedeckungr

Fis :- Pleuronautilus crassescens var. jugulatus Arto, pag. 38.

Exemplar mit theilweiser Schalenbedeckung.

Fig. $3 a, b$. Pleuronautilus ambiguus Art., pag. 38

Bruchstück mit theilweiser Schalenbedeckung.

Fig. 4

Fig. 5

Fig. 6)

Nautilus pertumidus Art., pag. $t^{2}$

Fig. + Abbildung der linken, Fig. 5 der rechten Flanke, Fig. 6 der Ventralseite

I $1,-7, \ldots$ Ceratites semiornatus Art., pag 43

Exemplar mit theilweiser Schalenbedeckung; c Querschnitt, in ${ }^{3}$ der letzten Windung ab zenommen.

Fig. $8 a, b, c$. Ceratites glaber Art., pas. 46 .

Exemplar mit theilweiser Schalenbedeckung. 

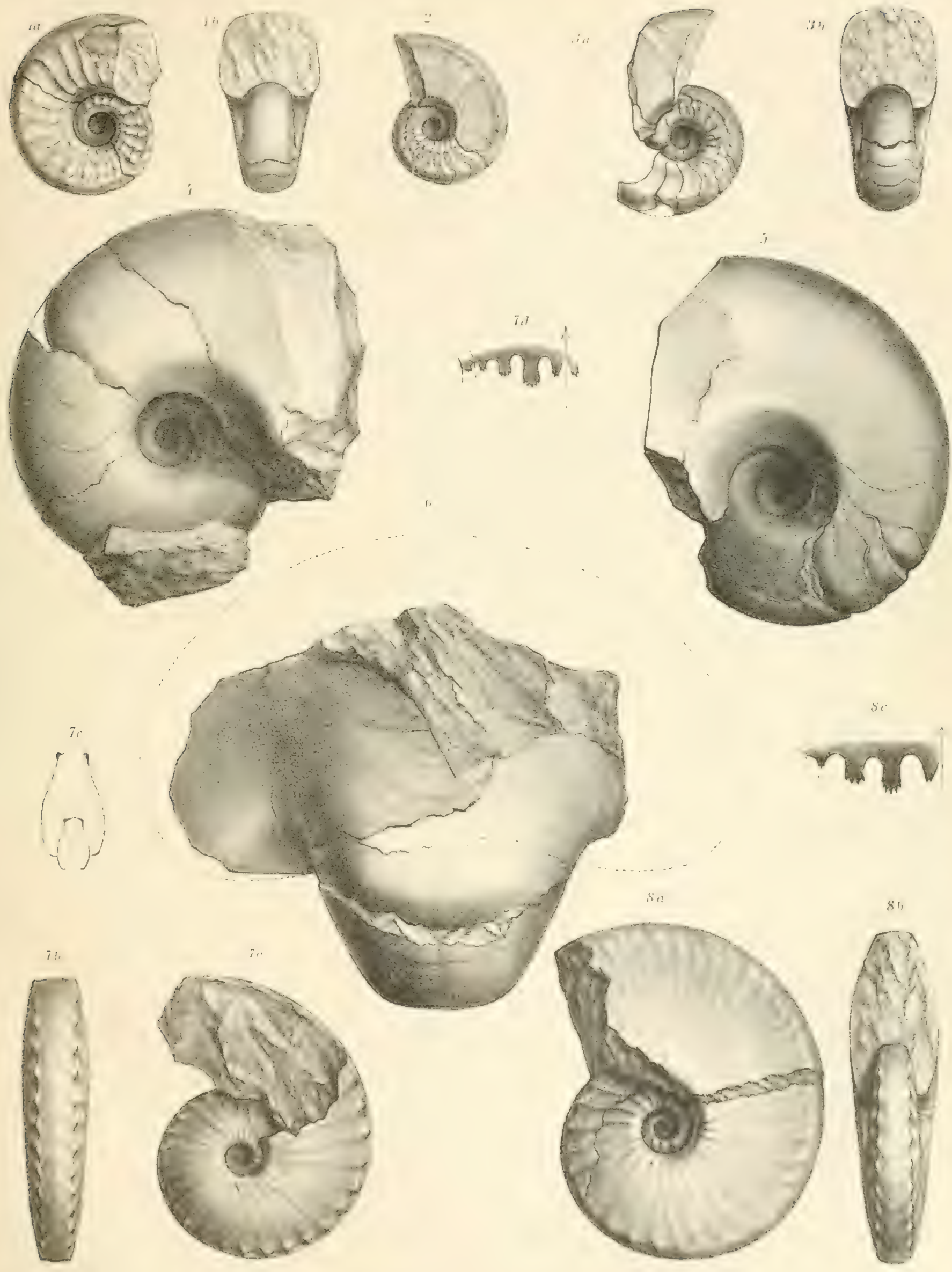

TAFEL IV (IV) 


\section{TAFEL IV (IV).}

Fig. I $a$, b. Ceratites nov. spec. indet, pag. 4 t.

Wohnkammerexemplar mit theilweise erhaltener Schale.

Fig. $2 a, b, c$. Ceratites planus Art., pag. 45 .

Vollständiges Exemplar mit grösstentheils erhaltener Schale.

Fig. $3 a, b, c$. Ceratites binodosus Hauer, pag. +8 .

Als Steinkern erhaltenes Exemplar.

Fig. $4 a, b, c$. Ceratites simplex Art., pag. 47.

a im Steinkern erhaltenes Wohnkammer-Bruchstïck; " durch Wegsprengen des letzten Umganges wurde ein Theil des früheren Umganges blossgelegt.

Fig. $5 a, b, c$. Ceratites Waageni Art., pag. 49 .

Vollständiges Exemplar mit theilweise erhaltener Schale.

Fig. $6 a, b, c, d$. Ceratites Mojsvari Art., pag. 50.

a vollständiges Exemplar mit theilweiser Schalenbedeckung; $b$ der Externtheil am Ende des letzten Umganges ist etwas verdrückt; $c$ nach Messungen gezeichneter Querschnitt.

Fig. $7 a, b$, Ceratites multinodosus Hauer, pag. 5 I.

Nach dem Originalexemplar Fr. $z$. Haw's aus dem Besitze des $k, k$. nat. Hofmuseums in Wien genau gezeichneter Querschnitt a und Lobenlinie $i$.

Fig. $8 a, b, c$. Ceratites nov. spec. ex aff. multinodosi Hauer, pag. 5 I.

Schlecht erhaltenes Bruchstick einer Wohnkammer (Steinkern). 


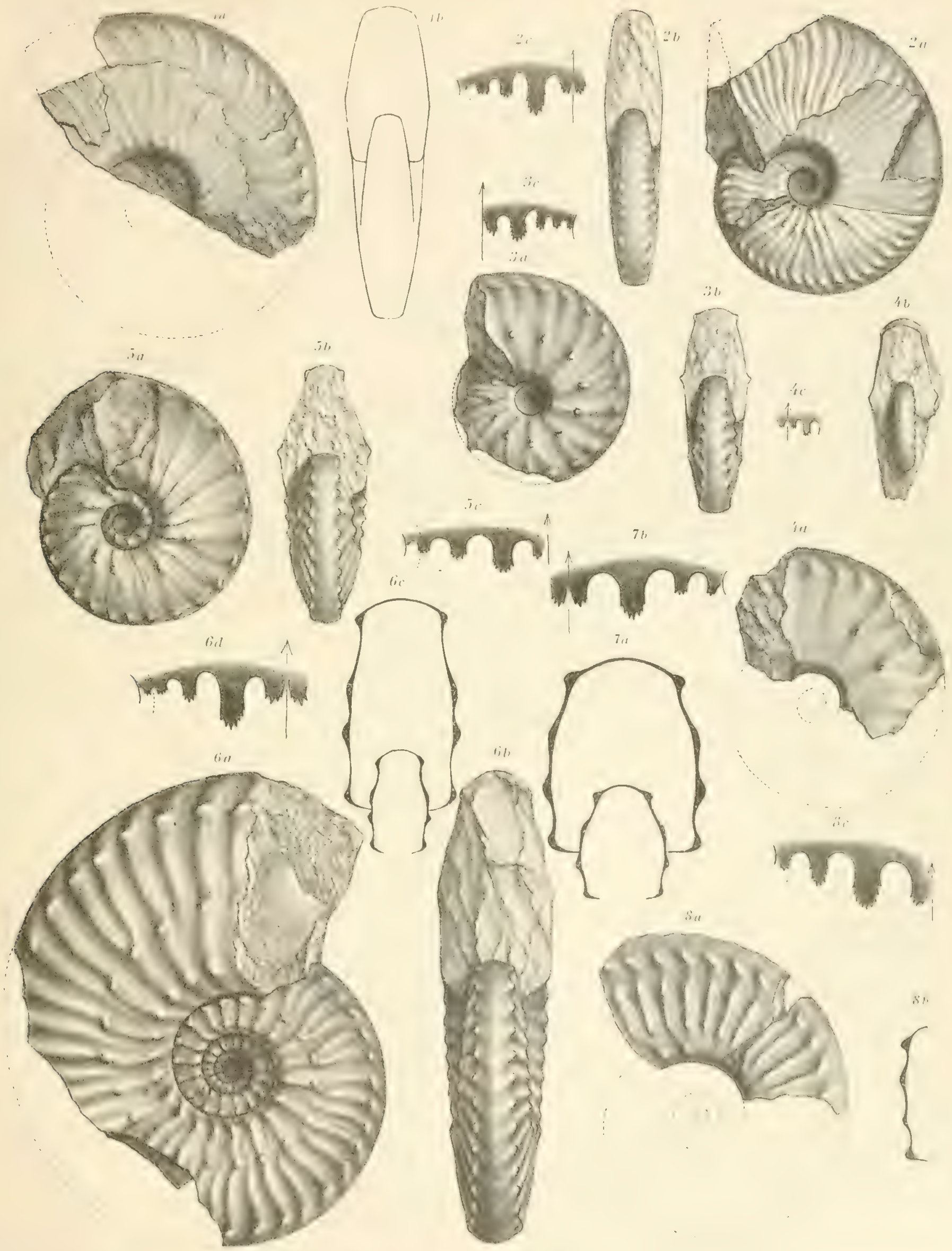



II. ABTHEILUNG. 


\title{
DIE CEPHALOPODENFAUNA DER REIFLINGER KALKE.
}

\author{
II. A ISTHEIL UN G:
}

DIE FAUNA DES FUNDORTES 》RAHNBAUERKOGEL .

\author{
Von \\ GUSTAV VON ARTHABER. \\ De. philo, Assistent am Palāontologischen Institut der Universităt Wien. \\ (Mit Taf. XXIII-XXVII $[\mathrm{XI}-\mathrm{XV}]$.)

\section{GEOLOGISCHER THEIL.}

Nachdem die Fauna des Fundortes 'Tiefengraben schon beschrieben und die Bearbeitung der sämmtlichen gewonnenen Resultate abgeschlossen war, gelang es bei einem abermaligen Besuche der Reiflinger Gegend, einen neuen Fundort zu entdecken, dessen Existenz auf pag. 5 dieses Bandes kurz angedeutet wurde. Bei der Durchbestimmung dieser neuen Funde, welche durch einen im Sommer I895 erfolgten zweiten und im November ausgeführten dritten Besuch sich recht bedeutend vermehrt hatten, stellte sich die Nothwendigkeit heraus, die Bearbeitung dieser neu gewonnenen Fauna, die ursprünglich nur als Nachtrag gedacht war, zu einem selbstständigen zweiten Theile zu erweitern, der lediglich die Fauna des neuen Fundortes » Rahnbauerkogel enthält und somit das Gegenstück zu dem ersten Theile bildet, dessen Fauna von dem alten Fundorte "Tiefengraben stammt. Diese Gegensätze sind nicht zufällige, locale, sondern sind vielmehr faunistischer Natur, wie im Folgenden erwiesen werden soll.

Als Anhang und Nachtrag zum ersten Theile schliesst sich an den zweiten Theil die Beschreibung einer kleinen Anzahl von Formen an, welche alle dem Niveau des Fundortes Tiefengraben entstammen und mir theilweise von den Findern Prof. Fr. Toula und Dr. A. Bittner freundlichst überlassen, theilweise von mir- selbst nachträglich noch gefunden wurden.

Gegenüber der Ortschaft Gross-Reifling liegt auf der dilluvialen Schotterterrasse das kleine Gehöft des ,Rahnbauer^, wie es die Specialkarte I:75.000 bezeichnet, welcher Name wohl eine dialectgemässe Verballhornung des Wortes ,Rain sein dürfte, der sich oben auf der kleinen Terrasse in saftigem Grün der Wiesen und Getreidefelder ausdehnt. Hinter dem Gehöfte dieses Bauern sam Rain erhebt sich ein kleiner Kogel, für den die Karte, wie erklärlich, keinen speciellen Namen angibt, der aber am besten als Rahnbauerkogel zu bezeichnen ist. Er ist auf der rechten Thalseite der Enns die letzte Erhebung des aus dem Tiefengraben herüberstreichenden Zuges, dem auf der linken Thalseite, hinter dem Orte Gross-Reifling, der Reiflingkogel entspricht. Auf dem Kogel selbst und in seiner nord- 
östlichen Fortsetzung längs des Grates treten die unteren Reiflinger Kalke allerorts zu Tage, sind aber meist fossilleer und zeigen nur auf den abgewitterten Schichtfächen die charakteristischen Hornsteinkügelchen. Das fossilführende Niveau unterlagert diese Kalke und ist hier sowie anderweitig linsenförmig entwickelt; eine dieser Linien steht auf dem Kamme, knapp hinter der Kuppe des Rahnbauerkogels an. Eine eben hier angelegte Holzrutsche war die Ursache, dass das Gestein dieser Linse durch die abrutschenden Holzstämme ausgebrochen wurde und nun das Gehänge des Kogels bedeckt. Die Blöcke konnten daher von allen Seiten prächtig anwittern, wođurch die harten Kalke mürbe wurden, so dass die Fossilien sich nun sehr gut gewinnen lassen.

Bei meinem vorletzten Besuche der Localität fand ich Herrn Dr. Bittuer in Gross-Reifling, den einige Revisionstouren und wohl auch die neuen Funde wieder in sein altes Aufnahmsgebiet geführt hatten; wir begingen daher gemeinsam das Profil dieses neuen Fundortes, das sich folgendermassen zusammensetzt:

$$
\text { Fig. II. }
$$

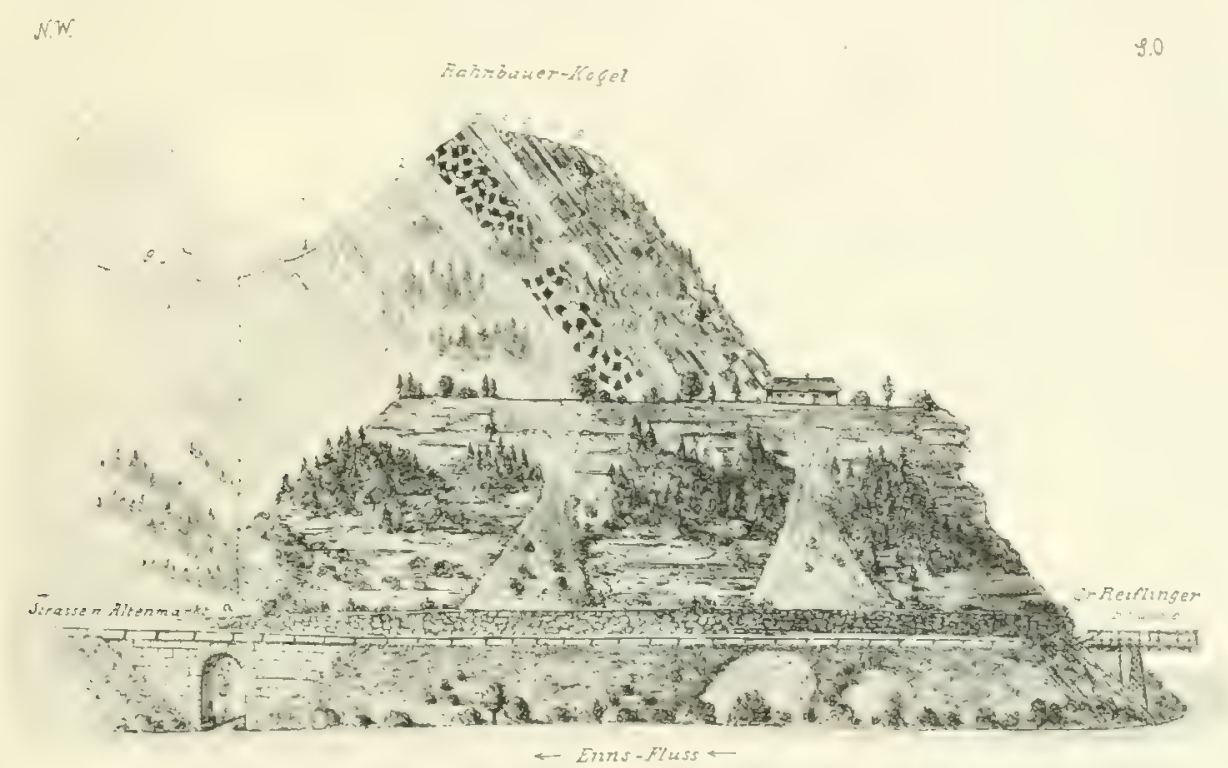

Profil durch die untersten Reiflinger lialke.

$\alpha-8$ Verwerfungslinie zwischen Hauptdolomit und der Serie der Reiflinger Kalke sammt deren Unterlage.

I Bräunliche bis dunkle sandige Kalke und Kalke mit Kalkspathadern, an die Guttensteiner Kalke erinnernd.

2 Bräunliche Kalke und darüber ein kleines Dolomitniveaus,
3 Stark zusammengeschobene bräunlich-sandige fossilleere Kalke.

4, 5, 6, 8 Bankweise varirende Kalke, theilweise mit Aus scheidungen von Hornsteinkügelchen.

Z KalkemitderFaunadesRahnbauerkogel-Niveaus. 9 Hauptdolomit.

Im Vordergrunde verdeckt die oben erwähnte Schotterterrasse die Sohle des Rahnbauerkogels, links setzt der Dolomit, rechts die Serie der geschichteten Kalke die Höhe zusammen, während zwischen beiden Complexen die Verwerfungsfläche $\alpha, \beta$ hindurchläuft. Das Streichen der Kalke ist auch hier wieder Nordost-Südwest, das Fallen ein ziemlich steiles, Südost gerichtetes. Von links, dort wo eine starke Quelle die Verwerfungstläche benützend zu Tage tritt, ansteigend trifft man zuerst ungeschichteten Dolomit von lichtgrau-röthlicher Farbe, meist fein zerfallend, seltener von gröberer, consistenterer Beschaffenheit, der zweifellos noch in den Hauptdolomit zu stellen ist. Auf diesen hinauf ist die Serie der geschichteten Kalke geschoben und durch eine vielfach gut sichtbare Verwerfungslinie getrennt, längs welcher stellenweise Reibungsbreccien sich beobachten lassen. Diese Serie beginnt mit grauen bis dunklen, dünngeschichteten, von zahlreichen weissen Kalkspathadern durchzogenen Kalken, welche hiedurch eine gewisse Aehnlichkeit mit den Guttensteiner Kalken erlangen und mög- 
licherweise diesen zuzuweisen sind, jedoch vollständig fossilleer auftreten; sie sind von dünngebankten, bräunlichen, harten Kalken in mässiger Mächtigkeit überlagert, die ihrerseits wieder von cinem kleinen, bankigen Dolomitniveau bedeckt sind, das wahrscheinlich dem auf pag. 4 vom Scheiblinggraben erwähnten Niveau entsprechen dürfte. Hierauf folgt ein Horizont dünngeschichteter, local vielfach gefalteter, zusammengeschobener und zerknitterter bräunlicher, etwas sandiger, fossilleerer Kalke, welche auch anderenorts in derselben Ausbildungsform an der Basis der Reiflinger Kalke, z. 13. in der Gallensteiner Schlucht bei St. Gallen in Steiermark auftreten. Gegen oben folgen sodann dicker gebankte, im frischen Zustande dunkelblau-graue Kalke, welche in flachen, langgestreckten Linsen die Fauna des Rahnbauerkogels enthalten. In der weiteren Nordost-Erstreckung dieses Niveaus fehlen meist diese Linsen, und an ihre Stelle treten dünner geschichtete Bänke, welche ebenfalls reichliche Fossilführung aufweisen, jedoch sind die Versteinerungen meist stark verdrückt. Dieser Horizont lässt sich durch Zwischenpunkte bis in den Tiefengraben verfolgen, woselbst er deutlich das im ersten Theile behandelte Tiefengraben-Niveau unterlagert, wie durch einen von Dr. Bitthcr daselbst gemachten Fund der neuen Halobia (wie sie in Verhandl. d. k. k. geol. R.-A., I896, Nr.3, pag. 122, bezeichnet wurde, welche aber genauer als whalobienartige Posidonomya zu bestimmen ist, wie mir Dr. Bittner freundlichst mittheilte) des Rahnbauerkogel-Niveaus erwiesen wurde. Die Schichten des letzteren bedecken in grossen

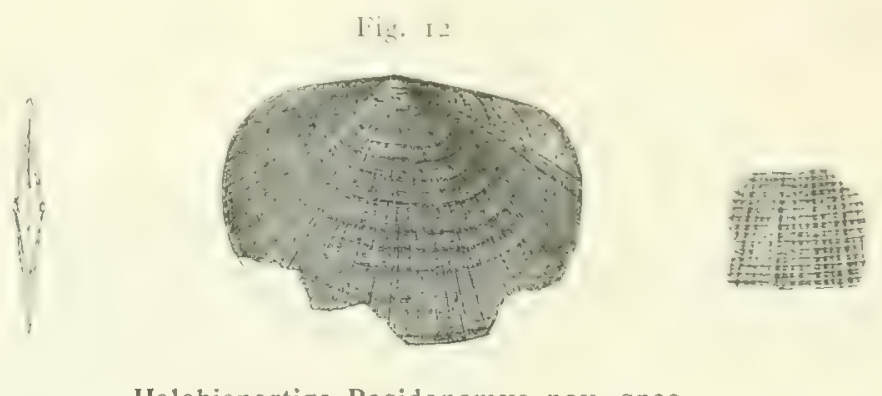

Halobienartige Posidonomya nov. spec.

Geröllhalden den Abhang längs des Fusssteiges, der, von der Strasse hinter der Reiflinger Brücke abzweigend, in den Tiefengraben führt, woselbst sich folglich leicht und gut sammeln lässt. Die Bedeckung dieses Horizontes wird von etwas lichteren, meist dicker gebankten Kalken gebildet, welche zahlreich die oben erwähnten Hornsteinkügelchen auf den Schichtflächen führen.

Die Fortsetzung dieser Serie nach oben fehlt hier auf dem Rahnbauerkogel und findet sich erst wieder im Tiefengraben, von wo dieselbe pag. 5 ff. ausführlich beschrieben wurde.

In faunistischer Beziehung finden wir als Hauptelement die Cephalopoden, denen zunächst die oben erwälınte

\section{Posidonomya nov. spec.}

in zahlreichen sehr schön erhaltenen Exemplaren folgt, welche die verschiedenen Altersstadien dieser Species trefflich beobachten lassen. Dann finden wir kleine, so weit ich beurtheilen kann, ziemlich charakterlose Bivalven, die nicht mit besonderer Häufigkeit auftreten. Auffallend hingegen ist das vollständige Fehlen der Gastropoden und Brachiopoden, die am Fundorte Tiefengraben, welcher, wie erwähnt, dem Alter nach jünger ist, mit ziemlicher Häufigkeit an Individuen auftraten, für welche aber die Lebensbedingungen während der älteren Ablagerungen anscheinend nicht so günstige gewesen sind.

Ich habe das gesammte Bivalven-Material Hern Dr. A. Bittner übergeben, der es in der Fortsetzung seiner sonographie ïber die Lamellibranchiaten der alpinen Trias (Bd. XVIII der Abhandl. d. k. k. geol. R.-A.') verwenden wird. Beistehend bringe ich nur die für das Niveau so besonders 
charakteristische Posidonomya nov. spec. in einer Textillustration, weil immerhin noch einige Zeit verstreichen dürfte, bis die umfassende Monographie Bittucr's abgeschlossen sein wird.

Es darf nicht Wunder nehmen, dass auch in der Fauna des Fundortes Rahnbauerkogel die Trachyostraca in überwiegender Menge auftreten, indem unter den Formen, welche derselbe bis jetzt geliefert hat, sich 25 Trachyostraca und nur 6 Vertreter der Leiostraca finden. Das Verzeichniss auf pag. 240 gibt in systematischer Folge eine Uebersicht über die Cephalopodenfauna.

Als geologisch bedeutsamste Glieder finden wir hier die Formen aus der Zone des Ceratites binodosus wieder:

\section{Ceratites binodosus Hauer, \\ Acrochordiceras pustericum Mojs., \\ Ptychites domatus Hauer,}

während beide Niveaux der Reiflinger Kalke, welche durch den hier in Rede stehenden älteren Fundort Rahnbauerkogel und den im ersten Theile beschriebenen jüngeren Fundort Tiefengraben repräsentirt sind, gegenwärtig durch die Formen:

\section{Ceratites binodosus Hauer, \\ Balatonites lineatus Arth., \\ Acrochordiceras undatum Arth., \\ Acrochordiceras pustericum Mojs., \\ Norites psilodiscus Arth., \\ Ptychites domatus Hauer}

verbunden sind. Es wurde daher, nachdem diese Resultate bekannt geworden waren, von meinem verehrten Lehrer Prof. Waagen die Vermuthung ausgesprochen, dass es sich bei diesem neuen Fundorte eventuell um eine neue, die tiefste Zone des europäischen Muschelkalkes handeln könnte, die durch das massenhafte Auftreten der Balatoniten und der Posidonomya nov. spec. gut charakterisirt wäre und etwa nach dem häufig auftretenden Balatonites egregius Arth. zu benennen wäre. Ich persönlich möchte aber noch nicht wagen, diesen Vorschlag anzunehmen, weil mil die Begründung der Neuaufstellung einer Zone auf das vorläufig noch vereinzelte Vorkommen vom Rahnbauerkogel doch nicht genügend sicher erscheint. Herr Prof. Suess hingegen, welcher ebenfalls die Güte hatte, seine Ansicht über diese Frage zu äussern, meinte, eher die Zone des Ceratites binodosus in zivei Theile trennen $z u$ müssen, einen unteren mit Balatonites egregius und einem oberen mit Balatonites balatonicus, während beide Theile durch das Vorkommen des Ceratites binodosus vereinigt wären. Dieser Vorgang würde jedoch wieder die Ausscheidung zweier Sub-Zonen bedingen, deren Aufstellung schon früher mit Recht bekämpft wurde, nachdem wir als die kleinste paläontologisch-geologische Einheit noch immer die Zone annehmen müssen. ${ }^{1}$ )

Haben wir aber hier in der Fauna des neuen Fundortes eine Vergesellschaftung von Formen, welche einem tieferen als dem Ceratites binodosus-Horizonte der ursprünglichen Auffassung entsprechen würde, dann hätten wir vielleicht eine theilweise Vertretung jener hydaspischen Stufe der indischen Triasprovinz ${ }^{2}$ ) gefunden, welche unseren Alpen noch fehlte und die bis nun erst in den oberen Ceratiten-Kalken der Salt Range (loc. cit. pag. I29I [2I]) nachgewiesen wurde, während die beiden Aequivalente derselben in den rothen Klippenkalken von Chitichun in Tibet und in den schwarzen Posidonomyenkalken von Spitzbergen noch fraglich sind. Vielleicht führt ein Verfolgen der Verwandtschaft der Reiflinger Posidonomya hier eine Klärung herbei.

i) Vgl. M. Mermayr, Erdgeschichte, Bd. II, pag. I7, und A. Billner, Zur neueren Literatur der alpinen Trias. Jahrb. d. k. k. geol. R.A. I894, Bd. XLIV, pag. 370, u. a. O.

2) Mojisorics, Miagtn, Dicner, Entwurf einer Gliederung der pelagischen Sedimente des 'Trias-Systems. Sitzungsber. d. k. Akad. d. Wiss, math.nat. Cl. vom 1. December 1S95, Bd. CIV, Abth. I, pag. 1279 [9]. 
Wir müssen daher, wenn wir uns an das neue 'Triasschema halten, daselbst den Begriff des Muschelkalkes, der anisischen Stufe, gegen unten erweitern und der balatonitischen Unterstufe eine neue Zone zufügen (vgl. loc. cit. pag. 19), während für die Eintheilung, wie sie A. Bitlncr (Bemerkungen zur neuesten Nomenclatur der alpinen Trias, Selbstverlag I896) pag. I7 gibt, die Nothwendigkeit einer derartigen Erweiterung entfällt.

Als weitaus wichtigstes Faunenelement nüchst dem stratigraphisch bedeutsamen Ceratites binodosus treten die Balatoniten in den Vordergrund, welche hier in 20 neuen Formen vorliegen, von denen nur der oben genannte Balatonites lineatus noch im oberen, Tiefengrabener Niveau vorkommt. Diese 20 Arten zusammen mit den neuen Arten des letzteren Horizontes vermehren bedeutend unsere Kenntniss der Formenmenge dieser Gattung, deren Anzahl mehr als verdoppelt wurde, nachdem wir bis heute erst 3 Formen aus der Zone des Tirolites cassianus, 5 aus der Zone des Ceratites binodosus gekannt haben, während aus der Zone des Ceratites trinodosus von den Nordalpen 2, den Südalpen 5 und von Han Bulog 2 bekannt geworden waren, und die zwei letzten Vertreter sich in der Zone des Protrachyceras Archelaus fanden. Bedeutsam ist das vollständige Fehlen des Balatonites balatonicus, der in einigen Exemplaren im Tiefengraben auftrat und ferner im Bakony und der Lombardei nachgewiesen wurde. Sollte derselbe eine vertical so enge Verbreitung besitzen? Dann würde dies ein Grund mehr für Abtrennung einer neuen Zone sein, was zur Folge hätte, dass der Ceratites binodosus seine Bedeutung als Leitfossil verlieren würde und an seine Stelle der Balatonites balatonicus treten müsste.

Gleichzeitig hätten wir dann der Thatsache Rechnung getragen, dass die so häufigen Formen, welche nur den mediterranen Gebieten eigenthümlich sind, auch die mediterranen Zonennamen geliefert hätten.

Endlich sei erwähnt, dass merkwürdigerweise sowohl Nautiliden als die sonst häufigen Orthoceraten hier vollständig fehlen.

Zum Schlusse ist insbesondere noch auf zwei Vertreter der Gattung Beyrichites Waagen hinzuweisen, von denen der eine, Beyrichites splendens, in sehr naher Verwandtschaft zu einer indischen Form, dem Beyrichites Gangadhara Diener spec. (s. pag. 230) steht und somit ein, wenn auch nur theilweise sicheres, Bindeglied mehr zwischen indischem und europäischem Muschelkalk bildet.

\section{Berichtigang.}

Nachdem die Benennung eines Ceratites simplex Arth. (s. Abth. I, pag. $47 \mathrm{ff}$.) schon vergeben ist (Mojsisovics E. $\%$, Arktische Triasfaunen, Mémoires Acad. Imp. Scienc. St. Petersburg, VII. Serie, Tom. XXXIII, Nr.6, pag. 30, Taf. VI, Fig. 2-4), ist die Neuaufstellung eines Ceratites simplex durch mich gänzlich unzulässig, und irrthümlich erfolgt, und ich bin daher leider gezwungen, einen neuen Namen zu geben, als welchen ich Ceratites vicarius vorschlage. Es ist daher im ersten Theile der vorliegenden Arbeit auf pag. 19, 47, $4^{8}$ und Tafelerklärung zu Taf. IV stets statt Ceratites simplex zu lesen: Ceratites vicarius Arth. 


\title{
PALÄONTOLOGISCHER THEIL.
}

\author{
Sectio II. Ammonea Mojs. \\ Ordnung: Trachyostraca Mojs. \\ Familie: Ceratitidae Buch. \\ Unterfamilie: Dinaritinae Mojs. \\ Gattung: Ceratites de Haan.
}

\section{Formengruppe des Ceratites binodosus. \\ Ceratites binodosus Hauer. \\ Taf. XXIII (XI), Fig. I.}

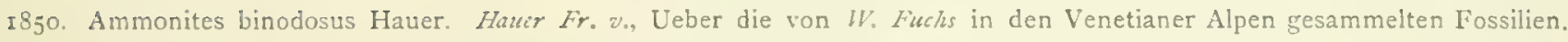
Denkschr. d. k. Akad. d. Wiss, math. nat. Cl. Wien, Bd. II, pag. II t, Taf. XIX, Fig. I- -

1865. Ceratites binodosus Hauer, partim. Hauer Fr. w., Cephalopoden der unteren Trias der Alpen. Sitzungsber. d. k. Akad. d. Wiss. math.-nat. Cl. Wien, Bd. LII, pag. 623.

I869. Ammonites binodosus Mojs., partim. Mojsisovics E. v., Beitrag zur Kenntniss der Cephalopodenfauna des alpinen Muschelkalkes. Jahrb. d. k. k. geolog. R.-A., pag. 58 r.

1879. Trachyceras binodosum Hauer. Mojsisovics E. v., Dolomitriffe von Südtirol und Venetien, pag. 46. Wien.

I88I. Ceratites binodosus Hauer, Bitner, Dr. A., Ueber die geologischen Aufnahmen in Indicarien und Val Sabbia. Jahrb. d. k. k. geol. R.A., Bd. XXXI, pag. 246 u. 247.

I882. Ceratites binodosus Hauer. Mojsisozics E \%., Cephalopoden der mediterr. Triasprovinz, pag. I9, Taf. XI, Fig. I-5.

1895. Ceratites binudosus Hauer. Arthater, Dr. G. \%, Die Cephalopodenfauna der Reiflinger Kalke, Abth. I, Beitr. zur Pal. u. Geol. Oesterr.Ung., Bd. X, pag. 48, Taf. IV, Fig. 3.

Auch im untersten Reiflinger Kalke fand sich dieser charakteristische Vertreter des unteren alpinen Muschelkalkes. Die beiden vorliegenden Stücke ähneln vollständig dem von dem Fundorte Tiefengraben stammenden und Taf. IV, Fig. 3, abgebildeten Stücke, welche folglich ebenfalls der kleineren, engnabeligen Varietät angehören.

Das eine, leider fast flach gequetschte Exemplar zeigt jedoch in trefflicher Erhaltungsweise die Schale, welche feine, gleichsinnig dem Rippenverlaufe angeordnete und enggestellte Schalenstreifen aufweist, die im Intercostalraum naturgemäss etwas deutlicher auftreten als auf den Rippen selbst, wo sie stärker abgenützt werden mussten; zeitweilig tritł die eine oder andere Linie etwas stärker heraus. Da man bisher nur Steinkerne des Ceratites binodosus gekannt hat, so gewinnt das vorliegende Stück durch seine Erhaltungsweise an Interesse, weil wir auch hier wieder dieselbe Zeichnung der Schale wiederfinden, die bei den meisten alpinen Ceratiten, Balatoniten etc. schon constatirt wurde.

Anschliessend an die Beschreibung des Ceratites binodosus des Fundortes Rahnbauertogel möchte ich einige Irrthümer berichtigen, welche ich gelegentlich der Beschreibung der Ceratiten des Fundortes Tiefengraben im ersten Theile der vorliegenden Arbeit begangen habe: Auf pag. $47 \mathrm{f}$. wird die Sculpturentwicklung bei Dinarites und 'lirolites besprochen und dann der Schluss gezogen, dass die Tirolitinen als ältere, Stammformen aufzufassen wären, von denen die Dinaritinen nur derivirt 
seien. Ich muss gestehen, dass ein Trugschluss mich zu dieser Erkenntniss geführt hat. Der Umstand allein, dass in den tiefsten Ablagerungen mariner. Trias, wie sie uns heute aus den Otoceras beds des Himalaya vorliegen, $\left.{ }^{1}\right)$ schon Vertreter der Dinaritinen-Reihe auftraten, während die 'irolitinen überhaupt fehlen und nur als eine Abzweigung vom Hauptstamme der Dinaritinen aufzufassen sind, welche ihr Verbreitungsgebiet in dem mediterranen Triasmeere allein hat, lässt den Irrthum erkennen, in dem ich befangen war und den ich jetzt aufgebe.

Ein zweiter Irrthum befindet sich auf pag. 54, woselbst zwei verticale, parallele Entwicklungsreihen angefüht werden, welche die Sculptur der ausseralpinen und alpinen Ceratiten in den horizontalen Stadien I--III durchmacht. Haben solche Entwicklungsreihen schon fast immer deshalb eine schwankende Basis, weil sie ja nur nach dem zufälligen und jeweiligen Stande unserer allgemeinen Kenntniss zusammengestellt sind, so befand ich mich in dem vorliegenden Falle ganz besonders im Irrthum bezüglich des ersten Entwichlungsstadiums der ausseralpinen Reihe, als welches ich Ceratites nodosus Autor. annehmen zu müssen glaubte. Wohl hegte ich gewisse Zweifel, ich liess daher in auffallender Weise Punkt I anders im 'Texte setzen als die übrigen; aber erst den freundlichen Mittheilungen Prof. Bcueck's und Dr. A. Tornquist's habe ich es zu danken, dass ich hier diese falsche Auffassung widerrufen kann. Ich wurde zu derselben durch Vergleich des Ceratites Vyása Diener und eines annähernd gleich grossen Exemplares des Ceratites nodosus gebracht. In Folge der Grösse zeigte derselbe in auffallender Weise, wie ich heute weiss, senile Merkmale, wodurch sich eine der inđischen ähnliche Ausbildungsform ergab. Das erste Glied der ausseralpinen Reihe würde uns daher heute noch fehlen oder ist eventuell in beiden Gebieten nicht gleichsinnig entwickelt.

\section{Unterfamilie: Tirolitinae Mojs.}

\section{Gattung: Balatonites Mojs.}

\section{Formengruppe der Balatonites gemmati.}

Die grosse Veränderlichkeit, denen die Individuen in den einzelnen Altersstadien unterworfen sind, erfordert es, letztere genauer zu charakterisiren. Man kann im Allgemeinen drei Altersstadien festhalten: das Jugend-, Reife- und senile Stadium. Ersteres finden wir gut vertreten durch die Abbildungen auf Taf. XXVI, Fig. 7, 8. Das Reifestadium, in dem wieder Anfang, Mitte und Uebergang zum nächstfolgenden, senilen Stadium gut zum Ausdrucke kommt, zeigen fast alle Abbildungen, am besten Fig. $5 a, 6 a$ im letzten Theile der Windung, ferner Taf. XXV, Fig. I $a, 3 a$, sowie die Uebergänge zum senilen Stadium in Taf. XXIV, Fig. I $a, 3 a, 5 a$; die senile Altersstufe endlich zeigen am deutlichsten die Abbildungen auf Taf. XXIII, Fig. $2 a, b$, wiederum Taf. XXIV, Fig. I $a, b$, und Taf. XXV, Fig. $8 a, c$.

Das Jugendstadium (Taf. XXVI, Fig. 7,8) hat bei einer Windungshöhe von $2 \mathrm{~mm}$ glatte, gerundete Umgänge; weitgestellte Einschnürungen theilen die Windung gliederartig ab; sie ist stärker in der Marginalals Umbilicalregion aufgetrieben, so dass, ohne dass eine eigentliche Marginalkante entwickelt wäre, der Eindruck von flachen, längsgestellten Marginalanschwellungen hervorgerufen wird, welche von jeder Einschnürung abgeschnitten werden. Die Schale ist mit sehr feinen Anwachsstreifen bedeckt, welche siemlich geradlinig und radial wie die Einschnürungen Flanke und Externtheil übersetzen. Nun beginnt die Windung sich rasch zu erhöhen, und schon bei $4 \mathrm{~mm}$ treten die jetzt schwächer werdenden Einchnürungen enger zusammen und verlaufen schwach sichelfürmig: sleichzeitig bereitet sich die Entwicklung einer Marginalkante und eines dachförmig zugeschärften Externtheiles vor, welche bei der Windungs-

1) Vgl. Diener, Ergebnisse einer geol. Expedition in den Central.Himalaya etc. Denkschr. d. k. Akad. d. WViss. math.nat. Cl., Bd. LXIII, pag. 543 (II) u. ff. 
höhe von $6 \mathrm{~mm}$ (Ende der letzten Windung, Taf. XXVI, Fig. 7 a) erreicht werden. Das nahe Zusammenrücken der Einschnürungen, aus denen sich, wie bereits E. v. Mojsisovics (Cephalop. Medit. Triaspr., pag. 87) hervorgehoben hat, späterhin die Rippen entwickeln, ist auch die Ursache der sich nun entwickelnden. Umbilicalknoten. Die positiven Rippen entstehen, wie nebenbei bemerkt sei, nicht aus den negativen Einschnürungen, sondern letztere treten so nahe aneinander heran, dass die zwischenstehende Schalenpartie von selbst Rippenform erhält. Die Contractionen bleiben bei vielen Formen durch alle Altersstadien bestehen, während sie bei anderen wieder entweder ganz verschwinden oder, wie im eben geschilderten Falle, sich vorwiegend nur auf die Flanke beschränken und dann als Pseudoeinschnürungen (vgl. pag. 67) zu gelten haben. Die Entwicklung der Rippen folgt auf diejenige der Umbilicalknoten.

Die Rippen treten meist als einfache Hauptrippen mit eingeschalteten Zivischenrippen auf, selten als Spaltrippen, und zeigen bei manchen Formen eine eigenthümliche Art der Abspaltung feiner Nebenrippchen von der Hauptrippe in der oberen Marginalpartie. Im senilen Stadium reducirt sich die Berippung wieder in der Form, dass die Rippen zu dicken, wulstigen Anwachsstreifen herabsinken, z. B. Balatonites Corvinus, Taf. XXV (25), Fig. 8 a.

Die Beknotung, welche den Formen der Gattung Balatonites nur in der Gruppe der Arietiformes fast ganz fehlt, beginnt, wie eben gezeigt wurde, als wulstige, längliche Auftreibung in der Marginalregion, während späterhin die ersten, deutlichen runden Knötchen auf dem Umbilicalrand auftreten (Taf. XXV, Fig. I a). Späterhin schreitet die Beknotung langsam von innen gegen aussen vor, tritt in Folge dessen zunächst in der Lateralpartie als Lateralknoten, in einem späteren Zeitmoment auf dem Marginalrande und zuletzt auf dem Externtheile als Kiel oder Mediandorn auf. Bei Formen, welche die Tendenz haben, ihre Schale höher zu verzieren, entwickeln sich submarginale oder sublaterale accessorische Knotenspiralen, welche jedoch an Grösse hinter den vier Hauptspiralen zurückbleiben. Die grösste Knotenanzahl besitzt gegenwärtig Balatonites transfuga Arth. (Taf. VIII, Fig. I, 2) mit acht Spiralen und zeigt daher schon den von E. v. Mojsisovics angenommenen Uebergang zu Trachyceras. Im Alter beginnt die Beknotung wieder von aussen gegen innen abzunehmen, indem zuerst die Medianknoten verschwinden, die Marginalen sich sehr stark reduciren, mitunter ganz verlöschen, während die Lateralen am längsten ihre Stärke beibehalten, im Gegensatze zu den Umbilicalen, die sich in ähnlicher Weise wie die Marginalen stark verringern.

Der Externtheil, dessen Ausbildungsform von der grössten systematischen Bedeutung ist, erfährt ebenfalls in den verschiedenen Altersstadien entsprechende Umformungen. Er ist, wie oben schon erwähnt, anfänglich vollkommen gerundet und geht ohne Marginalkante in die Flanke über; gleichzeitig mit Erhöhung der Windung im Anfange des Reifestadiums (Taf. XXV, Fig. I $a$, Taf. XXVI, Fig. 5, 6) bildet sich ein kantiger Marginalrand heraus, und bald darauf erhebt sich der Externtheil stumpf dachförmig, entwickelt in der Folge einen Kiel und setzt auf diesem längsgestellte Mediandornen an, welche dem Zusammentreffen der beiderseitigen Rippen ihren Ursprung verdanken und mitunter bedeutende Höhe erreichen (Taf. VI, Fig. $4 a$ ). In der Altersmitte des Reifestadiums ist dieses Sculpturmaximum des Externtheiles erreicht und nun beginnt in umgekehrter Folge wie die Zunahme eine allmälige Abnahme, indem die Medianknoten verschwinden, die allgemein dachförmige Gestalt sich rundet und spätcr abplattet, wobei die Rippen schwach bogenförmig, anstatt wie früher winkelig, die Externseite ïbersetzen: schliesslich rundet sich auch wieder die Marginalkante ab (Taf. XYV, Fig. Sa).

Der Umriss der Windung, welcher im Jugendstadium gerundet ist, erhöht sich sehr rasch und erlangt im Allgemeinen gestreckt rechteckige Gestalt, deren Höhe sich im Alter reducirt und sich mehr und mehr der jugendlichen Form durch stärkere Rundung wieder nähert.

So sehen wir ein Anwachsen der Sculptur gegen die Mitte des Reifestadiums bezüglich der Form des Externthciles, der Berippung und Belnotung, und dann nach einer Zeit des Stillstandes wieder eine bedeutend langsamere Abnahme der rasch erworbenen Sculpturmerkmale. Wir finden also 
nur bei Stücken des Reifestadiums, um das Altersmittel herum, die typische Entwicklung des BalatonitenCharakters.

Die Suturlinien, welche heute in reicher Zahl vorliegen, zeigen, wie bekannt, ceratitische Ausbildungsform. Ein breiter Externlobus, dessen beide Iilügel von je einspitziger Gestalt (Iaf. XXIV, Fig. $3 c$, Taf. XXV, Fig. 6 c) mit Uebergängen bis zur breiten und reichgezackten lorm sind (Taf. XXIII, Fig. 8, Taf. XXIV, Fig. I c, 5 c, Taf. XXV, Fig. $7 d, 8 d$ ). Zwei Laterale, von ziemlich gleicher Gestalt und Grösse, die Basis mitunter sehr reich gezackt, folgen zunächst auf der Flanke, sodann ein Auxiliar, der in seiner höchsten Stellung knapp ober dem Umbilicalrand auftritt. Er ist meist klein, mit gezachter Basis, selten breit, die ganze Nabelwand einnehmend (Taf. XXIV, Fig. $2 d$, Taf. XXV, Fig. $7 d, 8 d$ ). Unterhalb der Naht folgt ein zweiter, viel kleinerer Auxiliar und ein einspitziger Internlobus (Taf. XXV, Fig. 6c). Die Sättel sind rundbogig und ganzrandig und der allgemeine Verlauf der Suturlinie entweder ein flach bogenförmiger (dann steht der erste Lateralsattel an höchster Stelle) oder ein ziemlich gerader, von aussen gegen innen ansteigender (dann steht der Externsattel zu tiefst, der zweite Lateralsattel zu höchst). Mitunter ändert sich auch der Verlauf der Suturlinie bei ein und demselben Individuum (vgl. Balatonites variesellatus, pag. 208, 'Taf. XXIV, Fig. I $c$ ).

Schliesslich sei insbesondere auf die ausserordentlich grosse Variationsfähigkeit der Art und speciell des Individuums hingewiesen, die schwer den richtigen Weg in Abgrenzung des Species einerseits und der Variationen derselben andererseits finden lässt. Es ist dies eine Formenmenge, wie wir sie nur bei jenen Gattungen finden, die auf der Höhe ihrer Entwicklung stehen und dem Erlöschen nahe sind. Als einziges triadisches Analogon betreffs der Variationsfähigkeit des Individuums vermag ich nur den Dinarites spiniplicatus Mojs. (Arkt. Triasfaunen, pag. Io ff., Taf. I, Fig. I-5, 8-I6, I8-26, Taf. II, Fig. I-5, 7) vom Olenek anzuführen.

Die Gruppe der Arietiformes (Judicarites Mojs.), welche von E. v. Mojsisovics kurz und prägnant (Cephal. Medit. Triaspr., pag. 84) charakterisirt wurden, zeichnen sich von den beiden anderen Formengruppen der Gattung Balatonites durch Fehlen einer eigentlichen Beknotung aus. Die Rippen, welche im Reifestadium einfach sind und sich fast stets nur durch Insertion je einer Secundärrippe in den Intercostalraum vermehren, schwellen in der Narginalregion und am Umbilicalrande in geringer Weise an und setzen entweder stark reducirt über den Mediankiel hinüber, wodurch dieser in schwacher Weise längsgeknotet wird, oder sie verlöschen noch vor Erreichen desselben. Auf Jugendwindungen, welche selten zu bekommen sind, deren ich aber einige in Judicarien aufsammelte, bemerkt man ein Zusammenfliessen zweier Rippen am Umbilicalrande, was natürlich mit einer Verdickung des gemeinsamen Rippenstückes verbunden ist. Diese Art der Bifurcation erklärt sich durch die enge Berippung, verbunden mit einem in der Jugend relativ engen Nabel.

Die Suturlinien haben einen der Ausbildungsform bei der Gruppe der Balatonites gemmati ähnlichen Verlauf.

Von grösserer Verschiedenheit ist die Gruppe der Balatonites acuti ${ }^{1}$ ) (Dorycranites Hyatt.). Von dem dachförmig zugeschärften Externtheil, auf dessen Schneide ein Kiel aufsitzt, bis zu dem schneidenden Externtheil, der ohne Marginalkante in die Flanke übergeht, wie wir ihn bei Balatonites bogdoanus Buch. sp. und dessen Verwandten finden, ist wohl kein zu weiter Schritt. Bedeutsamer erscheint mir die Art der Beknotung, die auf jüngeren Windungen, wo nach E. v. Mojsisovics die Marginalkante deutlicher hervortritt, dann in typischer Tirolitenform auftritt. Freilich liegen ganz kleine Jugendformen nicht vor, uns fehlt somit die Kenntniss der Ausbildung des Externtheiles und Marginalrandes bei denselben, jedoch ist es nach dem übrigen Gang der Entwicklung dieser stark abweichenden Formen zu 
schliessen, mehr als wahrscheinlich, dass sie in der Jugend ähnlich entwickelt seien, wie die anderen typischen Balatoniten auch.

Die Suturlinien zeichnen sich durch ganzrandige Loben und Sättel aus; bei ersteren beginnt erst die theilweise feine Zackung, letztere sind auffallend gross und flach; der ganze Verlauf ein flach bogenförmiger.

Die Balatoniten, von denen insonderheit die Gruppe der Gemmati einen plötzlichen und unerwarteten Zuwachs aus den tiefen Muschelkalkniveaux erlangt haben, scheinen, wie schon E. v. Mojsisovicsi) und später Diener ${ }^{2}$ ) hervorgehoben haben, auf die mediterranen Triasgebiete beschränkt zu sein. Wir müssen nach dem heutigen Stande unseres Wissens annehmen, dass sie im untersten Muschelkalk schon das Maximum ihrer Entwicklung erreicht haben. Als erste Vertreter dieser Gattung finden wir die Formen der Gruppe der Balatonites acuti rom Bogdoberge der Astrachan'schen Steppe in den Kalkmergeln, welche der Zone des Tirolites cassianus, also dem Werfener Niveau angehören. Im unteren Muschelkalke entwickelt sich in der Zone des Ceratites binodosus plötzlich die Gruppe des Balatonites gemmati zu reicher Formenmenge, lässt schon in der Zone des Ceratites trinodosus mehr nach, in der wir in den Südalpinen (Prezzokalken) die Gruppe der Arietiformes finden, die nur von dort bis heute bekannt geworden sind, und erreicht im obersten Muschelkalke, ${ }^{3}$ ) in der Zone des Protrachyceras Archelaus (Wengener Sch.), ihr Ende.

Eine einzige Ausnahme scheint nur der Balatonites punjabiensis Waagen ${ }^{b}$ ) zu machen, der als erster und einziger Vertreter von Balatonites und den Tirolitinen überhaupt aus den oberen Ceratiten-Kalken der Salt Range, der Zone des Stephanites superbus, beschrieben wurde. Wie Waagcn hervorhebt, ist das Stïck leider schlecht erhalten und daher die Bestimmung »mehr oder weniger unsicher (loc. cit. pag. 62). Er vergleicht die indische Form mit dem Balatonites golsensis Mojs. ${ }^{5}$ ) (pag. 83, Taf. V, Fig. 4, 6) aus der Binodosus-Zone von Neubrags im Pusterthal, mit dem gevisse Aehnlichkeiten nicht zu leugnen sind. Aber freilich drängt sich da die Frage auf, ob auch diese Form (sie ist ebenfalls schlecht erhalten) nicht vielleicht ihre systematische Stellung besser bei den Dinaritinen, speciell dem Dinarites Taramelli Mojs. (loc. cit. pag. I3, Taf. V, Fig. 5, Taf. XL, Fig. 9, Io) finden würde?

\section{Balatonites egregius Arth. $\left.{ }^{b}\right)$}

Taf. XXIII (XI), Fig. $2 a, b, c$, Fig. $3 a, b, c$, Fig. 4

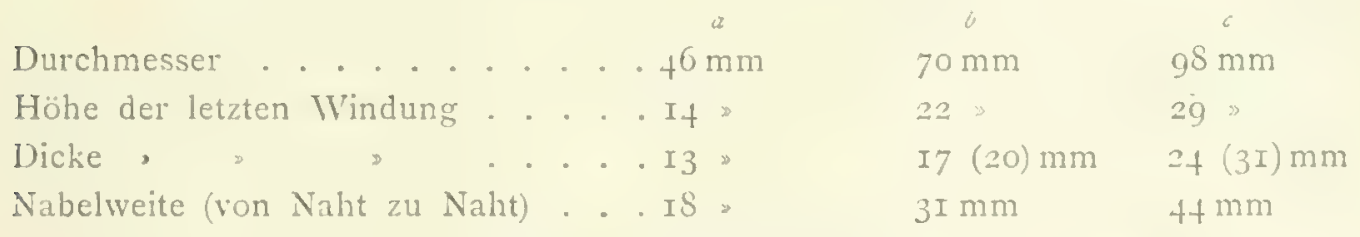

Die Form des Externtheiles ändert sich in den drei, oben durch die Maasse sub $a, b, c$ gekennzeichneten Grössenstadien derart, dass er bei der grössten Form, ausser auf einer kleinen Partie der beginnenden letzten Windung fast durchgehends, bei der mittleren grossentheils flachgewölbt ist, während die kileinste Form sowie die restirenden Theile der relativen letzten Windungen (ron $b$ und $c$ ) stumpfdachförmige Gestalt haben. Bei Jugendformen ist der Externtheil gerundet, später, bei einem Durch. messer von circa $25 \mathrm{~mm}$, schärft er sich zu und zeigt einen stumpfen Keil, der bei weiterem Wachs-

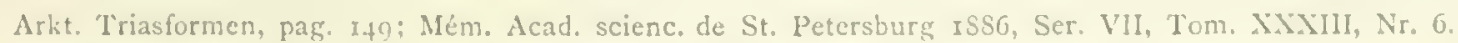

`) Himálayan Fossils, Cephal, of the Muschelkalk (pag. 92 ff.), l'al. Indic. IS95, Ser. XV, Vol. II. Part. 2.

3) Vgl. Verhandl. d. k. k. geol. R.A. ISg6, Nr. 3, pag. 125.

1) I'al. Indic. Salt Range lonss, Vol. II, pag. 64, Taf, XXIV, Mig. 5.

b) Cephalop. Medit. Triaspr.

"Von verschiedenen Seiten auf das Unpraktische der Schreibweise des Autornamens "Art. aufmerksam semacht, verwende ich von nun an die Bezeichnung s Arth.œ, 
thum des Individums in mehr oder weniger deutlicher Weise durch das Uebertreten der Rippen auf den Externtheil zart geknotet wird, beim vollständig erwachsenen Individuum sodann allmälig zu einer feinen Mittellinie wird und schliesslich ganz verschwindet.

Die Flanken sind flach gewölbt und erlangen im Lateralknoten, welcher etwas oberhalb der Flankenmitte sitzt, die grösste Dicke; der Marginalrand ist durch die aus scharfen Knoten gebildete Marginalspirale, der Nabelrand durch die kleineren Umbilicalknoten markirt; die Nabelwand ist hoch und anfangs steil, später flacher gestellt; die Windungen haben rechteckige, fast schon quadratische Form. Der Nabel ist sehr gross; die Involution erfolgt knapp unter dem Marginalknoten, die Aufrollung bei dem vollständig erwachsenen Individuum (mit den Maassen c) erfolgt in der Art, dass eine Abweichung von der Kreisform stattfindet und sich die beiden Durchmesser wie $76: 98$ verhalten, während bei der Grösse $b$ noch keine Spur davon zu sehen ist.

Die Radialsculptur besteht aus einfachen Rippen mit aufgesetzten Knoten. Die Anfangswindungen sämmtlicher Balatoniten-Arten meines Materiales sind fast ganz gleich entwickelt. Wir finden auf den ungefähr drei ersten Umgängen glatte Schale und sehr zahlreiche Einschnürungen; gegen Schluss der dritten Windung entwickeln sich umbilicale stumpfe Anschwellungen; später treten dieselben schärfer hervor, gleichzeitig mit kleinen Lateralknötchen, und bei einem Durchmesser von $25 \mathrm{~mm}$ endlich finden wir den Beginn der Radialsculptur, wie sie bei den vollständig entwickelten Individuen auftritt. Dieselbe besteht, wie schon erwähnt, aus einfachen Rippen. Sie ziehen, bei Schalenexemplaren deutlich sichtbar, auf Steinkernen in weniger deutlicher Weise über die Nabelwand herauf und tragen auf dem leicht gerundeten Umbilicalrande die kleinen Umbilicalknoten; von hier aus verflacht die Rippe etwas und schwillt erst wieder kurz unterhalb des Lateraldornes, der etwas oberhalb der Flankenmitte sitzt, an, erlangt sodann zwischen diesem und dem Marginaldorn abermals eine tlache Anschwellung, welche sich jedoch nie zum Knoten individualisirt, und tritt auf den Externtheil nicht als Rippe, sondern nur mehr als grobe Doppellinie über, welche ihn mit einem scharfgekrümmten, nach vorne convexen Stücke übersetzt. Ausser diesen Hauptrippen treten noch, besonders auf dem letzten Umgange des grössten Stückes, kurze inserirte Rippen auf, welche wechselnd bald einen kleineren, bald gleich grossen Marginaldorn wie die primären tragen, jedosh schon oberhalb der Lateraldornenspirale erloschen sind; mit ihrem Verlauf im Marginaltheile correspondirt auf dem Nabelrande ein ganz kleines, accessorisches Knötchen, und sie zeigen auf dem Externtheile dieselbe Form wie die Hauptrippen. Unter den Dornen der Flanke sind die Lateralen die kräftigsten und von etwas stumpferer Form auf Steinkernen als auf Schalenstücken, auf denen sie ehèr als gedrungene, spitze Stacheln erscheinen; an Grösse folgen sodann die Marginalen, welche spiral flach gedrückt und längsgestellt sind; auf Exemplaren der Mittelgrösse treten, wie schon eingangs erwähnt, in nicht sehr deutlicher Weise getrennt, kleine, längsgestellte Externknoten auf. Ferner ist noch im Raume zwischen den umbilicalen und lateralen Knoten eine Spirale minimaler accessorischer Knötchen zu erwähnen, welche jedoch nur beim grössten Stücke, und auch da nur auf den letzten Theilen der Wohnkammer, zu beobachten ist. An einigen Stellen treten Marginal-, Lateral- und manchmal auch die umbilicalen Knoten ganz unverhältnissmässig stark im Vergleiche zu den übrigen heraus, und zwar ist dies stets dann der Fall, wenn eine jener Einschnürungen auftritt, welche wohl auf der Flanke, nicht aber auf dem Externtheil deutlich sichtbar sind, und die daher im ersten Theile dieser Arbeit als »Pseudoeinschnürungen « bezeichnet wurden. Es ist dann entweder die jenen vorangehende oder die folgende, meist aber beide Rippen mitsammt den Knoten kräftiger entwickelt, während auf dem Externtheil Gleichgewicht herrscht. Sechs solche Stellen treten beim grössten Stücke hervor, bei kleineren viel weniger, so dass man anzunehmen versucht ist, dass dies eben nur ein Charakteristicum der Wohnkammer vollständig erwachsener Individuen sei.

Die Schale ist mit ausserordentlich feinen, enggestellten Anwachslinien bedeckt.

Bei dem Taf. XXIII, Fig. $2 a$, abgebildeten Stücke ist deutlich der sehr schön erhaltene Mundrand zu sehen. Wir finden einen analog den Rippen verlaufenden Ventrallappen, auf der Flanke einen 
flacheren und grösseren oberen und kleineren unteren concaven Ausschnitt, welche beide durch ein kleines Convexstïck, das in der Höhe des Lateralknotens liegt, getrennt sind; am Interntheile folgt ein kleiner, scharf vorspringender Internlappen.

Die Suturlinie durchsetzt von aussen nach innen in etwas schräger. Weise die Radialsculptur und bildet, vom Externsattel zum ersten Lateralen sehr rasch ansteigend, dann fast radial verlaufend, einen sehr flach gewölbten Bogen. Die Loben sind bei den typischen Formen nieder und breit, die Sättel ebenfalls breit und rundbogig.

Der Externlobus hat einen niederen Medianhöcker mit einem grösseren basalen und zwei bis drei kleinen, seitlichen Zacken; die beiden Lateralen haben im Allgemeinen kugelige Form, sind fast von gleicher Grösse, ja es erscheint der zweite sogar noch etwas breiter und länger in Folge des hochsitzenden Auxiliars; ihre Basis ist mit zwei bis drei grösseren Zacken in der Mitte und rechts und links mit einigen Zähnchen besetzt, dieselben ziehen sich aber nicht höher hinauf; auf dem Nabelrande beginnt ein breiter, die ganze Umbilicalwand einnehmender Auxiliar mit einigen Zähnchen. Der Externsattel liegt grösstentheils auf der Flanke; von ihm zum ersten Lateral macht die Suturlinie einen grossen Sprung, während der zweite Lateral fast auf gleicher Höhe wie der erste liegt, aber viel kleiner ist; der Scheitel des Auxiliarlobus liegt in derselben Radiale wie der Scheitel des Externsattels.

Der Sculpturtypus und die äussere Form des Balatonites egregius erinnert an Balatonites cfr. Ottonis Buch sp., welchen E. . Ilojsisovics $^{2}$ ) (pag. 78, Taf. V, Fig. I, Taf. VI, Fig. I) von Neubrags im Pusterthal beschrieben hat. Vergleiche mit der Abbildung Beyric/i's ${ }^{2}$ ) sind ganz ausgeschlossen (pag. I Io, Taf. IV, Fig. I $a, b, c$ ), weil dieselbe nur schematisirt ist, abgesehen davon, dass bei jener Form der Externtheil anders entwickelt gewesen zu sein scheint. Hingegen ist ein gewisser Grad der Uebereinstimmung mit der Buch'schen Form ${ }^{3}$ ) selbst nicht zu leugnen. Freilich muss das Originalstück Leopold 0 . Buch's sehr stark abgewitterte Suturen gehabt haben!

Vie oben schon gelegentlich der Besprechung des Sculpturwechsels des als Typus der voranstehenden Art aufgestellten und abgebildeten Stückes erwähnt wurde, kennzeichnet sich die Variationsfähigkeit nicht nur in den verschiedenen Altersstadien desselben Individuums, sondern tritt auch deutlich in denselben Altersstadien verschiedener Individuen hervor, so dass es unmöglich ist, die Art hier so eng zu umgrenzen, wie es vielfach in der neueren Literatur der Brauch ist. Wir müssen hier der Art einen weiteren Spielraum für ihre individuelle Entwicklungsfähigkeit lassen, welche sich aber nicht allein auf die äussere Form, sondern auch auf die Suturlinien erstreckt. Verschiedenheiten minderen Grades werden daher in der Folge als $\gg$ Varietäten $(a, b, c$ etc. $)$ besprochen, während solche höheren Grades, die noch nicht die Aufstellung einer neuen Species rechtfertigen, als *Variatio * mit besonderen Namen ausgeschieden werden.

\section{Variatio $a$. \\ Taf. XXIII (XI), Fig. $3 a, b, c$.}

Die Maasse dieser Varietät sind oben unter der Rubrik a gegeben. Bei dieser Grösse tritt auf dem Externtheile noch eine kräftige Kiel-Linie auf, welche jeđoch beim Durchmesser von $55 \mathrm{~mm}$ schon vollständig verschwunden ist. Hier tritt in besonders deutlicher Weise jene Art der Radialberippung auf, wie sie L.. Mojsisovics ${ }^{-1}$ ) beim Balatonites Zitteli Mojs. (pag. 8I) erwähnt. Bis zu einem Durchmesser von circa $30 \mathrm{~mm}$ ist stets erst jede zweite Rippe kräftiger entwickelt; bei weiterem Wachsthum verschwindet die schwächere Rippe fast ganz, und es treten nur kräftige, primäre und kurze, von aussen inserirte Rippen auf. Erst auf der Wohnkammer wird die Sculptur wieder eng, aber viel unregelmässiger.

1) Muisisovics E. ve, Cephalop. Medit. Triaspr.

2) Bigrich E., Ueber einige Cephalopoden aus dem Muschelkalke der Alpen. Abhandl. d. königl. Akad. d. Wiss. für \& 866 , Berlin $\$ 867$.

3) Buch L. ú, Ueber Ceratiten. Abhandl. d. königl. Akad. d. Wiss. fïr ISłS (pag. IS, Taf. IV, Fig. 4-6), Berlin IS50.

4) Moisisozics $\mathrm{E}: 2$, Cephalop. Medit. Triaspr. 
Umbilicale und laterale knoten sind fast von gleicher Stärke; die Marginalen sind die kleinsten und die Lateralen sitzen hier unter der halben Flankenhöhe.

Die Unterschiede der Suturlinie sind gering; der erste Laterallobus ist breiter und grösser als der zweite, die Loben überhaupt etwas länger als bei dem Art-lypus. Hiedurch bildet die Varietät $a$ ein Uebergangsglied zur Varietät $b$.

\section{Variatio b.}

Taf. XXIII (XI), Irig. 4

Diese Art kennzeichnet sich durch fast denselben Sculpturtypus wie die Varietät a; ein Unterschied liegt in den Loben. Sie sind sehr lang im Vergleiche zu den typischen Loben in Fig. $2 c$, und der Auxiliarlobus, welcher höher auf der Flanke schon beginnt, nimmt den ganzen Raum bis zur Naht ein und ist ziemlich reich gezackt, so dass hiedurch fast schon ein erster kleiner Auxiliar auf der Flanke individualisirt erscheint, an den sich ein zweiter, breiterer dann auf der Naht anschliessen würde.

Die Suturlinie, als Ganzes, durchsetzt in noch schrägerer Weise die Radialsculptur.

Zahl der Exemplare: 9 ('Typische Stücke: 3, Variatio a: 2, Variatio b: 4).

Balatonites egregius var. mirus Arth.

Taf. XXIII (Xi), Irig. $5 a, b$,

Durchmesser . . . . . . . . $68 \mathrm{~mm}$

Höhe der letzten Windung. . . . . 22 22

Dicke " $»$. . . . I6,

Nabelweite (von Naht zu Naht) . . . 3I D

$\mathrm{Zu}$ Beginn der letzten Windung ist der Externtheil noch stumpf-dachförmig entwickelt mit schwach hervortretender Mittellinie, welche sich theilweise noch bis fast drei Viertel des letzten Umganges, der mehr als zur Hälfte aus der Wohnkammer besteht, verfolgen lässt; deutlich abgesetzte Externknoten fehlen und auf den letzten Partien der Wohnkammer ist der Externtheil flach gerundet geworden; die Flanken sind flach gewölbt und erhalten etwas unterhalb der Flankenmitte die grösste Breite; die Rippe erscheint dick, aufgesetzt, und ihr sitzt wieder der Lateralknoten auf; so ergibt sich, über letztere gemessen, eine Breite, welche fast gleich der Windungshöhe ist; die Marginalkante ist in Folge der vorspringenden Dornen scharf entwickelt, die Umbilicale leicht abgestumpft; die Nabelwand ist anfangs nieder und senkrecht gestellt, später erhöht sie sich etwas mehr und nimmt besonders auf den letzten Theilen der Wohnkammer eine schräge Stellung an; die Involution erfolgt knapp unter dem Marginalknoten. Die Form ist sehr weitnabelig und die Windungen machen, die letzte ausgenommen, einen flach scheibenförmigen Eindruck.

Wie bei der typischen Form des Balatonites egregius zeigen auch die jüngeren Umgänge der Varietät eine langsame Entwicklung der Sculptur von ganz glatten, nur durch Einschnürungen segmentirten Windungen zur Sculpturhöhe des letzten Umganges; auf dem vorletzten wird rasch diese Entwicklung erlangt, die kurz vorher mit Umbilicalknoten beginnt; dann treten zarte Rippchen mit Lateralknoten auf, von denen stets die zweite kräftiger hervortritt, etwas später erscheinen Marginalknoten und zuletzt die niederen, undeutlichen Externverdickungen.

Die Rippen sind auf dem letzten Umgange dick, kräftig und sind während ihres ganzen Verlaufes fast von gleicher Stärke; sie haben einen kleinen, spitzen Umbilicaldorn, unterhalb der Flankenmitte einen dicken Lateralknoten, der nur stellenweise dornförmig auftritt und auf der Marginalkante einen spiral verlängerten Marginalknoten, der auf der Wohnkammer allein dornförmig wird. Ausser diesen drei Knotenspiralen treten, erst nach Beginn des letzten Umganges, zwischen der Umbilical- und Lateralspirale eine accessorische untere, und zwischen Lateral- und Marginalspirale eine - auf der 
Wohnkammer des abgebildeten Stückes sogar zwei - accessorische obere Spiralen, aus kleinen Knötchen gebildet, auf. Neben den Hauptrippen finden sich von aussen her eingeschaltete Insertionsrippen, welche aber nur bis zum Lateralknoten reichen; sie haben einen gleich starken Marginalknoten, sowie eine (eventuell zivei) obere accessorische Knotenspirale; am Umbilicalrand entspricht ihr wieder ein kleines Knötchen, wie bei Balatonites egregius, so dass man sie auch als reducirte Hauptrippe auffassen kann. Auf der Wohnkammer verliert die Sculptur an Regelmässigkeit; meist ist die Hauptrippe im unteren und die Nebenrippe im oberen Theile der Flanke besser entwickelt. Sowohl die primäre als die inserirte Rippe treten gleich stark und rasch verflachend auf den Externtheil über und bilden einen kurzen, nach vorne convexen Bogen am Ende der letzten Windung und einen stumpfen Winkel am Anfang derselben.

Die Suturlinie entspricht ziemlich genau derjenigen bei der typischen Form, durchsetzt ebenfalls schräg die Radialsculptur, zeigt aber auf der Kante, ähnlich wie die Varietät $b$ (Fig 4), einen individualisirten, kleinen Auxiliar.

Diese so beschaffene Form wurde deshalb nur als Varietät und nicht als getrennte Species abgeschieden, weil mir die Unterschiede in Folge der pag. 203 begründeten Fassung des Speciesbegriffes nicht bedeutsam genug erschienen. Sie bestehen in der unregelmässiger sculpturirten Wohnkammer, den durch die dicken Rippen fast quadratisch gewordenen letzten Windungen, dem etwas anders geformten Externtheil und in dem Auftreten der beiden accessorischen Knotenspiralen.

Zahl der Exemplare: 3.

Balatonites armiger Arth.

Taf. XXIII (XI), Fig. $6 a, b, c, 7,8$.

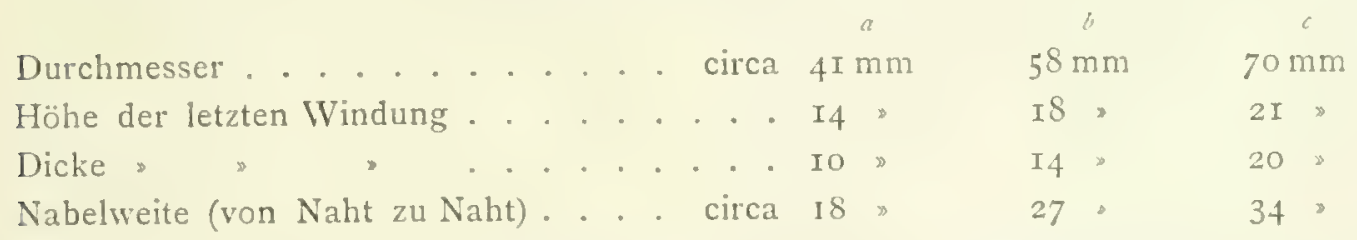

Dem grössten Stücke, welches zur Abbildung gebracht wurde, entsprechen die unter $c$ gegebenen Maasse, a gehört dem kleinsten Bruchstücke an; bei fortschreitendem Wachsthum verdicken sich die Windungen und machen einen mehr gerundeten Eindruck.

Der Externtheil ist beim ausgewachsenen, oder wenigstens beim grössten vorliegenden Individuum, flach gewölbt; in früheren Altersstadien ist er erst beim Durchmesser von 4I mm hoch gewölbt, zeigt spitzdachförmige Gestalt mit kleinen, kräftigen Externknoten, und stumpft sich späterhin allmälig ab, ım schliesslich die gerundete Form zu erreichen.

Die Flanken haben einen dicken, fast rechteckigen Querschnitt mit aufgesetzten massiven Rippen, welche Dornenspiralen tragen; der Marginalrand ist durch die seitlich kräftig vorspringenden Marginaldornen gut markirt, der Umbilicale leicht abgestumpft; die Nabelwand ist anfänglich nieder und senkrecht stehend, später auf der letzten Windung des grössten Individuums schräg gestellt; die Involution reicht bis knapp unter den Marginalknoten und lässt die obere accessorische Spirale frei; die Form ist daher sehr weitnabelig und die Involution beträgt bcim ausgewachsenen Exemplare fast die Hälfte des Durchmessers (siehe die Maasse von c).

Die Sculptur wird von radial verlaufenden, bei grossen Stücken leicht bogenförnig gekrümmten, "kräftigen Rippen gebildet. Nach den jugendlichen Entwiclilungsstadien (glatte Umgänge, später Auftreten von runden Umbilicalknötchen, sodann feine Radialrippen in weiten Distanzen mit stärlieren Lateralund ganz kleinen Marginalknoten besetzt) beginnt beim Durchmesser von circal fomm die Normalsculptur. Neben den Hauptrippen treten von aussen her cingeschoben kurze, inserinte Rippen auf, welche 
auf dem Externtheil und in der Marginalregion dieselbe Stärke wie die Hauptrippen erlangen, jedoch schon oberhalb des Lateralknotens erlöschen.

Die Beknotung wird aus den drei normalen Knotenspiralen und einer regelmässig auftretenden oberen accessorischen und einer nur stellenweise zu beobachtenden untern accessorischen Spirale, aus kleinen Knötchen bestehend, gebildet. Die umbilicalen Knötchen sind klein, auf Schalenexemplaren hie und da verschwindend; die grössten Individuen sind die mitunter sehr gross und dornförmig entwickelten Lateralen; die Marginalen halten das Mittel zwischen beiden; kräftiger sind die oberen accessorischen Knötchen zwischen dem Lateralen und Marginalen, kleiner die unteren, zwischen Lateral- und Umbilicalknoten auftretenden, die nur auf dem letzten Umgang bei grösseren Exemplaren, und auch da nicht mit Regelmässigkeit, zu beobachten sind.

Die dicke Schale verändert insoferne das Aussehen der Steinkerne, dass hiedurch die Sculptur etwas weniger scharf hervortritt. Feine, gedrängt stehende Schalenstreifen deuten auf die Form des Mundrandes hin, der einen identen Verlauf wie der bei Balatonites egregius abgebildete (pag. 202, 'laf. XXIII, Fig. $2 a$ ) gehabt haben muss.

Breite, nur auf der Flanke der letzten Windung des grössten Exemplares sichtbare Schalen. depressionen treten sehr häufig meist nach zwvei, seltener nach drei Hauptrippen auf.

Die Suturlinie hat schrägen, die Radialrippen durchschneidenden Verlauf dadurch, dass der Externlobus und Sattel sehr tief sitzt. Am auffallendsten ist die Höhendifferenz zwischen Extern- und zweitem Lateralsattel bei der Suturlinie des abgebildeten Stückes, geringer bei den in Fig. 7 u. 8 gegebenen Lobenlinien, welche auch sonst im Detail gewisse, mitunter nicht unbedeutende Variationen aufweisen.

Der Externlobus (Fig. $6 c$ ) ist breit, von einem niedern Medianhöcker in zwei kurze Arme gespalten; der erste Laterale ist sehr breit, an Tiefe etwas über den Externlobus hinabreichend und an der Basis mit grösseren, sowie darüber rechts und links mit kleineren Zäckchen besetzt; der zweite Laterale ist bedeutend schmäler, ungefähr nur halb so lang wie der erste und ähnlich gezackt; auf der Nabelwand folgt ein kleiner, runder Auxiliar. Extern- und erster Lateralsattel sind breit, rundbogig, der zweite sehr klein, sämmtliche Sättel ganzrandig.

Die Suturlinie, Fig. 7, welche dem Stück mit den unter $b$ gegebenen Maassen angehört, das sich bei etwas geringerer Grösse durch kräftigere, etwas gedrängtere Sculptur und durch deutliches Auftreten der unteren accessorischen Knotenspiralen auszeichnet, verläuft viel flacher, hat im Grössenverhältniss untereinander ähnliche, jedoch bedeutend flacher gespannte Sättel und durchschneidet die Radialsculptur in viel weniger schräger Weise. Der Auxiliarlobus wird von der Naht geschnitten und zeigt drei kleine Zäckchen.

Die Suturlinie, liig. 8, gehört einem Individuum (Durchmesser $57 \mathrm{~mm}$ ) der eben besprochenen, enger sculpturirten Varietät an. Die Suturlinie zeigt schon bogenförmigen Verlauf, die Loben sind relativ breiter, die Sättel schmäler als die der letzteren Form, der Auxiliarlobus ist auf der Nabelwand vollständig und wieder mit Zäckchen entwickelt.

Bei einem kleinen Stücke, dem die unter a gegebenen Maasse entsprechen, sitzt der gezackte Auxiliar schon auf der Flanke. Gewisse Sculpturunterschiede, wie gedrängtere Stellung der hier leicht grekrümmt verlaufenden Rippen, Reduction der Zwischenrippen fast nur auf die Marginalpartie allein, höherer Ansatz des Lateraldornes und besonders scharf ausgebildeter Externtheil, der von den Rippen paarig (Haupt- und Nebenrippe) übersetzt wird, machen mich überhaupt zweifeln, ob dieses Stück hier richtig seinen Platz finde.

Der Unterschied des Balatonites armiger von Balatonites egregius var. mirus besteht darin, dass letztere Form engnabeliger ist, die Umgänge sind viel dicker, fast quadratisch, die Berippung enger, die Rippen selbst sschlanker; die Lateraldornen haben bedeutend höhere Stellung; die Unterschiede der Suturlinien lassen sich von selbst erkennen.

Zahl der Exemplare: 6. 


\section{Balatonites diffissus Arth.}

Taf. XXIII (XI), Fig. $9 a, l, c, d$.

Durchmesser. . . . . . . . . . $27=$
Höhe der letzten Windung
Dicke, " . . . $42=$
Nabelweite (von Naht zu Naht) .

Der Externtheil ist bei der vorliegenden Grösse am Ende der Wohnkammer sehr flach, am Anfange derselben etwas höher gewölbt; der Querschnitt der Umgänge ist fast rechteckig; die grösste Dicke wird im Lateralknoten ungefähr in der halben Flankenhöhe erlangt; der Marginalrand ist durch die seitlich vorspringenden Marginalknoten scharf begrenzt, der Umbilicale ist leicht abgestumpft. Die Involution erfolgt knapp innerhalb des Marginalknotens; die Art ist sehr weitnabelig.

Die Radialsculptur macht, je nachdem das Stück als Schalenexemplar oder Steinkern erhalten ist, verschiedenartigen Eindruck, so dass ausser den Altersunterschieden noch die Unterschiede der Erhaltungsweise in Betracht kommen. Die inneren Windungen sind bis zum Durchmesser von ungefähr $20 \mathrm{~mm}$ glatt, dann beginnt in analoger Weise, wie schon bei früheren Gelegenheiten beschrieben wurde, die Entwicklung der Sculptur, welche beim Durchmesser von ungefähr $40 \mathrm{~mm}$ vollständig erlangt ist. Bis zu den letzten Windungspartien verstärkt sich dieselbe nur mehr, und eine eigentliche Vermehrung der Berippung und Beknotung findet nur in untergeordneter Weise mehr statt. In der Sculpturreife besteht dieselbe auf dem Steinkerne aus kräftigen, massiven, minimal bogenförmig gekrümmten Rippen. welche leicht sichtbar über die Nabelwand heraufsteigen und auf dem Rande einen kleinen, abgestumpften Umbilicalknoten tragen; sodann schwillt die Rippe in der halben Flankenhöhe zur grössten Dicke und Höhe an, ohne dass jedoch diese Anschwellung sich stets als Dorn individualisiren würde; auf dem Marginalrand tritt eine kleinere, scharfe Marginalanschwellung auf, welche durch die knieförmige Beugung der Rippe nach vorn fast spiral gestellt erscheint; auf dem Externtheil ist sie fast vollständig verschwunden und tritt nur mehr als stärkere Linie hervor, welche denselben auf dem Ende der Wohnkammer (nach vorne convex) übersetzt. Bei Formen der Mittelgrösse scheint der Externtheil höher gewölbt zu sein, die Rippen treten jedoch auf denselben nicht über, so dass sich nur durch die rippentragenden und rippenlosen Partien der oberen Flanke allein eine Art von Sculpturirung auf demselben ergibt. Möglich ist hingegen, dass im jüngeren Altersstadium ein geknoteter Convextheil auftritt. Stellenweise ist unterhalb des Marginalknotens eine kleine, accessorische Knotenspirale sichtbar, jedoch nur gegen Ende des Umganges bei ausgewachsenen Individuen. Eine Vermehrung der Rippen erfolgt selten durch Einschaltung kurzer Insertionsrippen ron aussen, welche einen gleich starken Marginalknoten wie die Hauptrippen tragen; die Regel sind einfache Rippen. Nur gegen Ende der Wohnkammer bei Fig. $9 a$ wird die Sculptur stellenweise regellos, indem sich von der Primären in der oberen Flankenpartie kleine scharfe Rippchen losspalten, welche Marginalkötchen tragen, und den Externtheil von den Primären unabhängig übersetzen. Durch diese Losspaltung wird die Hauptrippe in ihrer Stärke geschwächt.

Auffallend ist ein vielleicht pathologischer Zustand cinzelner Rippen der einen Flankenseite des abgebildeten Stückes, indem dieselben nicht auf der Oberfläche gerundet, sondern im Gegentheile wie mit einem spitzen Instrumente, etwa einer Spachtel, von oben her ein-oder auseinander gedrückt erscheinen. Diese Erscheinungsform ist übrigens häufig in dem ganzen vorliegenden Balatonitenmateriale zu beobachten, alterirt jedoch nie die Beknotung.

Ist die dicke Schalc erhalten, so ändert diese die eben beschriebene Sculpturform derart, dass sie die Höhenunterschiede zwischen Flankenebene und Rippenwulst vermindert, wodurch die Ornamentirung an Schärfe verliert. 
Die Suturlinie hat einen ausserordentlich an den bei Balatonites armiger (Taf. XXIII, I'ig. 6 c) erinnernden Verlauf, in dem die Verbindungslinie der Sättel in noch schrägerer Weise dic Radialsculptur durchsetzt. Die Differenz zwischen der Basis des Externlobus und dem Scheitel des Auxiliarsattels beträgt hier I3 mm; die Loben sind breit, kurz und ebenso die Sättel. Der Externlobus ist breit und wird von dem niedern Medianhöcker in zwei kurze Aeste getheilt, welche an der Basis einen grösseren und an der Innenwand kleineren Zacken tragen; der erste Lateral ist etwas schräge gestellt, reicht ungefähr ebenso tief wie der Externe herab und trägt an der Basis drei grosse Zacken; von gleicher Breite ist der zweite Lateral, der aber nur ungefähr halb so tief wie der erste herabreicht und an der Basis kleinere Zacken trägt; der Auxiliar nimmt die Nabelwand ein und ist in der Mitte gespalten. Die Sättel sind breit, ganzrandig und flach gewölbt; der grösste ist der Externe, welcher grösstentheils auf der Flanke liegt, der kleinste der zweite Laterale, welcher von der Nabelkante halbirt wird: der Ansatz eines Auxiliarsattels ist noch an der Naht sichtbar.

Oberhalb der letzten Suturlinie sieht man bei dem Fig. 9a abgebildeten Stücke eine dicke, braune Linie besonders in den äusseren Windungspartien auftreten. Ich kann mir dies nur als Depôt organique erklären, welches das Thier vielleicht ablagerte, um die bedeutende Höhendifferenz zwischen den Extern- und Internpartien der Wohnkammer theilweise auszugleichen.

Es ist nicht zu leugnen, dass zwischen Balatonites diffissus und Balatonites cfr. Ottonis

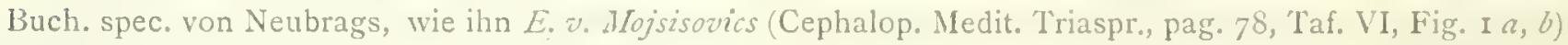
abbildet, gewisse Aehnlichkeiten bestehen. Die Unterschiede liegen besonders in der Suturlinie und dem (loc. cit. Fig. I b) gegebenen Querschnitt der letzten Windung, welcher einen zugeschärften Externtheil zeigt.

Zahl der Exemplare: I.

Balatonites variesellatus Arth.

Taf. XXIV (XII), Fig. I $a-\ell$.

Durchmesser ...... . . . $45 \mathrm{~mm}$
Höhe der letzten Windung $63 \mathrm{~mm}$

Der Externtheil ist bei Formen, welche ungefähr der Grösse $a$ entsprechen, spitzdachförmig und mit den Rippen correspondirenden kleinen, längsgestellten Externknötchen besetzt; auf der vorangehenden Vindung (Durchmesser circa $18 \mathrm{~mm}$ ) ist der Externtheil noch hochgerundet; bei einem Durchmesser von $56 \mathrm{~mm}$ beginnt er sich abzuflachen und die Externknoten beschränken sich nur mehr auf die Hauptrippen allein; bei einem Durchmesser von $63 \mathrm{~mm}$ stumpft er sich immer mehr ab, gleichzeitig verschwinden die Knoten und ihre Stelle übernimmt eine Kiellinie, welche jedoch nur auf Steinkernen auftritt: ist die Schale hingegen erhalten, so ist der Externtheil mittelhoch gerundet und glatt; endlich bei weiterem Wachsthum flacht er sich immer mehr ab und ist dann nur mehr durch die stark reducirten und abgeflachten Rippen, welche sich in der Scheitellinie stumpfwinkelig treffen, sculpturirt. Die Form des Umganges bleibt in den verschiedenen Altersstadien ziemlich constant, ist nur in der Mittelgrösse etwas mehr gerundet und entspricht ungefähr einem sehr steilen Trapez, dessen Basis in der Höhe der Marginalknoten liegt. Die Marginalkante ist, bei Ausnahme der Jugendformen, scharf entwickelt durch die längsgestellten Marginalknoten, die Umbilicale leicht gerundet und dient als Ansatz der Umbilicalknoten; die grösste Dicke wird ungefähr in der Mitte der Flanke in den spitzen, kräftigen Lateraldornen erlangt; die Nabelwand ist anfänglich nieder und senkrecht stehend, erhöht sich jedoch späterhin und stellt sich immer schräger; die Involution ist anfangs bedeutender, bei einem 
Durchmesser von $20 \mathrm{~mm}$ beginnt die Windung sich auszuschniiren und bedeckt sodann nur mehr knapp den Externtheil des rorangehenden Umganges; die Form ist sehr weitnabelig.

Auf das glatte Jugendstadium folgend, beginnt sich die Sculptur bei einer Flankenhöhe von ungefähr Io $\mathrm{mm}$ mit Umbilical-, Lateralknoten und linienförmigen Rippen zu entwickeln; bei einer Flankenhöhe von ungefähr $15 \mathrm{~mm}$ ist das Reifestadium erlangt. Die Sculptur besteht dann aus schlanken, geraden, von der Radiale nach vorn abweichenden Hauptrippen, welche im oberen Theil der Nabelwand deutlich sichtbar sind, auf dem Nabelrande einen kleinen, stumpfen Umbilicalknoten tragen, sodann sich stark reduciren, kurz unterhalb des grossen Lateraldornes wieder anschwellen, sodann fast dieselbe Stärke bis zum Marginaldorn beibehalten, von da aus sich nach vorn weriden und in der Weise, wie schon oben angedeutet wurde, verschwinden. Stellenweise, und dies selten, tritt im Alter ein kleines accessorisches Knötchen oberhalb und eines unterhalb des Lateraldornes auf; der Marginaldorn ist bei der Mittelgrösse spiral verlängert, später von rundlicher, dorniger Gestalt. Ausser den Hauptrippen treten kurze, von aussen eingeschaltete Nebenrippen auf, welche auf Extern- und Marginaltheil dieselbe Form und Grösse wie erstere haben, jedoch in der Höhe der Lateralknoten erloschen sind. Ihr Auftreten ist kein regelmässiges ausser, bei Formen der Mittelgrösse; im Alter verschwinden sie vielfach, so dass nur mehr Hauptrippen vorkommen, ja gegen Ende des letzten Umganges ändern sich auch diese vielfach in der Art ab, dass die eine in der unteren, die nächstfolgende in der oberen Flankenhälfte kräftiger entwickelt ist, was aber vielleicht auch nur individuelle Eigenthümlichkeit des grössten vorhandenen Stückes ist. Auf der Schale treten ausserordentlich feine Anwachsstreifen analog dem Verlaufe der Rippen auf.

Die Suturlinie besteht aus kurzen, breiten Loben und Sätteln. Der Externlobus ist breit, nieder und ist von einem kurzen Medianhöcker getheilt, beide Arme des Lobus haben seitlich kleine Zäckchen; der erste Lateral ist ungefähr zweimal so tief wie der Externe, erscheint jedoch durch seine Breite viel kürzer; der zweite ist etwas schlanker, reicht aber tiefer als der Externe herab: beide sind an der Basis gezackt; yon der Nabelkante zur Naht tritt ein breiter Auxiliar auf, der auf der Kante einen deutlichen, isolirten Zacken aufweist, welcher in Folge dessen vielleicht schon als ein erster Auxiliar aufzufassen wäre. Die Sättel sind rundbogig und ganzrandig; der Externe liegt grösstentheils auf der Flanke; der erste Lateral ist etwas schmäler und bedeutend höher, der Zweite sehr klein.

Auffallend ist der verschiedenartige Verlauf der beiden .übereinanderliegenden Suturlinien: die untere durchsetzt in etwas schräger Weise die Radialsculptur und der zweite Lateralsattel liegt fast auf derselben Höhe wie der Erste, während bei der oberen Linie die Sutur stark bogenförmig verläuft, so dass der zweite Lateralsattel noch tiefer als der Externe zu stehen kommt. Da die Sculptur vollständig regelmässig entwickelt ist, kann man diese Abweichung nicht als krankhafte Bildung erklären.

Einen ganz ähnlichen Wechsel des Suturverlaufes finden wir auch bei Balatonites armiger (pag. 205, laf. XXIII, Fig. 6, 7, 8), besonders bei den Fig. 7 u. 8 gegebenen Suturlinien. Die ausserordentliche Variationsfühigkeit der Balatoniten dieses Niveaux zeigt sich daher auch in den Suturen, die hier keineswegs dieselbe Sicherheit für die Bestimmung bieten, wie man sonst anzunehmen gewolnt war.

Zahl der Exemplare: 3 .

Balatonites stenodiscus Arth. Taf. XXIV (XII), Fig. $2 a-t$

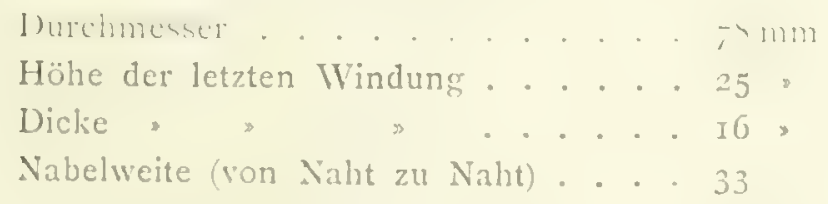

Der Externtheil dieser schlanken, hochmündigen Form ist am Ende der letzten Windung sanft gewölbt, im Anfange stumpf dachförmig mit niedern, längsgestellten Medianknoten; Marginal- und 
Umbilicalkante sind scharf entwickelt, die Nabelwand anfänglich nicder und senkrecht gestellt, später schräger und bedeutend höher; die Flanken sind thach gewölbt und erlangen in den Lateralknoten, die in halber Seitenhöhe stehen, die grösste Dicke; die Involution beträgt bis zur Windungshöhc von $6 \mathrm{~mm}$ ungefähr ein Drittel, später schnürt sich die Form stärker aus, so dass nur mehr der Externtheil und die Marginalkante des vorangehenden Unganges bedeckt werden; die Form wird daher schr weitnabelig.

Die Radialsculptur besteht bei erwachsenen Individuen aus mittelstarken, geraden Hauptrippen mit Knoten. Ungefähr in demselben Altersstadium, in dem die Windung stärker zu egrediren beginnt, fängt auch die Beknotung und Berippung an, und zwar in derselben Weise wie bei den früher besprochenen Formen, nur dass hier das glatte Jugendstadium etwas früher als gewöln nlich sein Lindo findet; auf dem vorletzten Umgang haben wir enggestellte, sehr zarte Rippen, welche auf der Schale sich nur als Linien verrathen, kraftige Umbilicalknoten und kleine, zarte Lateraldornen; gegen Ende dieses Unganges wird die Berippung liräftiger, indem die Rippen in der Mitte anschwellen, was auch mit stärkerer Entwicklung des Lateraldornes verbunden ist; nun kann man auch die Externseite beobachten, auf welcher kleine Marginal- und minimale, längsgestellte Externknötchen auftreten, dic aber im letzten Viertel des Umganges wieder verschwunden sind. Auf der Wohnkammer, die bei dem vorliegenden Stücke ungefähr die Hälfte des letzten Umganges beträgt, ändert sich die Berippung wieder in gewissem Sinne, indem die Hauptrippen zeitweise die Tendenz zur Abspaltung schwacher Rippenfragmente zeigen, was aber nur auswärts des Lateraldornes geschieht (diese Nebenrippen haben dann am Marginalrand dieselbe Stärke wic die Hauptrippen) oder aber es ist eine Hauptrippe in der unteren Flankenpartie sehr schwach, in der oberen normal entwickelt. Auf diese beiden Arten findet cine Vermehrung der Rippen und Knoten in der Aussenpartie statt; auf dem Marginalrande selbst wenden sich die Rippen in der Marginalanschwellung, die folglich leicht schräg restellt ist, in einem kurzen Kiniestück nach rorne und verlöschen schnell.

Ob oder wie sich die Sculptur des Externtheiles in jüngeren Altersstadien ändert, lässt sich — da leider ein einziges Exempiar dieser Art vorliegt - nicht beobachten. Im Grossen und Ganzen sehen wir aber hier wieder drei Sculpturstadien: das Glatte des jugrendlichen Alters, das rollkommen entwickelte des Reifestadiums und die Sculpturform der Wohnliammer vollkommen erwachsener Individuen mit stärkerer oder schwächerer Alteration der Sculptur des Mittelstadiums. Zwischen diesen bestehen natürlich allmälige Uebergänge.

Die Suturlinie zeigt einen schief bogenförmigen Verlauf, so dass die Rađialsculptur schräg durchsetzt wird. Der Externlobus ist breit, sehr tiefstehend, und wird ron einem niederen, breiten Medianhöcker in zwei Theile getheilt, welche seitlich kleine Zacken tragen; der erste Lateral ist von mittlerer Grösse, reicht tiefer als der Externe herab und ist an der Basis reich zerschlitzt; der Zweite, fast von gleicher Breite, reicht nicht ganz so tief wie der Externe herab. Schon auf der Flanke beginnt ein breiter Auxiliar, der sich schräg aufwärts zur Naht zieht und in undeutlicher Weise ein bis zwei Zäckchen zeigt. Die Sättel sind rundbogig und ganzrandig; der Externsattel ist der grösste und liegt grösstentheils auf der Flanke; von ihm macht die Suturlinie einen grossen Sprung zum ersten Lateral, der etwas kleiner und flacher gewölbt ist; etwas niederer steht der kleine zweite Lateral. Die Suturlinie erinnert in ihrem schrägen Verlauf an diejenige von Balatonites egregius Arth. (pag. 203, Taf. XXIII, Fig. 2c), Balatonites armiger Arth. (pag. 206, Taf. XXIII, Fig. 6 c), đessen Varietät (pag. 206, Taf. XXIII, Fig. 8) und Balatonites diffissus Arth. (pag.208, Taf. XXIII, Fig. 9d), ohne dass sich jedoch diese Arten selbst vereinigen liessen. Die grösste Aehnlichlieit von allen besitzen noch Balatonites stenodiscus und Balatonites diffissus; doch auch hier ist die eine Form hochmündig und flach, die anderc niedrigmündig und dicker. Sollten die Suturen sich vielleicht so bedeutend mit dem Altersstadium ändern?

Zahl der Exemplare: . 
Balatonites Haueri Arth.

Taf. XXIV (XII), Fig. $3 a, b$,

Durchmesser . . . . . . . $69 \mathrm{~mm}$
Höhe der letzten IVindung . . . . . 22,
Dicke $\$$. . . 6 .
Nabelweite (von Naht zu Naht) . . . $30 \%$

Der Externtheil des flach scheibenförmigen Gehäuses ist im Anfange der letzten Windung stumpf-dachförmig, am Ende desselben flach gewölbt; der Uebergang der einen in die andere Ausbildungsform findet rasch statt; die Flanken sind bei kleinen Jugendformen von nicht mehr als $8 \mathrm{~mm}$ Durchmesser rundlich aufgetrieben, flachen sich dann stark ab und behalten diese flach gewölbte Form auch im Alter bei; die Medianlinie des Externtheiles ist durch eine Kinotenlinie, aus länglichen Individuen bestehend, markirt, welche gegen Schluss des Umganges immer kleiner, schliesslich zu Punkten werden und endlich ganz verschwinden; die Marginalkante ist ziemlich scharf entwickelt, stumpfer die Umbilicale; die Nabelwand ist nieder, anfänglich steil gestellt, später flacher liegend. Die Involution ist bei Jugendformen grösser, wird dann geringer und bedeckt im Alter eben noch die marginale Knotenreihe der früheren Windung. Diese Form ist sehr weitnabelig.

Die Sculptur besteht bis zu einer Windungshöhe von ungefähr $4 \mathrm{~mm}$ lediglich aus enggestellten, radialen Einschnürungen und die Schale ist mit feinen, engen Anwachslinien bedeckt. Dann beginnt sich die Sculptur des Reifestadiums zu entwickeln, erst mit kleinen Umbilicalknötchen, dann kommen zarte Radialrippen gleichzeitig mit den Flankenknötchen hinzu und zuletzt die den Lateralen gleichenden Marginalen; bei Beginn des Reifestadiums hat auch der Externtheil seine meist etwas länglichen Knoten erlangt. Anfänglich treten die Rippen in grösseren Abständen auf und zwischen ihnen liegt eine sehr schwache, nicht zur Entwicklung gelangte Rippe; späterhin wird jedoch auch diese kräftiger, ist jedoch nur in seltenen Fällen bis zum Nabelwand zu verfolgen und ist meist im oberen Flankentheil gut entwickelt. Sie ist wohl nur als Neben-oder Zwischenrippe aufzufassen, welche ein Engerwerden der Sculptur bedingt; im Anschluss an die Hauptrippe tritt sie auch wie diese auf den Externtheil über und schwenkt auf der Marginalkante nach vorne. Da die beiderseitigen Rippen correspondiren, treffen sie sich parig und spitzwinkelig im Medianknoten. Gegen Ende des Umganges bei dem rorliegenden Stücke wird die Sculptur wieder spärlicher, die Umbilicalknoten treten stark zurück, die Lateralknoten werden zu kräftigen, stumpfen Stacheln, welche auf der Flanke höher hinauf bis oberhalb der Flankenmitte rücken und die Marginalknoten werden spitzig; knapp unter ihnen tritt eine accessorische vierte laterale Knotenspirale auf, aus kleinen Individuen gebildet, welche aber nur liure Zeit bestehen bleibt. Die letzten Rippenpare vor Ende der Windung haben die Marginale und die accessorische Knotenreihe schon wieder verloren und übersetzen mit einem hochgewölbten Bogenstück den Externtheil. Auch in diesem Alter zeigt die Schale äusserst feine Anwachslinien.

Die Suturlinie besteht aus kurzen, breiten Elementen und hat flach bogenförmigen Verlauf. Der Externlobus ist breit von einem niederen Medianhöcker in zwei cinspitzige Zacken zertheilt; der' erste und zweite Lateral sind fast von gleicher Grösse und haben an der Basis zwei kleinere und zwei grössere Zacken; auf dem Nabelrand folgt cin vollständig entwickelter Auxiliar. Die Sättel sind rundbogig und ganzrandig; der breite Externsattel wird von der Marginalkante halbirt und steht in derselben Höhe wie der zweite Laterale; der erste ist schmal und liegt am höchsten, der zweite ist bedeutend kleiner; der flache Auxiliarsattel liegt auf der Nabelwand.

Diese reich sculpturirte Form hat gewisse Verwandtschaft mit Balatonites stenodiscus (pag. 209, Xaf. XXIV, lïg. $2 a-d)$, von dem sie sich durch die engere Sculptur, durch gewisse Abweichungen in ber Gestalt des Externtheiles, etwas niederere Umgänge und eine nicht kreisförmige, sondern siclı eher der Ellipse nähernde Windungsform unterscheidet. 
Ein kleineres Bruchstiick, das wahrscheinlich derselben Art angchört, zeigt die Variationsfähigkeit der Species in dem Sinne, dass die Zwischenrippe kräftiger entwickelt ist, mitunter in der Zweizahl auftritt und wohl einen kleinen Umbilical- und Marginalknoten, aber nur winzig kleines Lateralknötchen trägt. In I*olge dessen hat nur jede dritte, eventuell vierte Rippe erst einen grösseren Lateralknoten.

Von älteren, in der Literatur bekannten Formen scheint Balatonites Zitteli Mojs. ${ }^{1}$ ) (pag. So, Taf. V, lig. 2, ' 'af. XIX, Iig. 3), beschrieben aus dem oberen Muschelkalk der Schreyeralm (Zone des Ceratites trinodosus), ebenfalls in die Verwandtschaft dieser neuen Art zu gehören. Die Zeichnungr auf Taf. V, Fig. 26, ist zweifelsohne irrthümlich und die Seitenansicht nicht entsprechend ergänzt, denn es ist hier auch gegen Ende des Umganges noch ein scharfer, medianer Knotenkiel angenommen, der in Anbetracht der Reiflinger Irormenmenge, bei welcher fast stets ein Verschwinden des Kieles im Alter zu beobachten ist, nunmehr unwalurscheinlich geworden ist.

Die geologisch jüngere Form zeigt schlankere und höhere Umgänge, wächst somit rascher an; die Involution ist bedeutender und daher der Nabel relativ kleiner; die Sculptur ist auf den jüngeren Umgängen bedeutend weiter und spärlicher, die Ansatzstelle des Lateraldornes liegt unterhalb der halben Flankenhöhe, und die accessorische vierte Knotenspirale scheint länger zu persistiren, jedoch nur aus undeutlicheren Verdickungen und nicht wie bei Balatonites Haueri aus wohlausgebildeten, sehr kleinen Knötchen zu bestehen.

Zahl der Exemplare: 3, Var.: 2 Exemplare.

Balatonites Joris Arth.

Taf. XXIV (XII), Fig. $+a, b$,

Durchmesser . . . . . . . circa $68 \mathrm{~mm}$

Höhe der letzten W'indung .....24,

Dicke $"$ " .. circa 18 "

Nabelweite (ron Naht zu Naht). . * 27

Der Externtheil erweist sich bei jüngeren Formen schmal, gerundet, wird später breiter und stumpf-dachförmig und scheint diese Ausbildungsform aucl noch bei einer Windungshöhe von $24 \mathrm{~mm}$ beizubehalten. Nach dem rundlich aufgeblähten Jugendstadiun der Umgänge, welche nur durch zahlreiche Einschnürungen sculpturirt sind, beginnen die Windungen rascher anzuwachsen, wobei sie eine flache Wölbung erlangen; die Nabelwand ist anfangs senkrecht gestellt und nieder, flacht sich aber auf der letzten Windung nicht unbedeutend $a b$ und wird höher. Die Involution reicht knapp über die Externkante der früheren Windung; die Nabelweite ist bedeutend.

Zu Beginn des mittleren Wachsthumsstadiums besteht die Sculptur aus zarten, weitabstehenden Rippchen, welche kräftige, runde Umbilicalknoten und ganz kleine Laterale tragen; Marginal- und Externknoten sind ebenfalls äusserst zart entwickelt, sowie auch schon eine Spur der später kräftigen accessorischen Küütchenspirale unterhalb der Marginalkante. Dann - zu Beginn des letzten Umganges - wird die Radialsculptur bedeutend enger, gleichzeitig treten die Limbilicalknoten stärker zurück und die Lateralen gewinnen an Stärke. Im weiteren Wachsthum verdicken sich die Rippen im oberen Flankentheil, wodurch die Sculptur noch enger erscheint und erst am Ende der Windung - beim vorliegenden Stück - wieder weiter auseinander tritt. Dies geschieht dadurch, dass jede zweite Hauptrippe sich bedeutend reducirt, indem sie nur mehr in der oberen Flankenpartie als feines Rippchen mit kleinen Marginalknoten und kleiner Anschwellung in der Höhe der oben erwähnten accessorischen Spirale auftritt und schliesslich nur mehr als klciner Marginallnoten allein, der bei weiterem Wachsthum wohl auch verschwinden diufte.

\footnotetext{
1) Alojisoutics L. Z, Cephalop. Medit. Triaspr.
} 
Die Suturlinie zeigt einen flachbogenförmigen Verlauf und breite, niedere Suturglieder. Der Externlobus ist breit, kurz und wird von einem plumpen Medianhöcker in zwei zweispitzige Arme getheilt. Der erste Laterallobus erlangt fast die doppelte Tiefe des Externen, ist breit und von derselben Form wie der zweite, der etwas kürzer entwickelt ist. Am Grunde sind beide Loben mit zwei grösseren Zacken und ein bis drei Zähnchen besetzt. Auf der Nabelkante selbst folgt ein kleiner, mit zwei Zacken besetzter wohlentwickelter Auxiliar. Der erste Lateralsattel ist das grösste Sattelelement, von fast gleicher Grösse ist der zweite Lateral- sowie der Externsattel, welcher zum grösseren 'Theile auf der Flanke liegt; der kleine Auxiliarsattel liegt auf der Nabelwand.

Balatonites Jovis schliesst sich verwandtschaftlich zunäichst an den im Folgenden beschriebenen Balatonites Doris an.

Zahl der Exemplare: 4 .

Balatonites Doris Arth.

Taf. XXIV (XII), Fig. $5 a, b, c$

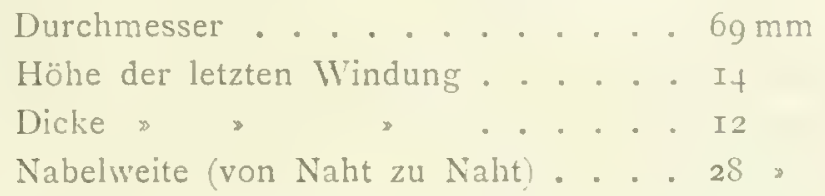

Der Externtheil der flachen, in oberen Flankentheile leicht aufgetriebenen Umgänge ist zu Beginn der letzten Windung spitzdachförmig und stumpft sich gegen Ende derselben immer mehr und mehr $a b$, ist anfänglich mit kleinen, scharfen, spiral gestellten Medianknoten besetzt, welche später rundlichere Gestalt annehmen und beim Weiterwachsen der Form schliesslich verschwinden. Marginal- und Umbilicalkante sind entwickelt und mit Knoten besetzt; die Nabelwand ist anfänglich nieder und senkrecht gestellt und wird am Ende des letzten Umganges schräger und höher; die Involution ist anfangs grösser und zu Beginn der letzten Windung ungefähr ein Viertel der Flankenhöhe.

Die Sculptur besteht aus Rippen mit Knoten oder Dornen. Auf das glatte Jugendstadium mit wenig gewölbten Umgängen folgt beim vorliegenden Stück ungefähr im ersten Viertel der vorletzten Windung der Beginn der Sculpturirung, wieder in der Folge wie bei den früher besprochenen Formen, mit Umbilicalknoten und aus den Einschnürungen sich entwickelnden zarten Rippen. Von diesen trägt jede zweite ein kleines Lateralknötchen; bei der Hälfte des vorletzten Umganges ist auch schon ein kleines, marginales und längsgestelites Externknötchen entwickelt. Iiurz vor Beginn der letzten Windung trägt auch die blinde Rippe ein kleines Lateral-, Marginal- und Externknötchen, so dass die Sculptur sich auf diese Art stark verengt und gegen Ende der letzten Windung ausserdem noch durch Einschaltung neuer 'Lwischenrippen, welche bis zum Lateralknoten reichen, vermehrt wird, Gleichzeitig wölbt sich auch die Flanke in der oberen Partie stärker und die Kinotenzahl vermehrt sich, indem zwischen Umbilical- und Lateralknoten, den letzteren mehr genähert, zwei kleine accessorische linötchen hinzutreten, die beim Fortschreiten der Windung grösser werden und eine tiefere Lage einnehmen. Erst in der Hälfte des letzten Unganges beginnen auch unterhalb des Marginalknotens erst ein, später noch ein zweites accessorisches Knötchen sich zu entwickeln. Auf den Zwischenrippen, welche, wie erwähnt, dieselbe Externbeknotung tragen, treten diese kleinen, accessorischen Knötchen ebenfalls auf, jedoch ohne Regelmässigkeit.

Am Ende der letzten Windung tragen die relativ zarten Rippen, welche schwach bogenförmigen Verlauf haben und ohne Kinickung auf den Externtheil übertreten, folgende Kinoten: Dornige, kraftige Umbilical- und Marginalknoten und oberhalb der Flankenmitte stehend, spiral untereinander, theilweise durch eine Linie rerbunden, etwas kleinere Laterale; in der unteren Flankenpartic zwei grössere, in del obcren zwei lileinere accessorische Knötchen; auf dem lixterntheil ist der Externdorn sehr stark reducirt und nur noch auf den Hauptrippen erhalten. 
Die Suturlinie zeigt schwach bogenförmigen Verlauf. Der Externlobus ist breit, nieder, wird von einem schlanken Medianhöcker in zwei breite Arme zerlegt, deren Lobengrund gezackt ist; der erste Laterale ist gross und reicht am tiefsten herab; kleiner aber von ahnlicher form ist der zweite Laterale und beide haben gleichmässig durch drei grosse und seitlich je einen kleinen Zahn gezackte Lobenbasis; ausserhalb der Nabelkante sitzt noch ein kleiner zerschlitzter Auxiliar. Die Sättel sind manzrandig und rundbogig; der Externsattel liegt grösstentheils auf der Flanke, der erste Laterale reicht am höchsten hinauf und alle drei Sättel sind von annähernd gleicher Grösse; del Auxiliarsattel beginnt auf der Flanke und nimmt die ganze Nabelwand ein.

Balatonites Doris schliesst sich zunächst an den im ersten 'Thcil dieser Arbeit ${ }^{1}$ ) beschriebenen Balatonites transfuga Arth. (pag. 70, 'Taf. VII, Fig. I, 2) an und steht in weiterer Verwandtschaft mit Balatonites Jovis Arth. (pag. 212, Taf. XXIV, Fig. 4) und bildet zusammen mit diesen Reiflinger Formen und dem Balatonites gemmatus Mojs. ${ }^{2}$ ) (pag. 8I, Taf. VI, Fig. 3) den Uebergang der Balatoniten zu den stammverwandten Trachyceraten.

Die vorliegende neue Form hat mit dem Balatonites transfuga die dem Ovale sich nähernde Einrollung gemeinsam, unterscheidet sich aber durch die rasche Ausschnürung und den minderen Grad der Spiralsculpturirung. Bei Balatonites Jovis finden wir auf der Flanke, hier freilich erst in der Entwicklung begriffen, fünf Knotenspiralen, bei Balatonites Doris und Balatonites gemmatus Mojs. deren sieben und bei Balatonites transfuga sogar neun, und doch sind diese vier liormen alle von annähernd gleicher Grösse; den kleinsten Durchmesser besitzt der Balatonites gemmatus mit 6r mm, den grössten Balatonites transfugir mit $71 \mathrm{~mm}$.

Zahl der Exemplare: I.

\section{Balatonites Galateae Arth.}

Taf. XXIV (XII), Fig. $6 a, b, c$, Fig. $7 a, b$, Fig. S.

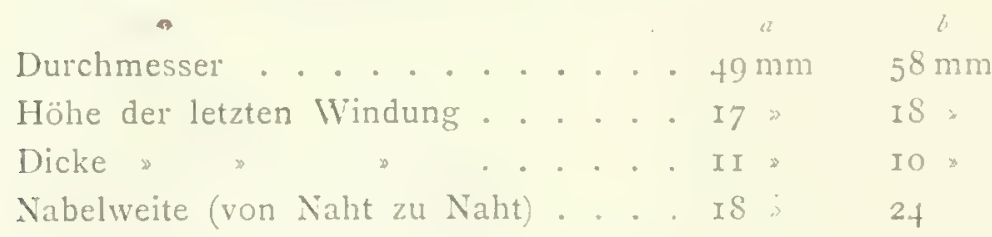

Der Externtheil dieser tlachen Form ist im Jugendstadium gerundet, schärft sich in Reifestadium dachförmig zu und trägt auf der Mediankante runde, zugespitzte Knötchen; bei der flachen Varjetät Fig. $7 a, b$ mit den Massen $b$ sind dieselben stärker in die Länge gezogen, und bei einer Windungshöhe von $20 \mathrm{~mm}$ erscheint der Externtheil knotenlos und gerundet. Die Flanken sind flach gewölbt; die Marginalkante ist scharf entwickelt und durch Knoten markirt, die Umbilicale, anfangs kantig, stumpft sich mit Flacherwerden der Nabelwand leicht ab. In der Jugend ist letztere senkrecht und nieder, später erhöht sie sich und nimmt schiefere Lage an. Aehnlich ändert sich die Involution, welche bei Jugendformen fast die Hälfte beträgt und erst später geringer wird, indem die Form sich rasch ausschnürt. Die Nabelweite ist insonderheit bei der Varietät Fig. 7 bedeutend, da wir hier relativ weniger hohe Umgänge bei grösserer Nabelweite finden.

Die Sculptur besteht, abgesehen vom Jugendstadium, das bis zur Windungshöhe von circa $4 \mathrm{~mm}$ reicht und gerundete, glatte Umgänge mit zahlreichen Einschnürungen zeigt, aus bedornten Rippen. Zu Beginn des Reifestadiums finden wir kräftige Umbilicaldornen, von denen aus je eine, sehr selten zwei feine, fast nur als Schalenstreifen auftretende Rippen in radialer Richtung über die Flanke ziehen; sie tragen ungefähr in der Mitte der Flankenhöhe kräftige, kleine und spitze Lateralknötchen,

1) Beiträge zur Pal. u. Geol., Bd. X, Heft I u. 2.

2) Mojsisozics E. थ. Cephalop. Medit. Triaspr. 
welche durch eine deutliche Spirallinie untereinander verbunden sind; auf der Marginalkante sitzt ein viel kleineres Marginales. Es scheint, so wie bei zahlreichen anderen Formen, auch hier eine Zwischenrippe in der Laternalbeknotung übersprungen zu sein, welche jedoch in diesem Altersstadium noch nicht als Rippe kenntlich ist. Dies geht daraus hervor, dass hier einem Umbilicalen und Lateralen je zwei Marginale entsprechen und wir ferner bei weiterem Wachsthum des Individums finden, dass sich eine Zwischenrippe zwischen je zwei Hauptrippen einschaltet, welche anfänglich tief hinab bis zur Nabelkante reicht, später die Höhe der Laterallinoten nicht mehr überschreitet. Auf dem letzten Umgang sind die Umbilicalknoten stumpfer geworden, die Lateralen sind plump und kräftig, zugleich die grössten Knotenindividuen und sitzen relativ höher als auf dem früheren Umgang; etwas kleiner und ein wenig spiral in die Länge gezogen sind die Marginalen und zwischen diesen und den Lateralen tritt, den Ersteren genähert, besonders auf den Hauptrippen ein kleines accessorisches Knötchen auf. Dieselben vereinigen sich zu einer accessorischen Spirale, deren Anfänge zu Beginn der letzten Windung eben erst sichtbar werden.

Bei der Varietät $a$, Fig. $7 a, b$, die wir schon oben durch weniger breite und hohe Windungen und grösseren Nabeldurchmesser sich auszeichnend, angeführt haben, ist auch die Sculptur durch zartere Berippung variirt. Auch hier sehen wir den eigenthümlichen Wechsel im Anschwellen der Rippen auf dem Ende des letzten Umganges, der auch beim Typus selbst auftritt und darin besteht, dass durch einige Rippenpaare statt der Haupt- die Nebenrippe im oberen Flankentheile kräftiger entwickelt ist, ein Merkmal, dem aber wohl nur untergeordnete Bedeutung zukommt. Mit Ausnahme der eingangs erwähnten Unterschiede in der Beknotung des Externtheiles zeigt die Varietät diesbezüglich keine weiteren Eigenthümlichkeiten.

Die Suturlinie beim Typus Fig. $6 c$ hat schwach bogenförmigen Verlauf und ist aus niederen, breiten Elementen gebildet. Der Externlobus ist kurz und breit, wird von einem breiten Medianhöcker in zwei schmale Arme getheilt, deren Basis gezaclit ist, und nimmt fast den ganzen Externtheil ein. Der erste und zweite Laterallobus sind fast von gleicher Breite und Tiefe und haben gezackten Lobengrund; auf dem Nabelrande und von der Kante halbirt sitzt ein kurzer, breiter, ebenfalls gezackter Auxiliar. Die Sättel sind rundbogig und breit; der Externe liegt grösstentheils auf der Flanke und ist von gleicher Grösse wie der zweite Laterale, während der erste die grösste Breite und Höhe erlangt und auf der Nabelwand ein kleiner Auxiliarsattel sichtbar wird.

In der Suturlinie zeigt die Varietät $b$, Fig. 8, wieder gewisse Unterschiede, so dass wir die schwankende Form des Gesammtverlaufes derselben und die Variationsfähigkeit auch dieser Species beobachten können, wie wir ähnliche Schwankungen der Suturlinien schon bei Balatonites egregius (pag. 203, Taf. XXIII, Fig. 3c, 4, 5 c) und Balatonites armiger (pag. 206, Taf. XXIII, Fig. 6c, 7, 8) fanden.

Von bekannten Formen zeigt die nächste Verwandtschaft der Balatonites balatonicus Mojs.") (pag. 78, Taf. IV, Fig. 2), welcher daselbst von Mencshely im Bakonyerwalde beschrieben ist. Unterschiede ergeben sich in der Form der inneren Windungen, welche daselbst keineswegs die beiden Entwicklungsstadien beobachten lassen, die wir bei der Reiflinger Form finden; es sitzen auch die Lateralknoten viel tiefer und die Rippentrennung erfolgt schon im Umbilicalknoten; endlich zeigt der Externtheil deutlich das parige Uebertreten der Haupt- und Nebenrippen von der Flanke her.

Mit den Maassen:

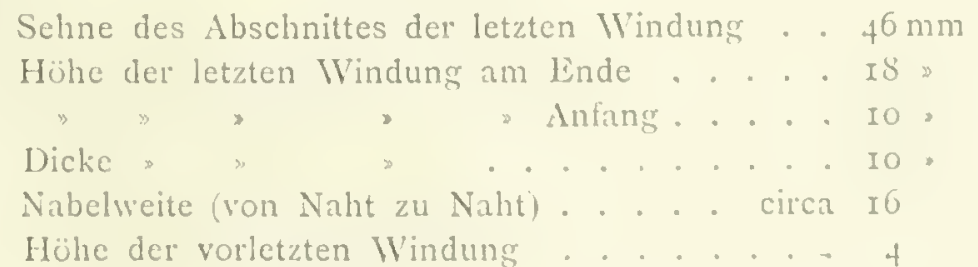

1) Mojsisorics E. i', Cephalop. Meclit. 'l'riaspr. 
wurde auf 'af. XXV (XIII), Fig. I a-d, ein Bruchstück, das allerdings auch wieder gewisse $A b$ weichungen rom Typus zeigt, zur Abbildung gebracht. Es geschah dies besonders aus dem Grunde, um die Sculpturveründerung des Externtheiles, der hier trefflich zu sehen ist, zu veranschaulichen. Wir finden hier auf der vorletzten Windung bis ungefähr zur Hälfte derselben den gerundeten Externtheil, der zu Beginn des letzten Umganges sich dachförmig zuschürft und später linoten erlangt, die am Schluss der Windung schon wieder beträchtich abgestumpft sind.

Die Suturlinie ist, neben abermaligen Abseichungen vom Typus, auf beiden Seiten asymmetrisch entwickelt und der Medianhöcker liegt nicht in der Mitte des Externtheiles. Wir haben also hier eine pathologische Erscheinung vor uns.

Zahl der Exemplare: If (Typus: 4, Varictät $a: 6$, Varietät $b: 4 \%$

\section{Balatonites jubilans Arth.}

Taf. XXV (XIII), lig. $2 a, b, c$.

Durchmesser . . . . . $64 \mathrm{~mm}$
Höhe der letzten Windung . . . 21 .
Dicke ". . I6"
Nabelweite (von Naht zu Naht). . 24 "

Der Externtheil ist anfangs der letzten Windung mehr, gegen Schluss weniger zugeschärft und auf der Mittellinie mit scharfen, längsgestellten Knoten besetzt, welche sich im Alter reduciren; die Flanken sind flach gewölbt und erlangen etwas oberhalb der Flankenmitte die grösste Dicke; die Marginalkante tritt durch scharfe, längsgestellte, im Alter etwas schrägstehende Dornen besonder's scharf hervor; die Umbilicale ist mehr gerundet; die Umbilicalwand ist auf den friheren Windungen niederer und erhöht sich auf dem letzten Umgang, bleibt jedoch stets senkrecht gestellt. Die Involution umfasst bei einer Flankenhöhe von $6 \mathrm{~mm}$ knapp die Hälfte des Umganges, beginnt abe1 von da an sich zu verringern und umfasst schliesslich wenig mehr als die Marginalpartie. In Folge dessen erscheint bei einer Grösse, wie sie das abgebildete Exemplar besitzt, diese Form sehr weitnabelig.

Die Sculptur ist innerhalb einer Windungshöhe von $4-17 \mathrm{~mm}$ kräftig, macht aber im Vergleich mit der äusserst energischen Sculpturirung der späteren Umgangspartien einen zarten Einđruck. Sie besteht aus von der Radiale leicht nach vorne abweichenden Rippen, über welchen auf der Flanke drei Knotenspiralen liegen, zu denen sich gegen Ende des Umganges noch eine sehr schwache sublaterale und accessorische Spirale gesellt. Auf die jugendlich glatten Umgänge, deren Anfangspartien nur die charakteristischen Einschnürungen zeigen, beginnen sich ungefähr bei der Windungshöhe von $6 \mathrm{~mm}$ die Umbilicalen, etwas später die äusserst zarten Lateralknoten zu entwickeln. In welchem Alter Narginal- und Externknoten zuérst auftreten, lässt sich, da nur ganze Exemplare vorliegen, die ich nicht deshalb zerstören will, nicht genau fixiren. Bis zur Windungshöhe von circa $14 \mathrm{~mm}$ sind die Umbilicalknoten die grössten Knotenindividuen der Flanke; von da ab treten sie mehr zurück und bleiben nun als spitze, niedere Stacheln auf rundlicher Basis bestehen. Die stärksten Individuen werden jetzt die Lateralen, welche in der Flankenhöhe der grössten Dicke stehen und als grosse, runde Stacheln erscheinen; die Ifarginalen haben ein mehr schneidendes Aussehen, verursacht durch ihre anfangs streng spirale, später etwas schräge Stellung. Die Berippung besteht nur aus Hauptrippen allein, von denen an der Nabelkante je zwei in einem Umbilicalknoten entspringen; in den meisten Fällen trägt jede zweite Rippe ein Lateralknötchen, hie und da ist wohl auch auf der blinden Rippe ein (dann minimales) Lateralknötchen zu sehen; manchmal strahlen von einem Umbilicalknoten drei Rippen aus, aber selten folgen zwei Rippen mit je einem Nabelknoten aufeinander. Kurz, die Sculptur ist variabel und wird erst in drei Viertel der letzten Windung regelmässig, indem die eine - die knotenlose - Hauptrippe in der unteren Flankenpartie verschwindet, somit den Anschein einer Secundär- 
rippe hat und entweder in der Mitte zwischen den bedornten Hauptrippen bleibt oder sich der nächst. folgenden nähert. Sie besitzt dann einen kleineren Marginal- und Externknoten als die dornentragende und tritt paarig mit letzterer leicht nach vorne gewendet auf den Externtheil über. Ungefähr im letzten Drittel des letzten Umganges bei dem abgebildeten Stücke tritt, wie schon erwähnt, ein kleines, sublaterales Knötchen auf der Hauptrippe auf.

Die Suturlinie hat einen von aussen nach innen aufsteigenden Verlauf, durchsetzt schräge die Rippen und besteht aus breiten, niederen Elementen. Der Externlobus nimmt radial die tiefste Stelle ein, ist breit, nieder, von einem schmalen Medianhöcker getheilt, und die Basis der hieraus resultirenden beiden Externäste ist gezackt; das grösste Element ist der breite, niedere, erste Laterallobus, bedeutend höher steht der in den Formverhältnissen ähnliche, jedoch kleinere zweite, beide mit reich gezackiter Basis; von der Nabelkante wird ein relativ breiter, ebenfalls gezackter Auxiliar halbirt, dessen Basis höher liegt als der Externsattel. Die Sättel sind flachbogig, ganzrandig und in Folge der schrägen Anordnung der Suturlinie etwas verzogen; hier ist der Externsattel das grösste Element und liegt grösstentheils schon auf der Flanke; die höchste Stellung hat der kleine zweite Auxiliar, und bis zur Naht folgt noch ein kleiner Auxiliarsattel.

In besonders naher Verwandtschaft mit anderen Formen, auch von dem neuen Fundorte, steht Balatonites jubilans vorläufig noch nicht. Zunächst wäre der im I. Theile dieser Arbeit (pag. 65, Taf. VI, Fig, 9) beschriebene Balatonites gracilis zu nennen, dem kleinere Exemplare der vorliegenden Art recht ähnlich sehen. Als Unterschied diene die bedeutend gröbere Sculpturirung der letzteren Art.

Zahl der Exemplare: 2.

Balatonites jubilans Arth. var.

Tafo XXVI (XIV), Fig. $6 a-d$.

Durchmesser

$\therefore \mathrm{mm}$

Höhe der letzten Windung. .... II

Dicke » ». . . . 8

Nabelweite (ron Naht zu Naht)... It

Im Allgemeinen die Charaktere der neuen Art zeigend, besitzt das abgebildete Exemplar gewisse Merkmale, welche die Identificirung desselben mit Balatonites jubilans zweifelhaft erscheinen lassen. Vorerst sei erwähnt, dass das in Fig. 6 abgebildete Exemplar in der Grösse ungefähr mit der vorletzten Windung des auf Taf. XXV, Fïg. 2, gegebenen Stückes übereinstimmt, dass aber gerade bei diesem Exemplar diese Windungspartien nicht deutlich sichtbar sind, weil sie mit einem Kalkhäutchen überzogen sind. Die Beknotung und Berippung ist bei der Varietät noch liräftiger als beim Typus, und schon bei einer Flankenhöhe von $6 \mathrm{~mm}$ (nicht wie dort erst bei $4 \mathrm{~mm}$ ) sind die Lateralknoten die grössten Knotenindividuen des Umganges; in ziemlich regelmässigen Abständen von je drei Rippen auftretende Einschnürungen sind die Ursache, dass stets die letzte Rippe vor derselben (die Wohnkammer als Ende annehmend) ganz besonders stark an Dicke und Formengrösse hervortritt. Ferner hatten wir dort nur Hauptrippen, das sind solche, denen ein Umbilicalknoten entspricht, gleichzeitig bei voller Marginalbeknotung, während hier eingeschaltete Rippen auftreten, welche auf dem Marginaltheile die Berippung verdichten.

Die Suturlinie ist sehr ähnlich derjenigen von Balatonites jubilans selbst und zeigt schwach bogenförmigen, von aussen gegen innen aufsteigenden Verlauf.

Stärker als bei Balatonites jubilans tritt bei der Varietät die Verwandtschaft mit dem vie] zarter berippten Balatonites gracilis (pag. 68, Taf. VI, Fig.9) hervor.

Zahl der Exemplare: 2. 
Balatonites Scylla Arth.

Taf. XXV (XIII), Fig. $3 a, b, c$, Fing. 4 .

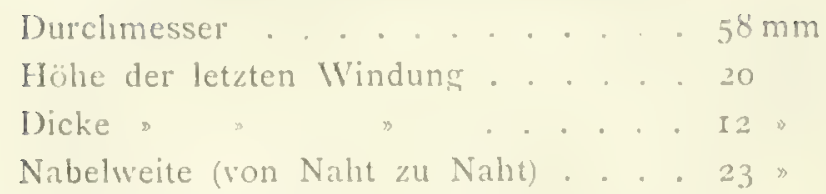

Der Externtheil ist dachförmigg zugeschärft, stumpft sich gegen Ende der letzten Windung (Fig. 3a) ab und erscheint bei der Flankenhöhe von $20 \mathrm{~mm}$ (Fig. 4) schon vollständig abgeplattet; die Mittellinie ist durch längsgestellte kleine und stumpfe Externknoten bezeichnet, welche sich schliesslich vollständig verlieren, und nur jener Punkt, in dem sich die beiderseitigen Kippen auf dem Externtheil vereinigen, deutet noch die Stellung des Knotens auf früheren Windungspartien an. Die Flanken sind sehr flach gewölbt; die Marginalkante ist durch längsgestellte Marginalknoten deutlich entwickelt, die Umbilicale leicht gerundet. Die Nabelwand ist ursprïnglich nieder und fast senkrecht gestellt, später neigt sie sich immer stärker und nimmt schliesslich eine sehr schräge Lage an. Die Involution ist anfänglich grösser, auf dem letzten Umgang umfasst sie knapp den Marginalrand der früheren Windung allein; die Form ist sehr weitnabelig.

Die Sculptur besteht im Reifestadium aus kräftigen Rippen und plumpen, kleinen Knoten. Das glatte Jugendstadium reicht bis zur Windungshöhe von circa $6 \mathrm{~mm}$, dann treten zuerst dicke Umbilicalknoten, später kleine Lateralknötchen und minimale längsgestellte Marginalanschwellungen auf; sodann individualisiren sich diese zu Knötchen und noch später treten kleine, wohl entwickelte externgestellte auf. Bei der Windungshöhe von II mm ist die Sculptur vollständig entwickelt und wir finden grobe Hauptrippen mit gleich grossen Umbilicalen und Lateralen sowie etwas verlängertem Marginalknoten; zwischen je zwei dieser derartig belinoteten Rippen tritt eine etwas schwächere Hauptrippe ohne Lateralknoten und mit bedeutend kleineren Umbilical-, Marginal- und Externknötchen auf. Bei weiterem Wachsthum reducirt diese Rippe ihren unteren Flankentheil, erscheint nur im oberen und erreicht bei erwachsenen Individuen nicht mehr die Höhe des Lateralknotens, macht also den Eindruck einer kurzen inserirten Rippe. Diese sowie die Hauptrippen treten in gleicher Form und Stärke, leicht nach vorne gewendet, über die Marginalkante auf den Externtheil über. Bei der Windungshöhe von $19 \mathrm{~mm}$ (Fig. $3 a$ ) sind die Zwischenrippen fast vollständig reducirt und im ausgewachsenen Zustand (Fig. 4) treten, ähnlich wie wir es schon Taf. XXIII, Fig. $2 a$, beobachten konnten, die restirenden Hauptrippen so nahe aneinander heran, dass anzunehmen ist, dass hier sofort der Mundrand gefolgt sei.

Die Suturlinie steigt schräge gegen die Naht auf und besteht aus minder breiten Loben und kleineren Sattelelementen. Der Externlobus ist nieder und wird von einem niederen Medianhöcker halbirt; die Seitenäste sind kurz und ihre Basis zweimal gezackt; der erste Lateral reicht etwas tiefer herab und ist breit; von ähnlicher Form ist der zweite, nur im Ganzen etwas kleiner, beide mit kurzen Zacken an der Basis; knapp unterhalb des Nabelrandes folgt ein kleiner, gezackter Auxiliar. Die Sättel sind relatiy klein, rundbogig und ganzrandig; der Externe liegt zum grössten Theile auf der Flanke und nimmt die tiefste Stellung ein; ron gleicher Grösse ist der erste und zweite Lateralsattel, der Auxiliar schliesst an der Naht ab und reicht am höchsten hinauf.

Als nächster Verwandter dieser Form ist vielleicht der Balatonites golsensis Mojs. ${ }^{1}$ ) (pag. 83, Taf. V, Fig. 4, 6) zu nennen, welcher aus der Zone des Ceratites binodosus von der Localität Neubrags im Pusterthal bekannt geworden ist. Einen weiteren als rein oberflächlichen Vergleich lässt der leider ungünstige Erhaltungszustand des Bragser Stückes nicht zu, da nur die Wohnkammer und Bruchstücke der Luftkammer bekannt geworden sind; jedoch lässt es sich nicht leugnen, dass gewisse Aehnlichkeiten bestehen, insbesondere mit dem Fig. $4 a, b$ abgebildeten Exemplare.

Zahl der Lxemplare: 4.

1) Mrojsiserics E. vo, Cephalop. Medit. Triaspr. 
Balatonites Peleus Arth.

Taf. XXV (XIII), Fig. $5 a, b, c$.

Durchmesser. . . . . . . $53 \mathrm{~mm}$
Höhe der letzten Windung. . . . 20 ,
Dicke „ . . . II,
Nabelweite (von Naht 24 Naht). . . 20

Der Externtheil dieser flachen Art ist spitz-dachförmig und stumpft sich bei grossen Exemplaren gegen Schluss der Windung ab, ohne sich aber ganz abzurunden; die Medianlinie ist mit längsgestellten, zugeschärften Dornen besetzt, welche sich erst bei einer Flankenhöhe von mehr als $6 \mathrm{~mm} \mathrm{zu}$ entwickeln beginnen; bis dahin ist der Externtheil gerundet. Die Flanken sind flach gewölbt und erlangen ungefähr in der halben Höle im Lateraldorn die grösste Breite; die Marginalkante ist scharf entwickelt, die Umbilicale gerundet; die Nabelwand ist nieder, senkrecht gestellt und erhöht sich erst gegen Schluss der Windung. Diese Form ist sehr weitnabelig; die Involution umfasst etwas mehr als die Marginalkante.

Die Sculptur wird aus leicht geschwungenen, nach vorne von der Radiale abweichenden, zarten und ziemlich enggesteliten Rippen in Verbindung mit vier Knotenspiralen gebildet. Auf das glatte Jugendstadium, welches bis zur Windungshöhe von $6 \mathrm{~mm}$ reicht, folgt die Entwicklung der Umbilicalknoten, dann die der zarten Rippen, später der Lateralknötchén, schliesslich der Marginalen und der externen Knoten in ähnlicher Reihenfolge, wie wir sie bei vielen anderen Balatoniten schon beobachten konnten. Auch hier ist in der Regel wieder nur jede zweite Rippe mit einem Lateralknoten versehen, so dass sie gezwungen ist, wie die knotentragende, sich aus demselben Nabellinoten zu entwickeln, trägt aber auf der oberen Flankenpartie Knoten wie die Hauptrippe. Es gibt freilich auch hier Ausnahmen von dieser Sculpturregel, indem auch die blinde Rippe stellenweise mit einem kleinen Umbilicalknötchen beginnt, mitunter auch ein kleines laterales, aber selten beide trägt. Im Alter reducirt sich diese Rippe in der unteren Flankenpartie und tritt nur mehr auswärts des Lateraldornes auf. Die Hauptrippe beginnt bei allen Schalenexemplaren gut sichtbar über die Nabelwand heraufzusteigen, trägt auf dem Rande einen gedrungenen, kräftigen Umbilicalknoten, in halber Flankenhöhe starke Lateraldornen, welche spiral untereinander mit einer zarten Verbindungslinie vereinigt sind; trägt auf der Marginalkante kleinere, längsgestellte Marginalknoten und zwischen beiden auf älteren Schalenexemplaren eine leichte Verdickung. Die Rippen setzen ihren leicht geschwungenen Verlauf auch auf dem Externtheil fort und vereinigen sich beiderseits im länglichen Externknoten.

Die Suturlinie hat einen schrägen Verlauf und durchsetzt theilweise die Radialsculptur; die Loben sind im Vergleiche zu den Sätteln gross. Der Externlobus ist breit, flach und wird von einem breiten Medianhöcker in zwei schmale, zweispitzige Theile zerlegt; der erste und zweite Laterallobus sind fast gleich gross und reich zerschlitzt; auf der Flanke folgt ein kleiner, gezackter Auxiliar. Die Sättel sind rundbogig und ganzrandig; der erste Laterale ist der grösste, deı zweite von gleicher Grösse wie der Externe, welcher von der Marginalkante halbirt wird; bis zur Naht folgt ein kleiner Auxiliarsattel, welcher radial die höchste Stellung einnimmt.

Von ähnlichen Formen kommt hier der Balatonites Galateae (pag. 2I.t, Taf. XXIV, Fig. 6, 7, 8, 'Taf. XXV, Fig. I) in Betracht, der sich jedoch durch dickere Umgänge, stärkere und radial verlaufende Rippen, sowie durch die submarginale Knotenreihe unterscheidet; auch zeigt die Suturlinie einen bogenförmigen Verlauf. In zweiter Linie ist Balatonites lineatus (pag. 69, Taf. VI, Fig. Io) zu nennen, dessen Sculptur spärlicher ist. Gemeinsam hat dieser mit Balatonites Peleus (Taf. XXV, Fig. 5) die spirale Verbindungslinie der Lateraldomen und die schräge Stellung der Suturlinie. Zahl der Exemplare: 2. 


\section{Balatonites bullatus Arth.}

Taf, XXV (XIII), Iigr. $6 a, h$,

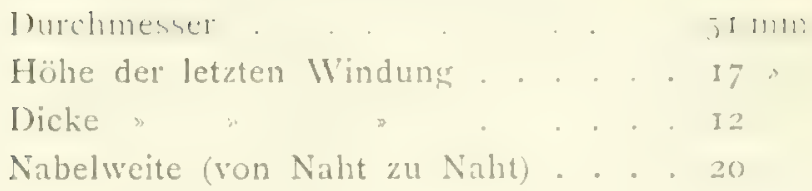

Der Externtheil ist im Jugendstadium vollständig abgerundet, schärft sich bei einer Flankenhöhe ron $7 \mathrm{~mm} z u$ und setzt dann längsgestellte stumpfe Externdornen an, welche sich gegen Schluss der letzten Windung des abgebildeten Exemplares schon wieder vollständig verloren haben; auf Steinkernen bleibt eine Medianlinie noch bestehen, welche durch das Zusammentreten der beiderseitigen Rippen fein gekörnelt erscheint, während sie auf Schalenstücken nicht mehr erkennbar ist. Der Marginalrand ist als Kante deutlich ausgebildet, der Umbilicale erscheint leicht gerundet; die Nabelwand ist anfänglich nieder und senkrecht gestellt, wird später höher und bekommt eine schräge Lage. Die Involution dieser ziemlich weitnabeligen Form beträgt linapp ein Viertel der früheren Windung.

Abgesehen von dem glatten Jugendstadium besteht die Sculptur zu Beginn des Reifestadiums, also bei einer Höle von $7 \mathrm{~mm}$, aus zarten Rippen, welche in weiten Abständen folgen und kräftige Umbilical-sowie Lateralknoten tragen; Marginal- und Externknoten fehlen theils noch, theils sind sie minimal entwickelt. Bei einer Höhe ron I mm verengt sich die Sculptur, indem die bisher nur als Schalenstreifen vorhandenen unbeknoteten Rippen ebenfalls die Bedeutung von Hauptrippen erlangen. Zwischen je zwei derselben stehen dann zwei schwächere, welche besonders durch die kleineren Umbilical- und Lateraldornen kenntlich sind, während die Marginalbeknotung dieselbe Stärke besitzt. Allmälig tritt eine weitere Sculpturvermehrung ein, indem sich jede Rippe in zwei fast parallel verlaufende Rippchen theilt, welche meist ihr eigenes Umbilical-, Marginal- und Externknötchen besitzen, während die stärkeren Knoten jener Rippe verbleiben, welche die Stellung der früheren Hauptrippe einnimmt. Daher kommt es, dass ein vollständig entwickeltes Exemplar ein beperites Aussehen erlangt. Accessorisch findet sich eine kleine, submarginale und sublaterale Knotenspirale auf dem Ende der letzten Windung ein, jedoch in deutlicher Weise nur auf der Schale selbst. Letztere ist mit feinen, sehr enggestellten Anwachsstreifen besetzt, welche gleichsinnig mit den Rippen verlaufen und stärker in den Intercostalräumen, schwächer auf den Rippen selbst auftreten. Auf der Schale selbst erscheinen auch die Knoten des Steinkernes als kleine, spitze Dornen, und die accessorischen Spiralen finden sich auf dem Steinkerne nur als Anschweliung, während sie auf der Schale als kleine Knötchen individualisirt sind.

Die Suturlinie besteht aus breiten Sätteln und Loben und hat einen bogenförmigen Verlauf, wobei aber Extern- und Internlobus auf derselben Radiale stehen. Der Extemlobus ist breit, nieder und wird von eirem breiten Medianhöcker, dessen Scheitel flach eingesenkt ist, in zwei schmale, einspitzige Theile zerlest; der erste und zweite Laterale sind fast ron gleicher Grösse und an der Basis gezaclit; auf der Flanke, oberhalb der Marginalkante, folgt ein ziemlich breiter, gezacliter, erster Auxiliar, unterhalb der Naht ein kleinerer, ebenfalls gezachter zweiter und ein kleiner Internlobus, welcher in der Form dem Externen ähnelt. Die breiten Sättel sind ganzrandig; der Externe liegt grösstentheils auf der Flanke und besitzt die grösste Spannweite; auf ihn folgt an Grösse der erste Latcrale, welcher gleichzeitig auch mit seinem Scheitel am höchsten emporreicht; nun schliessen sich segen den Internlobus zu in absteigender Folge bezüglich Grösse und Höhe ein zweiter Lateralsowie erster und zweiter Auxiliarsattel an.

Balatonites bullatus zeigt nahe Verwandtschaft mit Balatonites lineatus var, confertus (s. diesen) und daher auch mit der Grundform selbst.

Lahl der Exemplare: 4 . 


\section{Balatonites lineatus Arth.}

IS95. Balatonites lineatus Arth.; Cephalopodenfauna der Reiflinger halle, I. Theil, pag. 69, Taf, VI, Fig. $x$.

Die Beschreibung dieses Species wurde loc, cit. schon gegeben und ein von dem neuen Fundorte stammendes Stück abgebildet, weil dasjenige des Fundortes *Tiefengraben zu mangelhaft erhalten war.

Zahl der Exemplare: 3 .

Balatonites lineatus var. confertus Arth.

Taf. XXV (XIV), Eig. $5 a, b$,

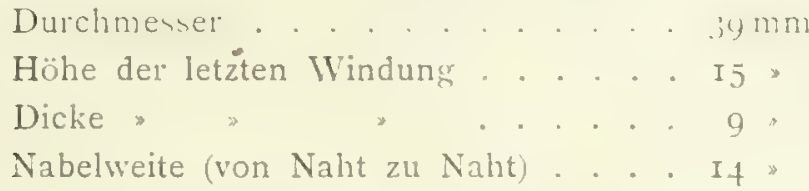

Der Externtheil dieser eng sculpturirten Form ist in der Jugend bei einer Windungshöhe von $2 \mathrm{~mm}$ gerundet, schärft sich bei $+\mathrm{mm}$ zu und trägt bei $9 \mathrm{~mm}$ kleine, längsgestellte Knoten, welche sich bei einer Windungshöhe von $16 \mathrm{~mm}$ wieder zu zarten, kleinen Perlen reducirt haben; die Flanken sind flach gewölbt und erlangen ungefähr in der halben Höhe im Lateralknoten die grösste Dicke; die Marginalkante ist deutlich markirt durch die spiralgestellten Marginalknoten, die Umbilicale leicht gerundet; die Nabelwand ist anfangs nieder und senkrecht stehend, wird später höher und legt sich schräge; die Involution umfasst ungefähr ein Drittel der früheren Windung.

Die Flankensculptur besteht aus zarten, im Reifestadium enggestellten, sehr flach gebogenen Rippen, kräftigen Umbilical-, zarten, spitzen Lateral- und längsgesteliten Marginalknoten.

Auf das glatte Jugendstadium mit Einschnürungen und Schalenstreifen folgt, ungefähr bei der Windungshöhe von $9 \mathrm{~mm}$, individuell früher oder später eintretend, eine Epoche, in welcher wir spärlich gestellte Radialrippen und drei Knotenspiralen in den oben angegebenen Stärkeverhältnissen finden. Von da ab schiebt sich eine Zwischenrippe ein, welche auf der Marginalpartie gleich kräftig entwickelt ist, selten ein kleines Lateralknötchen trägt und in der Umbilicalpartie theils verschwunden jst, theils einen Anschluss im Ümbilicalknoten an die folgende Hauptrippe findet. Bei einzelnen Stücken zeigt sich die Variabilität des Species in dem Sinne, dass auf die spärlich berippte Periode eine sehr engberippte folgt, indem sich wohl keine Zwischenrippe bildet, aber an ihrer Stelle eine Hauptrippe, so dass wir nur enggestellte Hauptrippen finden. Später theilt sich bei der Normalform jede Rippe in zwei 'Theile, welche deutlich auf dem Steinkern, undeutlicher auf der Schale hervortreten, so dass dieselbe ein schwach gekerbtes Aussehen hat. Auf dem Externtheile setzen sich die Rippen analog dem Verlaufe auf der Flanke bis zur Mittellinie fort. Die Lateralknoten sind durch eine deutliche, spirale Verbindungslinie vereinigt; im Zwischenraume zwischen diesen und den Marginalen finden wir bei vollkommen erwachsenen Formen ein bis zwei accessorische Spiralen von Knötchen.

Die Suturlinie zeigt flach bogenförmigen Verlauf, welcher die Radialsculptur in schwach schräger Weise ron aussen gegen innen durchsetzt. Der Externlobus ist breit und wird ron einem niederen, spitz-kegelförmigen Medianhöcker halbirt; die beiđen Arme sind relativ breit und gezackt; der erste Laterallobus ist tief und breit, der zweite erreicht radial dic Tiefe des Externen und ist ron ähnlicher Form wie der erste; beide haben den Lobengrund mit vier Zacken besetzt; von der Nabelkante wird ein erster Auxiliar von ziemlicher Breite und gezackter Basis fast halbirt. Die Sättel sind gerundet und ganzrandig: der Externsattel liegt grösstentheils auf der Flanke und ist ron gleicher Grösse wie der erste Lateral, welcher radial die höchste Stellung einnimmt; der zweite Lateral ist klein und der Auxiliarsattel schliesst an der Naht ab. 
Die vorstehende Varietät steht dem Balatonites lineatus, ihrer Grundform, sehr nahe: die Suturen sind fast ident und die Sculptur unterscheidet sich nur durch bedeutendere linge, indem die bei Balatonites lineatus nur als Zwischenrippen auftretenden Rippchen bei der Varietät die Bedeutung und Entwicklung von Hauptrippen erlangt haben. Einschnürungen treten bei letzterel nur undeutlich als Depression des Steinkernes der Flanke im Reifestadium hervor; andererseits haben die pag. 60 erwähnten Spiralstreifen hier sich zu einer, bei einzelnen Stücken sogar zu zwei submarginalen und accessorischen Knötchenspiralen entwickelt.

Eine zweite Form, Balatonites bullatus Arth. (pag. 220, 'laf. XXV, Fig. 6) steht ebenfalls dieser neuen Varietät sehr nahe. Die Unterschiede bestehen in der, wie der Name besagt, s beperlten A Ausbildung der Marginalkante, der dickeren Umgänge und des Externlobus, welcher bei Balatonites bullatus in zwei je einspitzige Arme zerfällt, während die vorstehende Varietät bedeutend breiter ist und gezackte Arme im Externlobus besitzt.

Zahl der Exemplare: 7.

Balatonites Corvini Arth.

Taf. XXV (XIII), Fig. $7 a-d$, Fig. $8 a-a$

I.

Durchmesser . . . . . . $50 \mathrm{~mm}(=\mathrm{I})$

Höhe der letzten Windung . . . $20 \%\left(0^{\circ} 4\right)$

Dicke * * . . . 10, $\left(0^{\circ} 2\right)$

Nabelweite (von Naht zu Naht) . . I7 * (0.3)
II. $94 \mathrm{~mm}(=\mathrm{I})$

$3 I,(0 \cdot 33)$

$20 \times(0.2 \mathrm{I})$

$38>(0 \% 40)$
III.

$$
\begin{array}{rrcc}
\text { I2 } 2 \mathrm{~mm}(=\mathrm{I}) & \text { I } 43 \mathrm{~mm}(=\mathrm{I}) \\
37 \Rightarrow\left(0^{\circ} 32\right) & \text { c. } 45 \Rightarrow & \left(0^{\circ} 32\right) \\
23 & \left(0^{\circ} 10\right) & - & - \\
57 & \left(0^{\circ}+4\right) & 64 & \left(0^{\circ} 45\right)
\end{array}
$$

Der Externtheil dieses grössten der bis jetzt bekannt gewordenen Balatoniten ist bei einer Windungshöhe von $4 \mathrm{~mm}$ breit gerundet und beginnt dann sich allmälig höher zu wölben; er wird bei circa $20 \mathrm{~mm}$ stumpf-dachförmig und setzt späterhin in der Mittellinie längsgestellte, stumpfe Knoten an, welche er jedoch von der Windungshöhe von $30 \mathrm{~mm}$ an aufwärts wieder verliert; Marginal- und Umbilicalkante sind abgestumpft und dienen als Ansatzstelle für Marginal- und Umbilicalknoten; die Nabelwand ist bèi Jugendwindungen nieder, wird im weiteren Verlaufe höher und stellt sich senkrecht, während sie bei vollkommen erwachsenen Individuen mit Abflachung der WVindung in der Nabelregion sich bedeutend reducirt und flachlegt. Die Involution beträgt knapp ein Drittel der Windungshöhe und wird bei ausgewachsenen Formen noch geringer; der Anschein, dass die Species anfänglich sehr stark, später bedeutend weniger involvire, wird lediglich dadurch hervorgerufen, dass etwa von der Windungshöhe von $6 \mathrm{~mm}$ angrefangen die Umgänge sehr rasch an Höhe zunehmen. Die Nabelweite ist aus demselben Grunde bei Jugendformen gering und wird erst später sehr gross.

Die Sculptur besteht aus einfachen Rippen und meist stumpfen Knoten. Ich übergehe die Entwicklungsstadien, welche hier in derselben Weise aufeinander folgen wie bei allen anderen Balatonitesformen und wende mich der Sculptur im Anfange des Reifestadiums, also bei einer Windungshöhe von circa $20 \mathrm{~mm}$, zu. Hier finden wir flache, gerade, von der Radiale etwas gegen vorne abweichende Rippen, welche in einem stumpfen Nabelknoten beginnen; in der Regel trägt nur jede zweite etwas oberhalb der Flankenmitte einen stumpfen Lateralen; mitunter folgen zwei beknotete aufeinander. Die Rippe ohne Lateralknoten — die blinde — zeichnet sich auch durch einen kleineren Nabelknoten aus. Bei der Höhe von $27 \mathrm{~mm}$ (Fig. 7, Mitte der letzten Windung) beginnt die Flankensculptur sich zu verengen, indem die Rippen dicker und breiter werden und in den Zwischenraum zwischen je zwei Hauptrippen zwei Zwischenrippen eintreten. Auch sie tragen jetzt, wenn auch nur kleine Lateral- und Umbilicalknötchen, während auf Marginalkante und Externtheil kein Unterschied zwischen der Beknotung der Haupt- und Zwischenrippen existirt. Wir finden gleich grosse, spiral gestellte, stumpfknotige Anschwellungen auf dem Rande, von wo aus sich die Rippen nach vorne 
wenden und in ebenfalls stumpfen Externknoten mit dem Rippenstück der anderen Flanke zusammentreffen. Bei weiterem Wachsthum (Fig. 8, Ende der Windung) variirt die Sculptur wieder in der Art, dass sich neue Zwischenrippen einschieben - je eine nach jeder Haupt- und primären Zwischenrippe - welche aber nur in der äusseren Flankenpartie auftreten und in die Umbilicalregion nicht mehr hinabreichen. Die früheren Hauptrippen bleiben nur mehr durch stärkere Beknotung kenntlich, während die secundären Zwischenrippen keine Lateralknoten, wohl aber einen kleinen Marginalen tragen. Gleichzeitig sind die Externknoten verschwunden und der Externtheil rundet sich ab, während eine submarginale und sublaterale accessorische Anschwellung neu hinzutritt. Diese Art der Rippenvermehrung scheint weiter fortzuschreiten gleichzeitig mit Reducirung der Rippen an Höhe und Dicke, so dass wir bei der Flankenhöhe von $37 \mathrm{~mm}$ nur mehr eine grobe Schalenstreifung finden, aus der sich in weiten Abständen gröbere Streifen herausheben, welche einen verschwommenen Umbilical-, etwas stärkeren Lateralknoten und undeutliche Marginalanschwellung zeigen; die accessorischen sind wieder verschwunden. Bei einem als Steinkern erhaltenen Windungsbruchstück (Höhe $35 \mathrm{~mm}$ ) erkennt man jedoch, dass diese grobe Schalenstreifung nicht nur der Schale allein angehört, sondern thatsächlich vorhandenen Rippen entspricht.

Die Schale ist glatt, mit ausserordentlich feinen Anwachsstreifen dicht besetzt, während gleichzeitig breitere, matte, ziemlich engstehende Spiralbänder auftreten.

Die Suturlinie zeigt flach-bogenförmigen Verlauf, die einzelnen Linien untereinander gewisse Variationen (vgl. Fig. $7 d$ und Fig. $8 d$ ).

Der Externlobus ist sehr breit und wird von einem breiten Medianhöcker mit abgeflachtem Scheitel in zwei dicke Arme getheilt, welche an der Basis gezackt sind; die beiden Lateralen sind breit, mit grob gezacktem Grunde; die ganze Nabelwand nimmt ein einziger flacher, gezackter Auxiliar ein. Die Sättel sind breit und ganzrandig; der Externsattel liegt ganz auf der Flanke und ist relativ klein; der grösste und höchste ist der erste Laterale, dem bis zum Nabelrand ein zweiter, kleinerer folgt.

Zahl der Exemplare: 4.

Balatonites nov. spec. indet.

Taf. XXVI (XIV), Fig. I $a, b, c$.

Länge der Sehne............ . . $90 \mathrm{~mm}$

Höhe der letzten Windung ......... 23

Dicke (bis zur Spitze des Lateraldornes)..... circa 22

Breite des Externtheiles der vorletzten Windung. . . . 6 ,

Der Externtheil zeigt zu Beginn des erhaltenen Theiles der letzten Windung stumpf-dachförmige Gestalt und in der Mittellinie (auf dem Steinkerne) stumpfe längsgestellte Knoten; bis zum Schlusse des Umganges haben sich letztere verloren und der Externtheil hat flach gerundete form angenommen. Marginal- und Umbilicalrand sind leicht abgerundet; die Nabelwand ist im Vergleich zur dicken Form des Umganges ziemlich nieder und steil gestellt. Die Involution umfasst etwas mehr als die Marginalkante; die Nabelweite ist nicht gross.

Die Sculptur besteht aus einfachen, sehr flach geschwungenen Rippen, über welchen drei Knotenspiralen liegen. Die Rippe steigt von vorn gegen rückwärts leicht schräge über die Nabelwand an, trägt auf dem Umbilicalrande einen kleinen, aber kräftigen, spitz zulaufenden Nabelknoten, in zwei Drittel der Flankenhöhe einen circa $5 \mathrm{~mm}$ hohen starken Lateraldorn und auf dem Marginalrande ein kleines Marginalknötchen. Die Rippe selbst ist wulstig, mit je einer flach auslaufenden submarginalen und sublateralen Anschwellung; sie wendet sich nach vorwärts, ihren Flankenverlauf fortsetzend, über den Rand und vereinigt sich in der Mittellinie mit der Rippe der anderen Flanke in einem stumpfen Extcrnknoten oder übersetzt in der Mittc bogenförmig den Externtheil. Zwischen 
diesen groben, Lateraldornen tragenden Rippen, welche in weiten Abständen aufeinandel folgen, treten meist drei kleinere Zwischenrippen auf, welche in der Marginalregion der lilanke ähnlich, wenn auch nicht so kräftig geformt sind wie die Hauptrippen: sie reichen aber nur etwa bis zur Flankcnmitte hinab und zeigen selten eine nur mehr linienförmige Fortsetzung bis in die Nabelregion und stellenweise auch einen kleinen Nabelknoten: auf dem Externtheil sind sie sehr stark reducirt. I Flache Einschnürungen sind vorhanden, welche analog dem Rippenverlauf Flanke und Externtheil übersetzen; durch sie wird die Berippung in der Weise beeinflusst, dass dann vor und nach der Einschnürung sich je eine, Lateralknoten tragende, Rippe findet.

Die Schale ist dick und mit feinen Anwachslinien bedeckt; durch sie erhöht sich die Beknotung nicht unbeträchtlich.

Von den Loben ist nur ein Theil des breiten ersten Lateralen zu sehen, dessen Grund reich geschlitzt ist; der Sattel ist relativ klein und ganzrandig.

Zahl der Exemplare: I.

Balatonites spec. indet.

Taf. XXVI (XIV), Fig. $2 a, b, c$.

Grösster Durchmesser . . . . $68 \mathrm{~mm}$

Höhe der letzten Windung ... . 22 ?

Dicke * : (imSteinkern) I 5 ,

Am unteren Ende des Bruchstückes ist der Externtheil stumpf-dachförmig und rundet sich allmälig gegen Ende desselben; Externknoten treten in dem vorliegenden Altersstadium nicht mehr auf; die Marginalkante ist leicht abgestumpft, die Umbilicale weit gerundet und geht in die hohe, schräg gestellte Nabelwand über; die Involution umfasst knapp die Marginalkante der vorhergehenden IVindung; die Nabelweite ist sehr gross.

Die Sculptur der letzten Windung besteht aus ziemlich engstehenden, kräftigen Hauptrippen. Sie verlaufen fast gerade, von der Radiale etwas gegen vorne abweichend, beginnen am Nabelrand mit einem kleinen, spitzen Nabelknoten, erniedrigen sich sodann etwas und schwellen oberhalb der Flankenmitte zu einem kräftigen Lateraldorn an; auf dem Marginalrand sitzt ein dem Umbilicalen ähnelnder Marginaldorn, unter welchem die Rippe in flacher Weise anschwillt; sie übersetzt den Externtheil zu Beginn des Bruchstückes stumpfwinkelig, gegen Ende desselben in einem flachen Bogen. Zwischen den Hauptrippen treten stark verkürzte Nebenrippen auf, welche schliesslich nur mehr als feine Knötchen auf dem Marginalrand sichtbar sind, während sie auf dem Externtheil viel deutlicher als Rippen hervortreten. Auch auf der vorletzten Windung, welche leider stark verdrückt ist, scheint die Sculpturirung schon sehr ähnlich entwickelt zu sein. Die Schale ist dick und lässt die Sculptur stumpfer erscheinen als der Steinkern; sie ist mit sehr feinen, enggestellten, linienförmigen Anwachsstreifen bedeckt.

Die Suturlinie ist nicht mit wünschenswerther Deutlichkeit zu beobachten; sie steigt vom Externsattel zum ersten Lateralen sehr rasch an, verläuft dann fast geradlinig und durchsetzt im Ganzen die Flankensculptur in schräger Weise, so dass z. B. der Externsattel in der Höhe einer Hauptrippe am Marginalrande, der Auxiliar knapp unter dem Umbilicalknoten der übernächsten Hauptrippe sitzt, also eine Rippe übersprungen wird. Der Externlobus ist, so viel überhaupt zu sehen ist, sehr breit und wird von einem grossen Medianhöcker in zwei Arme zerlegt, welche am Grunde gezackt sind: erster und zweiter Lateral sind fast von gleicher Grösse, breit, nicht sehr tief und dürften wohl am Grunde gezaclit gewesen sein; auf der Nabelkante schon beginnt ein breiter Auxiliar. Die Sättel sind relativ klein im Verhältniss zu den Loben; der Externsattel liegt ganz auf der Flanke und ist 
von gleicher Grösse wie der erste Laterale, welcher die höchste Stellung einnimmt; der zweite ist sehr klein; ein beginnender Auxiliarsattel ist vielleicht vorhanden.

Dieses der Art nach nicht bestimmbare Bruchstück schliesst sich zunächst an Balatonites stenodiscus (pag. 209, Taf. XXIV, Fig. $2 a-d$ ) an. Die Berippung ist ähnlich wie dort und zeigt besonders gegen Ende des Umganges eine starke Reduction der Zwischenrippen. Der Externtheil hingegen ist verschieden, indem er bei dem Bruchstücke das breite Uebersetzen der Rippen über den Externtheil zeigt, welche erst gebrochen und dann an der Beugungsstelle schwach beknotet, später flachbogenförmig wird. Die Suturlinie gemahnt uns ebenfalls an die oben citirte Form; ihre Elemente sind dieselben, nur hier bedeutend schmäler und länger.

Eventuell liesse sich auch der vorliegende Balatonites nov. spec, indet. als Varietät zu Balatonites stenodiscus Arth. stellen.

Zahl der Exemplare: I.

Balatonites spec. indet.

Taf. XXVI (XIV), Fig. 3,Fig. $4 a, b$.

Grösster Durchmesser . . . . . $49 \mathrm{~mm}$

Dicke der Windung ....... Io $\#$

Höhe »,$\ldots . .$. I 2 , .

Der Externtheil dieses kleinen Bruchstückes zeigt zu Beginn spitz-dachförmige Gestalt und rundet sich gegen Ende der Windung ab. Er besitzt eine auf dem Steinkerne deutlich hervortretende Mittellinie, längs welcher sich die beiderseitigen Rippen vereinigen und an der Vereinigungsstelle zu Beginn der Windung ganz kleine, spitze Externknötchen tragen, welche gegen Ende derselben fast ganz verschwinden. Die Flanken sind flach gewölbt und erlangen im Lateraldorn die grösste Breite. Die Rippen sind kräftig und verjüngen sich stark gegen den Nabelknoten. Dieser ist klein und spitz; ihm folgt unterhalb der Flankenhöhe der kleine Lateraldorn und auf der Marginalkante, welche kräftig entwickelt ist, ein stärkerer Marginaler; dazwischen treten zwei wohlentwickelte accessorische Knötchen auf. Die Nabelwand scheint nieder und schräg gestellt zu sein und die Nabelweite ist gering.

Theile der letzten Suturlinie sind zu sehen; der allgemeine Verlauf ist stark schräge die Radialsculptur durchsetzend. Wir finden einen grossen Externlobus mit breitem Siphonalhöcker und stark gekerbter Spitze, was wohl mit der deutlich sichtbaren Mittel- oder Siphonallinie zusammenhängt; die Arme scheinen beiderseits nur einspitzig zu sein, die beiden Lateralloben fast von gleicher Breite und Tiefe zu sein, nur nimmt der zweite eine bedeutend höhere Stellung ein; auf dem Marginalrand scheint ein breiter Auxiliar zu folgen. Von den Sätteln liegt der Auxiliarsattel am tiefsten und der zweite Lateral am höchsten; der Externe liegt fast ganz auf del Flanke, ist von gleicher Grösse wie der erste Lateral, der zweite ist sehr klein.

Auch diese Form scheint, obgleich viel engnabeliger, in die Verwandtschaft des Balatonites stenodiscus (pag. 209, Taf. XXIV, Fig. $2 a-d^{\prime}$ ) zu gehören, sowie einige andere kleinere Bruchstücke, die jedoch nicht mehr zwei, sondern nur eine oder auch keine submarginale accessorische Knotenreihe besitzen.

Zahl der Exemplare: 4 . 
Familie: Tropitidae Mojs.

Unterfamilie: Stephanitinae Arth.

Gattung: Acrochordiceras Hyatt.

\section{Acrochordiceras pustericum Mojs.}

IS78. Trachyceras pustericum Mojs. Mlojsisovics E. $v$., Dolomitriffe von Südtirol und Venetien, pag. 78 .

1882. Acrochordiceras pustericum Mojs. Mojsisozics F: 2 , Cephalop. Medit. 'Triaspr., pag. I 43 . 'Taf. VI. Fig. 4.

I895. Acrochordiceras pustericum Mojs. Arthaber, Cephalopodenfauna der leiflinger Kalke. I3eiträge zur l’al. u. Geol. Oesterr.Ung. Bd, $\mathbb{X}$, pag. So. Wien.

Auch hier liegen nur kleinere Bruchstücke vor, welche sich in liolge der charakteristischen Berippung - enge, fast gleichstark vom Nabel zum Externtheil, erst schwach concar, später leicht convex verlaufende Radialrippen - dennoch gut identificiren lassen. Schalenfragmente weisen auch hier wieder enge, feine linienförmige Streifung auf, welche schon pag. 8 r loc. cit, erwähnt wurde.

\section{Acrochordiceras undatum Arth.}

I895. Acrochordiceras undatum Arth. Arthabir, Cephalopodenfauna der leiflinger Kalke. Beiträge zur Pal. u. Geol. Oesterr.-Ung., Bd. X, pag. 79, Taf. VII, Fig. 7, 8.

Ein einziges vorliegendes kleines Bruchstück zeigt dennoch genug, um diese Form mit Sicherheit identificiren zu können. Wir sehen die enggestellten groben Falten, welche mit geringer Stärke am Nabelrand beginnen, sodann anschwellen und in der Gegend des Externtheiles die grösste Dicke erlangen. Ihr Verlauf ist in der Flankenmitte leicht concav, auf dem Externtheil convex.

Die Schale zeigt feine, analog den Rippen verlaufende Schalenstreifen.

Bei dieser Gelegenheit sei ein Fehler corrigirt, der im ersten Theile dieser Arbeit, gelegentlich der Beschreibung der Acrochordiceraten des Fundortes "Tiefengraben«, von mir begangen wurde. Es wird daselbst (pag. 8o ff.) bei Beschreibung der Formen: Acrochordiceras undatum Arth., Acrochordiceras enode Hauer, Acrochordiceras erucosum Arth. stets von zwei Lateralloben gesprochen, während die Gattungsdiagnose, wie sie E. . Alojsisovics $^{1}$ ) pag. I40 vervollständigt hat - denn Hyalt war die Suturlinie noch unbekannt - nur einen Laterallobus anführt und angibt, dass bei ganz grossen Formen die projicirte Vindungsspirale bestenfalls die Hälfte des zweiten Flankenlobus abtrennt, dieser somit noch als Auxiliar zu gelten hat. Dieser Auffassung folge ich ebenfalls, und es ist daher stets statt zweiter Lateral: erster Auxiliar das Richtige, und in die Beschreibung des Reiflinger Exemplares des Acrochordiceras enode Hauer (pag. 8I) statt Auxiliar: zweiter Auxiliar einzusetzen.

1) Cephalop. Medit. Triaspr. 


\title{
Ordnung: Leiostraca Mojs.
}

\section{Familie: Noritidae Waag. \\ Gattung: Norites Mojs.}

\author{
Norites arcuatus Arth. \\ Taf. XXVI (XIV), Fig. $9 a, b, c$.
}

Durchmesser . . . . . . . . $44 \mathrm{~mm}$
Höhe der letzten Vindung
Dicke,
Nabelweite (von Rand zu Rand) . . 6 , 6

Der Externtheil ist flach gerundet, die Flanken sind flach und erlangen tief unterhalb der Flankenmitte die grösste Dicke, von wo aus sie sich gegen den Nabelrand rasch herabsenken und vor Erreichen desselben eine zarte Einschnürung aufweisen; der Marginalrand ist scharf entwickelt, der Umbilicale leicht abgestumpft; die Nabelwand ist nieder und steil gestellt; die Involution ist fast vollständig, wodurch nur ein schmaler Nabelrand frei bleibt; der Nabel selbst ist im Vergleiche mit den schon bekannten Arten von mittlerer Grösse, jedoch kommen auch enger genabelte Gehäuse vor; da die ganze Gestalt dieses Noriten eine flache ist, so erscheint auch der Nabel flach treppenförmig eingesenkt.

Sämmtliche vorliegende Formen sind Steinkerne, welche nur an einzelnen Stellen Reste der Schale aufweisen. Auf letzterer treten mit grosser Deutlichkeit und Schärfe die sichelförmig verlaufenden Anwachslinien auf, welche den Externtheil bogenförmig convex übersetzen und deren bereits gelegentlich der Beschreibung von Norites falcatus Arth. (Abth. I der vorliegenden Arbeit, pag. 90, Taf. VIII, Fig. I) Erwähnung gethan wurde. Die Noriten besassen eine sehr dünne Schale und die Anwachsstreifen durchsetzten die Schale selbst und waren daher auch auf der Unterseite sichtbar, wie die Steinkerne zeigten.

Der Erhaltungszustand eines vorliegenden Stückes ist derart, dass sich die Länge der Wohnkammer, als ungefähr einen ganzen Umfang betragend, beobachten lässt.

Norites arçuatus erlangte bedeutende Grösse, wie ein Bruchstück beweist, das zu einem Exemplar von circa $58 \mathrm{~mm}$ Durchmesser gehören dürfte.

Die Suturlinie ist leider nicht in wünschenswerther Deutlichkeit sichtbar, da die Gehäuse meist bei Beginn der Wohnkammer verdrückt sind. Die abgebildete Suturlinie ist daher theilweise reconstruirt und besonders die Einzelheiten der Lobenzacken nach Analogie der bekannten Noriten ergänzt.

Die Suturlinie als Ganzes zeigt einen sehr flach gespannten Bogen, dessen Scheitel der erste Lateralsattel bildet. Die Loben sind im Vergleich zu anderen Formen schmal, ebenso die Sättel. Der Externlobus ist relativ hochstehend, sehr breit, zeigt am Medianhöcker je ein kleines herabhängendes Zäckchen, wie wir es bei Norites falcatus schon kennen gelernt haben, und seitlich zwei schmale, lanzettliche Seitenblätter, deren Spitzen convergiren und so tief wie der zweite Lateral hinabreichen; der crste Lateral ist schmal, an der Basis leicht verbreitert und erlangt die grösste Tiefe; der Zweite ist fast ebenso breit, jedoch viel kürzer, so dass er einen noch breiteren Eindruck macht. Auf der lilanke treten ferner noch zwei kurze Auxiliarloben auf, ein dritter wird vom Nabelrand halbirt. Sämmtliche Sattelstiele sind durch die Form der Loben an der Basis leicht verjüngt. Die Sättel sind schmal und ganzrandig; der Externsattel erlangt die Höhe des ersten Auxiliarsattels. 
Norites arcuatus hat die grösste Verwandtschaft mit dem schon oben erwähnten Forites falcatus, ron dem er sich durch die liorm des Querschnittes unterscheidet, welche dasellust einen etwas schlankeren Externtheil, eine leichte Verjüngung knapp unter demselben bei relativ starker dufblähung unterhalb der Seitenmitte zeigt, während bei der vorliegenden neuen Form der Externtheil relativ breit ist und die Flanken fast Hach erscheinen.

Tahl der Exemplare: 2.

\section{Norites psilodiscus $\Delta r$ th.}

I895. Norites psilodiscus Arth. Arthaber, Cephalopodenfauna der Reiflinger Kalke. Beiträge zur Pal, u. Geol. Oesterr. L'ng., Bd. X, pag. 92, Taf. VIIII, Fig. 4 .

Ein vorliegendes Bruchstück lässt sich am ehesten als Jugendstadium obiger Art deuten, welche der alte Fundort Tiefengraben geliefert hat. Der Externtheil ist relativ breit, das Maximum der Anschwellung erfolgt ungefähr in der Flankenmitte, der Nabel ist gross. Nachdem das Exemplar mit Schale erhalten ist, lassen sich die marginalen und umbilicalen Kielkanten sowie die sichelförmigen Anwachslinien, kurz die meisten charakteristischen Merkmale dieses Noriten sehr gut beobachten.

\section{Familie: Neekoceratidae Waag. Unterfamilie: Meekoceratinae Waas. Gattung: Beyrichites Waag.}

Wie schon in der ersten Abtheilung der vorliegenden Arbeit pag. 30 kurz angedeutet worden war, hat IV. Waagen in der Palaeontologia Indica (Ser. XIII, Salt Range Fossils, Vol. II: Fossils from the Ceratite formation; Calcutta I\$95), pag. I60, die Gattung Beyrichites aufgestellt, speciell für die Formen:

$$
\begin{array}{cl}
\text { Meekoceras } & \text { Khanilofi Opp. spec., } \\
* & \text { maturum Mojs., } \\
* & \text { reuttense Beyr. spec., }
\end{array}
$$

weil sich dieselben durch die äussere Form (Art der Sculptur, der Involution) zu weit vom Typus .Meekoceras : entfernen, um bei diesen noch systematisch verbleiben zu können. IVaggen schloss diese neue Gattung enge an Proptychites und im weiteren Sinne an die Ptychitidae an.

In der Folgezeit hat $C$. Dicncr eine nicht unerhebliche Anzahl von verwandten Formen aus dem Muschelkalke des Himalaya beschrieben, welche unsere Kenntniss diesbezüglich bedeutend erweitern und die er in seiner Arbeit über die" Cephalopoda of the Muschelkalk ${ }^{1}$ ) noch als Meekoceras beschreibt (pag. $46 \mathrm{ff}$.).

In einer weiteren Publication desselben Autors, in den $*$ Cephalopoda of the lower Trias,${ }^{2}$ ) welche sich wahrscheinlich gegenwärtig in Druck befindet, werden diese Meekocerasformen, nachdem Diener indessen die „Fossils from the Ceratite formation "Wargcn's kennen gelernt hatte, den neuen Gattungen Waagcri's Proptychites und Beyrichites zugetheilt.

Waagen hatte, wie auch schon im ersten Theile der vorliegenden Arbeit (pag. 93) erwähnt wurde, seine Gattung Beyrichites zu den Ptychitidae gestellt; Dicner hingegen gelang es mit Hilfe von besserem Material den Nachweis zu liefern, dass diese Gattung zu den Meekoceraten gehöre. Bei den Ptychiten nämlich überwiegt nach Dicncr im Jugendstadium stets die Dicke über die Höhe, 
während genaue Messungen ergaben, dass dies bei jungen Beyrichiten nie der Fall sei, und dass sich bei diesen dieselben Anwachsverhältnisse constatiren lassen wie bei Meekoceras. Er schliesst deshalb Beyrichites, den er nur als Untergattung von Meekoceras gelten lassen möchte, an Meekoceras an und stellt ihn demzufolge zu den Meekoceratidae.

Diese Beweisführung ist sehr einfach und ich schliesse mich dieser Auffassung an.

\section{Beyrichites splendens Arth.}

Taf. XXVII (XV), Fig. I $a, b, c$

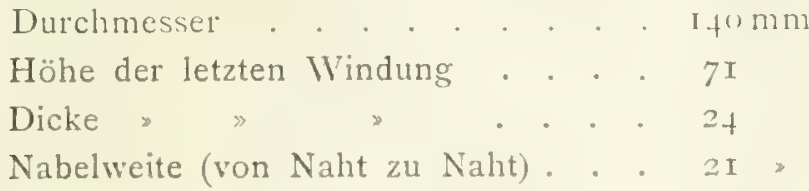

Der Externtheil ist sanft gerundet, die Flanken sind fast flach zu nennen und erlangen etwas unterhalb der Flankenmitte die grösste Dicke, von wo aus sie etwas rascher zum Umbilicalrand abfallen; derselbe ist leicht abgestumpft, die Nabelwand hoch und senkrecht stehend; die Involution beträgt drei Viertel der früheren Windung, wodurch ein flach treppenförmig abgesetzter Nabel entsteht.

Die Flankensculptur besteht aus sichelförmig gebogenen schmalen und flachen Falten, welche deutlich sichtbar über die Nabelwand aufsteigen, am Nabelrande stumpf-knotenförmig verdickt sind, sodann sehr schwach concav, im Mittelstücke kräftiger convex gekrümmt sind und mit einem, jetzt stärker concav gebogenen Stücke am hypothetischen Marginalrande zugleich mit einer leichten Verdickung enden. Anfangs- und Endpunkt der Falten liegen in einer Radiale. Dort, wo der Scheitel des convexen Theiles liegt, also etwas unterhalb der Flankenmitte, sitzt ein abgestumpfter kleiner Knoten mit breiter Basis. Von hier aụs tritt eine Insertion von gleichsinnig verlaufenden Secundärfalten ein, während im Zwischenfeld zwischen den Knoten oder Primärfalten feine, ebenfalls sichelförmig gebogene Streifen sichtbar werden. Die Anzahl der Lateralknoten steht in keinem regelmässigen Verhältnisse zur Anzahl der Umbilicalanschwellungen. Am Beginn der letzten Windung, woselbst wir noch gekammerte Partien haben, kommen auf drei Umbilicale zwei Lateralanschwellungen, während im zweiten Drittel des letzten Umganges, also kurz nach Beginn der Wohnkammer, auf fünf Umbilicale schon sieben Lateralknoten entfallen. Hingegen ist das letzte Drittel der Wohnkammer wieder überhaupt knotenlos, so dass wir zu dem Schlusse berechtigt zu sein scheinen, dass diese Art der Beknotung überhaupt nur ein Merkmal ausgewachsener Individuen sei, und dass sie ihr Maximum am Beginne der Wohnkammern erreiche. Am Ende derselben beschränkt sich auch die Radialsculptur nur mehr auf die oben erwähnten feinen Streifen, welche hier etwas kräftiger geworden sind, da sie auch die Rolle der primären Falten übernommen haben.

Die Schale, welche theilweise auf der Wohnkammer, vollständig jedoch am Beginne der letzten Windung erhalten ist, zeigt flache, sichelförmig gebogene Faltenbänder, und auf diesen, sowie auch im Zwischenfeld zwischen denselben feine, linienförmige Schalenstreifen.

Die Suturlinie ist leider nicht vollstündig erhalten, weil beim vorliegenden Stücke die äussere Seite des letzten, gekammerten Windungstheiles verdrüiclet ist; wir können daher den Externund ersten Laterallobus gar nicht oder nur mangelhaft sehen. So viel man jedoch bemerkt, hat die Suturlinie im Allgemeinen einen flach bogenförmigen Verlauf, dessen Scheitel der erste Lateralsattel bildet. Vollständig erhalten ist erst der zweite Laterallobus, welcher kräftig und breit entwickelt ist; der Lobengrund trägt eine seitlich gestellte kleinere und drei grössere spitze Zacken, kleinere Zäckchen zichen sich bis zum Sattelkopf hinauf; nun schliesst sich ein kürzerer, jedoch im Verhältniss der Breite zur Höhe cbenso geformter Auxiliar mit gezackten Wänden an, dessen Grund dreizackig ist; bis zum 
Nabelrand folgen noch zwei kleinere Auxiliarelemente, welche in eine stumpfe Spitze - etwa ähnlich wie bei Popanoceras - enden, und auf der Umbilicalwand ein viertes ganz kleines Auxiliarelement. Die Sättel sind breit gerundet und der erste Auxiliar zeigt die grösste Spannweite; der zweite Lateralsattel sowie der erste Auxiliar hat zwei kleine Zacken, wodurch je drei kleine brachyphyllische Sattelblätter entstehen; der zweite und dritte Auxiliarsattel ist klein und ganzrandig, während der vierte Auxiliar grösser, jedoch flacher gespannt ist und mit dem absteigenden Theile die Naht erreicht.

Beyrichites splendens hat seinen nächsten Verwandten im indischen Muschelkalk des Hima. laya gefunden. Es sind dies: Beyrichites (Meekoceras) Khanikofi Oppel, der zuerst von Oppel'1) aus schwarzgrauem Kalk von Hundes und Spiti (pag. 275, Taf. LXXVI, IVig. 4), neuestens von Dicner von verschiedenen Fundstellen in Johar und Painkanda beschrieben wurde, ${ }^{2}$ ) und Beyrichites (Meekoceras) Gangadhara Diener (loc. cit. pag. 49, P1. IX, Fig. 4) vom Shalshal Cliff bei Rimkin Paiar E. G.

Von beiden differirt Beyrichites splendens durch die bedeutende Grösse des ausgewachsenen Individuums - die Reiflinger Species ist die grösste bisher bekannt gewordene Art - ferner durch geringere Dicke, Involution und Grösse des Nabels. Die Lateralknoten treten hier schon auf gekam. merten Theilen auf und häufen sich bei Beginn der Wohnkammer, während deren Ẽnde wieder knotenlos wird; beide indischen Formen sind hingegen auf den gekammerten Theilen ohne Knoten. Letztere treten besonders bei dem mir im Originale vorliegenden Beyrichites Gangadhara, erst gegen Ende der Wohnkammer in spärlicher Weise auf (vide Pl. IX, Fig. 2 und $4 a$ ).

Bedeutender sind die Unterschiede in den Suturen. Die indischen Formen haben im Allgemeinen viel bogenförmigeren Verlauf, stärker bei Beyrichites Khanikofi und Hacher bei Beyrichites Gangadhara gespannt. Auffallend ist bei Ersterem das rasche Absinken der Auxiliarelemente zur Naht (welche hier ebenfalls in der Dreizahl vorhanden sind), was bei Letzterem besonders stark ausgebildet ist. Hier sehen wir *a very remarkable umbilical lobe, the numerous denticulations of which slope obliquely towards the umbilical suture . Eben dies fehlt bei Beyrichites splendens; wir sehen vielmehr auf der Nabelwand nur einen kleinen Zacken. Der erste Auxiliarsattel ist hier auch viel stärker entwickelt als bei den indischen Formen.

Zahl der Exemplare: I.

\section{Beyrichites Bittneri ${ }^{3}$ ) Arth.}

Taf. XXVI (XIV), Fig. II $a, b, c$.

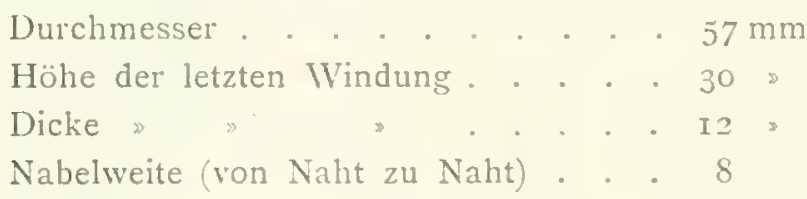

Der Externtheil ist etwas höher gewölbt als bei Beyrichites splendens, die Flanken sind sanft anschwellend und erreichen etwas unterhalb der Seitenmitte die grösste Dicke; ein ausgesprochener Marginalrand ist nicht entwickelt, der Umbilicale ist abgestumpft. Die Involution beträgt mehr als drei Viertel des letzten Umfanges, wodurch nur ein schmaler Rand desselben am Nabel frei bleibt, der hiedurch flach-treppenförmig abgesetzte Form erhält; die Nabelöffnung selbst ist relativ klein. Die Sculptur ist aus Rippen mit knotigen Anschwellungen gebildet. Es treten niedere, breite Haupt- und cbensolche inserirte Zwischenrippen auf; erstere beginnen am Nabelrand mit einer kleinen Umbilical-

1) Paaläontologische Mittheilungen, I, vide Literaturverzeichniss auf pag 23 .

Pelaeontologia Indica, Ser. XV, Himálayan Fossils, Vol. II, Part. 2: The Cephalopoda of the Muschelkalk by Cirl l)icner (pag. 41, 1'l. VIII, Fig. 3, IX, Iig. 1, 2, 3, 9). Calcutta I 895.

) Ich benenne diese Form zu lihren ihres Finders Dr. A. Wilmer. Das Stück selbst ist im Besitze der k. k. Geologischen Reichsanstalt in Wien. 
anschwellung, verlaufen sodann schwach-sichelförmig gebogen zum hypothetischen Marginalrand, woselbst sie mit einer etwas radial verlängerten Anschwellung enden; dort wo die Flanke die grösste Dicke erlangt, also unterhalb der halben Seitenhöhe, sitzt auf dem Convexstücke der Hauptrippe je ein stumpfes Lateralknötchen auf. Die Zwischenrippen, welche in der Marginalpartie vollständig das Aussehen der Hauptrippen haben, erscheinen von Aussen her (von der Mündung aus) stets hinter der Primärrippe eingeschaltet und reichen beim abgebildeten Stücke auf dem letzten Drittheil bis in die Höhe des Lateralknotens, ohne sich in diesem an erstere anzugliedern, bei Beginn der letzten Winduno jedoch reichen sie über denselben noch hinaus.

Theilweise ist bei dem vorliegenden Stücke noch die Schalenbedeckung vorhanden; sie zeigt dieselben Erscheinungen bezüglich der Beknotung und den Falten, und ausserdem noch eine gleichsinnig mit den Letzteren verlaufende, ganz feine, linienförmige Zeichnung, ähnlich derjenigen, welche wir bei Beyrichites splendens beobachten konnten. Das eine vorliegende Stück ist bis zum Ende gekammert, so dass wir berechtigt sind, für ein mit Wohnkammer erhaltenes Exemplar einen Durchmesser von ungefähr 95 - I0o $\mathrm{mm}$ anzunehmen.

Die Suturlinie zeigt zwei Lateral- und drei Auxiliarelemente auf der Flanke. Der allgemeine Verlauf der Lobenlinie ist ein flachgewölbter Bogen, dessen Scheitel der erste Lateralsattel bildet.

Der Externlobus ist relativ schmal, tiefliegend, von einem Siphonalhöcker halbirt und erreicht mit seiner Spitze die Tiefe der längsten Spitze des ersten Laterals; er besitzt auf der Innenseite drei, auf der Aussenseite nur einen kleineren Zacken.

Der erste Laterallobus ist der breiteste und tiefste, hat am Grunde drei grössere und auf der Innen- und Aussenseite je kleinere Zäckchen, welche sich bis zum Sattelkopf hinaufziehen; der zweite Laterale reicht ungefähr halb so tief wie der Extern- und Laterallobus herab, hat in der Tiefe zwei grössere Zacken, während sich kleinere Zäckchen ebenfalls bis zu den Sattelköpfen hinaufziehen; der erste Auxiliar hat ungefähr die Form des zweiten Lateralen, ist jedoch schmäler als dieser und reicht an Tiefe etwas über die Hälfte desselben herab; dann schliessen sich zwei wie bei Beyrichites splendens gleichgestaltete, Popanoceras ähnliche Auxiliarelemente an, deren zweiter mit der Nabelkante abschliesst. Die Sättel sind rundbogig; Extern- und beide Lateralsättel sind am Kopfe selbst ganz. randig; der erste Auxiliarsattel ist von gleicher Grösse wie der zweite Laterale, zeigt jedoch einen vom Scheitel herabhängenden kräftigen Zacken, während der zweite klein und ganzrandig ist. Auf der Nabelwand schliesst sich ein breiter dritter Auxiliarsattel an, welcher zweimal gezähnt erscheint, so dass die Tendenz, ein neues Auxiliar-Lobenelement zu entwickeln, deutlich hervortritt. Auffallend ist die bedeutende Sprunghöhe zwischen dem Extern- und ersten Lateralsattel.

Beyrichites Bittneri unterscheidet sich von dem oben beschriebenen Beyrichites splendens durch die höchstwahrscheinlich überhaupt geringere Grösse, ferner durch geringere Dicke des Externtheiles, sowie durch grössere Involution und folglich durch den kleineren Nabel. Die Suturlinie ist im Ganzen stärker gewölbt und unterscheidet sich insbesondere durch die ganzrandigen Lateralsättel und den breitgeschwungenen gezackten dritten Auxiliarsattel, der diesbezüglich grössere Aehnlichkeit mit dem oben besprochenen (loc. cit.) Beyrichites Gangadhara hat. Einen deutlichen Unterschied zwischen diesen nordalpinen und den indischen Beyrichiten bildet die Art der Lateralbeknotung, welche hier nur als senile Errungenschaft, bei den alpinen Formen hingegen als zeitlich frühere Acquisition auf. zufassen ist.

Zahl der Exemplare: I. 


\section{liamilie: Ptychitidae Waag. \\ Unterfamilie: Proptychitinae Waag. \\ Gattung: Ptychites Mojs. \\ Formengruppe der Ptychites megalodisci Mojs. \\ Ptychites domatus Hauer. \\ Taf. XXVI (XIV), Fig. Io $a, b$.}

I851. Ammonites domatus Hauer. Hauir, Ueber die von Bergrath W. Fuch in den Venetianer Alpen gesammelten Iossilien. Denkschr. d. k. Akad. d. Wiss. math.-nat. Cl. Bd. II, pas. II5, Taf. XVIII, IVig. I2. WVien.

186n. Arcestes domatus Hauer spec. Mojsisovies, Beiträge zur Kenntniss der Cephalopodenfauna des alpinen Mluscheikalkes. Jahrb. d. k. k. geol. R.-A., Bd. XIX, pag. 574. WVien.

1873. Ammonites domatus Hauer. Bückh, Geol. Verhältnisse des südlichen Theiles des Bakony, I. Th., pag. 75. Mitth. aus dem Jahrb. d. kön. ung geol. Anst., Bd. 11. Budapest.

I882. Ptychites domatus Hauer spec. Wojsisovics, Cephalop. Medit. Triaspro, pag. 250, Taf. LXII, Mig. 4, 5. Abh. d. k. k. geol. R.-A., Bd. X. Wien.

1895. Ptychites domatus Hauer spec. Arthaber, Cephalopodenfauna der Reiflinger Kalke, Abth. I, pag. 97. 13eiträge zur Pal. u. Geol. Oesterr.-Ung., Bd. X. Wien.

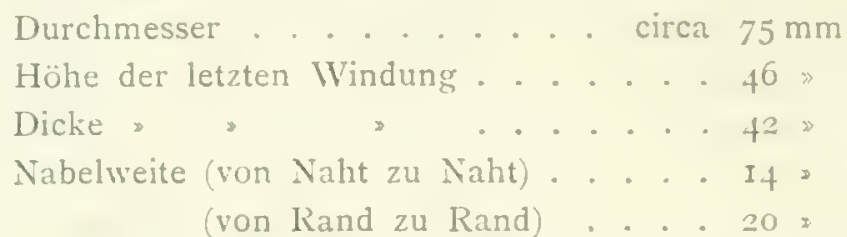

Der Externtheil der letzten Windung ist hoch gewölbt und schmal, die Seiten flach abfallend gegen die Nabelregion, woselbst sie die grösste Dicke erlangen; die Nabelkante ist leicht abgestumpft, die Umbilicalwand hoch und steil; der Nabel ist eher klein als gross zu nennen; die Involution findet vollständig statt, wodurch ein trichterförmig eingesenkter tiefer Nabel entsteht.

Auf der letzten Windung tritt eine schwache, aus flachen, breiten Falten bestehende Radialsculptur auf, welche fast ganz verflachend den Externtheil übersetzt. Auf der Schale lässt sich eine analog verlaufende feine Linienzeichnung wahrnehmen.

Die Suturlinie ist bei dem vorliegenden Stücke nicht zu beobachten.

Es ist interessant, dass Ptychites domatus, der auch am jüngeren Fundorte Tiefengraben sich in einem grösseren Exemplare fand als jene sind, welche bis jetzt aus den Südtiroler Alpen und dem Bakony beschrieben worden sind, nun auch an dem neuen Fundorte, und zwar wieder in einem sehr grossen Individuum, nachgewiesen wurde. Leider ist dasselbe nicht vollständig, sondern nur ein grosses Segment davon erhalten.

Das kleinste der bisher abgebildeten Stücke hatte einen Durchmesser von $22 \mathrm{~mm}$, das grösste von fI mm, während das vorliegende Stück annähernd von doppelter Grösse ist. Man kann hier gut beobachten, wie erst auf der letzten Windung sich das Verhältniss der Höhe zur Dicke ändert, indem im Anfang des letzten Umganges sich Dicke zur Höhe wie 26: I8 verhalten, ja noch in mehr als der Hälfte desselben die Dicke die Höhe bedeutend überwiegt, $36: 32$, und erst auf dem Ende der Windung sich die Flanke bedeutend streckt, der Externtheil schmal wird, so dass das Verhältniss sich umkehrt $(42: 46)$.

Wie schon E. v. Mlojsisovics (loc. cit. pag. 250) und später F\%. v. Hauer-1) (pag. 38 [286]) betonte, sind als nächste Verwandte des Ptychites domatus der Ptychites Pauli Mojs. (loc. cit. pag. 25I, Taf. LXII, Fig. 2) und Ptychites impletus Oppel spec. ${ }^{2}$ ) (pag. 294, Taf. LXXXV, Fig. 5) zu nennen. Bd. I.IX. Wien ISg2.

1) Houer fr. a, Cephalopoden aus dem Trias ron Bosnien. Denkschr. d. k. Akad. d. Wiss. math.-nat. Cl., 2) Opšl, Paläont. Mittheilungen, Bd. I. IV.: Ueber ostindische Fossilreste. München I863. 
Ptychites nov. form. indet.

Ein grosses Wohnkammer-Bruchstück liegt vor, von zu ungenügendem Erhaltungszustand, um eine Identificirung oder Aufstellung einer neuen Art zuzulassen, welches zu einem Stücke gehört, dem ungefähr folgende Maasszahlen entsprechen dürften:

Durchmesser. . . . . circa $130 \mathrm{~mm}$
Höhe der letzten Windung . . . . 72
Dicke » $\gg$. . . 35,
Nabelweite (von Rand zu Rand) circa I2,

Wie man aus den Maassen entnimmt, hat diese Art dicke Umgänge und einen relativ engen Nabel. Der Externtheil ist breit gewölbt, die Flanken sind auffallend flach und erlangen ihre grösste Dicke oberhalb der Flankenmitte, von wo aus sie natürlicherweise rascher gegen den Externtheil und nur sehr minimal gegen den Nabel abfallen. Die Sculptur besteht aus niederen Falten, welche etwas gegen vorne von der Radiale abweichen und auf der Flankenmitte einen nach vorn convexen, sehr flachen Bogen beschreiben. Sie beginnen erst jenseits des Nabelrandes deutlich sichtbar zu werden und zeigen in der Gegend der grössten Flankenbreite die grösste Anschwellung. Auswärts derselben löst sich die Rippe plötzlich in $4-5$ kleinere Rippchen auf, welche aber erst deutlich auf dem Externtheile werden und diesen sanft nach rückwärts gebogen übersetzen. Bei einzelnen Rippen liegt diese Theilungsstelle tiefer gegen den Nabel zu.

Auf der Schale ist diese Sculptur ebenso, nur in etwas verwischterer Weise zu sehen.

Die Gestalt und Berippung dieser Form ist freilich für Ptychiten höchst ungewöhnlich, die ja sonst keinen so breitgewölbten Externtheil zu haben pflegen, die grösste Dicke'meist in der Umbilicalregion erlangen und, wenn Berippung vorhanden ist, diese nicht über den Externtheil hinüberführen. Jedoch lässt sich dieses Bruchstück trotzdem nirgends besser anschliessen. Es käme eventuell das Genus Beyrichites in Betracht, das jedoch ganz anders geartete Sculptur hat.

In jüngster Zeit hat G.v.Bukoruski aus dem oberen Mluschelkalke von Braič in Dalmatien (Verhandl. d. k. k. geol. R.-A., I895, Nr. I2, pag. 3 I9 ff.) einen Ptychites nov. form. beschrieben, der eine ähnliche Radialsculptur aufweist: ausserhalb des Nabelrandes beginnend, verdicken sich die Rippen gegen den Externtheil zu und lösen sich vor Erreichen desselben in kleine Rippchen auf, welche ihn übersetzen.

Wir haben also möglicherweise hier Vertreter einer neuen Formengruppe von Ptychites, welche sich, wenn auch in seltenen Exemplaren, im unteren und oberen Muschelkalke finden.

\section{Flossenstachel?}

Taf. XXVII (XV), Fig. 5 .

Ein kleines, zur näheren Bestimmung gänzlich ungeeignetes Fragment liegt vor, mit einer Länge von $29 \mathrm{~mm}$, Breite von II mm und grösste Dicke von $8 \mathrm{~mm}$.

Die Umrandung wird auf der einen, der vorderen Seite, von einer glatt abgerundeten Kante gebildet, welche auf der anderen zu fehlen scheint. Die Fläche ist im Ganzen flach gewölbt und zeigt in der Mitte eine erhöhte Mittelpartie, welche rechts und links von zwei ebenfalls längslaufenden Vertiefungen begrenzt wird. Die Sculpturirung besteht nur aus kleinen, knopfförmigen Kinötchen mit gerundeter Oberfläche, welche in gegen abwärts gerichteten Bogen angeordnet sind. Die Knötchen stehen in der erhabenen Mittelpartie am engsten und treten gegen die Ränder weiter auseinander. Diese Anordnung tritt in der Zeichnung nicht genügend scharf hervor. Wohl stehen die Knötchen auch longitudinal reihenförmig, jedoch tritt dies im Vergleich zur bogenförmigen Folge weniger deutlich hervor.

Der Flossenstachel nimmt von vorne gegen rückwärts an Dicke zu, ist seitlich flachgedrückt, besitzt eine kräftige Rinde, welche eine annähernd ovale Alveole umschliesst. Die merkwürdige Verzierung fnd das Fehlen einer Längsstreifung machen die Bestimmung als Flossenstachel zweifelhaft. 


\title{
NACHTRAG
}

\section{zur Fauna der Reiflinger Kalke des Fundortes ,Tiefengraben .}

\author{
Nautilea Mojs. \\ Familie: Nautilidae Owen. \\ Gattung: Nautilus Breyn.
}

\author{
Nautilus Anisi Arth. \\ Taf, XXVII (XV), Fig. $+c-d$.
}

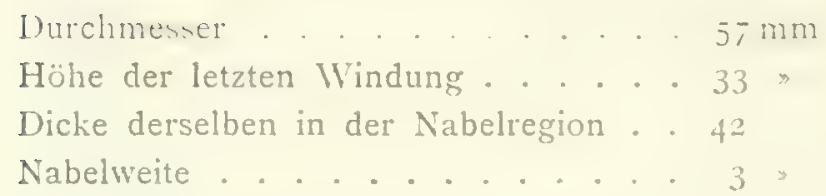

Der Externtheil dieser rasch anwachsenden Form ist schlank und die Flanken flachgewölbt und erlangen in der Nabelregion die grösste Breite, von wo aus sie, ohne eine ausgesprochene Nabelwand zu entwickeln, sich rasch zum auffallend kleinen Nabel hinabwölben.

Die Schale ist mit sanft gewölbten Anwachsstreifen bedeckt, welche nur etwas deutlicher in der Nabelregion hervortreten; die untere Schalenschichte hingegen zeigt - leider nur auf der Wohnkammer allein sichtbar - feine, enggestellte Spiralstreifung, in der einzelne Linien stärker hervortreten und daher eine bandförmige Zeichnung hervorrufen. Darüber liegt eine ganz ähnliche bandartige Radialzeichnung, wodurch eine feine, nur aus Linien allein gebildete Gitterung entsteht. Die in radialer Richtung verlaufenden Linien und Bänder bilden auf der Flanke einen nach vorn gerichteten Bogen, auf dem Externtheil eine schmale, nach rückwärts gekehrte Bucht; sie verlaufen daher fast in entgegengesetztem Sinne wie die Kammerscheidewände.

Letztere (Fig. 4d) steigen leicht nach vorne gekrümmt über die Nabelwand herauf, besitzen auf der Flanke einen flachen, nach rückwärts gerichteten Bogen, und auf dem Externtheil ein fast radial verlaufendes Stück. Die Lage des Sipho lässt sich nicht ermitteln.

Nautilus Anisi schliesst sich wohl zunächst an den im ersten Theile dieser Arbeit (pag. 42, Taf. III, Fig. 4, 5, 6) beschriebenen Nautilus pertumidus und dessen Verwandte an. Sehr nahe scheint

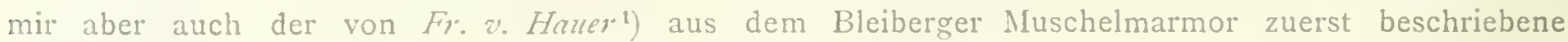
Nautilus Sauperi zu stehen, der jedoch im Ganzen schlanker ist und einen callös verschlossenen Nabel besitzt.

Die Abbildung dieser neuen Species ist nicht sonderlich gut gelungen, da der Convextheil etwas zu stark gewölbt angegeben ist, wodurch er stumpfer erscheint, als er thatsächlich ist. Ferner ist der Concavtheil der Flanke der Kammerscheidewand (Fig. 4d) etwas kleiner und demzufolge die Externpartie etwas zu gross angegeben, was hiemit ausdrücklich bemerkt sei.

3) Ilaidinger, Naturwissenschaftl. Abh., I3d. I, pag. 26, 27, Taf. I, Irig. I-4. I846. 


\section{Familie: 'Tropitidae Mojs. Unterfamilie: Stephanitinae Arth.}

\section{Gattung: Acrochordiceras Hyatt.}

\section{Acrochordiceras undatum Arth.}

Taf. XXVII (XV), Fig. $2 a-d$.

1859. Acrochordiceras undatum Arth. Arthaber, Cephalopodenfauna der Reiflinger Kalke. Beiträge zur Pal. u. Geol Oesterr.-Ung., Bd. X, pag. 79 ff., Taf. VII, Fig. 7, 8.

Durchnesser . . . . . . . . . . 5;mm
Windungshöhe . . . . . . . . . 27,
Dicke (ïber die Nabelknoten) . . . . 27,
Nabelweite (von Naht zu Naht) . . . I4,

Nachdem bisher sieben Bruchstücke, die verschiedensten Altersstadien repräsentirend, vorgelegen waren, gelang es endlich im Sommer I896 ein vollständiges Exemplar zu finden, wodurch die Möglichkeit geboten wurde, heute Irrthümer wieder gut zu machen, welche ich, die Speciesdefinition betreffend, beging. Ich konnte aber auch die gute Lehre aus dem Funde ziehen, dass es mehr als gewagt ist, auf Grundlage eines nicht tadellosen Materiales, nur mit Hilfe von Combinationen, wenn auch zahlreicher Bruchstücke, eine neue Species aufzustellen.

Als wichtigster Fehler ist zu betonen, dass diese neue Species nicht knotenlos ist, sondern dass sie auf dem Ümbilicalrande Knoten ansetzt, von denen je zwei Rippen ausstrahlen; in seltenen Fällen folgt knapp neben einem kräftigen Knoten noch ein schwächerer zweiter, der ebenfalls zwei Rippen vereinigt. Bei weiterem Wachsthum scheint die Regelmässigkeit der Beknotung aufzuhören und nur hie und da sich eine Rippe am Nabelrande knotig zu verdicken, wie sogar auf Taf. VII, Fig. $7 a$, zu sehen ist. Dies gilt aber erst für Exemplare mit einer ähnlichen Windungshöhe, wie eben dieses Stück (Windungshöhe $42 \mathrm{~mm}$ ) aufweist. Zwischen je zwei Knoten treten meist drei, nur auf jüngeren Exemplaren zwei Rippen ein, welche knapp ober dem Nabelrande enden. Die übriggen, die äussere Form betreffenden Merkmale sind pag. 79 ff. richtig wiedergegeben.

Ein Fehler hingegen findet sich wieder in der Lobenzeichnung, bei welcher sdie Verhältnisse einer kleinen Form auf die Flankenbreite der grossen übertragen sind *. Auch wieder ein Beweis dafür, wie zweifelhaft der Werth solcher Uebertragungen ist. Die Form wächst bis zum Altersmittel rasch an, in Folge dessen müssen die Loben und Sättel sich bei grösserer Flankenbreite ebenfalls verbreitern, da kein zweiter Lateral auf der Flanke zuwächst. Wir sehen dies bei Taf. XXVII, Fig. $2 d$. Das Suturenbild, Taf. VII, Fig. $7 c$, ist daher für die Windungshöhe von $16 \mathrm{~mm}$ unrichtig und gilt nur für die Höhe von $8 \mathrm{~mm}$, da es von einem so kleinen Stücke stammt, deren Sutur es in doppelter Vergrösserung wiedergibt. Der Unterschied zwischen den Lobenzeichnungen Taf. VII, Fig. $7 c$, und Taf. XXVII, Fig. $2 d$, ist in die Augen springend. Extern- und Laterallobus wachsen bedeutend rascher in die Breite als Höhe an; auffallend hingegen ist das hohe Hinaufreichen des Auxiliarsattels, der bei der kleineren Form viel tiefer sitzt.

Bei der Tafel XXVII, Fig. 2, abgebildeten Grösse stehen die Suturen noch weit von einander $a b$, was dafür spricht, dass die Species bedeutendere Grösse erlangte (vgl. Taf. VII, Fig. $7 a$ ), bei welcher sich dann die Windung rasch erhöhte (Fig. 76 ).

In Folge dieser Darlegungen ist selbstverständlich auch die angegebene Verwandtschaft mit den knotenlosen Formen: Acrochordiceras pustericum und Acrochordiceras enode unrichtig. 


\section{Familie: Ptychitidae Waag. \\ Unterfamilie: Proptychitinae Wags. \\ Gattung: Sturia Mojs.}

\section{Sturia Sansovinii Mojs.}

I882. Sturia Sansovinii Mojs. Mojsisovics E. v, Cephalop. Medit. 'Triaspr. (pag. 241, Taf. XiLIX, Iig. 5, 6, 7, Taf. L, Fig. 2). Abhandl. d. k. k., geol. R.A., Bd. X.

I887. Sturia Sansovinii Mojs. Fonecr Fr. v., Cephalopoden des bosn. Muschelkalkes von Han Bulog bei Sarajevo (pag. 46). Denkschr. d. k. Akad. d. Wiss. math.-nat, Cl., Bd. LIV.

ISg2. Sturia Sansovinii Mojs. Ilautr Fr. v., Beiträge zur Kenntniss der Cephalopoden aus dem 'I'rias von Bosnien. I. Neue Funde von Han Bulog bei Sarajevo (pag. 283 [35], Taf. X, Fig. 7). Denlischr, d. k. Akad. d. Wiss. math,-nat. Cl., Bd. IIX.

1895. Sturia Sansovinii Mojs. Diener C, Cephalopoda of the Muschelkalk (pag. 6r, Taf. XV). Palacont. Indica, Ser. XV, Himálayan Fossils, Vol. II, Trias Part. 2, Mém. of the geolog. Survo of India, Calcutta.

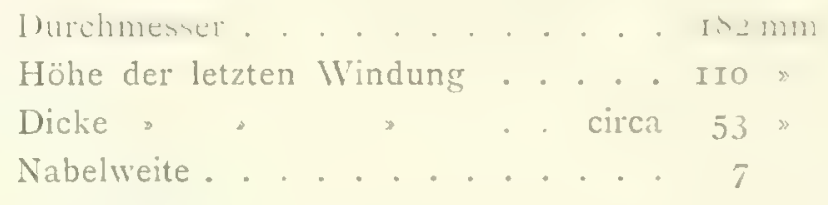

Dieses Stück gehört zu der von E。 Mojsisovics angeführten (loc. cit.) dickeren Varietät. Die grösste Dicke wird in einer von aussen sanft anwachsenden Wölbung ungefähr in der Flankenmitte erlangt, von deren Scheitel sie rasch zum Nabelrand absinkt; der Nabel ist klein und scheint sich bei so grossen Individuen rasch zu verengen, daher ist die Involution ausserordentlich gross und bedeckt die vorhergehende Windung fast vollständig.

Die Flanken sind mit der charakteristischen Spiralstreifung versehen, welche nahe dem Nabelrande aus dicken, kräftigen Spiralrippen gebildet wird, die in der Distanz von $2 \mathrm{~mm}$ aufeinander folgen und eine feine gekörnelte Linie im Zwischenraum aufweisen. Jenseits der grössten Dicke der Windung treten die Spiralstreifen rasch näher aneinander heran und schwächen sich ab; in drei Viertel der Windungshöhe ist die Schale schon fast glatt geworden und zeigt statt der Spiralrippen nur mehr feine Spirallinien; knapp unter dem Marginaltheile schwellen jedoch diese Linien wieder zu Rippen an, welche jedoch auch auf dem Scheitel des Externtheils etwas enger gestaltet sind, als in der Umbilicalregion.

Quer über diese Spiralsculptur verlaufen feine Streifen, die nur deutlich im glatten Schalenband oberhalb der Flankenmitte auftreten, daselbst eine flache Bucht nach rückwärts bilden, in weiten Abständen aufeinander folgen und wahrscheinlich stehen gebliebene Mundränder sind.

Die Lobenlinie ist nicht erhalten.

Stücke von der Grösse des vorliegenden scheinen in unserem alpinen Muschelkalke sehr selten zu sein, denn wir finden nur zwei freilich noch grössere Stücke von Fr. \%. Haucr von Han Bulog 1887 (loc. cit.) erwïhnt, von denen das Eine $245 \mathrm{~mm}$, das Andere $205 \mathrm{~mm}$ misst. Das grösste Exemplar ist wohl das von Dicner (loc. cit.) angeführte und abgebildete Exemplar rom Shalshal Cliff, welches einen Durchmesser von $247 \mathrm{~mm}$ aufweist und keine Wohnkammer erhalten hat. Da ich so glücklich bin, dieses indische Exemplar selbst zum Vergleiche zu haben, sei es mir gestattet, einige Worte darüber zu sagen. Wenn ich auch vollständig Diencr's Anschauung bin, dass die Bezeichnung des Stückes als Sturia Sansovinii die Richtige ist, so kann ich doch nicht umhin, auf eine kleine Verschiedenheit aufmerlisam zu machen, welche die indische von der europäischen Form trennt. Letztere zeigt deutlich 
das glatte spirale Schalenband oberhalb der Flankenmitte, dessen Zeichnung nur durch feine Spirallinien hervorgerufen wird, während bei der indischen Form die dicken, kräftigen Spiralrippen vom Nabel gegen den Externtheil zu allmälig enger zusammenrücken und kein derartiges glattes Feld zeigen. Da alle sonstigen Merkmale beider Formen übereinstimmen, ist die Richtigkeit der Bestimmung erwiesen. Sollten aber weitere indische Funde - gegenwärtig liegt nur ein Exemplar vor - dieselbe Differenzirung zeigen, dann wäre die Abtrennung einer Varietät vielleicht nothwendig.

Sturia Sansovinii wurde bisher als leitend für den oberen Muschelkalk (Zone des Ceratites trino. dosus) angesehen, nun ist deren Existenz auch im unteren MIuschelkalke (Zone des Ceratites binodosus) erwiesen, was freilich die Bedeutung dieser Species für ein bestimmtes Niveau ređucirt. Andererseits ist die weite horizontale Verbreitung von grösster Wichtigkeit. In Indien wurde diese Sturia in Schichten der Zone der Ptychiten rugifer (= Zone des Ceratites trinodosus) gefunden und sie bildet mit nur noch zwei anderen Formen, dem Proarcestes Balfouri Oppel (Proarcestes Escheri Mojs.) und Orthoceras cfr. campanile Mojs. gegenwärtig die einzigen Arten, welche den europäischen Muschelkalk mit dem indischen verbinden. $\left.{ }^{1}\right)$ Uns ist die Gattung Sturia somit heutigen Tages vom unteren Muschelkalk bis hoch hinauf in die Trias bekannt, und der jüngste Vertreter hat, wie Herr v. Mojsisovics so freundlich war mir mitzutheilen, juvavisches²) Alter, und auch dieses Stück hat, dem äusseren Eindrucke nach zu schliessen, grosse Aehnlichkeit mit der Sturia Sansovinii.

Das eine aus dem Reiflinger Kalk vorliegende Stück wurde von Professor Toua gelegentlich einer Excursion in das Reiflinger Gebiet knapp neben der alten Fundstätte sTiefengraben gefunden. Ich spreche Herrn Professor Toula, der mir in freundlichster Weise seinen interessanten Fund überliess, hier meinen besten Dank aus.

Das Exemplar befindet sich in der Sammlung der k. k. technischen Hochschule in Wien.

\section{Gattung: Ptychites Mojs. \\ Formengruppe der Ptychites opulenti Mojs.}

\section{Ptychites opulentus Mojs.}

1869. Arcestes cfr. Everesti Oppel. Moysisovics E. v', Beiträge zur Kenntniss der Cephalopodenfauna des alpinen Muschelkalkes. Jahrb. d. k. k. geol. li.-A., pag. 575 .

1882. Ptychites opulentus Mojs. Mo;sisovics E. v., Cephalop. Medit. Triaspr., pag. 259, Taf. LXXIII, Fig. I-4.

1892. Piychites opulentus Mojs. Ilawer Fr. \%, Cephalop. a. d. Trias v. Bosnien. Denkschr, d. k. Akad. d. Wiss. math.-nat. Classe, Bd. LIX, pag. 40.

r895. Ptychites opulentus Mojs. Arhaber, Cephalopodenfauna der Keiflinger Kalke. I. Theil. Beiträge zur Pal, u. Geol. Oesterr.Ung., Bd. X, pag. 100, Taf. VIII, Fig. 9.

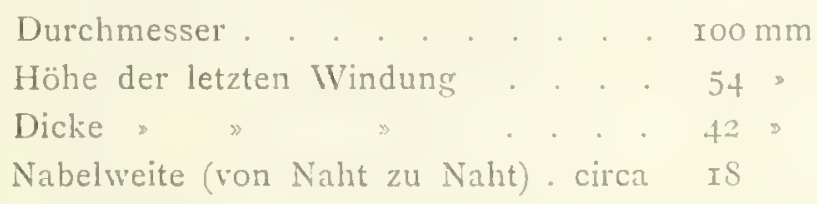

Es liegt ein grosses Bruchstück vor, dessen Zugehörigkeit zu der oben bezeichneten Species nicht ganz ausser 'Wweifel steht, da der Erhaltungszustand kein besonders günstiger ist.

Wir finden den gewölbten Externtheil und die dick aufgeblähten lilanken dieser Species wieder; der Umbilicalrand ist kurz gerundet, die Nabclwand hoch und steil abfallend; der Nabel jedoch ist

1) Vgl. diesbezüglich: Dicner, loc. cit. pag. 90; ferner Dicnes: Erçebnisse einer scolog. Exped. i. d. Central. Himálaya etc. Denkschriften d. k. Akad. Wiss. math.-nat. Classe, 13d. LXII, pag. 568 [36], IS95, und Mojsisovics, Miagren, Diener: Entwurf einer Gliederung der pelag. Sedimente des 'lrias-Systems. Sitzungsber, d, k, Akad. d. Wiss. math. nat. Cl., Bd. CIV, Abth. I, pag. I293 [23]. I895.

$\Rightarrow$ Juvarisch ist hier im Sinne der Eintheilung E. "2. Ifojsiserics" zu verstehen, also gleich s norischs (Billnir). 
bedeutend grösser, was als erstes trennendes Moment anzusehen, während das zweite die etwas abweichende Art der Flankensculptur ist. Die Form von der Schreyer Alm hat fast radial verlaufende, kräftige Rippen, welche gegen Nabel und Externtheil zu rasch verlöschen, während der Verlauf derselben bei dem Reiflinger Stück ein leicht bogenförmiger, nach vorne convexer ist.

Die Suturlinie ist nicht erhalten.

Ptychites opulentus lag vorläufig nur in Jugendformen (vide pag. 100) vor, nun besitzen wir auch ein völlig erwachsenes Exemplar, welches eine Ergänzung der Tiefengrabener Fauna bildet. Das Stück wurde wie die oben beschriebene Sturia Sansovinii von Professor Toula knapp neben dem alten Fundort Tiefengraben gefunden.

Das Exemplar befindet sich in der Sammlung der $k$. $k$. technischen Hochschule in Wien.

Ptychites cfr. opulentus Mojs.

Taf. XXVII (XV), loig. 3 .

Durchmesser.. I $27 \mathrm{~mm}$
Höhe der letzten Windung . circa $64=$
Dicke
Nabelweite (von Naht zu Naht). . $56 \Rightarrow$
I7

Es liegt nur ein grosses, theilweise mit Schale bedecktes Bruchstück vor. Es gehört einem Exemplare an, welches das grösste der bis jetzt beschriebenen wäre. Gewisse Unterschiede begründeten die nicht ganz sichere Bestimmung als Ptychites opulentus.

Obgleich die Maasszahlen bezüglich des Verhältnisses von Breite, Höhe und Nabelweite bis zu dem grössten belsannten Durchmesser (Cephalop. Medit. 'Triaspr., pag. 259) von $105 \mathrm{~mm}$ übereinstimmen, scheint die vorliegende Form von diesem Altersstadium an bis zu dem oben angegebenen Durchmesser sich doch plötzlich und auffallend zu erhöhen; damit geht ein langsameres Anwachsen in der Nabelregion und eine stärkere Ausschnürung des Nabels vor sich. Die für Ptychites opulentus charakteristischen, ziemlich. enggestellten Radialfurchen, welche auf Steinkernen hervortreten und leichte Faltung auf Schalenexemplaren verursachen, treten hier ebenfalls auf, jedoch sind sie spärlicher gestellt, flacher, breiter und nach vorne leicht convex gebogen.

Bedeutendere Unterschiede zeigt die Suturlinie, welche hier einen ziemlich breit angelegten, mit kräitigen und gespreizt gestellten und mit zwei seitlichen Zacken versehenen Externlobus besitzt, der einen niederen Medianhöcker zeigt. Der Externsattel ist viel niederer und bedeutend kleiner als der erste Laterale. Von den drei Lateralloben ist der erste der grösste, zeigt an der Basis Gabelstellung der zwei Zacken, bei stärkerer Entwvicklung des extern gestellten. Die Loben haben sonst symmetrische reiche Zerschlitzung, wobei aber stets die äussere Seite etwas kräftiger entwickelt ist. Bis zur Naht folgen noch drei Auxiliare. (Die Zeichnung gibt die Entfernung bis zur Naht um $2 \mathrm{~mm}$ zu gross an.) Von den Sätteln ist der erste Laterale der grösste und höchste; er ist in der Mitte durch einen srösseren Zacken getheilt, welcher sich beim zweiten Lateralen reducirt, wodurch sich die zwei nächstfolgenden Seitlichen kräftiger entwickeln können. Sowohl beim dritten Lateralen als wie bei den drei Auxiliarsätteln finden wir aber den grösseren Medianzacken wieder. Mit der Naht schliesst der dritte Auxiliarsattel ab.

Die Unterschiede, welche Ptychites opulentus und Ptychites cfr. opulentus in den Suturen zeigen, liegen daher: in dem dort schmalen, hier breiteren Externlobus und in den dort paarig geschlitzten Sütteln, welche hier unpaarig getheilt sind, während Extern- und zweiter Lateralsattel allein fast paarig zerschlitzt sind. 


\title{
Familie: Mleekoceratidae Waag. Unterfamilie: Kymatitinae Waag. \\ Gattung: Proavites Arth.
}

\author{
Proavites avitus Arth. \\ Taf. XXVI (XIV), Fig. I2 $a-c$.
}

1895. Proavites avitus Arth. Arthaber, Cephalopodenfauna der Reiflinger Kalke. Abth. I, pag. I05, Taf, X, Fig. 3; Beiträge zur Pal. u. Geol. Oesterr.-Ung, Bd. X. Wien.

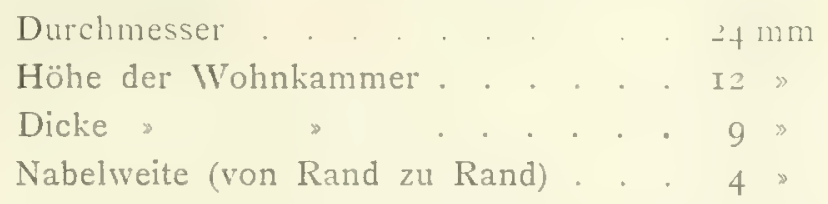

Es liegt ein jüngeres Exemplar als jenes vor, welches vom Fundorte Tiefengraben beschrieben wurde; da aber bei diesem kleineren Stücke die Suturlinien in ähnlich weiten Abständen aufeinander folgen wie bei dem zuerst beschriebenen, welches einen Durchmesser von $34 \mathrm{~mm}$ aufwies, so ergibt sich daraus, dass die erwachsene Form eine bedeutende Grösse erlangt haben muss.

Der auf pag. I05 gegebenen Beschreibung ist nur ein neues Merkmal hinzuzufügen; wir sehen nämlich, dass bei kleineren Durchmessern die Höhe der Windung nicht im gleichen Verhältniss zur Breite anwächst. Bei einem Durchmesser von $4 \mathrm{~mm}$ ist die Windung fast globos und der scharfkantige Externtheil fehlt auffallender Weise; trotzdem überwiegt aber noch die Höhe über die Breite, so dass wir, wie bei Beyrichites, den systematischen Schluss daraus über die Abstammung ziehen können, dass Proavites zu den Meekoceraten gehört.

Die Suturlinie zeigt ähnlichen Verlauf, wie die in Taf. X, Fig. 3, abgebildete. Kleine Unterschiede treten hier wohl auf, z. B. dass der Externsattel etwas schmäler erscheint und dem entsprechend der erste Lateral etwas breiter entwickelt ist. Da die Form überhaupt kleiner ist, tritt noch kein Auxiliarlobus auf die Flanke, sondern beginnt sich erst auf der Nabelkante zu individualisiren.

Von einigem Interesse ist die Suturlinie der Jugendwindung ron $4 \mathrm{~mm}$ Durchmesser, welche in Fig. I2 $b$ bei doppelter Vergrösserung zur Abbildung gebracht ist und einen kleinen Extern- sowie relativ grossen Laterallobus zeigt; der etwas höhere Lateralsattel wird theilweise ron dem Nabelrand zerschnitten.

Das Stück wurde bei einer gemeinsamen Begehung der Reiflinger Fundorte an dem auf pag. 5 an dritter Stelle genannten Fundorte von Dr. A. Bittner gefunden, befindet sich in der Sammlung der k. k. geologischen Reichsanstalt, und wurde irrthümlicherweise von mir in Verhandl. d. k. k. geol. R.-A. r895, Nr. 3, pag. I2r, als vom Fundorte Rahnbauerkogel stammend angeführt, was hiemit berichtigt sei. 


\section{Verzeichniss}

der Fauna der unteren Reiflinger Kalke.

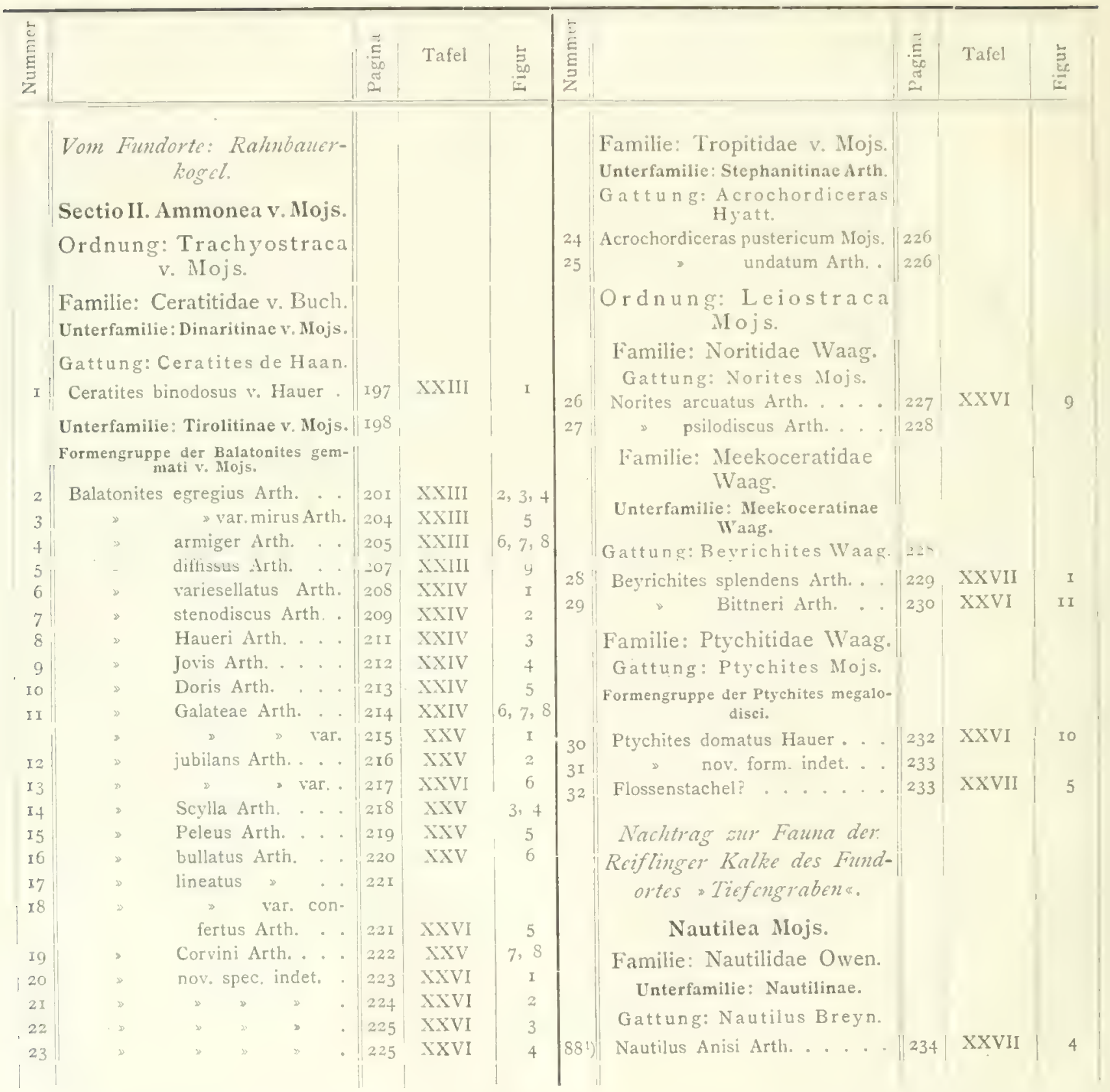

1) Die Zahlen bedeuten die laiffenden Nummern als Fortsetzung des Cephalopodenverzeichnisses auf pag. I 8 u. ff. Hiebei entfällt Nr. 30 Ceratites sondershusanus aus dem deutschen Muschelkalk und kommen von pag. 22 hinzu: Nautilus quadrangulus mit Nr. 85, Pleuronautilus distinctus mit Nr. 86 und Ptychites Studeri sp.? als Nr. 87. 


\begin{tabular}{|c|c|c|c|c|c|c|c|c|c|}
\hline 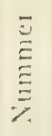 & & 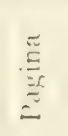 & lafel & 咅 & 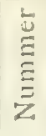 & & $\underset{z}{\approx}$ & Tafel & $\underset{\Xi}{\vdots}$ \\
\hline & $\begin{array}{c}\text { Ammonea Mojs. } \\
\text { Familie: Tropitidae Mojs. } \\
\text { Unterfamilie: Stephanitinae Arth. } \\
\text { Gattu n g: Acrochordiceras } \\
\text { Hyatt. }\end{array}$ & & & & 90 & $\begin{array}{l}\text { Gattung: Ptychites Mojs. } \\
\text { Formengruppe der Ptychites opulenti } \\
\text { Mojs. } \\
\text { Ptychites opulentus Mojs. } \\
\text { cfr. opulentus Mojs. }\end{array}$ & $\begin{array}{l}237 \\
23 \mathrm{~S}\end{array}$ & XXVII & 3 \\
\hline 89 & $\begin{array}{l}\text { Acrochordiceras undatum Arth. } \\
\text { Familie: Ptychitidae Waag. } \\
\text { Interfamilie Proptychitinae } \\
\text { Waag. } \\
\text { Gattung: Sturia Mojs. } \\
\text { Sturia Sansovinii Mojs. . . . }\end{array}$ & 235 & XXVII & 2 & & $\begin{array}{l}\text { Familie: Meekoceratidae } \\
\text { IVaag. } \\
\text { Cnterfamilie: Kymatitinae Waag. } \\
\text { Gattung: Proavites Arth. } \\
\text { Proavites avitus Arth. . . . . }\end{array}$ & 239 & XXVI & I2 \\
\hline
\end{tabular}

\section{Inhaltsverzeichniss.}

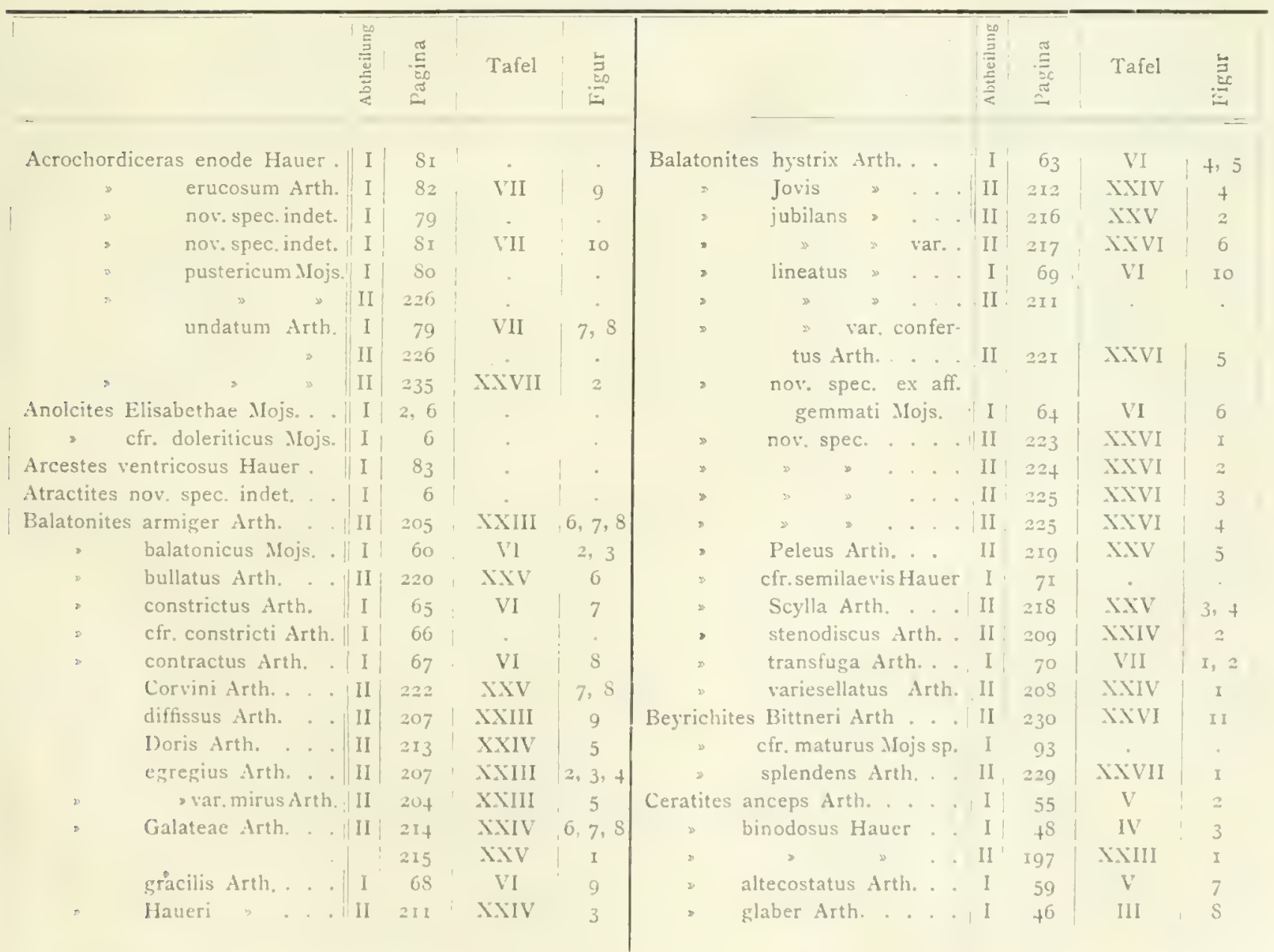




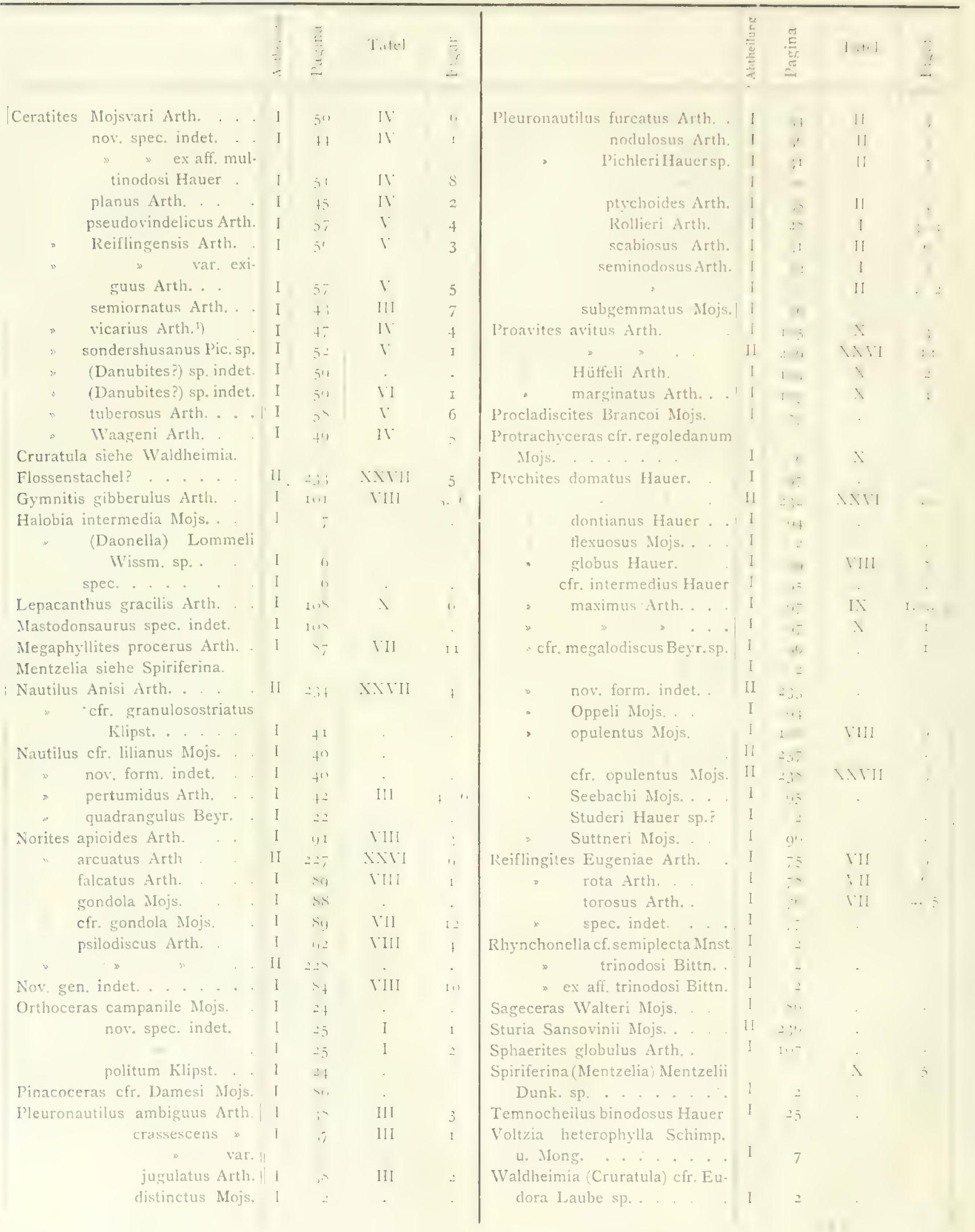

i) Im I. Theile als Ceratites simplex beschrieben, siehe Berichtigung auf Seite Igo. 
TAFEL XXIII (XI).

Ceratites, Balutonites. 


\section{TAFEL XXIII (XI).}

Fi. 1. Ceratites binodosus Hauer, pas. 197.

Vollständiges, aber theilweise flachgedrüicktes Schalenexemplar.

Fi.. $2 a-c$. Balatonites egregius Arth., pag. 20 r.

Vollständiges Schalenexemplar.

Fiı. $3 a-c$ Balatonites egregius Arth. var. a, pag. 203.

Vollständiges Exemplar, grösstentheils mit erhaltener Schale.

liif + Balatonites egregius Arth. var. 6, pag. 204

Lobenzeichnung eines grossen, dritten Exemplares.

liz. $5 a-c$. Balatonites egregius Arth. var. mirus, pag. 204.

Vollständiges, als Steinkern erhaltenes Exemplar.

Fin $6 a-c$. Balatonites armiger Arth., pag. 205.

Als Steinkern erhaltenes Exemplar.

Fie. 7. Balatonites armiger Arth., pag. 206.

Suturlinie eines zweiten Stückes.

$\mathrm{Fin}$ 8. Balatonites armiger Arth., pag. 206.

Suturlinie eines dritten Stückes.

Iii 9. Balatonites diffissus Arth., pag. 207

Als Steinkern erhaltenes Exemplar. 

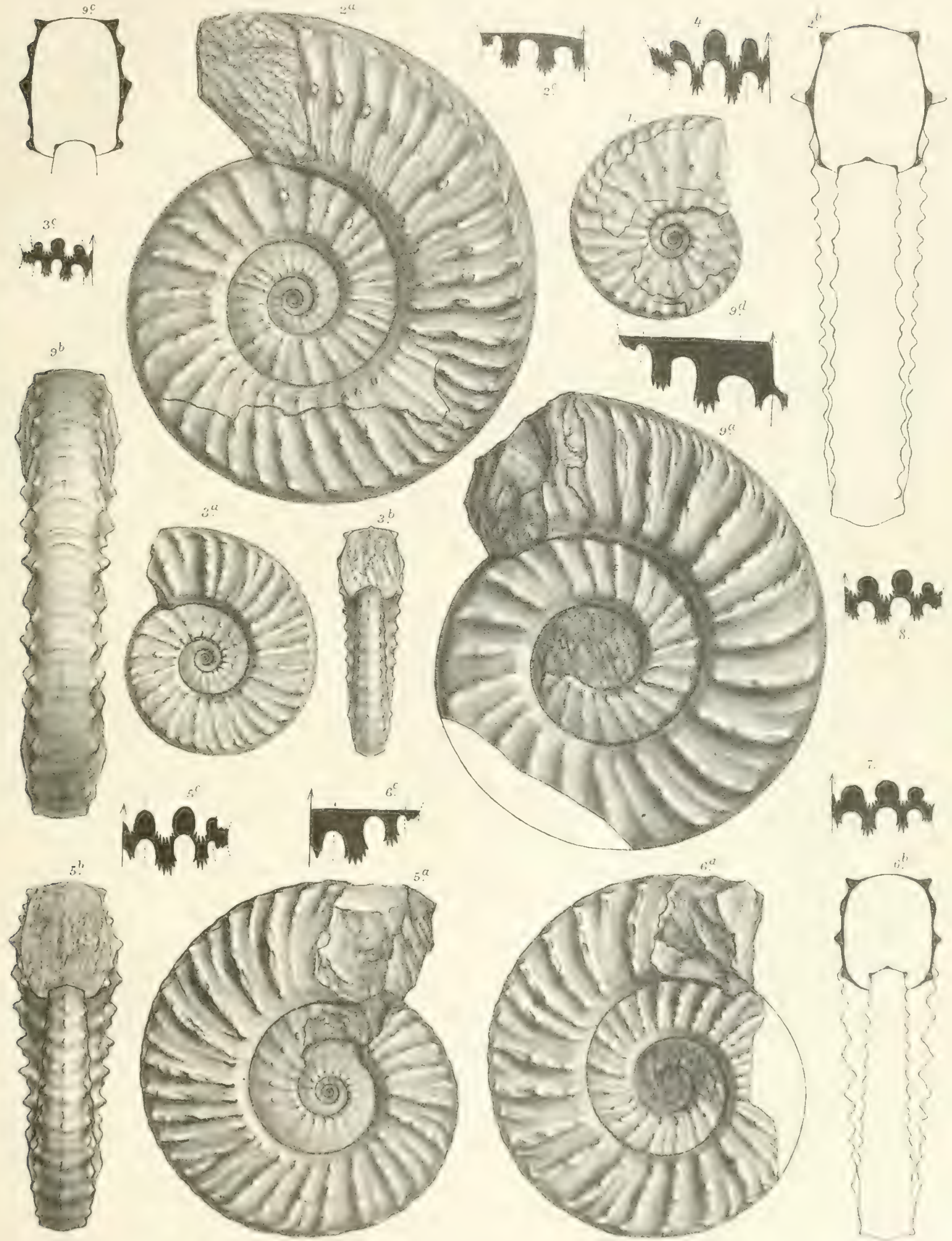

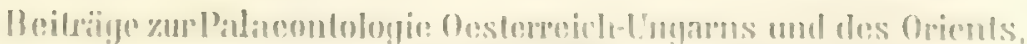

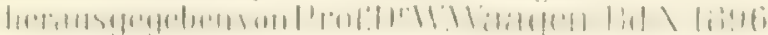



TAFEL XXIV XII.

Balatonites. 


\section{TAFEL XXIV (XII).}

Fis. I. . Balatonites variesellatus Arth., pag. 20 S,

Vollständiges Exemplar mit theilweise erhaltener Schalenbedeckung; die Lobenzeichnung trägt fälschlich statt I $t$ die Nummer I

Iis. : : Balatonites stenodiscus Artho, pag. 209

Vollständiges Exemplar, Steinkern.

Fik ; : Balatonites Haueri Arth., pag. 2 II.

Vollständiges Exemplar, grösstentheils mit erhaltener Schale.

Iif $4:$. Balatonites Jovis Arth., pag. $2 I_{2}$

Als Steinkern erhaltenes, fast vollständiges Exemplar.

Fin, 5.. Balatonices Doris Arth., pag. 213.

Vollständiges Exemplar; die inneren IVindungen besitzen noch Schalenbedeckung, sonst als Steinkern erhalten.

lie: of - Balatonites Galateae Arth., pag. 2 If.

Als Steinkern erhaltenes Exemplar.

Fis : : Balatonites Galateae Arth., pag. 215.

Als Steinkern erhaltenes Exemplar.

Iit: Balatonites Galateae Arth., pag. 2I5.

Suturlinie eines dritten Exemplares; vergl. die Varietät auf Taf. XXV (XIII), Fig. I $a-i$. 

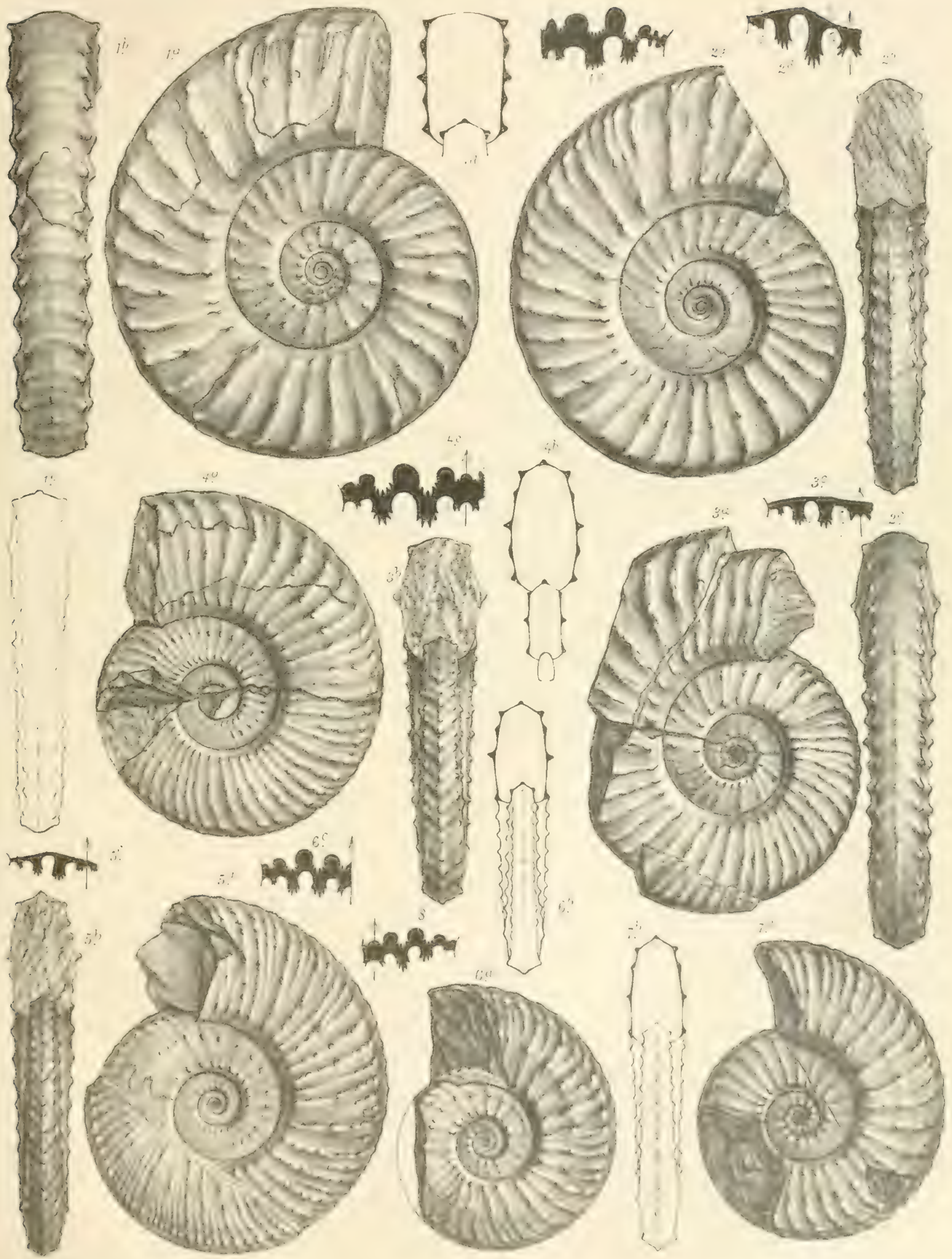

TAFEL XXV (YIII).

Balatonites. 


\section{TAFEL XXV (XIII).}

Fi: I. Balatonites Galateac Arth, var., pas. 216.

Grosses, theilweise mit Schale bedecktes Bruchstïck mit pathologisch verschobener Suturlinie.

[1 $1 \%$ : -.. Balatonites jubilans Arth., pag. 216 .

Vollständiges Exemplar mit geringen Schalenresten; vgl, die Varietät auf Taf. XXVI (XIV). Fig. $6 a-a$,

Iif. ; - . B Balatonites Scylla Arth., pag. 2 I8.

Als Steinkern erhaltenes Bruchstiick.

Iii: + Balatonites Scylla Arth., pag. zIS.

Bruchstïck mit Schalenbedecliung.

I... $5 \quad$. Balatonites Peleus Arth., pag. 2Ig.

Fast vollständiges Exemplar mit erhaltener Schale.

Iil. B... Balatonites bullatus Arth., pag. 220.

Vollständiges Exemplar mit erhaltener Schale. $\sigma c$ vollständige Suturlinie eines zweiten Exemplares.

Pi: ; - - . Balatonites Corvini Arth., pag. 222.

Grosses Bruchstïck mit geringer Schalenbedeckung. 7 i Skizze der zwei letzten Umgänge.

1.1: :- Balatonites Corvini Arth., pag. 222.

Abschnitt eines grossen Bruchstüclies mit theilweiser Schalenbedeckung. Der letzte Umgang ist künstlich losgelöst, um das Verschwinden der Externdormen zu zeigen. 86 Vorderansicht der vorletzten Windung: $S c$ perspectivisch gezeichnete Skizze, die Vorderansicht der letzten Vindung gebend; $8 d$ die Suturlinie ist von der letzten Windung abgenommen. 

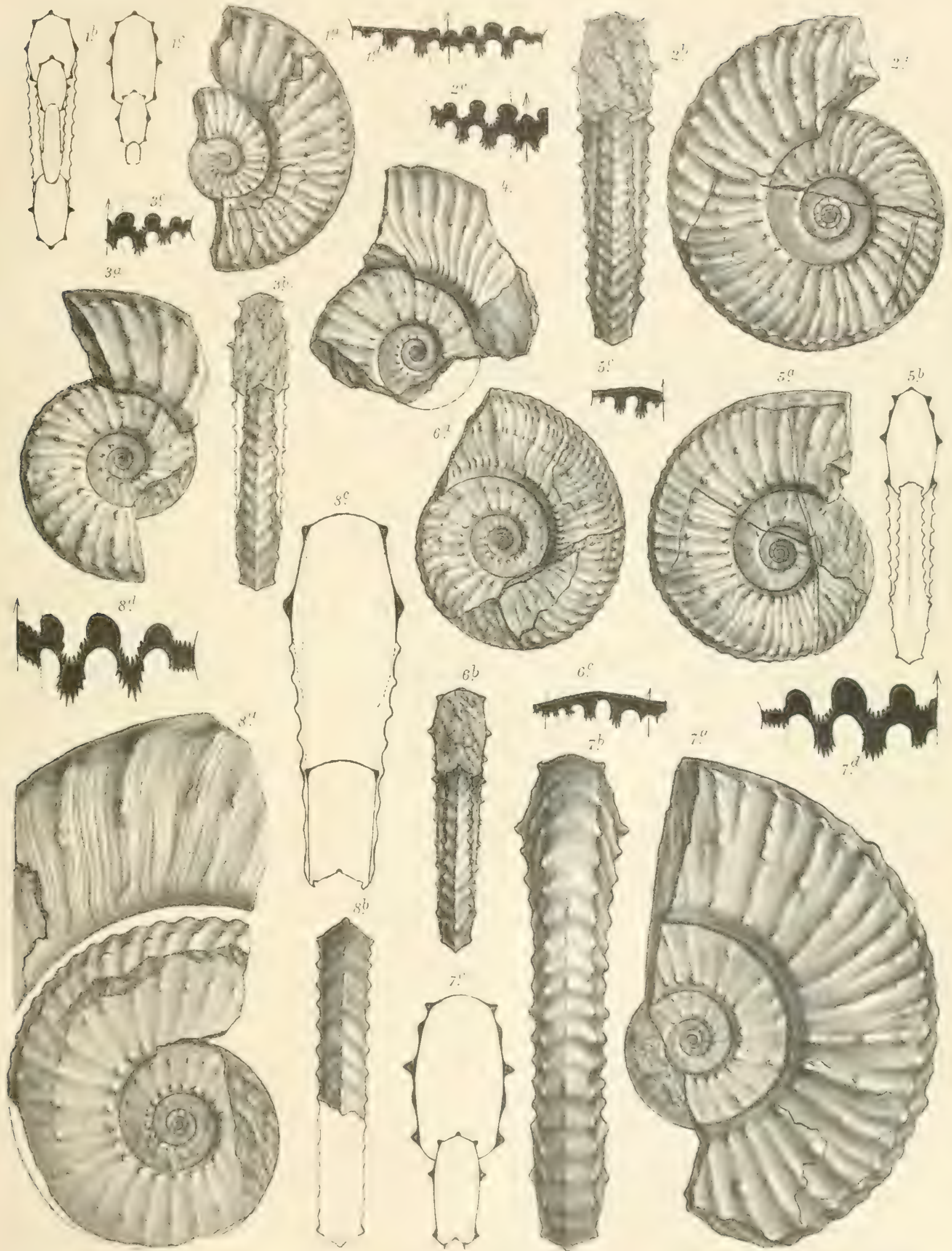

A.Swobedandilat gez.y.lith 

TAFEL XXVI (XIV).

Bulutonites, Norites, Beyrichites, Prouvites, Ptychites. 


\section{TAFEL XXVI XIV.}

Fig. In-c. Balatonites nov. spec. indet, pag. 223

Grosses Bruchstück mit theilweiser Schalenbedeckung. I c Skizze des Querschnittes der letzten Windung mit den gebrochenen Lateraldornen.

IFig. $2 a-c$. Balatonites nov. spec. indet., pag. 22 .

Bruchstück als Steinkern erhalten mit geringen Schalenresten.

lis. 3. Balatonites nov. spec. indet, pas. 225.

Steinkernbruchstück.

Fiv. $4 a, b$. Balatonites nov. spec. indet., pag. 225

4 $a$ Vorderansicht eines Steinkernbruchstückes

Fli. $5 n-\epsilon$. Balatonites lineatus var. confertus Arth., pag. 221.

Vollständiges Exemplar, als Steinkern erhalten; vgl. Balatonites lineatus Arth., pag. 69, Taf. VI, Fig. I0.

Fig. $6 a-d$. Balatonites jubilans Arth. var., pag. 217.

Voliständiges Exemplar mit theilweise erhaltener Schale; vgl. Taf. XXV, Fig. 2.

Fise. $7 a-d$. Balatonites spec., pag. I98.

Bruchstück mit grösstentheils erhaltener Schale. Jugendform.

IFis. 8. Balatonites spec., pag. I9S.

Vollständiges Schalenexemplar in fünffacher Vergrösserung, die innersten Windungen zeigend.

F.s. 9. Norites arcuatus Arth., pag. 227.

Grosses Bruchstück mit theilweise erhaltener Schale, $9 c$ reconstruirte Lobenzeichnung.

IF 10 - $a, b$. Ptychites domatus Hauer, pag. 232.

Grosses Bruchstück mit erhaltener Schale

I'ly. II $a-c$. Beyrichites Bittneri Arth., pag. 230.

Fast vollständiges Exemplar, als Steinkern erhaiten und auf dem Externtheile theilweise verdrückt. Aus dem Besitze der $k$. $k$. geologischen Reichsanstalt in Wien.

I1. $12 a-c$. Proavites avitus Arth., pag. 239.

Querschnitt eines Steinkernexemplares. Iz $b$ die Suturlinie der innersten sichtbaren Windung in circa dreifacher Vergrösserung. Aus dem Besitze der $k$. $k$. geologischen Reichsanstalt in Wien; vom oberen Tiefengrabener Niveau aus dem Scheiblinggraben westlich von Gross-Reifling stammend. 
G.x.Arthaber: Cephalopodenfauna der Reiflinger Kalke (I'Taf. XIV.)
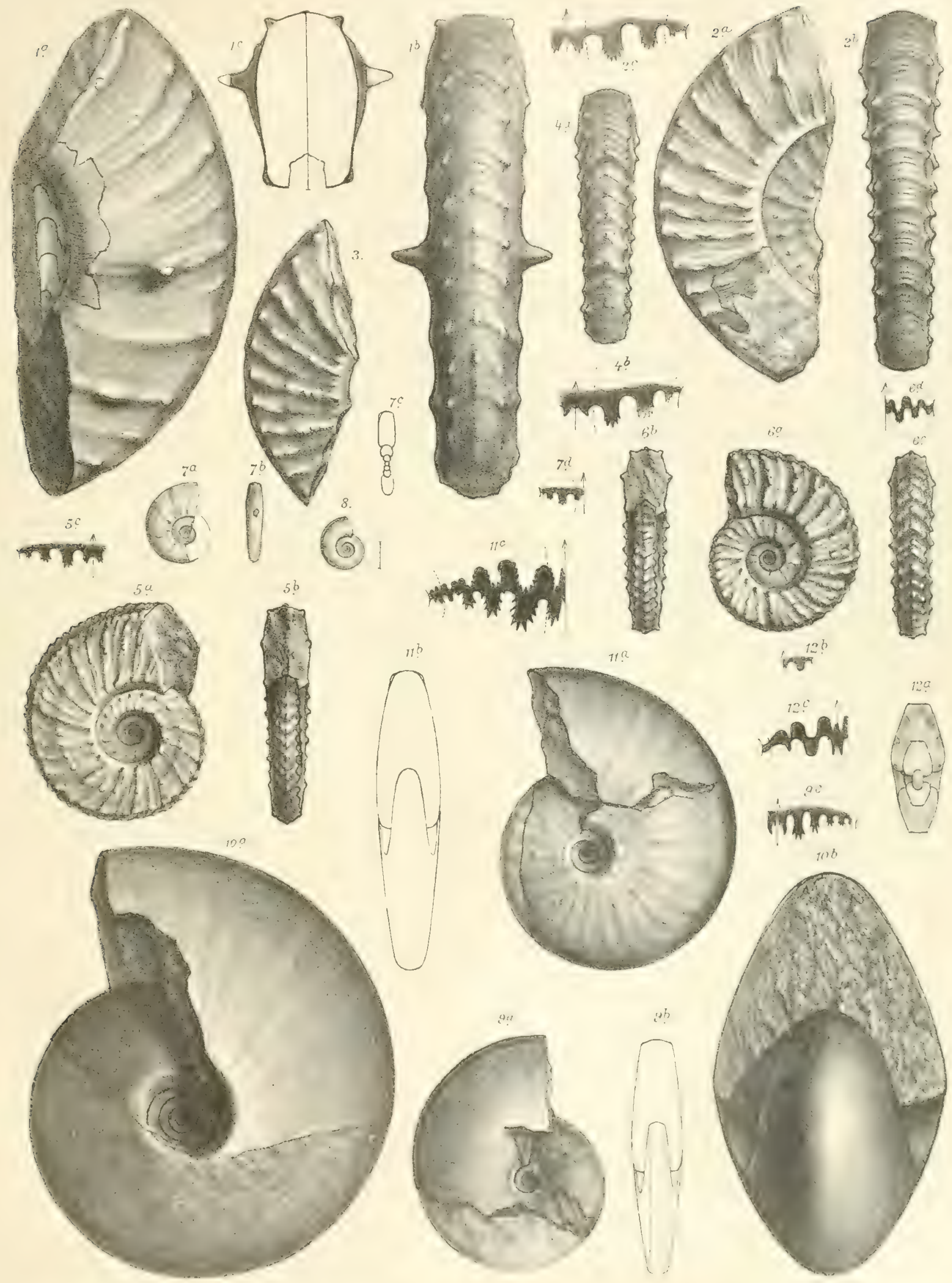

A. Swobodar.Nar.gez.w.7ith.

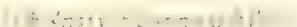

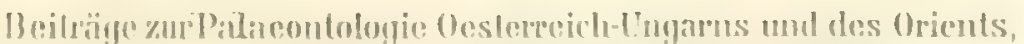

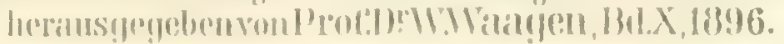



TAFEL XXVII (XV).

Beyrichites, Acrochordiceras, Ptychites, Nautilus, Flossenstachel? 


\section{TAFEL XXVII (XV).}

I'1 $; \quad 1 \ldots \quad \therefore$ Beyrichites splendens Arth., pag. 229.

Grosses, fast vollständig erhaltenes Exemplar mit theilweiser Schalenbedechung.

lie $2 a-d$. Acrochordiceras undatum Arth., pag. 235.

Vollständiges, im Steinkerne erhaltenes Exemplar vom Fundorte "Tiefengrabene stammend; vgl. pag. 79. Taf. VII, Fig. 7, S.

1:...3. Ptychites efr. opulentus Mojs., pag. 238.

Suturlinie eines grossen Bruchstückes vom Fundorte sTiefengraben

lis. + $a-a^{2}$. Nautilus Anisi Arth., pag. $23+$.

Vollständiges Exemplar, Steinkern mit theilweiser Schalenbedeckung, vom Fundorte oTiefengraben*.

I $\because$ 5. Flossenstachel pag. 233.

Kleines Bruchstuick. 


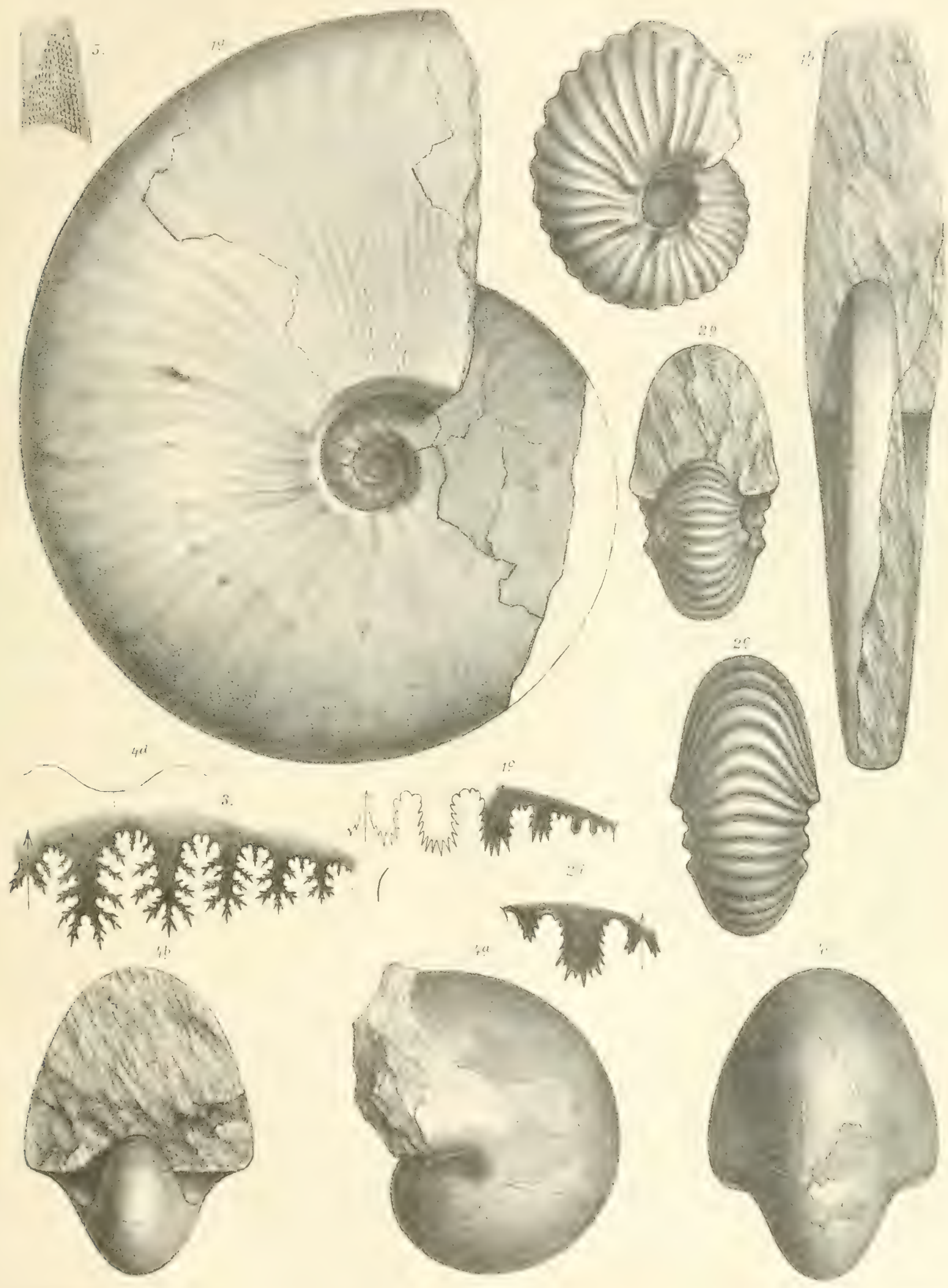

1.Swoboda nollilal gez u.lith.

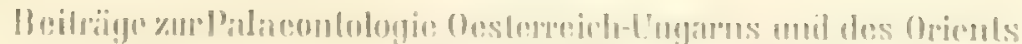

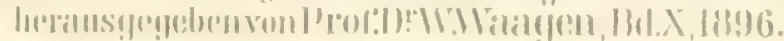





TAFEL V N.

Ceratites. 


\section{TAFFL $Y \quad 1$.}

Figr. I $a, b, c, d$. Ceratites sondershusanus Picard sp., par. 52 .

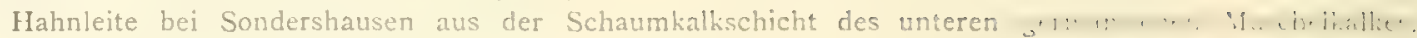
Nach einem Stearinabguss gezeichnet: is Querschnitt, am Ende des letzten ['?... at ; und theilweise ergänzt; areconstruirte Lobenlinie.

Figr. $2 a, b, c . \quad$ Ceratites anceps Art., pag. 55.

Als Steinkern erhaltenes Bruchstück; Q Querschnitt vom Ende des letzten U'mganges,

Fig. $3 a, b, c$ Ceratites Reiflingensis Art., pas. 56.

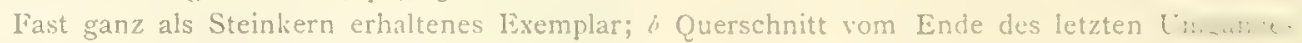

Fig. $5 a, b, c$ Ceratites Reiflingensis var, exiguus Art., pag. 57

Als Steinkern erhaltenes Frasment.

Fig. $4 a, b, c$. Ceratites pseudovindelicus Art., pag. 57.

Als Steinkern erhaltenes Fragment; 8 Querschnitt vom Ende des letzten U'mgang

Fig. $6 a, b, c, d, c$. Ceratites tuberosus Art., pag. 5 S.

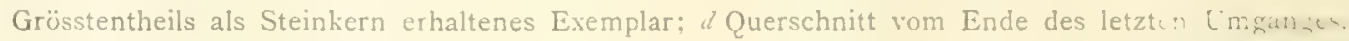

Fig. $7 a, b, c, d$. Ceratites altecostatus Art., pag. 59.

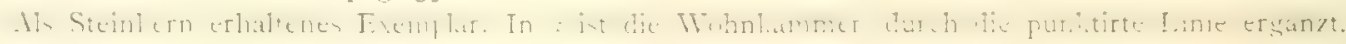



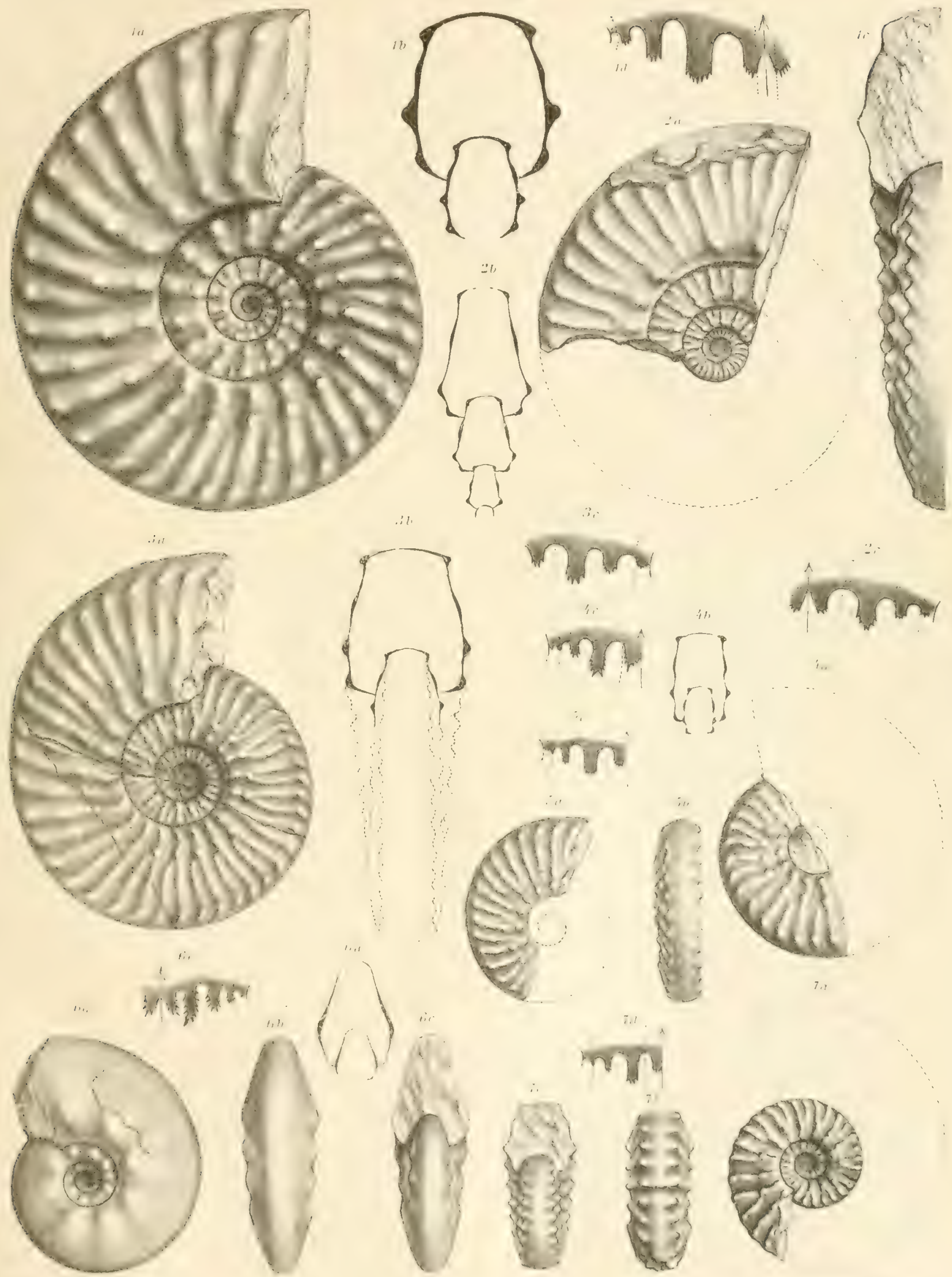

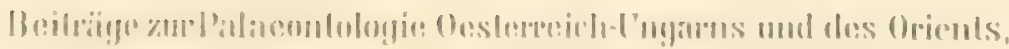

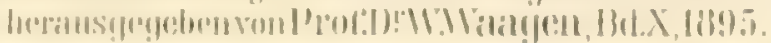



TAFEL VI (VI).

Ceratites, Bralatonites. 


\section{TAFEL VI (VI).}

Fis. I $a, b . \quad$ Ceratites (Danubites:) spec. indet., pag. 59.

Steinkern eines schlecht erhaltenen Wohnkammer-Bruchstückes.

Fis. $2 a, b, c, d$. Balatonites balatonicus Mojs., pas. 60 .

Steinkern eines fast vollständig erhaltenen Exemplares; bei dem in c gezeichneten Querschnitte ist auf der linken Seite der grosse Lateraldorn ergänzt.

Fis. $3 a, b, c . \quad$ Balatonites balatonicus Mojs., pag. 61 .

Bruchstück eines als Steinkern erhaltenen Wohnkammerexemplares.

Fin. 4a, b. Balatonites hystrix Art., pag. 63.

Bruclastück eines als Steinkern erhaltenen Exemplares.

Fis. 5.

Balatonites hystrix Art., pag. 63. Querschnitt, nach einem anderen Stüclie gezeichnet.

I. 6 . 6.6 .

Balatonites nov. spee, ex aff. gemmati Mojs., pas. 64.

Bruchstück eines als Steinkern erhaltenen Wohnkammerexemplares mit der letzten Kammerscheidewand.

Fis. $7 a, b, c$ Balatonites constrictus Art., pag. 65 .

Bruchstück eines als Steinkern erhaltenen Wohnkammerexemplares.

Fir $8 a . b, c . \quad$ Balatonites contractus Art., pag. 67.

Bruchstück eines als Steinkern erhaltenen Wohnkammerexemplares; in $b$ sind die Lateraldurnen theilweise ergänzt.

rici. $9 a, b, c, d$. Balatonites gracilis Art., pag. 68

Bruchstück eines theilweise noch mit Schale erhaltenen Exemplares.

I. ig. IO $a, b, c$. Balatonites lineatus Art., pag. 69 .

Vollständig erhaltenes Schalenexemplar 


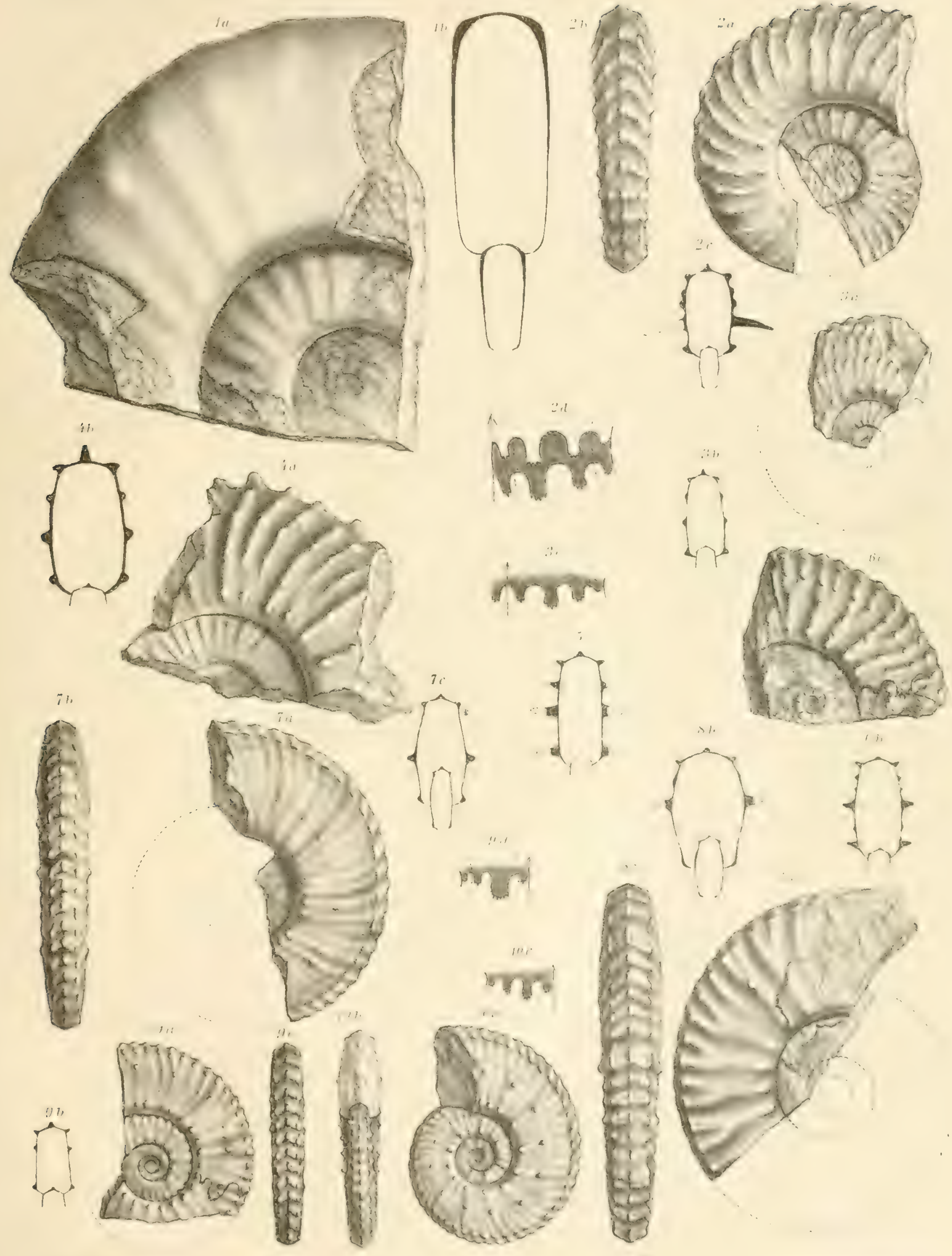

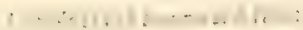

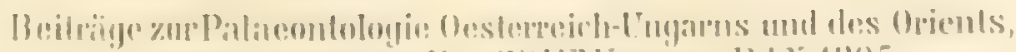

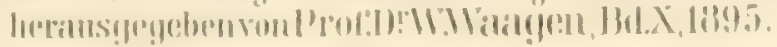



TAFEL VII, YII.

Balatonites, Roiflingites, Acrochordiceras, Mregaphyllites, Torites. 


\section{TAFEL VII (VII).}

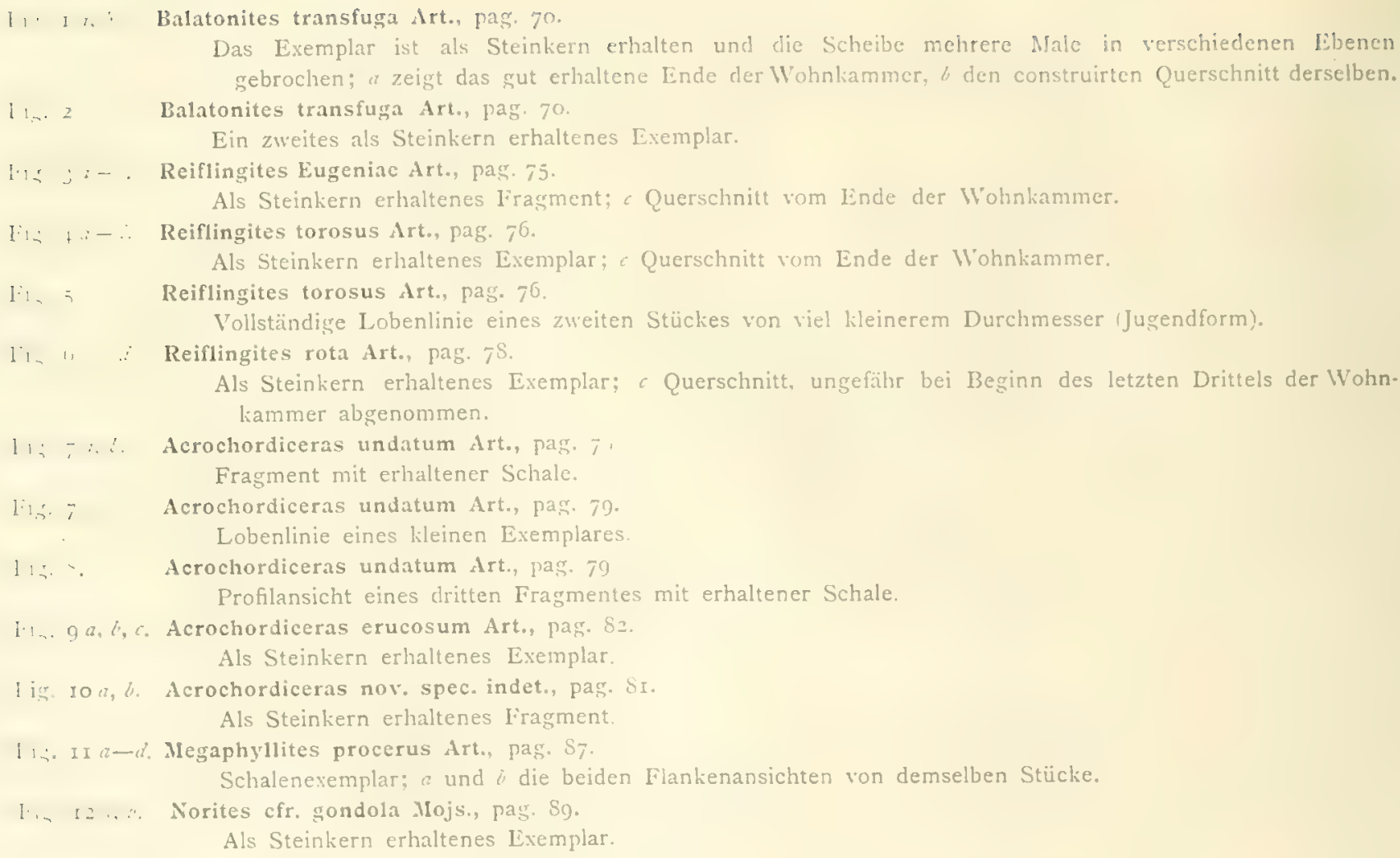



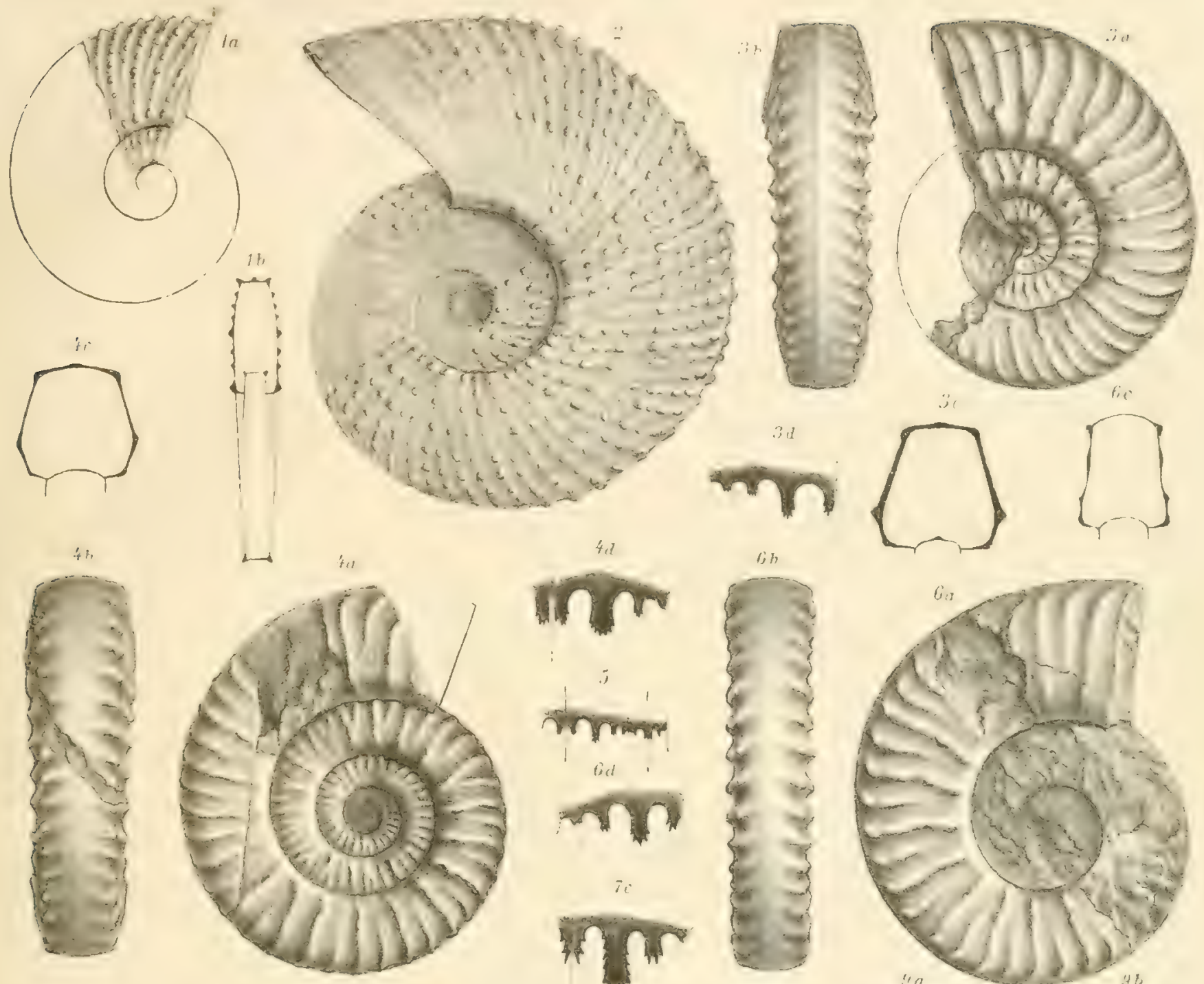

4,1
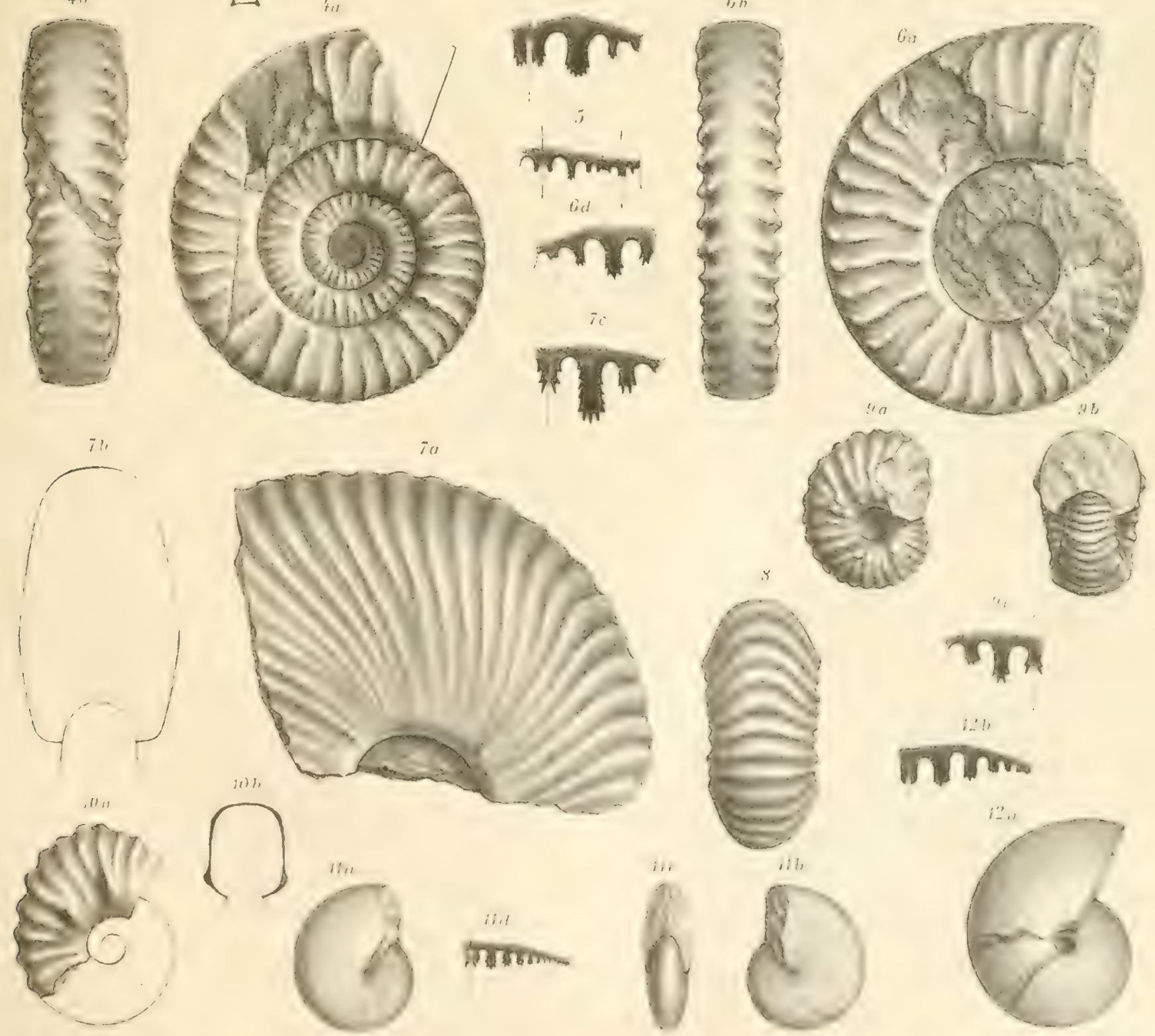

A.Swobodend.7\%ar.gez.u. Jith.

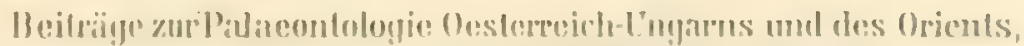

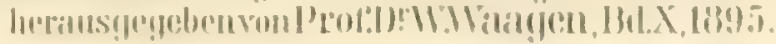



TAFEL VIII (VIII).

Norites, Gymnites, Ptychites, Nov. gen. indet. 
TAFEL VIII, VIII.

lis. Is: Norites falcatus Art., pag. 89 .

Exemplar mit theilweise erhaltener Schale.

Fis 2. Norites subcarinatus Hauer, pag. 90

Fundort: Han Bulog. Genau gezeichnete Suturlinie des Originalstückes Fr. v. Hauer's

Fis. $3 a, b, c$. Norites apioïdes Art., pag. 9I.

Als Steinkern erhaltenes Fragment; b Profilansicht, mit theilweise ergänzter letzter Windung.

$\mathrm{F}+\dot{f}+\mathrm{z}, \ldots$ Norites psilodiscus Art, pag 92.

Exemplar mit erhaltener Schale; brofilansicht theilweise ergänzt.

IFig. 5 a, b, c. Gymnites gibberulus Art., pag. IOI.

Grossentheils als Steinkern erhaltenes Fragment; Q Querschnitt vom Anfange der letzten IVindung; $c$ nur theilweise erhaltene Suturlinie desselben Stückes.

I:w, $6 a-d$. Gymnites gibberulus Art., pag. IoI.

Exemplar mit theilweise erhaltener Schale; b Querschnitt vom Ende der letzten Windung; $c$ Suturlinie vom Anfang, drom Ende der letzten Windung.

Iis 7 Gymnites incultus Beyrich sp.

Suturlinie des Originalstückes von Beyrich aus dem schwarzen Kalkstein von Reutte in Nordtirol, nach Mojsisoüs: Cephalopoden der mediterranen Triasprov. Abhandlg. k. k. geol. R.-A., Bd. X, Taf. 54, Fig. 2. (Diese Suturlinie war ursprünglich nicht zur Wiederabbildung bestimmt und wurde vom Zeichner nur irrthümlich wieder gezeichnet.)

Fig. 8 a.b.c. Ptychites globus Hauer, pag. 99 .

Exemplar mit theilweise erhaltener Schalenbedeckung.

Fig. $9 a, b, c$. Ptychites opulentus Mojs., pas. Ioo,

Exemplar mit theilweise erhaltener Schale.

Irig. Io $a, b$. Nor. genus indet., pag, $8_{4}$.

Exemplar mit erhaltener Schale. 

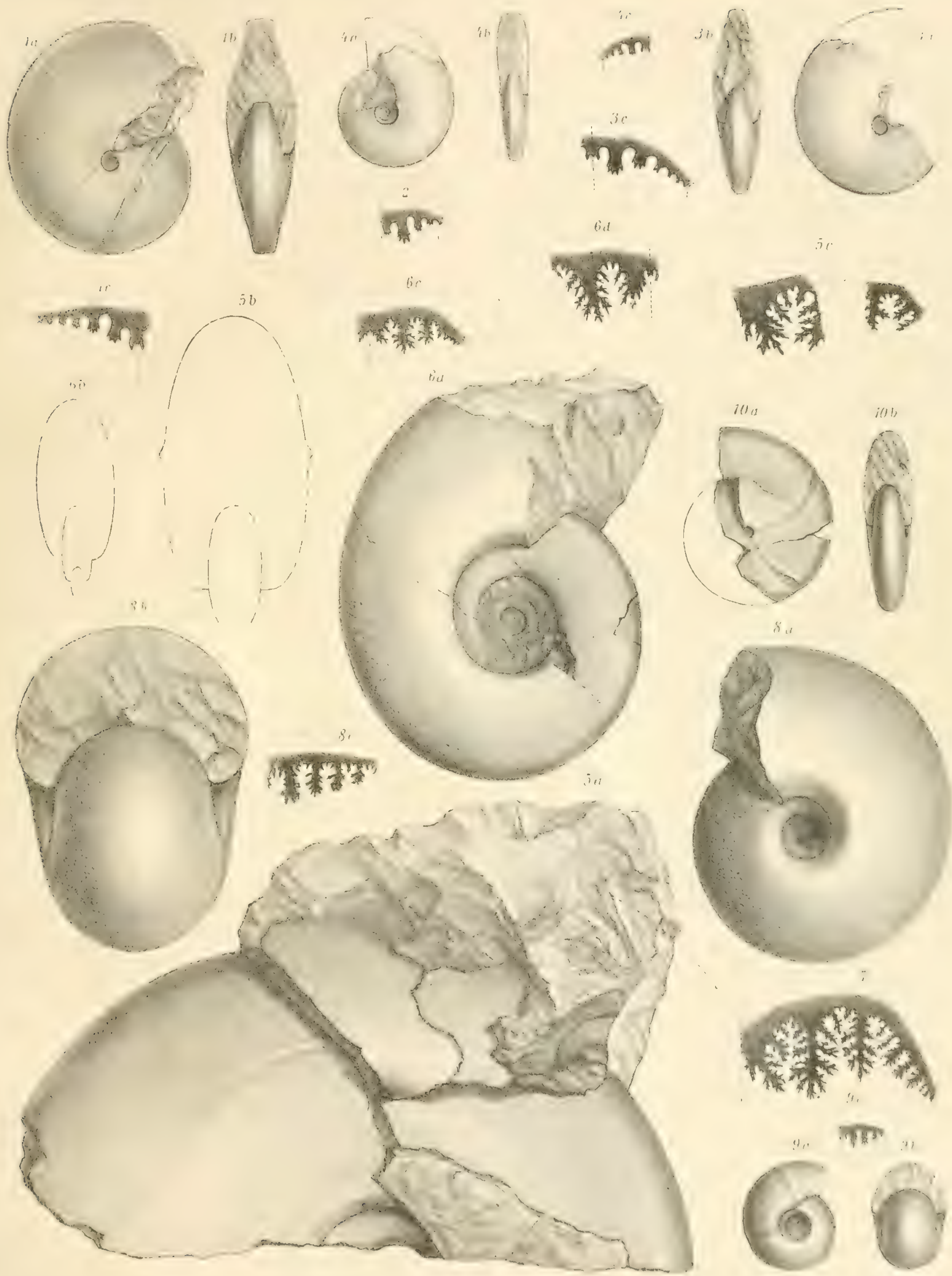

TAFEL IX (IX).

Ptychites. 
TAFEL IX (IX).

Fig. I $a, b$. Ptychites maximus Art., pag. 97.

Exemplar mit theilweise erhaltener Schalenbedeckung

Fig. 2. Ptychites maximus Art., pag. 98.

Abbildung eines Theiles der Schale von einem zweiten Stücke.

Fig. 3. Ptychites maximus Art., pag. 95.

Suturlinie des auf Taf. X. Fig. I, abgebildeten Exemplares. 


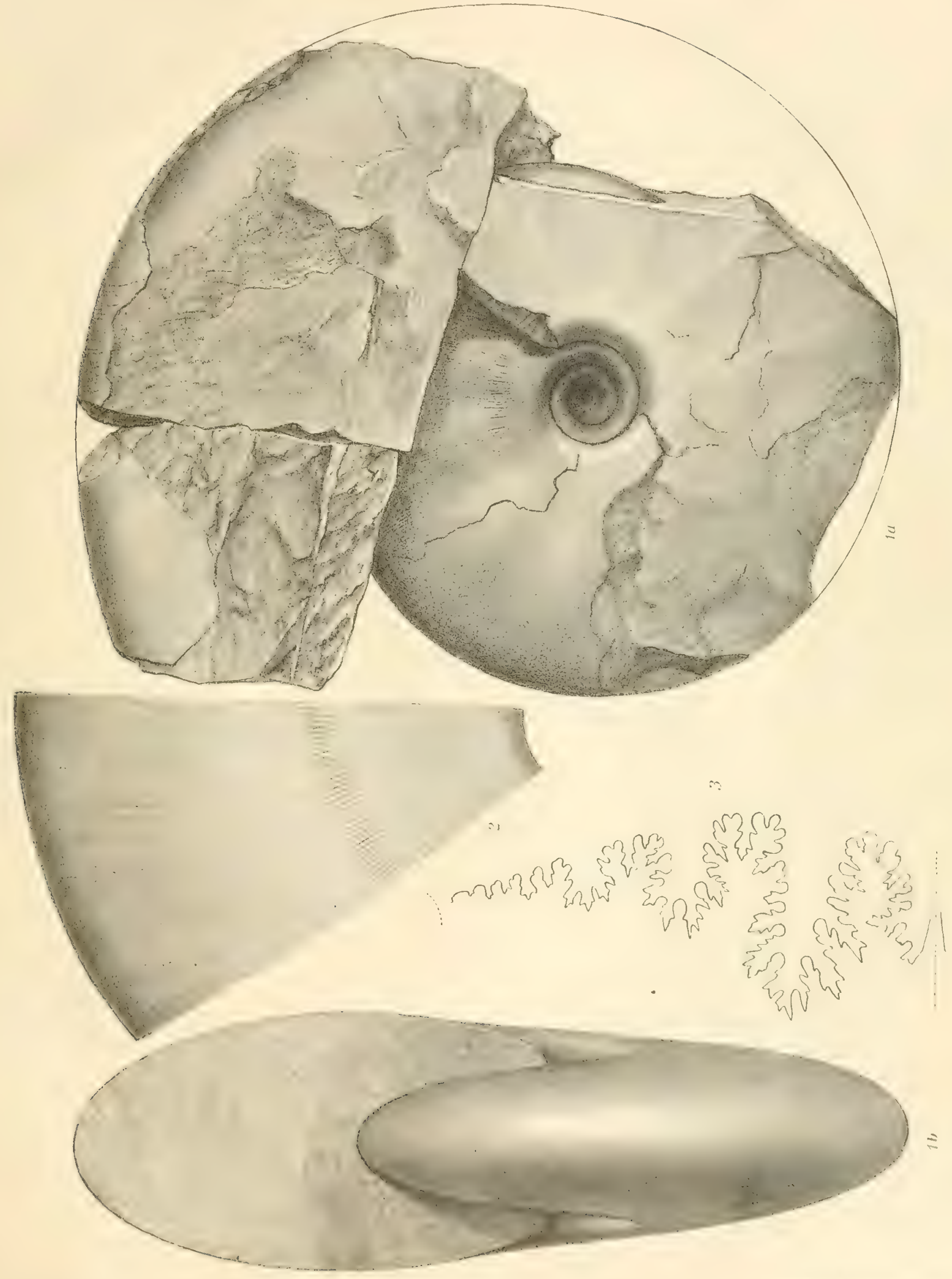

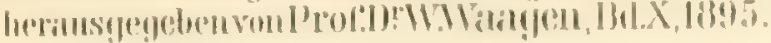



TAFEL X X.

Ptychites, Proavites, Sphaerites, Lepacunthus. 
TAFEL X (X).

Fig. I. Ptychites maximus Art., pag. 97.

Als Steinkern erhaltenes Exemplar. Die Suturlinie ist auf Taf. 1X. Fig. 3, abgebil le:

Fig. $2 a-d$. Proavites Hüffeli Art., pag. Io 4 .

Als Steinkern erhaltenes Fragment mit seringen Resten der Schale: c vollständiger () weruchnitt.

Fig. $3 a, b, c$. Proavites avitus Art., pag. 105.

Steinkern mit geringen Schalenresten.

Fig. $+a, b, c$. Proavites marginatus Art., pag. 105.

Als Steinkern erhaltenes Exemplar.

Fig. $5 a, b, c$. Sphaerites globulus Art., pag. I07.

Exemplar mit grossentheils erhaltener Schale; c die ungefähr 9 mal vergrösserte Suturine

Fig. $6 a, b, c$. Lepacanthus gracilis Art., pag. I08.

1. Ansicht der Flanke des Stachels bei ungefähr +maliger Vergrösserung; c Querschnitt be1 li" ;tahtr 3 maliger Vergrösserung. 


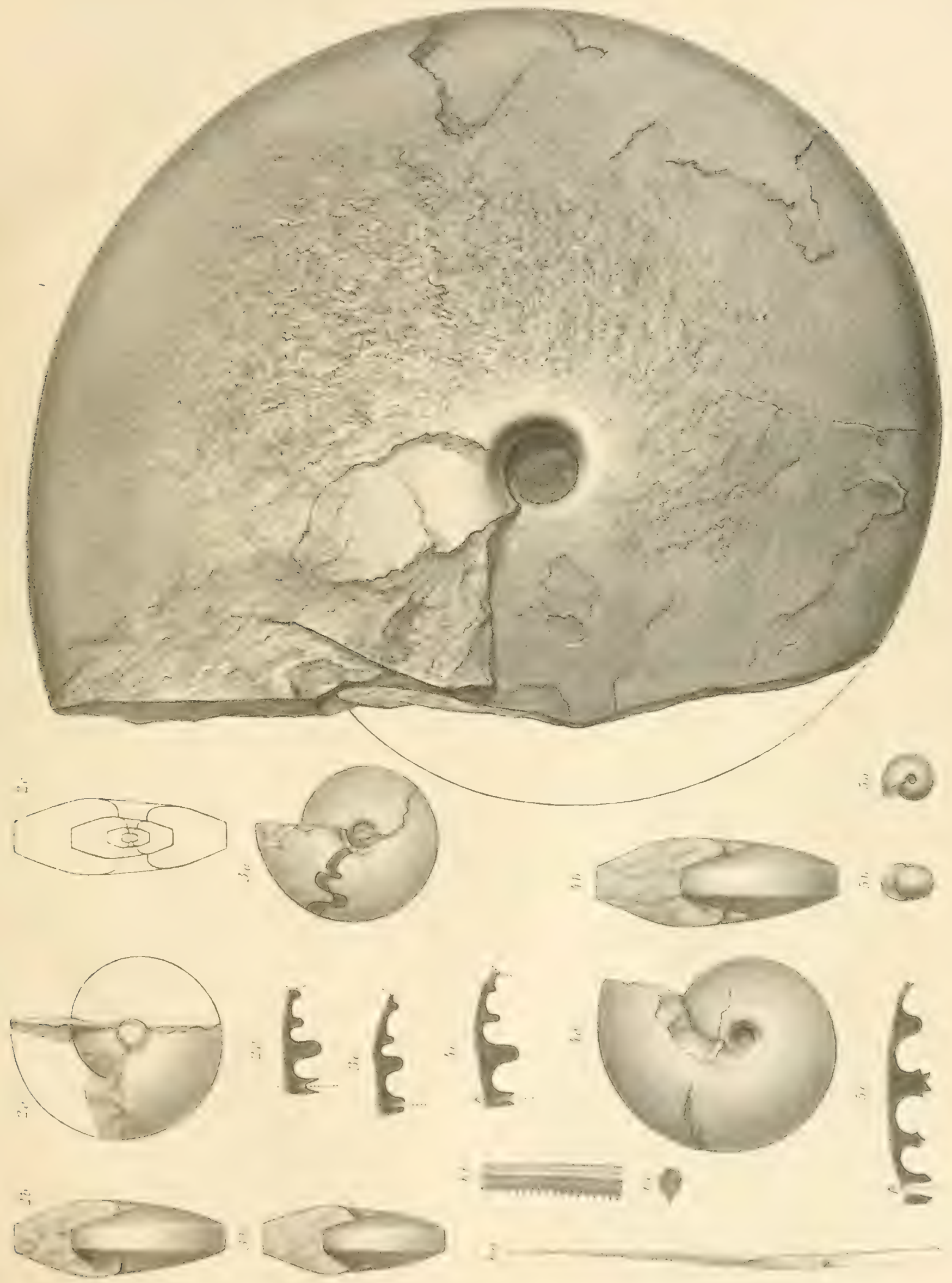

A.Swobodan.NAs. gez.u.lish.

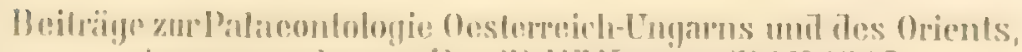

P $\therefore \therefore: r^{7}: \cdots \cdot, \because$,

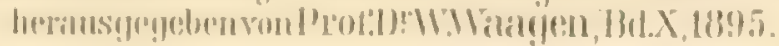






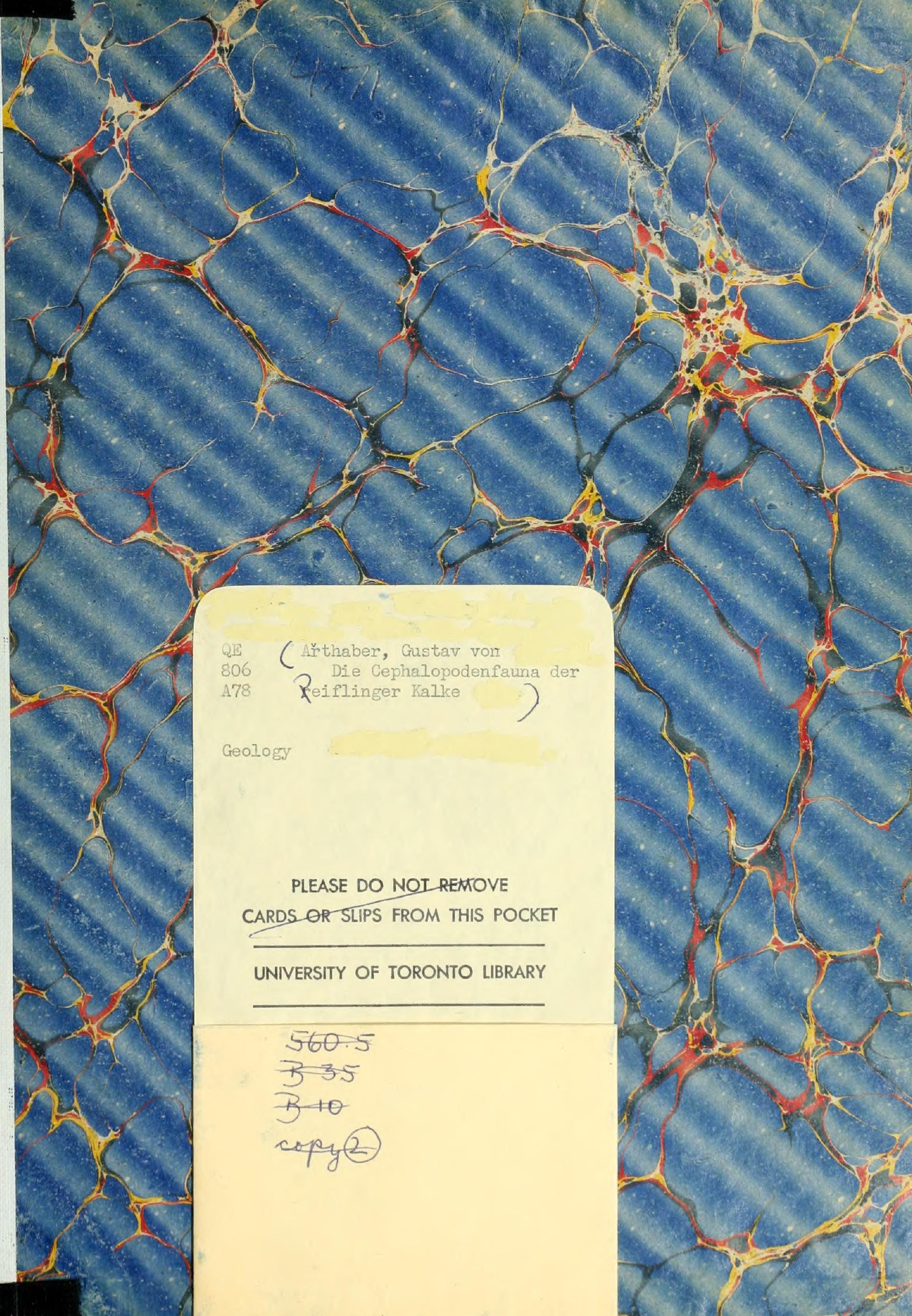


